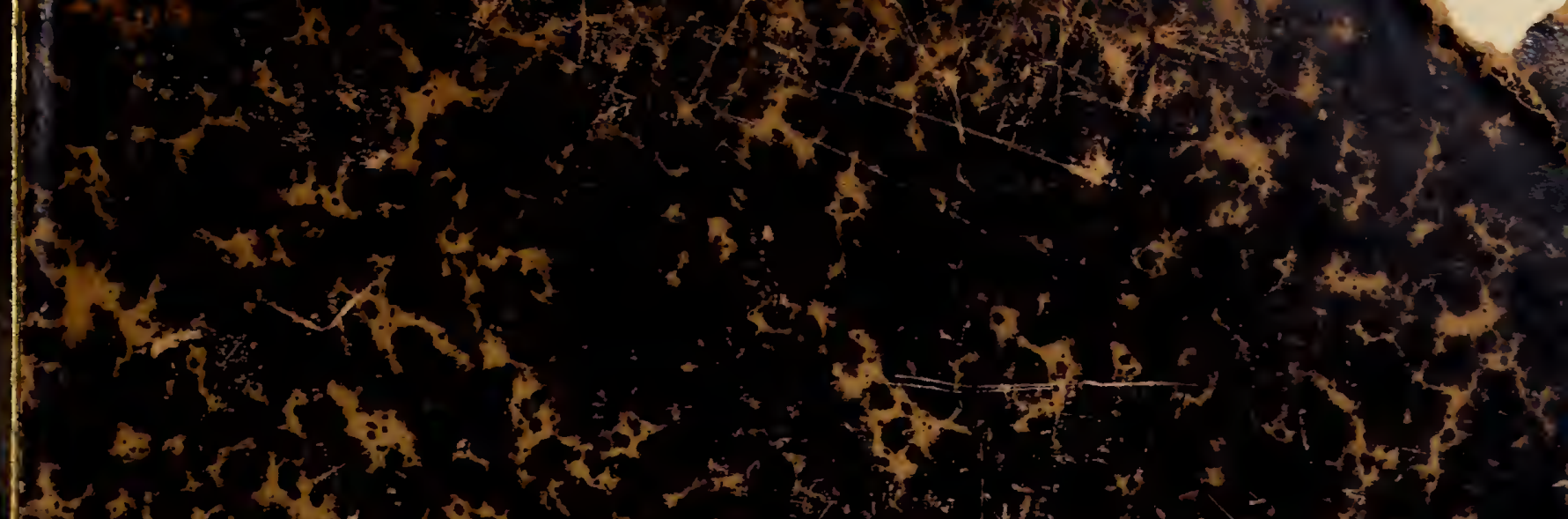

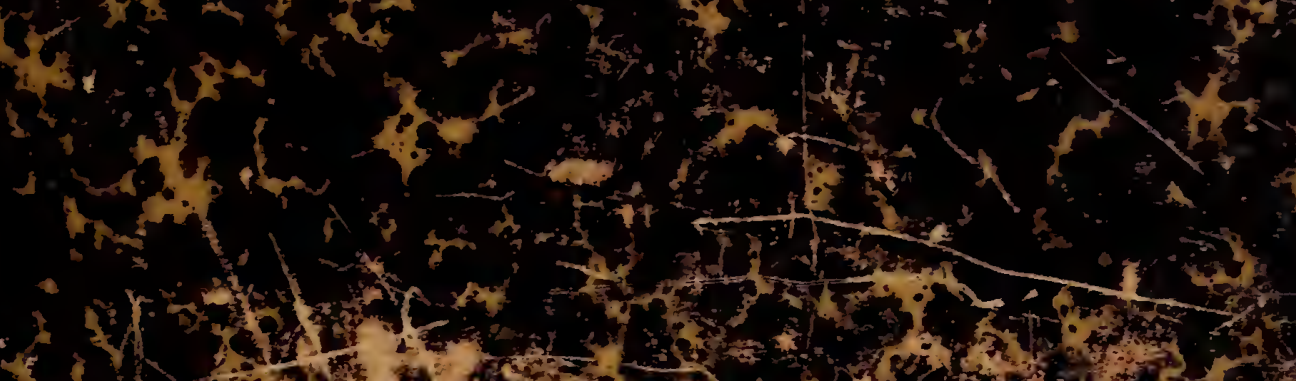

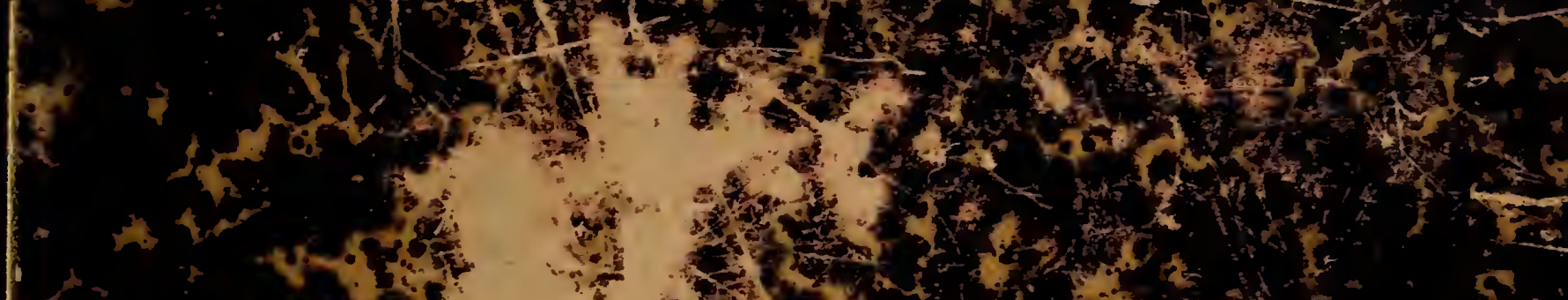

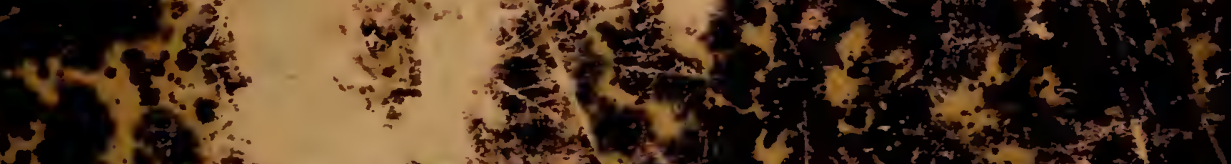

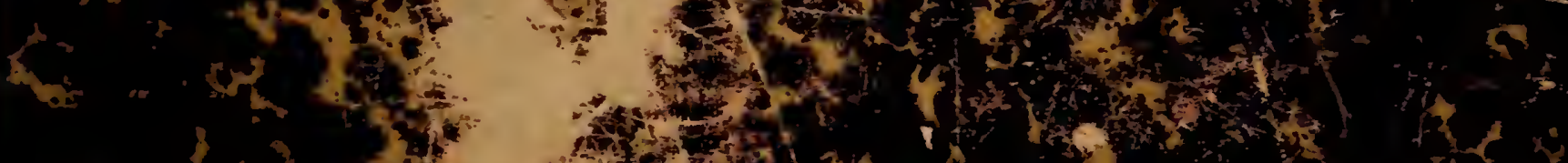

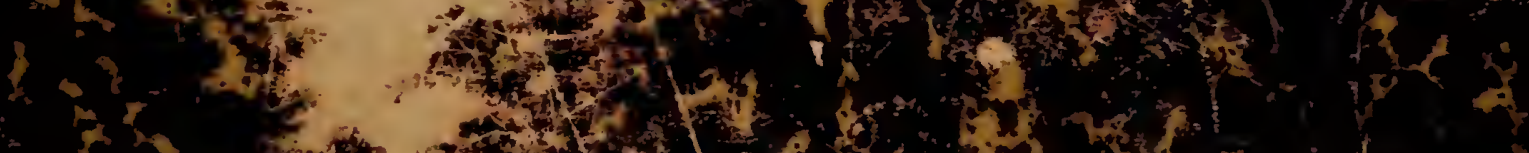
L

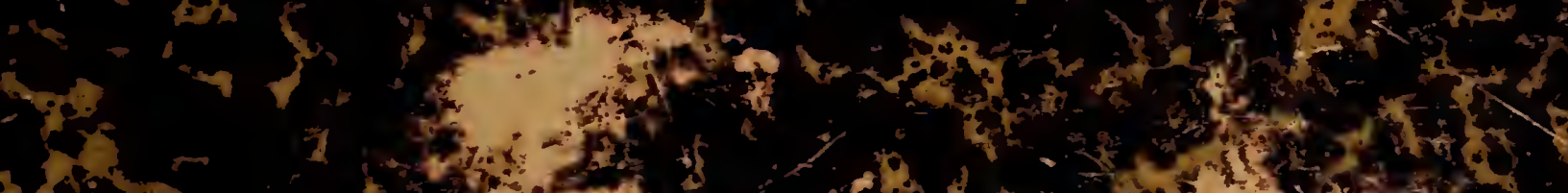

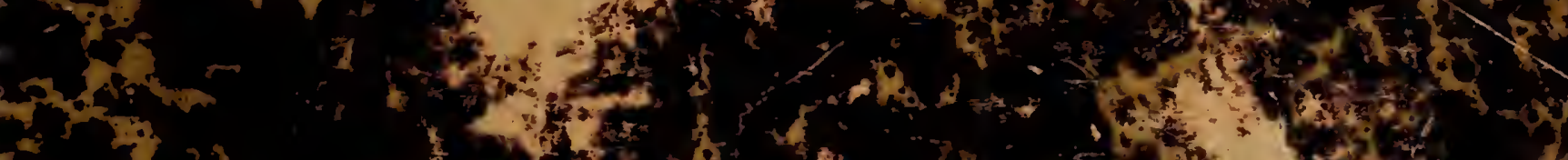
L

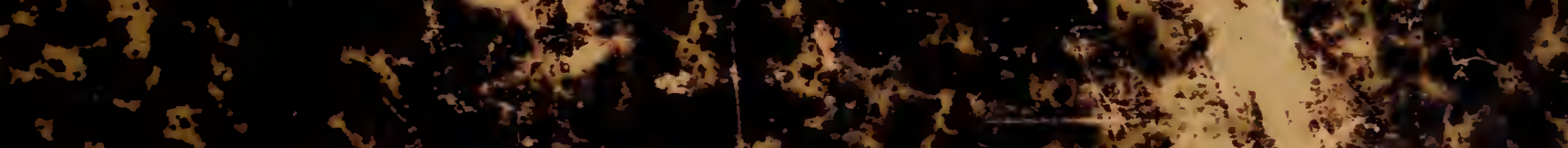

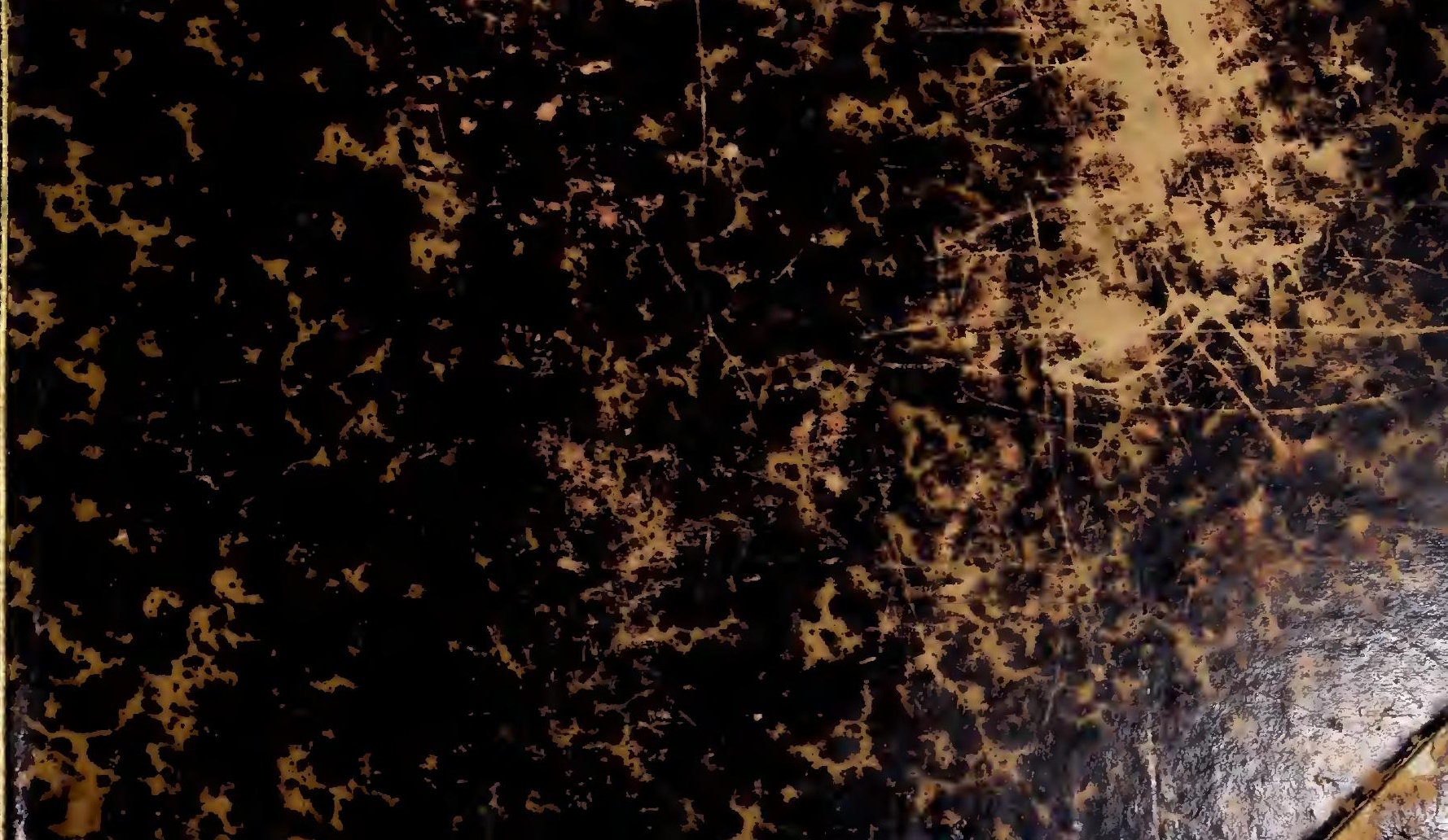



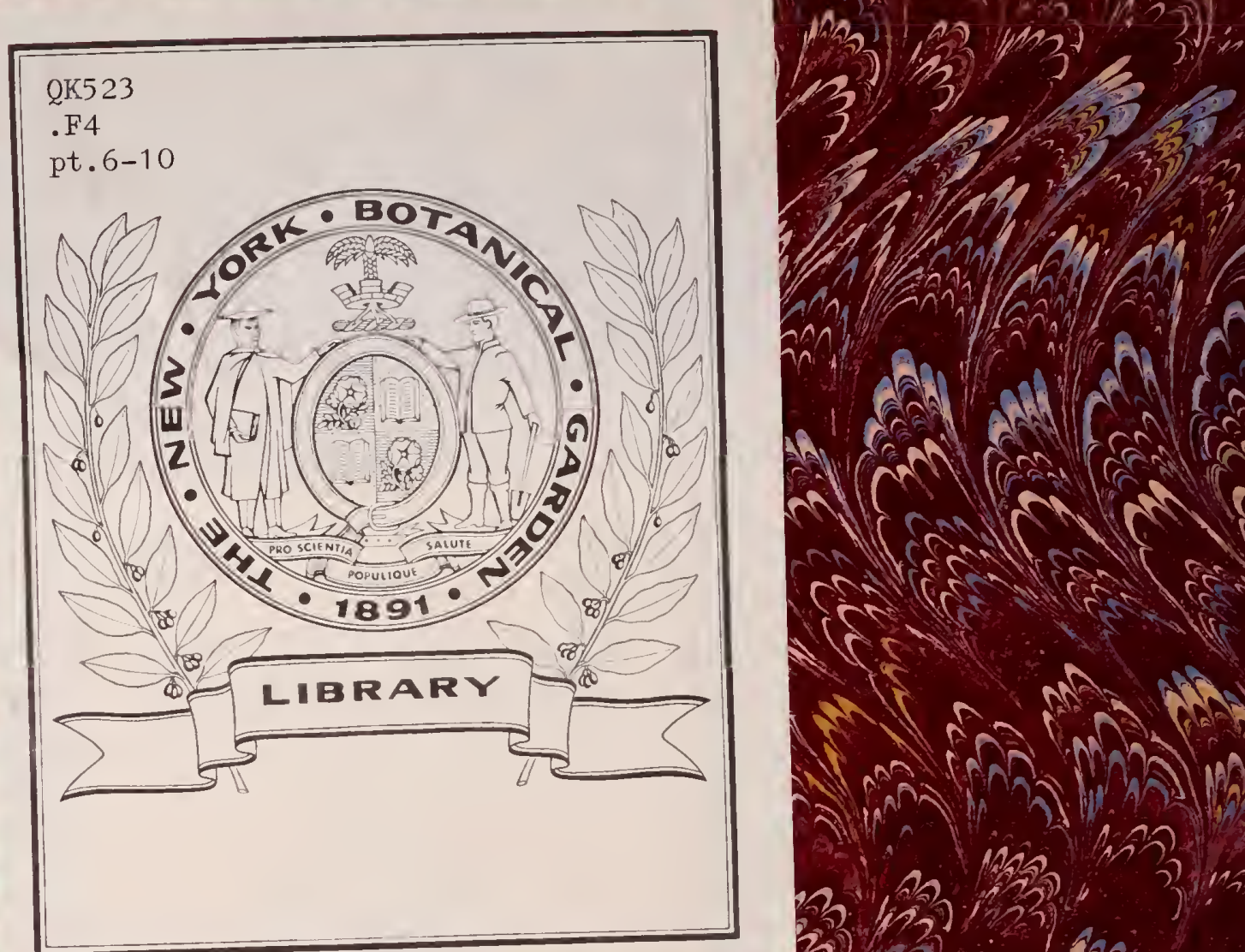

\section{Can fan ANA M. M. Barnard}

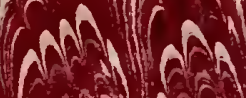

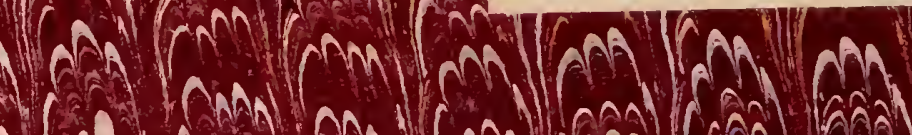

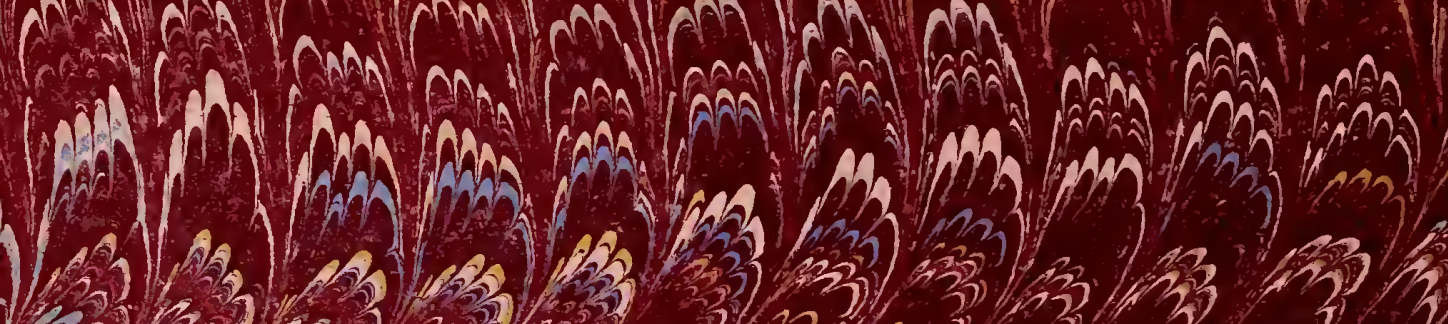

\section{(2)}

- 1 . 0 ?

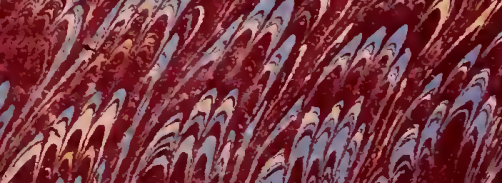

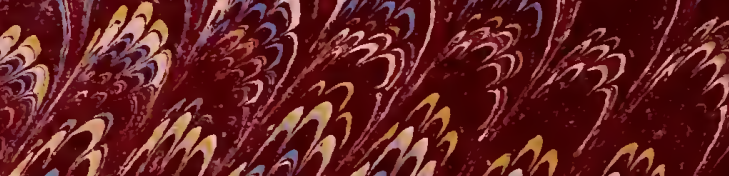

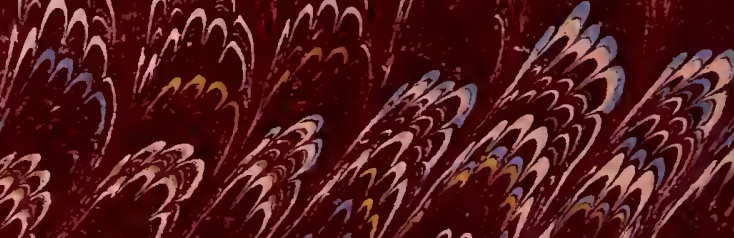
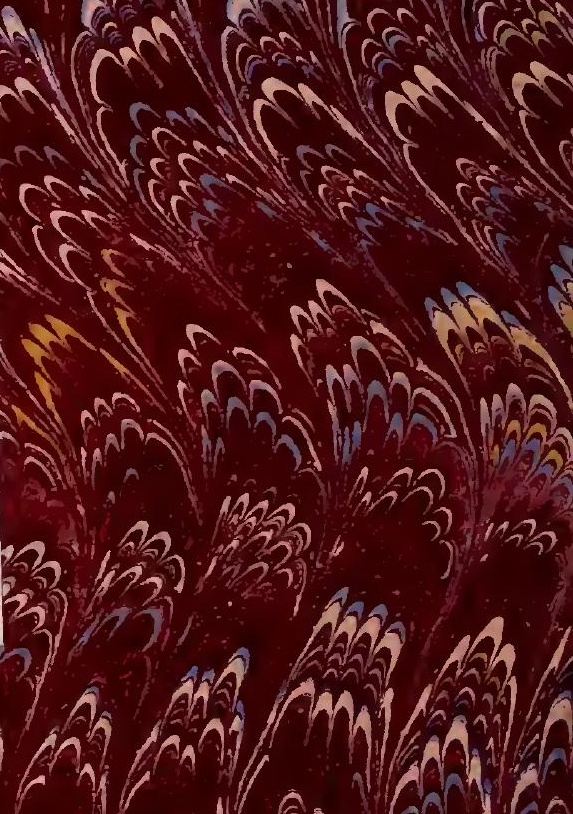

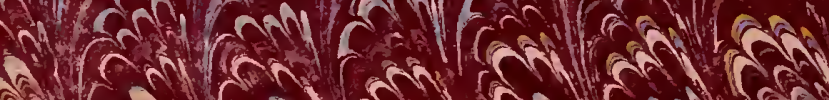




\section{Digitized by the Internet Archive in 2016}



QK523

pl. $6-10$

Ser becoming of The manor for tide page o Prefaces to Wearers 6, 7 and 8 .

$$
d_{a t}=1854-1857
$$




\title{
SIXIÈME MÉMOIRE
}

\section{SUR LA FAMILLE DES FOUGÈRES.}

\author{
ICONOGRAPHIE
}

DES

\section{ESPĖCES NOUVELLES, DÉCRITES OU ÉNUVÉRÉES}

DANS L L̇

\section{GENERA FILICUN.}

\section{ACROSTICHEAE.}

Sporangix effusæ, superficiem laminarum inferiorum aut rariùs laminas ambas totas vestientes.

\section{ACROSTICHUM, F.}

Histoire des Acrostichées, p. 8 et 27 , tab. I-XXIX.

Ejusd., Gener. filic., p. 41, tab. I, fig. 1-7.

1. Attenuatun, F., loc. cil., p. 43 .

Frondibus sterilibus ovalo-lanceolatis, acuminaio-allenuatis, undulatis; petiolis mesonevroque pallidis, pauci-squanıosis; squamis rufis, lanceolatis, acuminatis, perfacile codentibus; fertilibus nuinoribus, acuminatis, basi rotundis; petiolo helveolo, longissimo, squamoso, striato; sporangiis rufis, rotundis; annulo $11-12$ orticnlato; sporis ovato-subreniformibus.

Habitat?.. In horto Lipsiensicultum (teste Kunzeo) ex America australi proveniens. Filix repens; nervillis flabelliformibus, furcatis, remotis.

Icov. : Tab. I, fig. 1. 


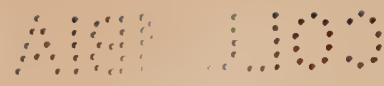

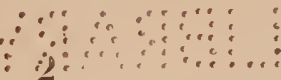

\section{ICONOGRAPHIE DES ESPECES NOUVELLES}

(Longueur de la fronde stérile : 25-30 centim. sur 4-5 cent. dans la plus grande largeur; le pétiole fait un peu moins du tiers de la longueur totale. Les frondes fertiles sont de même grandeur; la largeur est denviron 25 millim.; la lame est au pétiole :: $2: 5$. Les unes ct les aulres sont arrondies scnsiblenent à la base.)

Cette espèce, fort distincte, a quelque analogie avec l' $A$. erinacerm (Hist. des acrostich., p. 41); mais ces rapports sont très-éloignés. La pointe des lames est longuement acuminée; les nervilles, en approchant de la marge, tendent à se dilater, cornme si elles voulaient s'unir et faire passer cette fougère dans le genre Aconiopteris, séparé seulement de l'Acrostichum par une nervure marginale, aussi apparerte que celle qui caractérise l'Olfersia.

II. Crispatulem, F., loc. cit., p. 42.

Frondibus sterilibus ovalis, petiolatis, margine subrepandis, apice obunsis, basi leviter acutis; squamis rufescentibus, lunceolutis, crispatnlis, peliolos graciles longosque vestientibns; nervillis flabelliformibus, rnurginem attingentibus, apice incrassntis; ferlilibus parrim minoribus, basi cunealis; canlibus filiformibus, squamosis, ramis lateralibus brevioribus; sporis subrotnnlis.

Habitat in Quito (Jameson, n. 74 bis, in Herbar. nostro).

Filix repens, ramosa, rufescens; squamis crispis vestita.

Icos. : Tib. I, fig. 2.

Longucur totale indéterminable; des frondes stériles $4-6$ centin.; les lanres ne dépassent pas 18 millim. sur $\mathbf{T}$ millim. de largeur.)

Celte espèce, curieuse par son port, s'étend indéfiniment. Ses tiges sont rameuses, filiformes, ondulées, couvertes d'écailles roussâtres, crêpues et fortement déchiquetées en leur pourtour; elles ne renferment qu'un seul faisceau rasculaire. Les frondes son assez distantes les unes des autres, longuement pétiolées et revêtues des mêmes écailles que celles qui chargent les stipes.

iIt. Cochleariffolium, F., loc. cit., p. 42.

Frondibus sterilibus ovalis, crassis, cochleariformibus, peliolatis, glabris, siccilate pallidè glaucescentibıs, basi decurrentibus, margine inlegerrimis; petiolis longis, curvis, planinsculis; nervillis flabelliformibns, mesonevro evanescenti; canlibus sulcatis, parcè ramosis, magniludine pennce corvince, squamis lanceolatis, obınsissimis, imbricatis, bruneis, undiquè tectis; fasciculis unsorum ad centrmm caulium dnobus.

Reliqu desiderantur.

Itabital in Quito Andibus (Jameson, n. 213 ).

Filix repens, rigida; coule sqummoso; frondibus glabris, crussis, opacis, pallidè virescentibus.

Icos. : Tab. I, fig. 3 . 
(Longueur totalc indéterminéc : tiges de la grosseur d'une plnme d'oie lorsqu'elles sont convertes de squames; frondes stériles, les seules connues, 4 ccntin. arec le pétiole qui égale la lame; celle-ci, presquc orbiculaire, a près de 25 inillim. de diamètre.)

Quoique les frondes fertiles de cette espèce soient inconnues, elle est fort distincte de toutes les autres et sera facilement retrouvée. Les tiges sont roides. de couleur noirâtre et fortement sillonnées. Les frondes sont portées sur des pétioles brunâtres à la base, courbés dans le même sens et articulés; les lames. qui rappellent très-exactement les feuilles du Cochlearia officinalis, sont opaques et décurrentes; le mésonèvre est évanescent; des écailles abondantes, imbriquées, fort grandes et que l'on ne retrouve pas sur les frondes, chargent toutes les autres parties de la plante.

\section{HETERONEVRON, F.}

Hist. des Acrosticl., p. 20 et 91 ; Gener. filic., p. 59, tab. IV, A, fig. 2.

\section{P PaKadoxum.}

Frondibus sterilibus trilobatis simplicibusque, longè petiolatis; petiolis filiformibus, striatis, squanosis; laminis pellucidis, supernè glabris, infernè densè squamosis, squamis plunis, margine longè dentulis, centro affixis; apice glandulosis; nervillis tenuissimis, anastomosatis, appendiculis rectis, areolis incequalibus; fertilibus subintegris, minoribus; sporangiis cum squamis immixtis; sporis subrolundis.

Habilat in Mexico (Galeotti).

Filix paruula; frondibus congestis, fucie acrostichorum, sed nervillis anastomosulis.

Icos. : Tab. I, fig. 4 .

(Longueur de la plus grande frondc : 7 centim. La lame est au pétiole :: : : †, et elic atteiut : peine 15 millim. de largeur.)

Cette fougère présente cette singularité d'aroir, avec le port des acrostichum, la nervation de l'Heleronevron. Cependant les lames des quatre frondes dont se compose notre spécimen ont une tendance marquée à se diviser. Il en est deux trilobées, et la marge des deux autres est inégalement ondulée, comme si elles voulaient aussi se diviser. Nous avons trouvé cette curieuse espèce, confondue avec d'autres fougères mexicaines plus grandes, et qui nous ont élé généreuseinent communiquées par M. Galeotrı, voyageur sagace et éclairé ạuquel on doir la dérouverte d'une foule de plantes nouvelles. 


\section{ADIANTEAE.}

Receptaculum carnosum, nerrosum, dilatatum resupinatumque.

\section{ADIANTUM, Linn.}

F., Cener. filic., p. 112 , tab. XI, fig. 2 et 5.

JiaGELLCH.

Frondibus pinnatis, decumbentibus, radicantibus; stipitibus, ebeneo-rufescentibus, flexuosis, crassitudine fili enıporetici; radice fubrosa; frondulis longè pedicellatis, pedicello capillaceo; sterilibus obliquè ovoideis, ad apicem decrescentibus, margine incrquali, inciso, basi cuneatis; fertilibus fubelliformibus, multicrenatis; crenis omnibus proliferis; indusiis pellucidis, eleganter nervatis; sporangiis ovoideis, parvulis; annulo 16-18 articulato; sporis fusco-bruneis, trigonis.

Habilat in Brasilia (V. S. in Herb. Mloug.).

Filix tenera, slabra; stipitibus longissimis, apice rudicantibus; facie Adianti lunulati sed $\cdot a b$ aliis characteribus diversa.

Icos. : Tab. II, fig. 1.

(Longueur totale, 36-42 centim.; cellc des frondules ue dépasse pas $11-13$ inillin.)

Cet Adiantum est remarquable par son port, par ses tiges flexibles, proliferes vers le sommet, par ses frondules très-écartées, cunéiformes, crénelées à la narge et à crénulations denticulées. Le pétiolule est noiràtre et articulé avec la lame.

\section{PTERIDEAE.}

Receptaculum nervillare, rarò nullum, indusium continuum, membranaceum, pellucidum, planum.

\section{PELLAA，Lk.}

F., Gener. filic., p. 128 .

? Arabica, F., loc. cit., p. 150.

Frondibus triangularibus, supernè pinnatis, intermediis bipinnatis, basi tripinnatis pedatisque, suprà viridi-glaucescentibıs; stipitibus rıfo-fuscis, squamosis; squamis inaqualibus, linearibıs, longissinı̀ altenuatis, margine integris; segmentis ovoideis; sporangiis segnenta onıninò tectantibus; indusiis marginalibus, lıtissintis, plicatis, conniventibus, rufidulis; sporangïs ovoideis, sessilibus, cum pilis intestiniformibus, 
strangulatis immixtis; annulo angusto, 24-26 articulato; sporis crassis, rotundis, fuscis; sacculo erecto, fibroso, squamoso.

Cheilanthes Arabica, Decaisne, Arch. du mus., 11, p. 190.

Cheilanthes Decaisnii, Kze., Index fil. hort. Lips.

Habitat in rupibus vallis Mai Mezano, propè Ijeladjeranne (Abyssinia), Schimper, n. $^{\circ} 1431$, nec non in Arabia.

Filix Cheilanthis longe remota; facie Aleuritopteridis, sed indusio contiuno; fronde spissa, basi pedata.

Icon. : Tab. III, fig. 1.

(Longueur : 12 centim. et souvent moins; le pétiole est à la lame :: $3: 2$. Envergure des deux frondes inférieures, 4 à 5 centim.)

Nous avons placé avec doute cette jolie fougère parmi les Pellica à côté des $P$. pedata et geraniifolia, dont on avait fait des Pleris, qu'on ne retrouve plus dans la belle monograplie de ce genre, due à M. AGHaRD, fils. Elle a le port et la consistance des pellaca pédiaires, mais elle en diffère par un indusiun unarginal, large et plissé qui atteint la vénule médiane; de sorte que les deux indusium du même segment frondulaire se rencontrent et deviennent connivents. Ce tégument protecteur est surabondamment développé. Dans les pteris de la section des aquilinaires, les indusium couvrent parfois le segment; mais ils sont plans et sous-marginaux. Le port de ce pellaca est si différent de celui des vrais cheilanthes, qu'on a droit de s'étonner de le voir placé dans ce geure; cependant les poils mèlés aư sporanges et ceux qui couvrent les frondes, sont intestiniformes et étranglés d'espace en espace, comme daus les genres Myriopleris, Plecosorus, Eriosorus, Cheilanlhes et Nothochlonna. Cette disposition, qui ne se retrouve pas dans les autres ptéridées, a certainement de la valeur; cependant on ne peut la regarder comme caractéristique.

Le Pellca Arabica est une plante extrêmement embarrassante, et ses caractères génériques sont très-difficiles à préciser.

Par le port et la consistance de sa fronde pédiaire, c'est un aleurilopleris.

Par les sporanges qui sont sessiles et par le système pileux, c'est une chéilanthée.

Par la continuité de l'indusium et la forme des spores, c'est un pellcea.

Par le rapprochenent de deux indusium opposès devenant connivents, c'est un onychium.

Peut-être cette plante deviendra-t-elle le type d'un genre nouveau, et il serait hien placé à la suite de l'Aleurilop/cris.

Quelques botanistes sont disposés à penser que les poils, interrompus d'espace en espace, que nous qualifions d'étranglès (pili s/rangulali), ne doivent cette apparence qu'à l'affaissement du tube qui forme le poil ou à la manière dont il se contourne; vu par l'épaisseur de la partie aplatie, c'est-à-dire de champ, on a 
une ligne qui se continue jusqu'au point oin le poil reprend la régularité de sa forme. Cette opinion, parfois fondée, n'est pas admissible dans tous les cas. Il existe des plantes dans lesquelles l'universalité de ce caractère, ainsi que l'extrême régularité avec laquelle il se présente, ne permettent pas de croire à une circonstance accidentelle, mais bien à une cause organique. Il n'est guère possible de préciser dans les fougères la différence qui existe entre les poils et les écailles, tant le passage des uns aux autres est ménagé. Souvent ces poils semblent ètre des écailles réduites à une seule rangée de cellules. (Cfr. Gen. filic., poils étranglés, tab. XIII, A; XIV, C.; XVI, B.; XXIV, A. - Poils articulés, tab. XIV, C.; XV, A. - Poils glanduleux, tab. III, B.)

\title{
XVII. POLIPODIEAE.
}

Laminx frondium planæ seu rarissimè plicatæ, numquàm revoluta.

\section{GRAMIITIS, Sw.}

\author{
F., Gen. filic., p. 232 , tab. XX, A, fig. 3.
}

I. Loxis, F., loc. cil., p. 235.

Fiondibus longissimis, linearibus, utrinque allenuatis, marginibus inlegerrimis, repandis; stipile brevi, fliforni, laminis glabriuscnlis; sporolhecüs snprà impressis, ovoideis, distinctis, ramos superiores nervillamum bifnrcatarum occupantibus, circi mesonevron evolventibns; receplnculo elliplico; sporangiis ovoideis, pedicello longo, sacculo piloso; annulo 12.13 articulato; sporis globnlosis, nigrescentibus.

Habilal in Java. (Lobb., n. ${ }^{\circ}$ 271.)

Fïlix elata, linearis, angusta, flexibilis, fasciculala.

- Icos, : Tab. IV, fig. 1 .

(Dimensions : longueur totale, $24-26$ centim., sur $7-8$ millim. de largeur; le stipe est cont.)

Cette espèce est la plus grande du genre; le mésonèvre est assez étroit, proéminent du côté inférieur des lames, et chargé, dans toute son étendue et à sa base, de poils roides, noirâtres, pointus, succinoïdes au centre, vus au microscope; les nervilles sont fourchues, à branches inégales et fortement divariquées; leurs sommets, renflés, déterminent à la surface de la lame supérieure des éni-

- nences presque ponctiformes, brunâtres, régulièrement espacées el disposées sur. quatre rangées, deux de chaque côté; le rhizome est rampant.

II. Limiв.ta, F., loc. cil., p. 235.

Frondibus fasciculatis, linearibus, oblusiusculis, undulatis; nervillis sinplicibus, teuuibus, marginem nou allingentibus, mesonevro tenui; linen aterrima, lucitulu, 
DÉCRITES OU ÉNUMÉRÉES DANS LE GENERA FILICUM.

laminas marginante; sporolleciis ovoideis, centralibus; receptaculo elliptico; sporangïs rolundis, parvis; annulo $12-13$ articulato; sporis nigrescentibus, incequalibus, rolundis.

Habilat in insulu Guadalnpa. (Perrotet, 1824.)

Icon. : Tab. $V$, fig. 1.

(Dimensions : longueur des frondes, 10-11 centin., sur 5-7 millim. de largeur, les sporothèces, assez rapprochés, sont cependant toujours distincls; ils occupent le tiers supérieur de la fronde, sans en atteindre le sommet. Nous avons devant les yeux un spécimen qui mesure 18 centim. de longueur sur 8 millim. de largeur.)

Dans le Grammitis limbata, les frondes sont sessiles sur une petite souche fibreuse. Le mésonèvre est fort délié : il s'en détache des nervilles ténues, légèrement flabelliformes, se terminant assez loin de la marge. Elles supportent les sporothèces latéralement et le point prolifere est fléchi, ce qui indique une tendance à la bifurcation. Les nervilles stériles sont droites, roides, pointues. Le sporothèce est ovoïde; le réceptacle se présente sous la forme d'une petite tache elliptique et transparente. Les frondes sont translucides, parfaitement glabres, bordées d'une étroite bande très-noire et luisante. Ce caractère curieux suffit pour la faire reconnaître à la prenière vue. La plante, nommée par WiLldexow $G$. marginella, est absolument différente.

III. NANA, F.

Frondibus parvulis, obtnsis; lirtis, opacis, in petiolum desinentibus, pilis rigidis, aculis, nigris coopertis; nervillis simplicibus, scalptnratis; mesonevro valido; rhizomate. dendroideo; sporolheciis approximalis, conflnentibns, apicilaribns, cum pilis lominarnm immixtis; sporangiis subrotundis, pedicello tenui; annulo lato, articulis 11-12 crassis remolisque; sporis rotundis, nigrescentibus.

Habitat in Java (Lobb. ?)

Grammitis plsilla, Blum., Fil. Javre, p. 109 , var. 2 lasiosora, lab. 46 , fig. 6 ?

Icon. : Trab. VI, fig. 1.

(Longueur des plus grandes frondes, $15-17$ millim. sur 2,5 millim. de largeur.)

Le Grammitis nana est l'une des plus pelites fougères connues; mais il se pourrait que le spécimen adulte que nous possédons fut plus petit que les autres. Les frondes sont remarquables par la grande quantite de poils squamiformes, roides et noirâtres qui les recouvrent, et que l'on trouve toujours mêlés aux sporanges; celles-ci sont arrondies, assez grosses, un peu enfoncées dans la lame et confluentes, de manière à rappeler la disposition des acrostichées. Nous n'avons pas vu, sur le sacculus, les poils qui le retrouvent dans la plupart des ảutres espèces. Notre spécimen est chargé, sur divers points des lames, d'une usnea stérile qui parâit être l' $U$. filaris ou trichoidea Ach.; ce qui prouve que cette petite plante a une très-longue existence. $G$. pusilla, dont M. BLume a représenté 
trois formes dans son bel ouvrage sur les fougères de Java, est différente. Les expressions caudex brevissimus, crassitic fili ferrei mediocris.... frondibus membranaceis, sub averius ne conviennent pas. D'ailleurs nous croyons que parmi les variétés établies par le savant botaniste, il en est une qui mérite d'être élevée à la condition d'espèce. C'est la var. $\gamma$ lasiosora du $G$. pusilla, qui seule peut ètre rapprochée de notre espèce.

\section{POLYPODIUII, L., emend.}

F., Gen. filic., p. 23 午, tab. XX, A, fig. 2.

I. Microlepis, loc. cil., p. 235.

Frondibus pinnatifidis, longè stipilatis, stipite el rachi squamosis; rhizomate repente, fibrilloso, crassiludine pennce columbince; segmenlis oppositis, ellipticis, horizontalibus, suprà glabris, sublùs densè squamosis; squnmis parvulis, imbricatis, subrotundis, longè acuminatis, centro fuscis, acumine liberis; sporotheciis rolundis, approximatis, subsenis, tabacinis; sporrengiis rotundis; annulo lato, $12-13$ articulalo; sporis ovatis, reniformibus lcrvibusque.

Habitat in America Australi. (Collect. Pamplin, n. 38 , Herb. Hougeotiano.)

Filix reprens, parva, frondibus remotis, segmentis ferè oppositis.

Icon. : Tab. VI, fig. 2.

(Dimeusions : longueur totale, 5- i centim., dont la moitić est oceupéc par les segmeuts houdulaires; l'envergure est de $7-8$ millim.; nous comptons de $9-11$ segments; il s'en troure 3-4 sur une étendıe d'un centim.)

Cette espèce appartient à la section des polypodes écailleux qui se rapprochent plus ou moins du $P$. incanumr; elle grimpe sur les arbres auxquels elle s'attache par de nombreuses fibrilles très-rameuses, comme cancellées et tomenteuses. Les écailles envahissent les stipes, les pétioles et la lame inférieure des frondes; elles sont fortement inbriquées et colorées en leur centre; les frondes écartées les unes des autres, tout à fait opaques, ne laissent que difficilement reconnaitre la nervation, et c'est ce qui explique comment II. PresL a ru en faire des marginaria. Le $P$. microlepis a des frondes étroites, à segments trèsobtus et exactement opposés. Les sporothèces, peu nombreux, sont assez gros, et comme ils soulèvent la couche d'écailles qui couvre la lame, ils se montrent entourés par elle.

II. Gibbosum, F.

Frondibus pinnatifidis, fusciculatis, lanceolato-linearibus, rigidis, pilis bruneis, longis hirlis; segmentis oblusis, obliquis, supernè gibbosis, busi fructificnntibus; rachi hirto; petiolo nullo; rhizomate surculiformi, ranoso, squamis lanceolatis, acutis obsito; sporothecio crasso, ad basin segmentorum solitario; sporotheciis ovoideis; annulo lato, 11-12 articulato; sporis crassis, irregularibus, fuscis. 
Habilut in Mexico (Oaxaca, ad altitud. $2400-2600$ metr.)

Icon. : Tab. II , fig. 2.

(Dimensions: longueur totale, 6-7 centim., sur 4 millim. d'enrergure. Nous complons unt trentaine de segments de chaque côté du rachis.)

Nous avons reçu cette planı de M. Galeotti sous le nom de P. delicalulum, mais il y a eu quelque erreur d'étiquette, car il n'existe entre notre plante et celle du savant voyageur aucun rapport, même éloigné. Le rlizomie a la forme d'une souche et cette souche est rameuse vers sa partie supérieure. Clacune des divisions porte un assez grand nonbre de frondes étroites, presque linéaires. Les segments, gibbeux vers leur partie supérieure, se continuent dans tout le trajet du rachis, en diminuant de manière à ne plus se présenter que comme une sinuple dent. Les frondes sont fertiles jusque vers leur milieu, et chaque segment est monosore comme dans le $P$. trichomanoides, avec lequel notre plante a quelque ressemblance; mais ici les frondes sont roides, fasciculées sur un gros rhizome ranieux; enfin les segments des frondes portent une gibbosité marquée du côté supérieur ; ajoutons que l'insertion de ces mêmes seggments ouvre un angle droit avec le rachis. Les sporothèces sont aussi beaucoup plus gros.

Nous avions d'abord donné à cette plante le nom de $P$. monosorum, mais conıme la particularité exprimée dans la désignation nominale existe ailleurs, particulièrement dans le $P$. Trichomanes, nous avons dì le changer.

III. Serricula, loc. cil., p. 258.

Frondibus cerspitosis, rigidis, linearibus, acutis, sessilibus, dentato-pinartifidis; ¿lentibus integris, angulatis, oblusiusculis; lamina pilis prucis, criniformibus hirta; sporotheciis costalibus, in quaque dente solitariis; sporcangiis ovoideis, pellicellatis, sporis subrotundatis, atris; rhizomate fibrillis nigits, plumosis onusto.

Habitat in Antillis (Gundulupa), L'Herminier; Perrottet.

Icon. : Tab. VII, fig. 1.

(Longueur des frondes, 16 ccntin., sur 5 centim. de largeur; les dents sont un pen éloignées, obtuses; triangulaires; quelques poils roides liérissent leur surlace; vus au microscope, ces poil. sont continus.)

Cette fougère appartient à la section des trichomanoidées, établie dans le genre Polypodium. Les frondes sont en touffe, assez élastiques, mais très-souples; leur forme est linéaire, leur consistance ferme; les lobules opaques, paraboliques et chargés sur leurs deux faces de très-longs poils déliés et brunâtres, ont des contours réguliers que n'altère aucune gibbosité. Les sporothèces terminaux sont solitaires à la base de chaque lobule.

IV. Flexile, F.

Frondibus lunceolutis, flexilibus, mollissimis, elasticis, hirtis, lanceolatis, pilosissimis, pilis longis, cufo-pallidis vestitis; segmentis semi-ovatis, obtusis, superne fulcutis, 
basi un apicem decrescentibus, patnlis, apice fertilibus; radicè fibrosa; sporotheciis 2 -4 crassis, terminalibus, distinctis; sporangiis ovatis; annulo 13-14 articulato; sporis ovoideis, elongatis.

Habitat in insulis Borbonice el Marrilii.

Exsiccata Sieber, Flora mixta, 54 ct 291.

Polypodium cultrolmm, Sieber non Willd.

Icov. : Tab. II, fig. 3.

(Dimensions : longueur totalc des frondes, 16 centim., et souvent beaucoup moins, sur 12 millim. d'cus crgure.)

Une racine fibreuse, à longues radicelles, porte de 2 à 3 frondes étroiteurent lancéolées, dont les pétioles, très-courts, sont entourés de poils fauves trèsabondants que l'on retrouve sur toute la plante, mais épar's, mous et plus pâles. Les frondes se terminent en haut et en bas par des segments semi-orbiculaires. Ceux du centre sont arrondis supérieurement et coupés droits vers la base; la marge est entière et un peu onduleuse. Les nervilles sont flexueuses et courtes.

Willdesow a décrit, sous le nom de $P$. cultratum, une plante des Antilles toute différente, figurée par Plumer, Filic., tab. 68, et par Petrver, Filic. 36 , tab. 12 , fig. 13 ; elle a des segments auriculés à la base, du côté supérieur. La comparaison qui peut être faite de la figure que nous donnons avec celle de Plinter, mettra en évidence l'impossibilité de les confondre, lors même que Plimiter en aurait exagéré les dimensions. Notre plante a quelque analogie avec le P. subfalcatum de M. Bưve, mais les expressions laciniis alternis, linearioblongis, serratis ne lui sont point applicables.

1. Siccatcu, F., loc. cil., p. $23 \mathrm{~g}$.

Frondibns linearibus, fasciculatis, pinnalifidis, subsessilibus, nudis; segmentis creberrimis, ferè costam ullingentibus, obtnsis, horizonlalibus, glabris; nervillis simplicibus, apice fructiferis; sporolheciis rolındis, immersis, distinctis, suprà impressis, in depressione lanince nascentibıs, inargine revolulo subabsconditis; sporangiis rolındis, parvis, pedicello tenui; annulo 12-13 articulato, sacculo perfacilè soluto; sporis subrolundis, parvis.

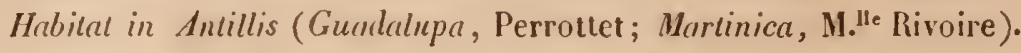

Filix parva, elongala, sporangiis immersis, marginibus segmentorum reflexıs.

Icos. : Tab. VII, fig. 3.

(Dimensions : longueur totale, 20 centim., sur 10-13 millim. d'envergure; lobules rapprochés, nombreux; nous en comptous jusquà 60 paires.)

Cette espèce se rapproche du Calymmodon par ses sporothèces à demi-cachés par le repli de la marge des lobules, et du Ctenopleris par des sporothèces en apparence enfoncés dans la lame; quoiqu'ils soient en réalité supra-cuticu- 
laires (voy. Calymmodon et Ctenopteris). On compte de 4 à 6 sporanges sur chaque lobule. Les lames, vers leur partie supérieure, sont bosselées au point correspondant à linsertion du sporothèce qui déprime la cuticule. Ces lobules sont allongés, entiers, obtus, horizontaux et glabres, ainsi que la plante tout entière qui est élıstique, transparente et à nervilles courtes.

VI. Filipexdulefoliti, F., loc. cit., p. 240.

Frondibus fascicnlatis, lanceolatis, pinnatifidis, curvatis, elasticis; stipite brevi el rachi flexuoso utroque pilosis; pilis rufescentibus, acutis; segmentis profundè incisis, dentibus obtusinsculis, subhorizontalibus, excurvatis, obthsis; nervillis brevissimis, apice turgido, glanduloso, pyriformi, fructifero; mesonevro flexuoso; sporotheciis subrotındis, 5-jugis, apicilaribus; sporangiis parvis, pedicello tenni; annulo 9-10 articulato; sporis rolındatis.

Habilat in Java. (Lobl), n. 269.)

Filix elegans; segmentis ad formam pimnatifidum tendentibus.

Icon. : Tab. $V$, fig. 2.

(Dimensions : longneur totale, $13-14$ centim., sur 2 eentim. d'enrergure; les segments soul au nombre de 30 curiron.)

Cette jolie espèce est très-élastique et très-souple; les lobules sont transparents, horizontaux, quelquefois même courbés en dehors; ils atteignent le mésonèvre et tendent à la disposition pinnatifide, ayant leur mäge fortement dentée. Le mésonèvre de chacun d'eux est ondulé; les nervilles sont très-courtes, dressées dans la direction de chaque dent et fructiferes au sommet. Les sporothèces sont assez gros et roides; nous en comptons de 5 à 6 sur claque segment.

VII. MAcrosonum, F., loc. cit., p. 241.

Frondibus ovoideis, basi tripinnatis, snpri bipinnatis; rachi complanato, squamis cancellatis, ovatis, integris, puncis, sparsis onnsto; stipite articuluto; rhizomate cylindrico, squamoso; segmentis, aliis pinnulifulis, aliis crenatis, obtusis, remolinsculis; sporotheciis crassissimis, terninalibıs, tabacinis, scepè ad axillas squanarum crescentibus; sporangiis aniplis, pedicello tenui; amnulo crasso, 12-13 articulato; sporis magnis, ovoideis, Imtescentibus.

Hubitut in Quilo, Jameson, 1845.

Fillix habiu proprio; sporcugiis magnis, lobos frucliferos onuninò legenlibus; squnmis pleopeltidearum.

Icos. : Tab. VIII, fig. 1.

(Dimensions : longueur totale; 32 centimetres; divisions latérales, il la base de la fronde. 5 centin., leurs principaux scgments mesurent de 1314 millim.)

Dans cette curieuse espèce la grosseur des sporohlèces est démesurée, si on la compare aux segments qui les supportent; le slipe est gros comme une plume 
de pigeon et parcouru par une dizaine de faisceaux vasculaires, à peu pres disposés en cercle. Le Polypodium macrosorum est une fougère arboricole qui rampe sur les écorces à l'aide d'un stipe muni de crampons radicellaires; ce stipe est très-délié relativement à l'inıportance de la fronde, presque réduite à la nervation. On trouve sur les lames des écailles brunâtres, éparses, bombées, fixées principalement sur les nervilles, et c'est souvent à leur aisselle que se développent les sporothèces; ajoutons qu'ils impressionnent la lame du côté supérieur au point de leur développement.

III. Fuxiculeu, F., loc. cil., p. 241.

- Froudibus profundè pinnalifudis, lanceolatis, abruptè terninatis, glabriusculis; stipite et rachi fuscis; caulibus longè repentibus, contortis, intermixtis, intricatis, funiculun simulautibus, crassitudine fili emporetici, passim gemmiferis; segmentis angustè lanceolatis, obtusinsculis, dentatis; nervillis unifurcatis; ramo superiori breviusculo, fertili; sporotheciis sub quinque paribus, parvis, distinctis, lrete fulvis; sporangïs ovoideis; annulo $13-14$ articulato; sporis ovoideis, subreniformibus.

Habitat in Cuba, Linden, ${ }^{\circ} 1885$.

Fillix singularis, longè repens; caulibus intricatis.

Ico.s. : Tab. VIII, fig. 2.

Cette fougère est arboricole et très-curieuse par ses stipes unis entre eux dune manière inextricable; des gemmes nombreux, en se développant, tendent encore à les rendre inséparables. C'est une sorte de plique végétale. Les frondes ont quelque ressemblance avec celles du $P$. filipendulafolium, dont la souche est dressée. Les sporothèces, formés d'un très-petit nombre de sporanges, sont assez rapprochés du mésonèvre de chacun des lobules, et ceux-ci ont une marge profondément dentée

IX. Ciscellatuin, F., loc. cil., p. 242.

Frondibus ovatr-lanceolatis, bipinnatis; stipite, rachi et lamina inferiori squamosis; squamis ovatis, imbricatis, in ambitu laceratis, puncto colorato notatis; pinnis piunatis; segmeutis linearibus, suprà viridi-olivaceis, glaberrimis, remolè dentatis, dentibus obtusis, omnibus proliferis; sporotheciis subrolundis, terminalibus, squamis circumdatis; sporangiis subrotundis; annulo crasso, 12.13 articulato; sports magnis, ovoideis, lavibus, lutescentibus.

Habilut in Cuba. (Linden).

Filix speciosa, pinnis et segmentis decussutis, cancellatis, squamis planis, imbricatis, adpressis cooperta.

Icon.: Tab. VII, fig. 2. 
DÉCRITES OU ÉNUMÉRÉES DANS LE GENERA FILICUM.

(Dimensions : longueur totale, 20 - 22 centim.; principales divisions, environ $2-3$ centim.; segments inférieurs, 8-9 millim.; le stipe est à la fronde :: 1:5; les spores sont remarquables par leur grosseur.)

Quoique cette fougère soit bipinnée et à segments linéaires, elle appartient à la même section des polypodium que le $P$. mitrolepis que nous avons décrit plus haut. C'est une espèce extrêmement remarquable. Elle vit sur les arbres et rampe à l'aide d'un stipe assez gros et écailleux; les pinnuless sont pyramidales et rapprochées. Les segments de la base, étant fort longs, recouvrent les segments des pinnules voisines et en sont recouverts, donnant ainsi à la fronde un aspect treillagé très-curieux. Le pétiole et la lame inférieure des frondes sont entièrement envahies par des écailles fortement appliquées, assez petites et maculées de rouge au centre. Les sporothèces occupent le sommet des firondes, et il en est abondamment chargé.

\section{PHEGOP'TERIS, F.}

Gen. filic., p. 242 , tab. XX, A, fig. 1.

I. Cordata, F., loc. cil., p. 244 .

Frondibus pinnatis, lanceolatis, glubris; rachi et slipile tenuibus, albidulis, pubescenlibus; rhizomate repente; frondulis ellipsoideis, obtusis, basi cordatis, brevè petiolatis, patulis; nervillis furcatis; sporotheciis parvis, ad bifurcationem nervillarum ferè semper sedentibus; sporangïs ovatis; annulo $12-13$ arliculato, crenis gibbosis; sporis ovoideis.

Habital in insula Cuba. (Linden, n. 1873.)

Filix tenera.

IcoN. : Tab. VI, fig. 3.

(Dimensions : Jongueur totale, 20 centim.; stipe assez court; $22-24$ frondules, ayant $16-17$ millim. de longueur, sur 5 millim. de largeur.)

Les frondes croissent très-rapprochées à l'extrémité d'un rhizome gros comme le petit doigt d'un enfant; le pétiole et le rachis sont blanchâtres et fortement pubescents. Les nervilles déliées, écartées les unes des autres, simples ou fourchues, atteignent la marge; le mésonèvre est flexueux à son extrémité.

Il. Nervosa, F., loc. cil., p. 2.í\}.

- Frondibus pinnatis, linearibus, acuminatis; stipite el rachi brevibus, villoso-tomentosis; frondulis ovalo-fulcatis, obtusissimis, brevissimè petiolatis, ullimis deflexis, basi. subcordatis, supernè auriculatis, in ambitu crenato-repandis; nervillis lenuibus, furcatis, suprì scalpturatis; sporotheciis rotundis, dorsalibus; receptaculo nullo; sporangiis rotundatis; annulo 13.14 articulato, luto; sporis brevibus, ovoideis. 
Habilat in insulis Plilippinis. (Cuming, sine nuntero.)

Filix parva, angusta, glabia; frondibus fasciculatis.

Icon. : Tab. II, fig. 4.

(Dimensions : longueur totale, 22-24 centim. et jusqu'à 30 dans un de nos spéeimens, sul environ 2 centim. de largeur; Te stipe est presque filiforme, el n'atteint guère que $2-4$ centin.: nous comptons une trentaine de paires de segments; les sporothèces sont peu nombreux.)

Fougère terréstre, émettant 6-8 frondes attachées sur une racine fibreuse; le pétiole et le rachis sont pubescents et presque tomenteux; le tomentum est court et blanchâtre; les frondes se terninent par une pinnule caudiforme dentée et sinuée; le sommet est pinnatifide. I.es nervilles se dessinent en relief sur la lame des frondules et elles atteignent la marge.

Le port de cette plante la rapproche beaucoup des polypodium, mais elle est pinnée et les sporothèces sont dorsaux.

\section{CAMPYLONEVRON, Presi.}

$$
\text { F., Gen. filic., p. } 257 \text {. }
$$

I. Jamesoni, F., loc. cil., p. 259.

Frondibus articulatis, lanceolatis, obuesiusculis, basi acutis, glabertimis, lavibus, lucidis, siccitate flavis, unargine incrassatis; petiolo brevi, undo; nervillis validis, scalputrutis, apice turgido, pellucido, Iroliferis longissinnis; rhizomute contorto, radicellis nigris, longissinis donato; sporolheciis remotis, ad apicem nervillarun liberarun evolvenlibus; spovangiis rolundatis; anuulo lato, 12-11 atticulato; sporis crassis, reniformibus, lutescentibus.

Habitat in Quito (Jameson).

Icon. : Tab. II, fig. 5 .

(Dimensions : longueur, 15 centim., sur $10-12$ millim, de largeur.)

Le rhizome est contourné, de la grosseur d'une plume d'oie; il porte de longues fibrilles noirâtres et les débris du pétiole des frondes appartenant aux générations antérieures. Les nervilles, légèrement colorées en brun, forment des aréoles à pans courbes, mais on ne voit guère de sporothèces que sur les nervilles droites et très-longues qui partent du mésonèvre.

II. Cubense, F., loc. cil., p. 259 .

Frondibus angustè lanceolatis, basi et apice altenuatis, glaberrinuis, lucidis, Inarginu subcrispis nervillis crassis, scalpturatis, petiolo rigido, sulcato; rhizomate inequali, squamoso; squanis pallidis, ovatis; sporolheciis auratis, multi-seriatis, aliis supra nervillam liberis, aliis supra nervillas curvatns, anastomosantes positis; recep- 
laculo puncliformi; sporangïs congestis, rolundis, brevè pedicellatis; annulo lato, $12-14$ arliculalo; articulis crassis; sporis obliquè ovalibus.

Habilal in Cuba. (Linden, n. $0^{\circ}$ 1912.)

Filix rigida, angusta, glaberrima, lucens; mesoneuro lucido, habilu C. tæniosi, sed minor; pedicello longiori el fronde angustè lanceolala, non lineare.

Icov. : Tab. III, fig. 2.

(Dimensions : longueur des frondes, 30 centim. et plus sur 9-10 millim. de largeur. Le pétiole égale la lame en hauteur.)

Jolie espèce très-férace et à sporothèces dorès; elle est fort glabre, lisse et luisante, fructifiée du sommet à la base; les sporothèces qui se rapprochent le plus du mésonèvre sont portés sur une vénule droite. Les autres, sur des courbes un peu flexueuses.

\section{CRASPEDARIA, Lk.}

I. Gestasiana, F.

$$
\text { F., Gen. filic., p. } 263 .
$$

Frondibus dissimilaribus, opacis, remotis; squamis basi scariosis, rolundis, pilos rufos, longissimos emillentibus, sublus el ad petiolos, majores el numerosiores; sterilibus ovalis, integris, peliolalis; ferlilibus subspalulatis seu ovalo-lanceolatis, in petiolum longum desinentibus; caulibus filiformibus, flexuosis, ramosis, radicantibus; squamis linearibus, longissimè altenualis, patulis, aureis; sporotheciis paucis, crassis, squamis piliformibus, rufis abscondilis; sporangïs rolundis, pedicello longo; annulo lalo, 16 articulato; sporis crassis, lecuibus ovoideis, comipressione deformibus.

Habitat Rio Janeiro. (De Gestas.)

Filix arboricolu, longè repens, squamis auratis tecul.

Icon. : Tab. IV, fig. 2.

(Longueur des frondes stériles, 2 centim. que se partagent le pétiole et une lame qui a 4 millim. de largeur; longueur des frorides fertiles, 2-3 centim. sur 2 millim. de largeur. Les tiges sont filiformes.)

Cette charmante espèce est la plus délicate du genre et en même temps la plus écailleuse. Elle est couverte de poils dorés conme le Polypodium aurisetum de RADDI; mais outre que les proportions diffèrent, les frondes stériles de notre espèce ne sont ni lancéolées ni ovales lancéolées, mais bien exactement ovales; en outre les frondes fertiles n'ont point leur marge débordée par les sporothèces. La conparaison qui peut être faite de la figure que nous publions arec celle donnée par RADDI, mettra en évidence les caractères différentiels de l'une et de l'autre plante. 
Nous consacrons cette espèce au souvenir de M. de Gestas, ambassadeur au Brésil, mort glorieusenıent dans la baie de Rio-Janeiro, après avoir sauvé plusieurs naufragés et tenté d'en arracher un plus grand nombre à la mort.

II. Numularia, F., loc. cil., 1. 264 .

Frondibus dissimiluribus, glaberrimis; sterilibus subroundis, obovatis opacisque, margine remotè dentato-crenatis; petiolo filiformi; mesonevro ad apicem evanescente; nervillis superioribus cnun proximis in arcus angulatos coalitis, areolas hexagonoideas efficientibus; fertilibus linearibus, undnlatis. petiolo filiformi; sporotheciis binis, suboppositis, in depressione laminarnm sitis; receptacnlo punctiformi, nigricante.

Habitat in Philippinis. (Luzon; Cuming, Filic. Plilip!., n. ${ }^{\circ} 121$. )

Crypsinus num mularius. (Presl, Epim.bol., p. 123.)

Marginaria nummularia. (Presl, in Mey. herb.; Presl, tentam. pterid., p. 188.,

Drynaria neglecta, J. Sm. in Hookr, J. bot., 111, 397. (Excl. syn., Blum.)

Polypodium pyrolıfoliun. (Goldm. in Nov. act. nut. cur. nat. 19, suppl. 1, 453.

Filix repens; rhizonate filiformi.

Icov. : Tab. $V$, fig. 3.

Cette plante curieuse a servi de type au genre Crypsinus, fondé par Prest. (Epim. bol., l. c.). C'est surtout la nervation qui a conduit le savant et regrettable ptéridographe à la distraire des marginúric arec lesquels il l'avait placee précédemment. Il est certain que la nervation, légèrement dissidente, la rapproche des goniophlebium.

La circonstance déterminante qui doit faire laisser cette plante avec les craspedaria, est déduite du port. Les frondes dissimilaires se constituent sur un rhizome traçant; elles sont ici tout à fait glabres, tandis que des poils abondants les recouvrent dans la presque totalité des autres craspedaria.

\section{DRYNARIA, Bory.}

F., Gen. filic., P. 269 , tab. XXI, B, fig. 1.

1. Vestita, loc. cil., p. 271.

Frondibus simplicibus, crassis, opacis, longè petiolatis, sparsis; caulibus repentibus, crassiludine pennce columbce; laminis lanceolatis, oblusiusculis, squanosis; squamis supernè sparsis, inferuè deusè imbricatis; mesonevro nigrescente, plano; sporolheciis pancis, marginulibus, ctassis, ovoideis, immersis; receptaculo elliptico, sul, immerso; sporangiis ellipticis, magnis, predicello longo; annulo 16-17 articulcto, tenui; sporis lcevibus, mugnis, lutescentibus, exuctè ovoileis.

Habitat in Mexico. (Talea, 5000, $\mathrm{n} .^{\circ} 6532$. .)

Filix repeus; frondibus distautibus, conformibus.

Icos. : $T \iota b . I V, f_{i}$. 3. 
(Dimensions : longueur totale des frondes, 6-8 centim., sur 5-7 millim. de largeur; le pétiole a $13-14$ millin. de longueur.)

Les écailles sont orbiculaires et portent au centre une large tache noire. Quoique cette plante soit couverte d'écailles de même forme que celles des Drynaric, sect. des pleopeltis, avec lesquels on ne peut se dispenser de la placer, les sporothèces en sont dépourvus. Le rhizome est flexueux et écailleux; les frondes,: dures, coriaces, opaques, jaunâtres, ont des pétioles courbés légèrement en arc. Le côté supérieur des lames porte quelques écailles éparses; le côté inférieur en est presque entièrement couvert; le mésonèvre de cette même lame est plan et trèsnoir; il se rétrécit et disparaît en approchant du sommet de la fronde.

II. Prieurei, F., loc. cil., p. 271.

Frondibus lineacibus, acutis, crassis, cartilugineis, in petiolun brevem attenuutis, squamis planis, fimbriatis vestitis; fertilibus angustioribus; rhizomate repente, lenui; sporolheciis ovatis, apicen laninacum invadentibus, magnis, margineur excedentibus, in sulco elongalo sitis; sporangiis ellipticis, longè pedicellutis; annulo crasso, 13-14 articulato; sporis ovoideis, brevibus lcrvibusque.

Habilat in Guyana Gallica (Leprieur); nes non in insula Murtinica (11."le Rivoire).

Filix parva, rigida, crassa, acuta, repens.

Icon. : Tab. II, fig. 6.

(Dimensions : longucur totale, $6-7$ centim., sur 3 millim. de largeur; $9-11$ sporstheces, vecupant le haut de la fronde.)

Le rhizome est rampant, roide, redressé, chargé d'abondantes fibrilles tomenteuses, portant à des distances assez rapprochées des frondes roides, épaisses et opaques. Les stériles sont lancéolées, les fertiles linéaires et fructiferes vers le haut; un large mésonèvre noirâtre et luisant les traverse: elles se teminent en pétiole. Les sporothèces occupent la moitié supérieure des lames proliferes. Jls sont ovales, assez allongés et très-rapprochés; les sporanges, portées sur un réceptacle épais, presque linéaire, ont un très-large anneau et débordent les lames qui prennent un aspect toruleux, comme il arrive à celles de l'espèce suivante.

III. Torulosa, F., loc. cil., p. ?7 1 .

Frondilus pinnalifidis; stipite fusco; rhizomate repente, unduluto, squamis riguidis, nigris, uciculariformibus vestitis; segmentis tigidis, linearibus, apice attenuatis, squan s angustis, fuscis conspersis; frucliferis uspectu toruloso; sporolheciis ovatis, crassissimis, geminato-conniventibus; receptaculo sublinear i, crusso, nigro, prominẹte; sporangüis longè ellipticis; annulo crusso, 12-13 acticuluto; sporis lecribus, reniformibus. 
Habitat in Cuba. (Linden, sine numero.)

Filix rigida; mesoneuro ebenteo; sporotheciis lamina lutioribus.

Icon. : Tab. $V$, fig. 4.

(Dimensions : longueur totale, 22-23 centim, dont le stipe fait un peu plus de lit moitie; segments 5-6, ayant 3 millim. de largeur.)

Les segments de la fronde sont fertiles jusque sur les décurrences qui marginent la tige. On peut compter environ 12 paires de sporothèces, et leur grosseur est hors de toute proportion avec les lames qu'ils débordent considérablement pour leur donner l'apparence en collies, indiquée par le nom spécifique. Les sporothèces tendent à la confluence. Le pétiole, le rachis et les mésonèvres sont noirs, les lames jaunâtres.

IV. Strecolona, F., loc. cil., p. 272.

Frondibus pinnatifidis; "stipitibus tenmibus, glabris, longis; rhizomate crassitudine pennce passerince; segmentis longissimis, flexuosis, linearibus, longè altenuatis, ussurgentibus; marginibus crispis, sıblus parcè squamosis, usque all coslam fiuclificcuntibits; receptaculo angusto, nigrescente; sporotheciis crassis, ovoideis, dislinctis; sporongiis elliplicis; annulo 13-15 articulalo; sporis curvatis reniformibusque.

Hrabitat in Mexico. (Talea altitml. 1500 -2000. Galeotti, n. ${ }^{\circ}$ 6532.) Nec non in Cuba (Antillis).

Icor. : $T a b . I V$, fig. 4.

(Dimensions: longueur totale jusqu'au somnet du segment terminal, 32-34 centim., six à hruit paires de segments presque opposés, ayant jusquä 15 eentim. de longueur sur $3-4$ millim. de largeur seulement; nous en possédons de beaneoup plus petits, trifides et fruetifères; il existe jusquà 20 paires de sporolhèees, s’étendant jusqu'au sommet de la pointe des segments; cette pointe est onduléc.)

Le thizome de cette plante est, relativement à la grandeur des frondes, extrêmement pelit. Il n'existe aucune espèce à segments aussi longs et aussi étroits. On troure, comme dans le $D$. torulosa, des sporothèces jusque sur les décurrences. Les sinus que forment les segments sont assez ourerts; les pétioles, le rachis et les mésonèvres ont une couleur noiràtre du côté supérieur; elle est hlanchâtre du côté inférieur.

V. Stejophilla, J. Sy.

Eudrysaria.

Frondibus articulutis, simplicibus, glabris, lanceolatis, oblusis, coriaceis, nargime dentatis; dentibns remotis, vix prominentibus; mesonevro crasso, apice evanescente; rhizomate subrotundo, crassiludine pennce columbince; sporotheciis apirilaribus, upproximatis, rolundis, saccatis, supernè gibbositate indicatis; sporangiis ellipsoideis; pedicello longo latoqne; annulo 14 articulato; sporis crassis, ovoideis, raro reniformibns. 
Habilat in insulis Philippinis. (Cuming, Fil. Philipp., n..$^{\circ} 122$. )

Drynaria stentopliylla, J. Sm. (Nomen solum.)

Icon. : Tab. VIII, fig. 3.

(Dimensions : longueur totale, $10-12$ centim., sur 12 millim. de largeur. Le pétiole est à la lame :: $1: 4$.

Le nom spécifique, stenophylla (à frondes étroites), donné à cette plante, n'est pas juste; un grand nombre de drynaria ayant des frondes bien plus étroites encore. Il eût èté bien plus juste de la qualifier de saccata ou d'immersa. En effet, les sporothèces naissent sur la fronde dans un enfoncement très-prononcé, d'une régularité parfaite et comme marginé en ses bords; la lame supérieure en est toute bosselée. Cette disposition existe dans quelques drynaria, mais d'une manière moins marquée. Les sporothèces occupent la partie supérieure des lames et nous en comptons quinze paires sur une étendue de 25 millimètres. Le rhizome, écailleux, conserve la base des pétioles des frondes qui s'y sont précédemment développées.

VI. Oodes, F., loc. cit., in Enumerat. specier., p. 270.

Frondibus ovatis, glabris, membranaceis, pellucidis, basi subcuneiformibus, margine leviter crenatis, apice obtusis; petiolo crinali, longissimo; nervillis remotis, areolis latiusculis; rhizomate filiformi, squanoso; squantis angustis, altenuatis; sporotheciis difformibus, subinmersis, ataxicis et pluriseriatis; sporangiis subrotundis; annulo 13 articulato; sporis globulosis, ovoideis, nigris.

Habitat in insulis Philippinis. (Cuming, Filic., Philipp., n. ${ }^{\circ} 58$. )

Polypodium oodes, Kze. (Nomen solum.)

Icon. : Tab. VII, fig. 4.

(Dimensions : longueur, 9-10 centim. Les lames ont entiron 4 centim. de longueur sur denx de largeur. Le pétiole est à la lame :: $2: 1$.

Cette fougère a un port et une consistance qui l'èloigne un peu des autres drynaria. Les sporothèces qui, dans les espèces à frondes simples, ne présentent qu'une seule rangée, en forment ici plusieurs, comme il arrive aux grandes espèces pinnatifides. Les pétioles ont une ténuité remarquable, ainsi que le rhizome qui est ranıant; les lames fertiles sont notablement ridées par la dessiccation. 


\title{
CYCLODIEAE.
}

\section{Indusium superum, in ambitu liberum.}

\section{POLYSTICHUII, Roth.}

\author{
F., Gen. filic., p. 277 .
}

I. Cyphochlamis, F., loc. cil., J. 279.

Frondibus lanceolatis, fasciculatis; stipile rachique squamulosis; squremis mollibus, margine strigillosis; frondulis pedicellatis, ovalibus, acutis, rigidis, mucronibus crassis, brevibus; inferioribus rhomboideis, basi truncalis, sursiim auriculatis, paucicrenatis; rhizomate crasso, squamis lanceolatis, nigrescentibus, lucilis; sporolhecuis globosis, crassis, approxinatis; indusio umbonalo, cupuliformi, caduco; sporangiis variabilibus, rolundis, obliquis, ellipticis; annulo 14-16 articulalo; sporis ovalibus, episporiatis.

Habilal in Cuba. (Linden, n.2175.)

Filix rigida, opaca, indusio cupuliformi notala.

Icon. : Tab. III, fig. 4.

(Dimensions : longueur totale, 30 centim. et sourent moins, sur 4 ceutin. d'euvergure; uю. vingtaine de pinnules sont attachées à la fronde qui est pinnatifide au sommet.)

Les frondes naissent en grand nombre et très-rapprochées sur un gros rhizome. Elles sont roides, robustes, pinnées; les pinnules ont une forme presque quadrilatère; les angles se terminent en une pointe dure et allongée. Toute la plante est de couleur paille. Lintérêt organique qui s'attache à la diagnose de cette plante, se trouve dans ses sporothèces presque apicilaires et formés de sporanges très-inimement unis, et serrées au point de paraitre comme aggglutinées. Ces organes naissent sous l'épiderme quills soulèvent plus ou moins complétement en le déchirant. Les débris de cet épiderne persistent et remplacent l'indusium, qui fait alors défaut. Lorsque ce tégument existe, on ne le voit guère à son état normal que dans la jeunesse du sporothèce. D'abord il est bonbé; mais bientôt les sporanges, en se développant, le soulèvent; si le pédicelle résiste, les bords de ce tégument protecteur sont portés en haut et il prend l'aspect d'un godet ou celui d'un parapluie renversé. Si le pédicelle cède, l'indusium tombe, ou bien sill persiste, il se flétrit et cette persistance n'a plus rien d'organique. 
II. Ilicifoliun, F., loc. cit., p. 279 .

Frondibus pinnatis, linearibus, fasciculatis, virgatis, stramineis, glaberrimis, apice scepè radicantibus; frondulis remotis, pedicellatis, rhomboideis, novellis subquadrangularibus, omnibus ad angulos aristatis; aristis longis, setaceis; sporotheciis crassis, rotundis, paululìm immersis, 4-6 in utroque latere laminarum; indusiv perfacilè delapso; sporangiis ovoideis, longè pedicellatis; annulo 18.19 articulato; sporis ovalibus, episporiatis.

Habitat in insula Cuba. (Santiago; Linden, n.0 2193.)

Filix singularis, aristata, virgata.

Icos. : Tab. VI, fig. 4.

(Dimensions: longueur totale, $42-48$ centim., sur 3 centim. d'enrergure; 34 paires de frondules; stipe radicant au sommet.)

Cette fougère, très-remarquable, est presque épineuse, tant les mucrons des frondes ont de rigidité; elle est glabre et le rachis ne porte que quelques écailles éparses. Le rhizone a la forme d'une petice souche dressée et écailleuse; ces écailles sont larges et de couleur fauve. Les frondes s'allongent considérablentent, se dénudent et deviennent prolifères; les frondules des jeunes plantes sont presque quadrilatères et chacun des angles est muni d'une nerville robuste, anincie en mucron. Les sporothèces sont de grande dimension. L'indusium est petit, caduque, et on ne peut le voir que sur les sporothèces jeunes.

III. Viviparuis, F., loc. cil., p. 280

Frondibus mixtis, infernè bipinnatis, supernè pinnatis, virgatis, radicanti-viviparis; rachi valido, canaliculato, rufescente; squamis lanceolatis, acuminatis, ad centrum nigrescentibus; frondulis obtusis; inferioribus basi pinnatis, segmentis mucronatis; mucronibus brevibus, crassis; frondulis superioribus subrhomboideis, sursim auriculatis, crenulutis, apice mucronatis; sporotheciis 4-6 remotis, suprò impressis; indusio orbiculari, fusco-rufescente; sporangïs rolundis; annulo 14 articulato; sporis parvis, nigrescentibus.

Habitat in Cuba [Santiago $]_{\rfloor}^{\top}$. (Linden, n. 1742 , partiml ${ }_{\perp}{ }^{\circ}$ )

Filix virgata, apice radicans, semi-bipinnata, flexibilis.

Icov. : Tab. III, fig. 3 .

(Dimensions : longucur totale, 36 centim., sans le stipe; les pinnules inféricures ont 2:-26 millin. de lougueur, sur 1 ecutim. de largeur à la base; les pinnules inférieures rarient de 1-2 eentim.; il existe une quarantaine de paires de pinuules environ.)

Plante curieuse et parfaitement distincte, flexueuse, très-allongée, étroite ; ì pinnules de la base, portant plusieurs lobes distincts; celles du sommet sont simplement auriculées rers la partie supérieure. Le pétiole et le rachis sont écailleux, à écailles blanchàtres sur les bords et brunâtres au centre. Dans le spé- 
cimen que nous décrivons, le rachis porte à son extrémité un véritable rhizome chargé de 7-8 frondes parfaitement conformées; l'indusium est caduque, orbiculaire et fortement coloré en brun-rougeâtre. Les sporothèces impressionnent la lame supérieure; les nervilles y sont imprimées en relief et très-rapprochées les unes des autres.

\section{ASPIDIEAE.}

Indusium reniforme, subhemispharicum aut cordatum sinu affixum.

\section{CISTOPTERIS, Bernh.}

I., Gen. filic., p. 299 .

Retresceis, F., loc. cil., p. 300.

Frondibus tripinnatis, in ambilu ovalibus; stipitibus flexuosis, filiformibus, squnnosis; squamis rufescentibus, cancellatis, al basim stipitis homomallis, dein sparsis; rachibus pilosis; pilis strigillosis, brevibns; pinnulis oblongis, basi pinnatifidis; segrmentis ovatis, pellucilis; sporolheciis terminalibus, rufescentibus, depauperalis; indusio rufescenle, parvulo; sporangïs lenticularifarmibus; annulo lato, 14-15 articulato; sporis ovoideis.

Habitat in Cuba. (Linden, no. 1877.)

Filix venusla, pellucida, aul rachides squumosa villosaque; statura mediocri.

Icos. : Tab. VI, fig. 5 .

(Dimensions : longueur totale, 18-20 centim. Les piunules de la base, 4 centim.: la pinnelle inférieure est plus grande que les autres.)

Cette espèce est très-élégante, ovale en son pourtour, tendre et délicate comme ses congénères, mais plus élastique. Les pétioles sont épaissis à la base et couverts, ainsi que le rachis, d'écailles roussâtres, en grillage. Ces mèmes parties sont chargées de poils courts et strigilleux. Les frondes et leırs divisions se courbent en arc. Les sporothèces ont une couleur roussâtre très-manifeste. 


\section{TABLE ALPHABÉTIQUE.}

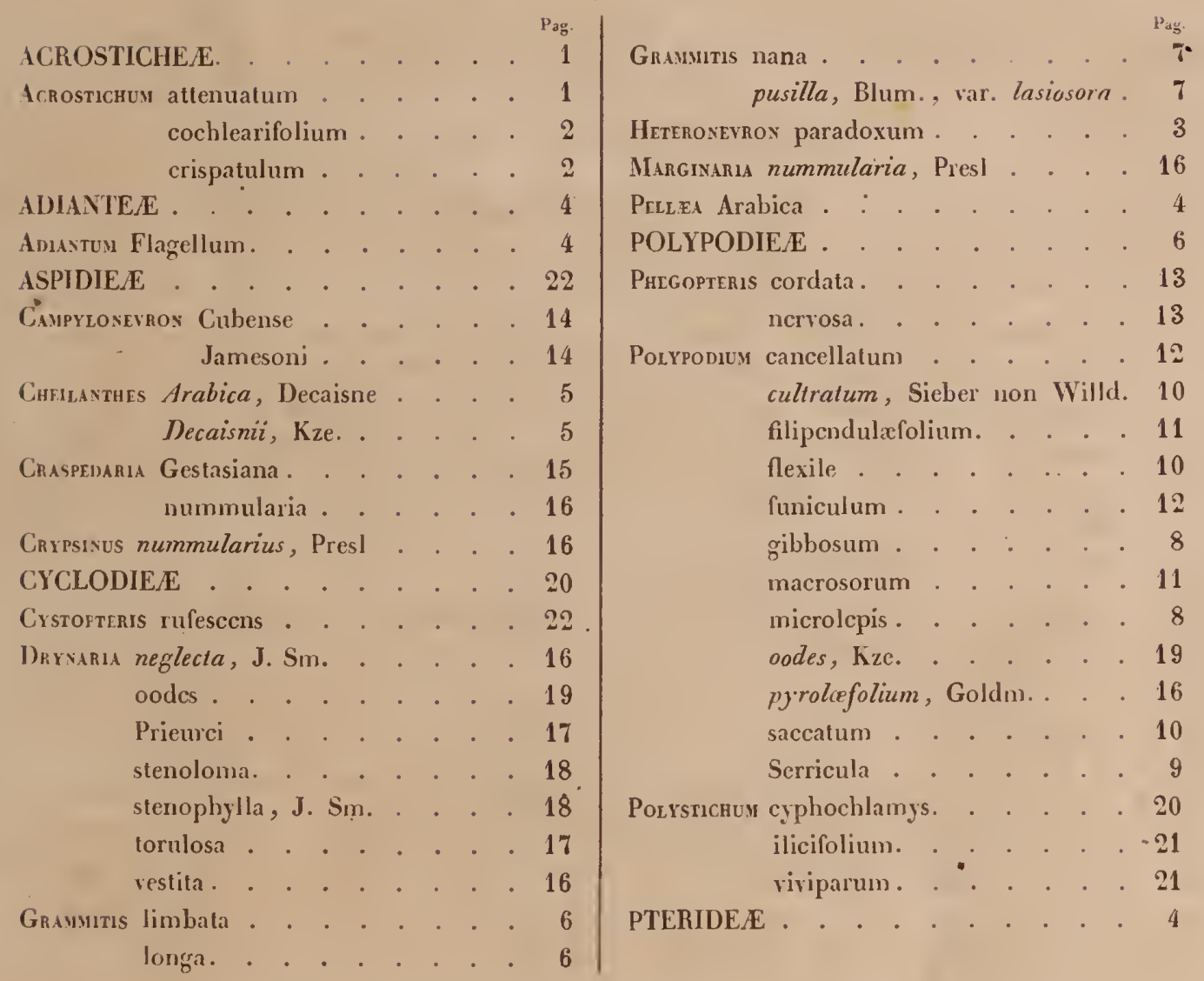

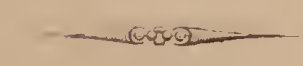





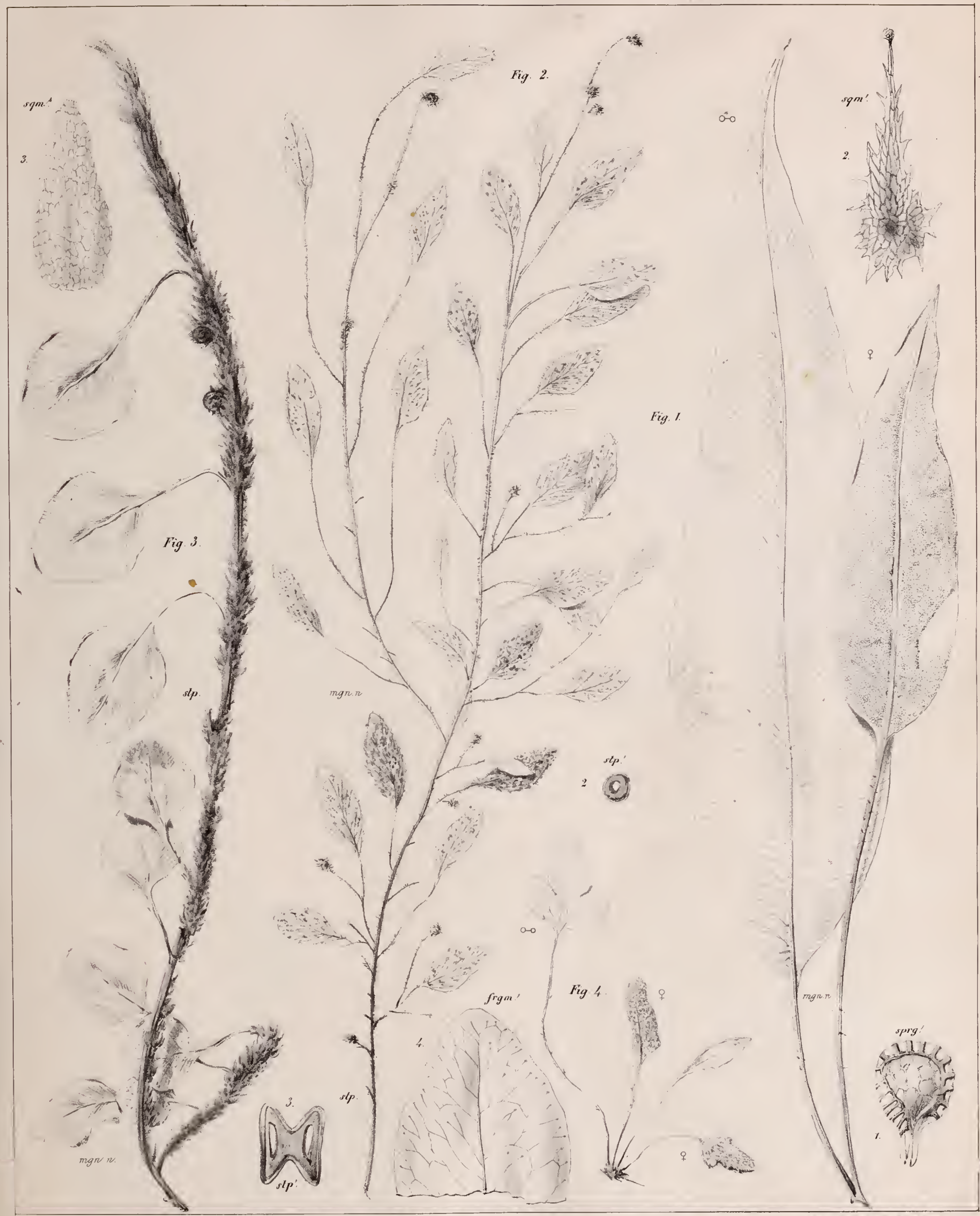

rig.t. Acrostichum allenualum, $f$ ? rig. 2.

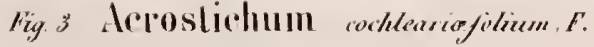

rigig, lleteronerron paradoxum, $F$. 
$\because$ 


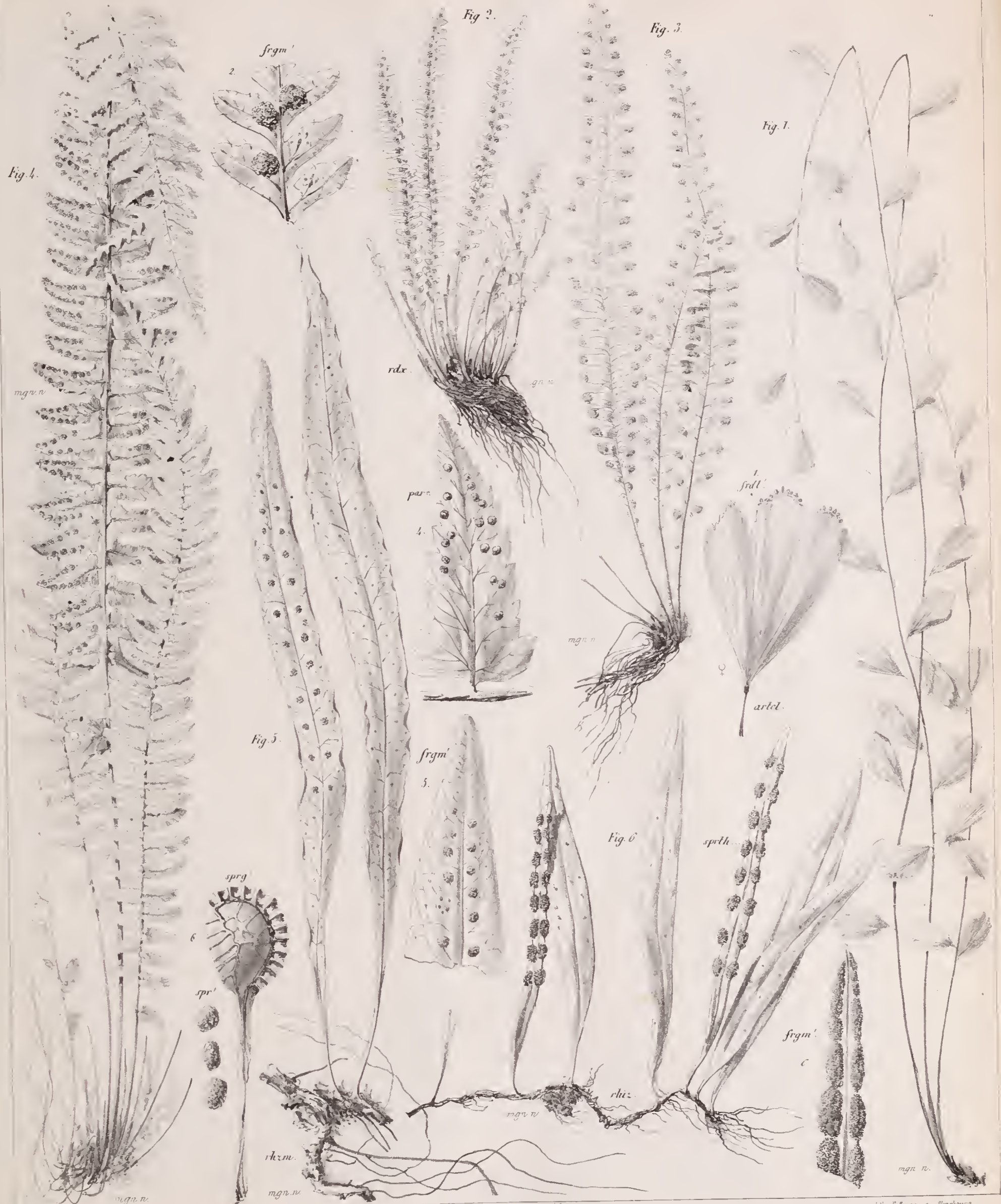

Fiy'. Adianlum Flagellum, $F$

Figy? I'olypodium giklesum. F

Fig. o.
Fiy.4. Phegopteris nervosu $F$ :

Fig.5. Caimpylonevroul Jamesoni, $F$

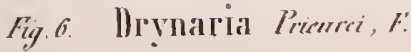





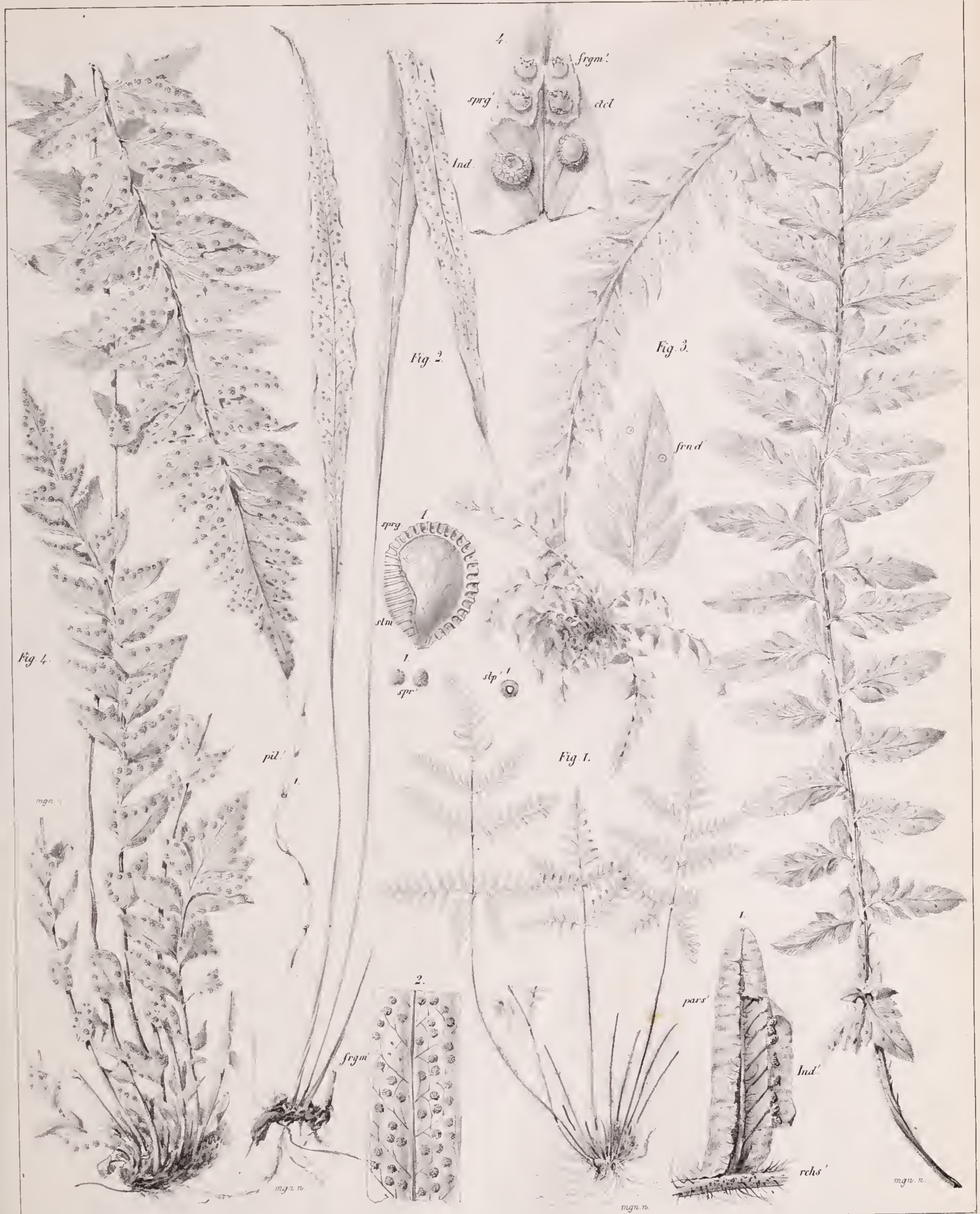

rig. 1. Pellita_traticare : 

Filices nova.

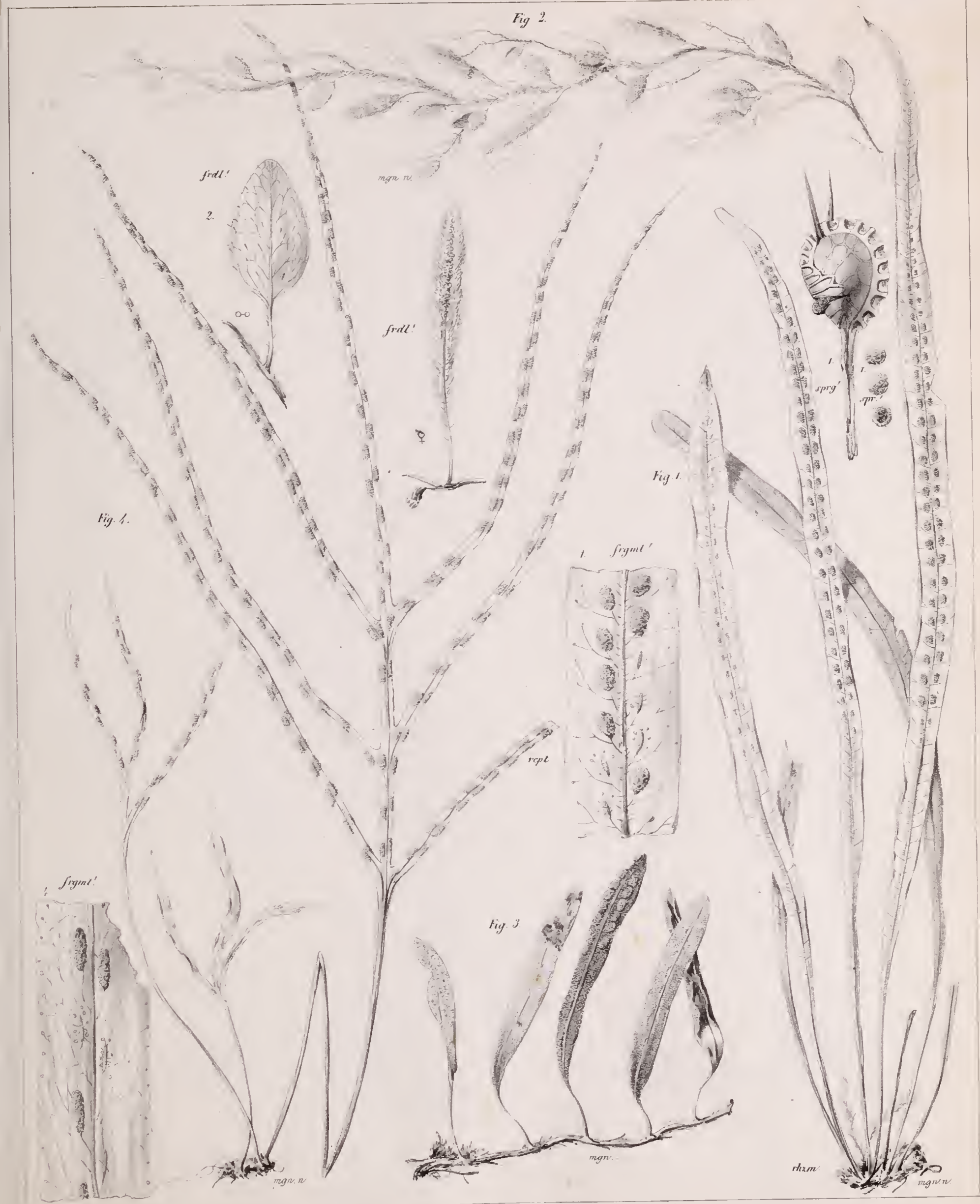

Frg. 1. Grammilis tonga $F$.

Fig. 3. Drynaria meslita $F$

figy \& Craspedarla Geslastand, $F$. 

$\therefore, \cdots$

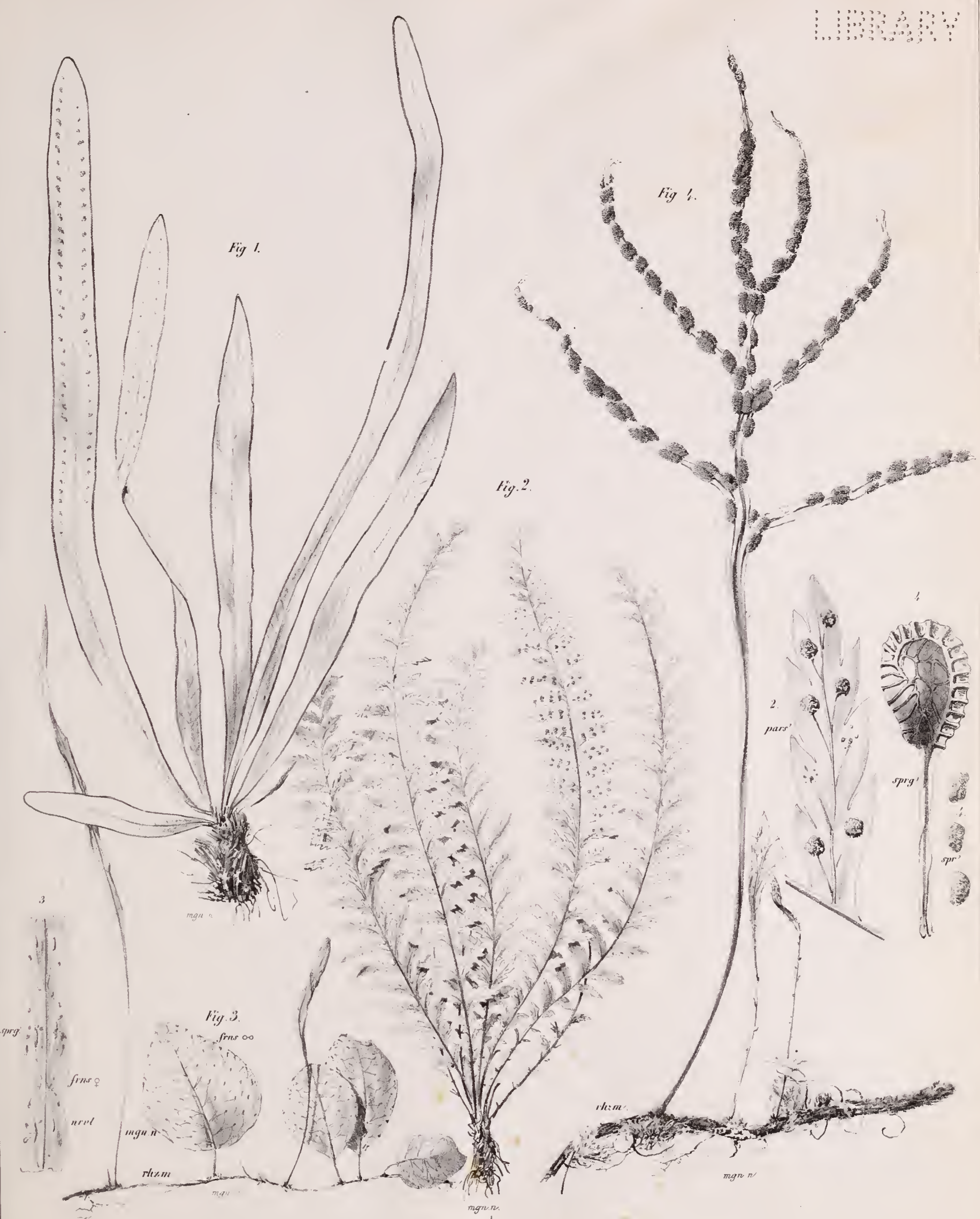

Fiy, Grammitis limbala, $r$.

Frig. 2. Polypodium firipendultefotinum $F$ :

Fig.3 Craspedaria nummalaria, $r$

rig.t. Mrynaria torulesa, $F$. 


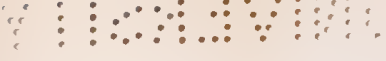

$\therefore \because \therefore \therefore$

$\because \because \ldots$ 


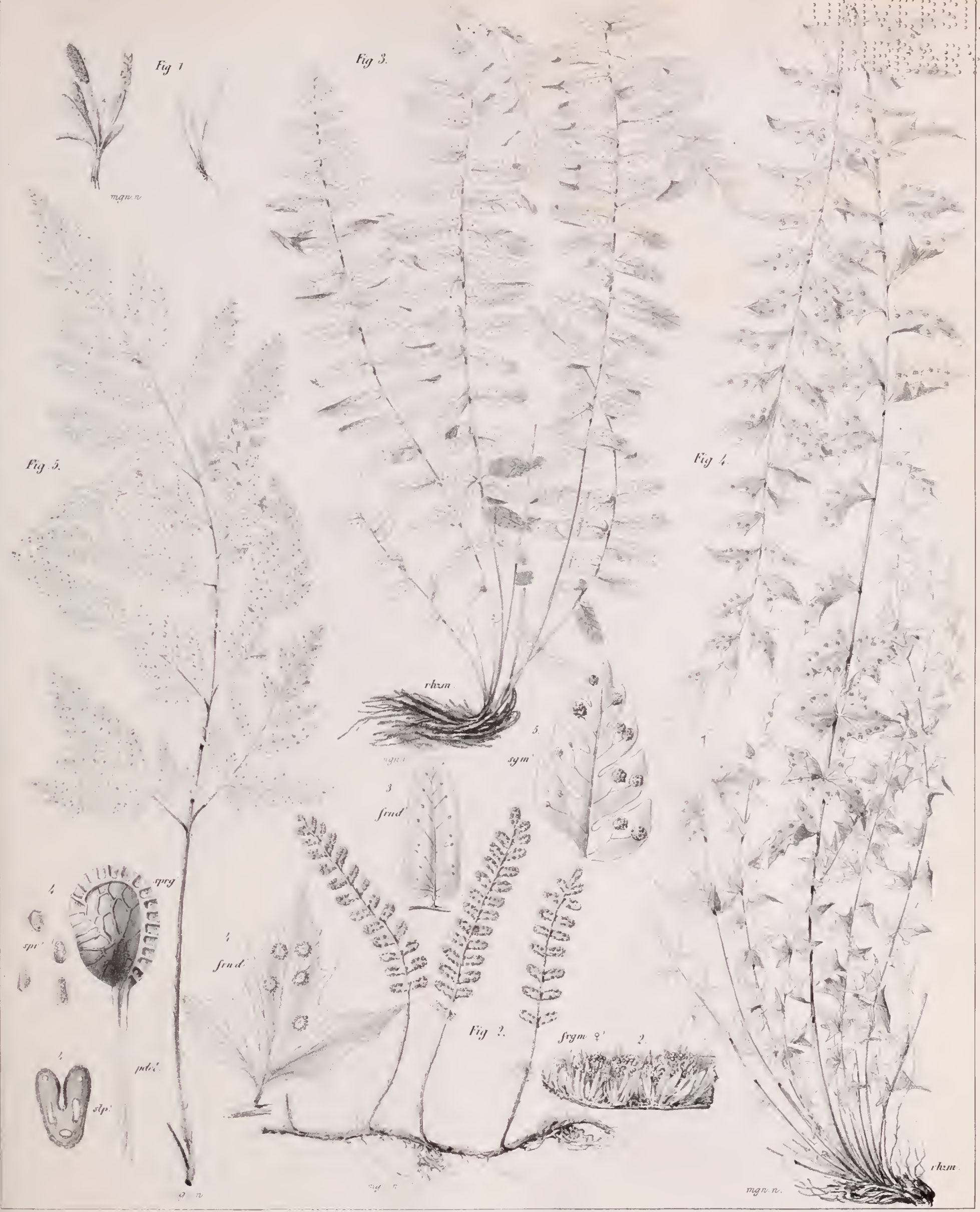

frig, Grammilis mand:

Fig. 3. Plegopteris mordatir. $F$

Fig.? l'olvposlium mescolopes, f'

rig.t. Polystichum ilicifilium, $F$.

rig.5. Cystopleris refescens, $F$. 

Pilices nova

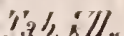

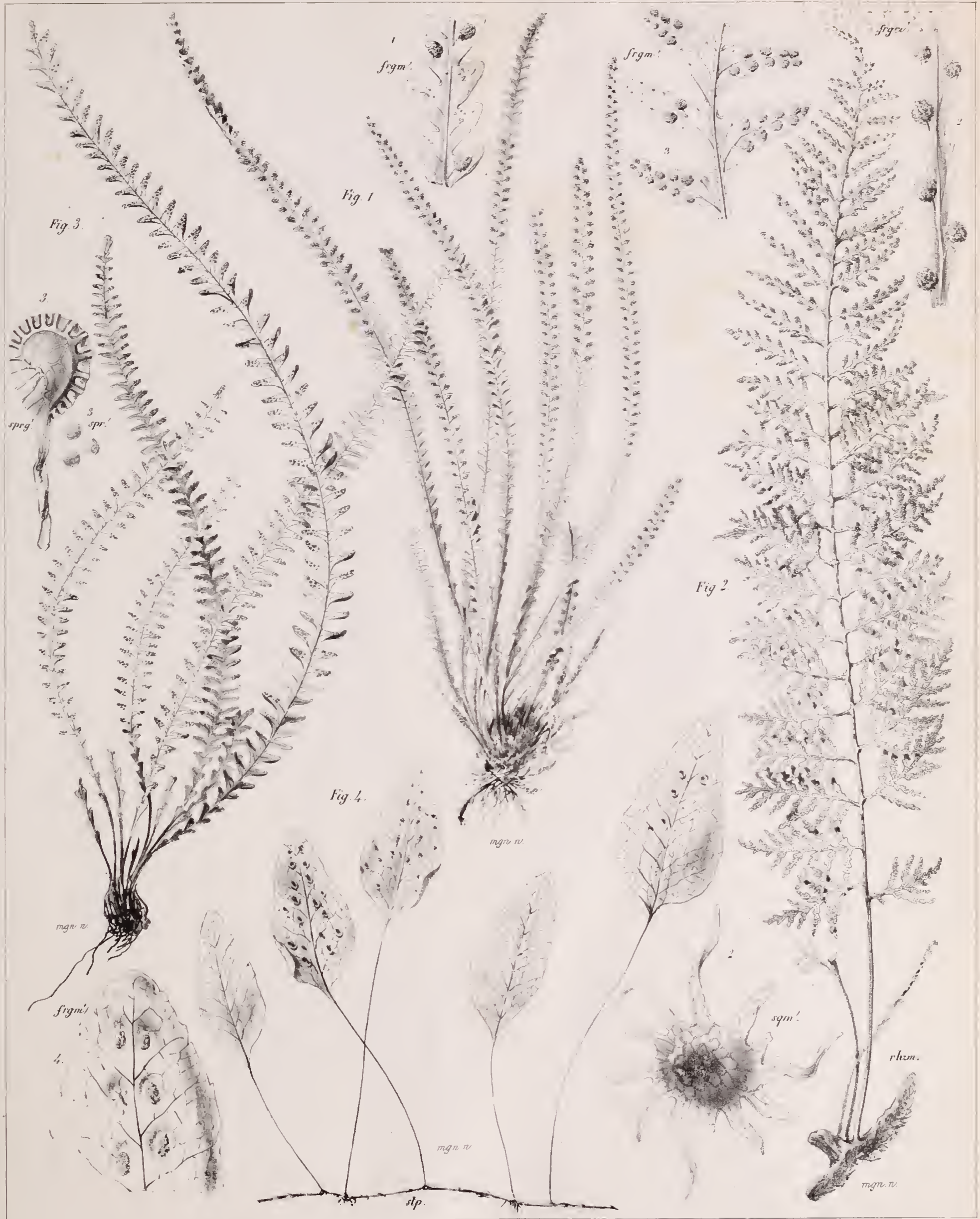

Fry. I. Polypodium Serricula F.

Fig 2 



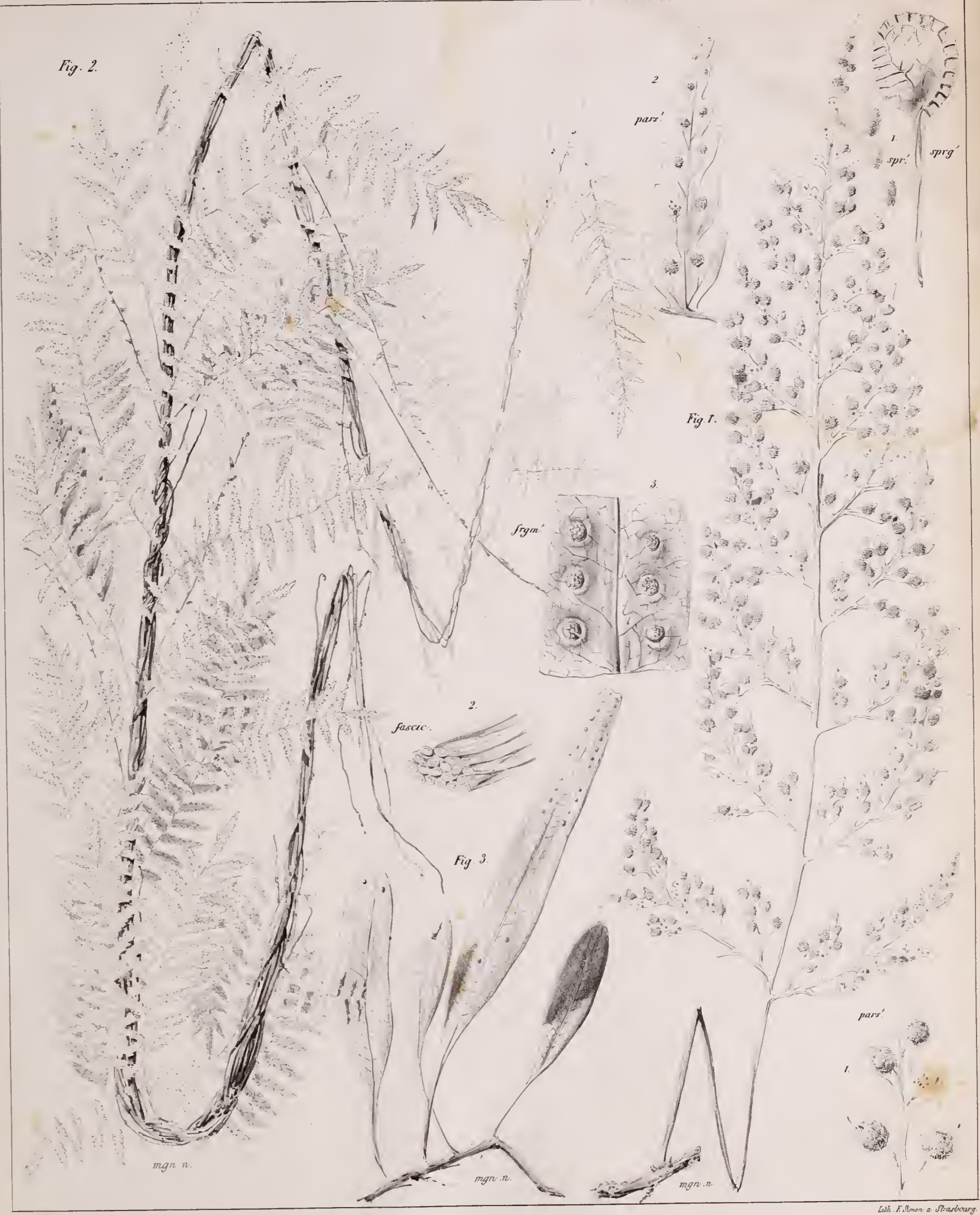

Fig. Polypodium macrosorum, $F$ | I Fig.2. Polypodium Frniculum, $F$ :

Fig.3. Drynaria slenopleylla JSm 



\section{IGONOGRAPHIE}

\section{DES ESPECES NOUVELLES}

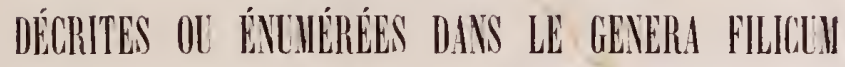

ET

\section{REVISION DES PUBLICATIONS ANTÉRIELRES}

RELATIVES A LA FAVILLE DES FOUGERES

PAR

A. L. A. FE,

PROFEsSeur DE BOTANIQUe a LA FACULTÉ DE MÉdecine DE -STRASBOURG.

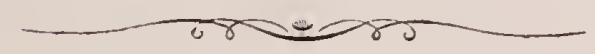

SIXIÈME, SEPTIÈME ET IIUITIÈME MÉIIOIRES.

VEUVE BERGER-LEVRAULT ET FILS, LIBRAIRES.

PARIS, rue des Saints-Pères, 8. | STRISBOURG, rue des Juifs, 26.

$$
\text { PARIS, }
$$

Rue Hautefeuille 19, J. B. BAILLIĖRE, libraire.

Place de l'École de médecine, VICTOR MASSON, libraire.

$1834-1837$. 



\section{PREFACE.}

Dans les sixième et septiène Mémoires, nous nous sommes attaché à reproduire par des figures, accompagnées de détails analytiques, les espèces nouvelles décrites ou énumérées dans le Genera, afin de tonner à ces espèces une existence définition, persnadé par une longue expérience, de l'insuffisance des descriptions les mieux faites, surtout lorsque les genres sont nombrenx et que les plantes, quoique distinctes, manquent le caracteres saillants.

Nous avons pensé qu'il était utile de décrire en outre, et inêmo de fig̨urer quelques espèces inédites curieuses que nous possédions en herbier, ce qui nous a permis de fortifier par de nombreux exemples, les bases nomelles de la classifica. tion des fougères; tel est l'objet du huitième Vémoire.

L'importance de la nervation comme caractère générique na pas encure prévalu complétement. Une génération nourelle est nécessaire pour yu’elle domine la ptéridographie. Les botanistes contemporains, qui se sont occupés ou qui s’oecupent des fougères, avaient tous, en quelque sorte, des engagrements pris: tous avaient suivi Swartz el Willdevow; l'un el l'autre si célèbres par lemrs travanx; ils liont pas voulu changer leur nomenclature, et peut-ètre ont - ils lésisté sans Io savoir à leur propre conviction. Parmi ces savants distingués, il en était deux surtont yui pouvaient faire adopter les nouvelles idées: Kuxze, anquel on doit les Analrat botanica, et les suites à Scmlumr, splendide onvage qui a malı i ce botaniste habile la réputation d'un homme exact et consciencieux, et M. Inoker. lequel possédant de vastes collections aime à décrire ce qu’elles renferment dintéressant. Ces auteurs féconds sont restés plus ou moins fidèles d leurs antécédrnts. Une route nouvelle leur était ouverte, et, quoiqu'elle fùt plus sùre que celle dans laquelle ils s'étaient depuis longtemps engagẹe, ils ont refusé de s’y engager.

Quel but se propose-t-on en créant des classifications? Faire des grunpes naturels et donner des moyens faciles détude. Or, ce serait refuser de se rendre 
à l'évidence que de ne pas accorder ce double mérite à la méthode que nous avons suivie, en cherchant à la confirmer et à l'étendre. Que l'on se donne la peine de comparer un herbier classé d'après les bases créées par SwarTz, et un lierbier disposé d’après les ptéridologues modernes, et l'on constatera bientôt la supériorité de ce dernier sur l’autre, à ce point même que les personnes étrangères à la botanique seront frappées de l'unité de physionomie des groupes formés.

Il est facile de montrer les côtés faibles d'une classification, qui est toujours, a rrai dire, une cuvre d'esprit. Mais l'équité veut que l’appréciation qui en est faite se préoccupe aussi des côtés avantageux, afin de voir s'ils l'emportent en valcur sur les côtés faibles, et c’est ce qu’on néglige trop souvent. Il y a dans les sciences, comme dans les aflaires de ce imonde, un parti pris. On examine noı pour juger, mais pour condamner. Il en résulterait un mal irréparable si le temps ne parvenait à donyter les résistances. C'est sur lui que nous comptons, et nous voyous à mille indices, quil tient ses promesses.

Dans mne publication nouvelle, Filices horli botanici Lipsiensis (1856), 11. Mettexius s'est efforcé de concilier le système ancien qui maintient la réduction des genres avec la méthode nouvelle qui les augmente. Un genre étant admis : Pulypodium, Asplenium, Aspidium, ou tont autre, et il est divisé par l'auteur en iutant de sections que les espèces renfermées dans le genre adopté offrent de nervations diflérentes, après toutefois qu'elles ont été au préalable partagées en rspèces à frondes simples ou divisées. Les noms de genre Marginaria, Goniophlebium, Cyprophlebium, Doodya, Phlebodium, Anaxetum, Pleocremia, appliqués à ces diverses nervations, reviennent donc on peurent revenir dans un mème genre. C'est là, sans doute, une concession faite au systène que nous suivons, mais ce llest point assez, car clııcun des sous-genres ainsi créés forme des groupes naturels qui peuvent ètre séparés sans inconvénient. C'est un pas de fait; il ne semble pas que ce soit assez.

11. Mettexios, dans une monographie du genre Polypodium, très-récemment publiée, y réunil presque tous les genres du groupe des polypodices. Liauteur déclare quil a cherché de bonne foi et sans les trouver, les caractères différentiels des genres admis par Prest el son école, et il me semble quil eût pu les voir. Car si lon voulait se montrer aussi rigoureux en planérogamie, la plupart des gemres, ainsi que les classes et les familles devaient être reformés, des caractères différentiels absolus n’existant pas toujours pour chacun d'eux.

Sans doute, on trouve des genres faiblement constitués parmi ceux de Presı, de J. Snitri, et même parmi les nòtres; mais il en est anssi un bon nombre de parfaitement distincts, aujourd'lui réunis au nouveau genre Polypodium, de 
M. Metrenius; aussi doutons-nous que ce travail satisfasse les esprits exigeants, et qu'ils consentent à ne plus reconnaître comme distincts les genres Adenophorus, Anaxetum, Calymmodon, Campylonevron, Clerysopteris, Craspedaria , Cryptosorus, Dipteris, Drynaria, Goniophlebium, Grammitis, Microsorium, Plectopteris, Pleuridium, Niphobolus, Loxogramme, Selliguea et Xiphopteris, qui grossissent ce genre, composé d'environ quatre cents espèces ou sous-espèces, partagées en un nombre considérable de divisions et de subdivisions.

Il résulte de l'examen d'un grand nombre d'ouvrages modernes relatifs à la botanique et aux sciences naturelles, travaux recommandables cependant à plusieurs titres, un sentiment de profond découragement. On se demande sur quelles bases la botanique descriptive pourra s'appuyer pour progresser, et l'on arrive à craindre que ces bases n'existent pas. Comme chaque auteur détruit, en débutant dans la carrière, les travaux de ses prédécesseurs, il ne doit pas s'attendre à être plus heureux pour les siens. On craint de ne plus trouver la vérité et l'on est disposé à croire que l'homme, en présence de la nature, est impuissant à grouper méthodiquement ses diverses productions.

Nous avions crusuivre une marche rationnelle en fondant nos genres sur la nervation qui détermine la forme, et sur la forme qui est subordonnée à la vie physiologique.

Ainsi le genre Adenophorus se trouvait justifié par un facies tout spécial, par des sporothèces naissant sur le dos de la nerville médiane, et par la production constante, sur des frondes à segments étroits, de glandes pyriformes nombreuses; le genre Cryptosorus par des sporanges endodermiques, déterminant à leur maturité une f'ente ovoïde à marge épaisse; le genre Plectopteris par une nerville prolifère, uniquement vers son bord supérieur;l'inférieur restant stérile afin de laisser à la moitié de la lame la possibilité de se relever pour couvrir les sporanges qui sont ainsi héliofuges, etc.; la nervation a une grande valeur taxonomique, c'est le squelelte de la plante; mais dautres organes peurent sembler tout aussi importants ou même le paraître davantage.

Nous ne pouvons penser que l'on réunisse désormais au Polypodium, le genre Niphobolus, si bien caractérisé par le mode d'arrangement des sporanges qui sont accombants les uns à l'égard des autres, et par la nature curieuse de ses produclions épidermoïdes, non plus que les genres Xiphopteris, Campylonevron, Drynaria, Selliguea, et tant d'autres si faciles à reconnaìtre à la première vue.

Certes tous les genres nouveaux n'ont pas la mème valeur. Le Grammitis confine avec le Polypodium, quoique avec un autre halitus. Le Goniophlebium et le Polypodium se touchent par certaines espèces; mais ce n'est pas une raison suffisante pour ne pas les admettre. 
Quoi qu'on fasse, les genres seront toujours quelque peu artificiels, et le nouveau genre Polypodium, plus étendu, le deviendra bien plus que s'il était divisé. Sans doute, on doit suivre pas à pas la nature, mais il faut aussi faciliter l'étude, et nous demeurons persuadé qu'un geıre de quatre cents espèces sera inextricable si l'on n'y fait des coupes nombreuses, en créant des genres ou des sous-genres, seul moyen de rendre possible la recherche des espèces. Sil est facile de reconnaitre à ses nervilles courbes un Campyloneuron, un Goniophlebium à ses nervilles ou anastomoses sans appendices, un Niphobolus à ses sporanges disposées en anneaux et plongées dans un tomentum épais, composé de poils étoilés, pourquoi ne pas adopter ces genres. On pourrat, en procédant par voie extrême de réunion de genres, parvenir à ne plus avoir qu’m seul genre Filix, et l'on reculerait de trois siècles pour se retrouver au temps des Pluduier el des DalÉchamp. Telles ne sont pas les idées des auteurs dissidents; ils sont comme nons désireux de faire progresser la science. Mais quelle est la route quil faut suivre? Le temps seul nous le dira. 


\section{SIXIENE, SEPTIÈIIE ET HUITIÈHE MIÉNOIRES}

\section{SUR LA FAMILLE DES FOLGERES.}





\title{
SEPTIÈME MÉMOIRE
}

SUR

\section{LA FAMILLE DES FOUGERES.}

\section{ICONOGRAPIIE}

\author{
DES ESPÈGES NOUVELLES
}

DÉCRITES OU ÉNUMĖRÉES

DANS LE

\section{GENEIRA FILCUM,}

AINSI QUE DE QUELQUES AUTRES ESPÈCES RARES OU MAL CONNUES.

( S U I T E. )

\section{ACROSTICHEA.}

\section{ACROSTICHUM, F., l. cit.}

Ad diagnosin Acrosticm attenuati, F. , 6 e Mémoire, p. 1; tab. I, fig. 1, Adde :

Les frondes fertiles sont assez souvent cordiformes à la base; les squammes des pétioles, assez petites, sont étalées et roussâtres, ainsi que celles de la souche, qui est dressée, assez grosse, munie de très-longues radicelles noirâtres, couvertes d'écailles linéaires, longues de deux centimètres, ondulées et entières; les lames sont ciliées de squammes semblables. Elle a été trouvée au Mexique, en 1855 , sur le Popocatepetl à 3000 mètres d'altitude, par M. N. Schaffrer, qui nous en a donné de nombreux spécimens de dimension variable, sous le $n^{0} 281$. Elle est terrestre.

Cette espèce diffëre de l'A. crinaccum, F. (A. hybridum, Hook. et Grev., Icon. $\mathrm{XXI}$, non Bory), par sa froṇde fertile, tronquée ver's le bas, ou même cordiforme. 


\title{
II. LOMARIE E.
}

Sporothecia indusiata, secundùm lineam rectam excurrentia, costalia aut marginata.

\section{LOMARIA, Willd.}

\author{
F., Gen. filic., p. 66 ; tab. V, B., fig. $1-10$.
}

I. Decrescens, F., Gen. filic., p. 68.

Frondibus in ambitu lanceolatis; caudicibus digiti minoris crassitudine, squamis mufs, lanceolatis, nitentibus, longissimè acuminatis vestitis; laciniis ${ }^{1}$ sterilium intermctiis lanceolatis, oppositis, obtusis, inferioribus hanisphcericis, alternis, tcrminalia longa, lanceolata; petiolo supernc helveolo, angustè canaliculato, infrì nigro levi; nervillis crassis, apicc promincntibus; dcutibus marginis inter se coalitis, membramulam cartilagincam simnlantibus; frondibus fertilibus subpinnatis; frondulis lincaribus, apice callosis, encrvis; indusio rufcscente, semper intcgro; recptaculo crasso, gibboso; sporangiis ovatis; ammulo $13-14$ articulato; sporis reniformilus, cpisporio delapso, vitreis.

Habitat in Cuba, Linden, $n^{0} 2019$.

Filix singularis, scandens, glaberrima; frondibus sterilibus pimatifidis; fertilibus subpinnatis; stipitibus bicoloribus.

lcos. : Tab. IX, fig. $1 .^{2}$

Plante grimpante; probablement appliquée contre l'écorce des arbres; frondes écartées sur une souche entièrement couverte d'écailles roussàtres, parcourue par des faisceaux vasculaires, disposés en cercle et rapproclıés. Stipe court et noirìtre; rachis faure-pâle. Elle est robuste et les nervilles se dessinent en relief sur les lames. La L. decrescens, F., est nettement caractérisée par des frondes stériles pinnatifides, tandis que les fertiles sont pinnées.

M. T. Moore nous écrit que cette espèce a des rapports évidents arec le $L$. Scholtii, Colla, Mém. de Turin, tom. 39, p. 72, aussi de San-Juan Fernandez. Nous n'avons pas le recueil cité pour établir les différences qui les séparent.

1. Nous nous servons du mol lacinia (segment), pour désigner les partilions des frondes pinnatifides, et de ceux de frondula (petite fionde), el de pinnella (diminulif de pinna) pour désigner les divisions de la fronde pinnée.

2. Nous n’indiquerons, a l’arenir, les dimensions que quand la plante n’aura été reproduite quo partiellement ou qu'elle aura été réduite, ce qui n’a eu lieu que deus ou trois fois dans ce Mémoire. 
11. GAYANA, F.

Frondibus pimnatis, lanceolatis, glabris; petiolo basi nigricante, canaliculato, depresso, prostrato, helveolo; frondulis sterilium lanceatis, obtusinsculis, maigine obscurè dentatis, scabris, basi lata adnatis, approximatis, alternis; frondulis fertilium angustioribus, obtusissimis, suboppositis, aduatis, sed basi inferiore solutis, patulis; indusio cinereo, maturitate leviter laccrato; sporangiis subrotundis, longè pedicellatis; anmulo 20 articulato; sporis subcurvatis.

Habitat in fissuris frigidis Andium Chilensium /Cordilleras de Talcaregue, provincia dicta de Colchagua). .

Lomaria Gayana, F. in F'. Chilense, t. VI, p. 481.

Filix flexibilis; statura médiocri; rhizomate repente, basibus stipitum persistentibus vestito.

Icon.: Tab. X, fig. 1.

Cette espèce est remarquable par les bases du pétiole, appliquées sur le rhizome dans une certaine portion de son étendue, après quoi la fronde se redresse et prend la station verticale. Il résulte de cette disposition que le rhizome est couvert par la partie inférieure des pétioles, au point d'être presque entièrement caché par eux. Ce rhizome est rampant et parcouru par cinq faisceaux vasculaires, qui en occupent presque tout le diamètre; deux supérieurs sont plus petits; trois inférieurs plus grands.

\section{BLECHNUM, Linn.}

F., Gen. filic., p. 72; tab. V, B., fig. $11-14$.

ANGUSTIFRONS, F.

Frondibus pinnatifidis, linearibus, subsessilibus; mesonevro helveolo; segmentis brevibus, lanceato-angulatis, obtusinsculis, lcvitcr auriculatis, infimis triangularibus, glabris, opacis, marginibus leviter rcvolutis; sporotheciis in medio lateris scgmentorum sitis; indusio superiore brevi; sporangiis magnis, ellipticis; annulo 16 articulato; sporis reniformibus.

Habitat in Repnblica Mexicana ad arbores annosos (Llano verde, Oaxaca), ad 2500 metr. altitudinis.

Blechnum polypodioides, Marl. et Galeotti, Filic. Mexic., p. 50, non Radd.

Exsiccata: Galeotti, nos 6284 el 6440.

Icon.: Tab. nostr. IX, fig. 2.

Une petite souche écailleuse, de laquelle partent des rejets aphylles, émet plusieurs frondes presque linéaires, sessiles. Les sporothèces n'atteignent pas la 
base des segments, et ils sont situés au milieu de chaque moitié des lames, ce qui en fait un Mesothema, selon PresL. Ce caractère n'existe pas dans le B. polypodioides, de Raddi; mais on le retrouve dans le $B$. asplenioides de Swartz, arec lequel notre plante a de l'analogie.

Presi a réuni le $B$. polypodioides de Martens el Galeotti, au B. unilaterale, de Swartz et de Willdenow; mais si cet auteur l'eût vu, il en aurait fait un Mesothema, puisque les sporothèces sont médians et non costaux. (Voy. la planche de Raddi, Filic. Urasil., tab. 60, fig. 2, et comparez-la avec la nôtre.)

\section{VITTARIE E, F.}

Sporothecia gymnosoria, secundùm lineam rectam excurrentia, parallela, marginalia, aut inter duas cuticulas nascentia.

27. VITTARIA, Smith.

F., Gen. filic., p. 85; tab. VIII, B, fig. 2, et Hist. des vittariẻes, $3^{c}$ Mlém. sur les fougères. liejota, F.

Frondibus lineari-lanceolatis, basi et apice attenuatis, leviler curvatis, acuminatis, fasciculatis; petiolis planis, flexuosis, rufescentibus; mesonevro continuo, basi lato, fusco; marginibus dentibus crassis, paucissimis; sporotheciis superficialibus, fuscis, a margine remotis; sporangiis ovalibus; anmulo 20 - 22 articulato; sporis magnis, reniformibus; sporangiastris scyphuliformibus.

Habitat in Novo-Granatensi; provincia Ocaña ad arbores sylvarum; altitudine 2400 metr. (1846-1852, L. Schlim, nº 611.)

Filix flexibilis, surculo recto; affmis cum Pteropside angustifolia, Desv., sed nervilla planè villariarum.

Icon. : Tab. XX, fig. 1.

Cette espèce est dressée et de nombreuses frondes croissent sur une souche de la grosseur d'une plume. Le diamètre transrersal des sporanges excède la hauteur de cét organe.

\section{DRYMOgLOSSUM, Presl.}

F., 3e Mém. sur les fougères: Hist. des vittariées, et Gen.filic.p. 94; tab. 1X, A., fig. 1 - 3. Abbreviatum, F.

Frondibus spissis, opacis, lanceolatis, acutis; fertilibus obusissimis, mesonevro tenui; sporotheciis brevibus, apicilaribus; receptaculis parallelis, angustis, fuscis; rhizomate repente, fili emporetici crassitudine. 
Habitat in Cochinchina propè Tourane. (Gaudichaud, Voy. de la Bonite.)

Filix parvula; facie Drynariæ angustæ, $H$. et $B$.

Icos. : Tab. $X$, fig. 2.

Les frondes sont homomorphes dans le spécimen que nous décrivons; mais il serait possible qu'il y eût des frondes de forme différente, qui la fissent rentrer dans le type, lequel, comme ses congénères, a des frondes stériles et fertiles différentes.

\section{ADIANTE E.}

(Vide supri, p. 4.)

\section{ADIANTUM, L.}

I. Gracile, F., Gen. filic., p. 116.

Frondibus bipinnatis, ovatis; stipite rachique squamis piliformibus, rufescentibus obsitis; pimis patulis, curvatiusculis, caudatis ; frondulis numerosis, approximatis, glaberrimis, dentatis, 30 jugis et ultri, basi cuneatis; rachibus ferrugineis, Rexibilibus, fili emporetici crassitudine; sporotheciis 3, 4; annulo 14 articulato; sporis irregulatim trigonis.

Habitat in Brasilia (Claussen).

Filix elegans, affinis cum Adianto hirto, Kl.

Icos. : Tab. XI, fig. 1.

Cette espèce porte 8 - 10 pinnules longues, étalées, étroitement lancéolées; les frondules, cunéiformes à la base, se chargent vers le sommet de 2, 3 et même quelquefois de 4 sporothèces inégaux, à indusium rufescent épais. Chaque pinnulc se charge de 25 à 30 frondules, cunéiformes à la base. Le rhizome est délié et muni de longues radicelles.

Le port de l'A. gracile rapproche cette fougère de l'A. hirtum, de KLotzsch; mais ici les sporothèces, fort petits, à indusium mince, sont en nombre triple ou quadruple; les frondules sont aussi plus longues, dentées en scie, et les écailles, qui recourrent le pétiole et le rachis, plus étroites, ressemblent à des poils.

II. Parvifolium, F.

Frondibus bipinnatis, curvatis, ccespilosis, subsessilibus; surculo crasso, fibris longis, undulatis, tomento ferrugineo vestitis; frondulis rotundo-cuneatis, persistentibus, integris; sterilibus apice denticulatis; pedicello setoso, articulato, longiusculo; sporotheciis pancis, 2-3, rassissimis, leviter arcuatis, flavidulis; indusio sex- 
nervato, nervillis oculo perfacilè manifestis; sporangiis ovatis, brevè pedicellatis; annulo 14-16 articulato; sporis triedricis, sub lente maculam nigram ferentibus.

Habitat in San-Domingo (Poiteau).

Filix parvula, glaberrima.

IcoN. : Tab. XXIII, fig. 2.

Cette espèce est certainement la plus petite du genre. Elle se rapproche un peu de l'A. trigonum, Labill., mais les frondules sont entières et le port est tout différent. Nous l'avons eue de Bory Saint-Vincent, qui l'avait nommée A.tenerum, Sw., espèce quadripinnée, de grande dimension, à frondules crénelées et incisées. Les frondules, au lieu de se désarticuler comme dans l'A. fragile, Sw., sont persistantes, beaucoup plus petites, quoique toutes fructifères. Les frondes sont pétiolées. L’indusium de notre espèce présente à l’œil nu 5- 7 nervilles en relief, qu'on ne voit pas sur l'A. fragile. Celle - ci eùt été mieux nommée desarticulans. L'extrême caducité de ses frondules est manifeste sur tous les spécimens desséchés de l'A. fragile que nous avons pu voir. C'est un fait général qui devient un caractère d'espèce, el, comme le dit M. Hooker, Sp. filic., p. 41, on n'a plus sous les yeux que le squelette d'une plante. C'est pour cela que cet anteur n'a pas cru devoir la figurer.

III. Nigrescens, F., Gen. filic., p. 117.

Frondibus bipimatis, basi tripartitis; pimis linearibus, longé decrescentibus, acuminatis; frondulis numerosis, dentatis, brevibus, ovalibus, basi truncatis, terminali caudatu; nervillis scalpturatis; rachibus vix nitentibus, nigris, brevè tomentosis; sporotheciis 3 - 4 marginalibus, $1-2$ apicilaribus et uno sapè ad marginem inferiorem sito; indusio crasso; sporangiis parvulis, ovoideis; anmulo 18-20 articulato; sporis triedricis, parvis.

Ilabitat in San-Domingo (Port-au-Prince), l'Épagnier.

Filix aspectu nigrescente, rigida, subtripinnata, glabriuscula; affuis cum A. striato, Sw.

Icon. : Tab. XI, fig. 2.

Fougère à longues pinnules linćaires, terminées en pointe, coudées et presque toutes arquées de dehors en dedans; elles sont écartées les unes des autres; à raclis courtement tomenteux et ferrugineux. Les frondules, très-rapprochées et luisantes, se chargent d'un petit nombre de sporothèces, à indursium épais. Les nervilles font saillie. Le pétiole est glabre dans le spécimen que nous décrivons.

Cette plante a des rapports évidents avec l'A. striatum, Sw., figuré tab.118 par Schiunr, et peut-ètre n'en est-elle qu’une forme à frondules plus courtes, denticulées et à sporothèces plus nombreux. Dans notre spécimen, les nervilles de l'indusium sont blanchâtres. 
IV. Pseudo-Capillus, F., Gen. filic., p. 118.

Frondibus subtripinnatis; stipitibus atro-fuscis; rachibus roseis, glaberrimis; frondulis crassinsculis, terminalibus, cuneatis, longè petiolatis, in segmenta 3-4 partitis, irregulatim dentatis; dentibus obtusinsculis, lateralibus obliquè cuneatis; sporotheciis incegualibus, arcuatis, receptaculo multi-nervato; sporangiis ouatis; sporis crassis, fuscis, roundis vel obscurè trigonis.

Habitat ad promontorium Bonce Spei.

Adiantum Capillus-Veneris, Spreng. in Schedul. Pl. Capensium Dregei non L.

Icox.: Tab. XII, fig. 1 et 2 A. Capilli-Veneris. L. fragm. ad comparandum.

Cette plante a les dimensions de l'A. Capillus-Veneris, L.; elle en diffère par la forme des frondules et par celle des sporothèces, inégaux, profondément arqués, plus étendus et conséquemment bien moins nombreux. La consistance est plus ferme dans notre espèce que dans l'espèce linnéenne, bien plus délicate et bien plus souple.

L'A. Capillus-Veneris, var. Africanum, distribué par M. Guevzius, est, en effet, une variété de l'espèce européenne, fort différente de notre plante.

I. Gratum, F., loc. cit., p. 119.

Frondibus patulis, ramis divaricatis, Rexnosis, tripinnatis, rachi et stipite lavibus, rubellis; frondulis semi-orbicularibus, cordatis, rarò subcuneiformibus, longè petiolulatis; nervillis fabellatis, scalpturatis; sporotheciis regularibus, mediocribus, in sinubus affuis, paucinervatis; indusio crasso, albidulo, concavo; sporaugiis rotundatis; ammulo 18-20 articulato; sporis ovoideis trigonisque.

IIabitat in Mexico; prope Nolasco ad 2000 metr. altid. Galeotti, $n^{0} 6542$.

Filix elegans, rigida; frondulis crenatis, dilatatis.

Icon. : Tab. XII, fig. 3.

(Dimensions de l'A. Capillus-Ieneris, L. Frondules un peu plus larges que hautes; les plus grandes pouvant alteindre jusqu'à 2 centim.)

Les rameaux sont flexueux, rougeâtres, lisses et luisants, les pétiolules sont divariqués, capillaires. Les frondules ne sont point articulées. Elle a des traits de ressemblance avec I'A. affine, Mart. et GaL.; et arec l'A. thalictroides de Willdenow, quoique, du reste, fort distincte.

VI. FeEI, TII. MoORE, in Litter.

Frondibns tripinnutis, in ambitu oblongis; ramis divaricatis, patulis, apice sursim cureatis; frondulis obliquè ovatis, crenato-incisis, crenis mucronatis, suprà glabris, subtis pilosis, petiolulatis; petiolo fusco-cylindrico, rigido, asperulo; 
pilis brevibus, simplicibus, rufis, crcberrimis hirto; rachi flexuoso; ramis remotis, Alexuosis, angulum $90^{\circ}$ ad insertionem aperientibus, denique curvalis; indusiis latis, pallidis, incequalibus, leviter hippocrepidibus; sporangiis ovatis; pedicello brevi; sporis iregulatim liedicis.

Habitat in-Republica Mexicana, propè Orizabau. IV. Schaffner, $\mathbf{n}^{0}{ }_{4} 46$.

Filix insignis, rigida, flexuosa; petiolo rachique tonentoso-hirtis; pilis brevibus rufis, sphacelatis.

Icos. : Tab. XXIV, fig. 1.

Le pétiole est droit, de la grosseur d'une plume de pigeon; le raclis et les rachéoles sont flexueux et en zigzag, comme si la plante avait une tendance à devenir grimpante. Les rameaux sont assez distants les uns des autres, d'abord horizontaux, puis courbés vers le sommet. Les frondules sont de grandeur inégale, incisées, crénelées, obliquement ovales, glabres en dessus et poilues en dessous, particulièrement sur les nervilles. Il est peu d'espèces aussi distinctes.

I. Petiolata, F.

\section{C.ISEBEERIA, KIfuss.}

F., Gen. filic., p. 119.

Frondibus trifoliatis; froudulis crassis, opacis, petiolatis; intermedia longiori, onnibus crenatis; petiolo, rachi mesonevroque cbeneis; rhizomate repente, crassiusculo, squamis fulvis, linearibus, acuminatis onusto.

IIabitat in Bonaria.

Filix parvula, clegans.

Icon. : Tab. XII, fig. 4 et 5, Casebeeria triphylla, Kauffm. (pars) ad comparandan.

Cette espèce, plus robuste que l'espèce-type de KallFuss, est plus grande; elle a des frondules plus épaisses, portant 8 - 9 crénulations régulièrement arrondies, qui vont en se dégradant de dimension de la base des lames au sommet. - Les frondules sont attachées sur le rachis par des pétiolules assez longs.

UI. Paradoxi, F.

Frondibus ccespitosis, palnatis, glabris; segmentis crassis, opacis, oblongis, obtusis, marginibus in sterilibus planis, integris, in fertilibus crcuatis; crenis subhippocrepidiformibus; petiolo longo, fliformi, squamoso, rufesccute; rlizomate repente; sporotheciis ad apicem ncivillain evolventibus; sporangiis 
pedicellatis, cum sporangiastris parvis, mastoideis immixtis; annulo 22-24 articulato; sporis triedricis; indusio undulato, crasso, retrorsim crenulato.

ILabitat in Brasilia; montes Orgaos; Gardner, $n^{0} 5930$.

Filix parvula, elegans, palmata, 5-7 lobata.

Icon. : Tab. XX. fig. 2.

Nous avons donné à cette curieuse espèce le nom de paradoxa, parce qu'elle s'éloigne un peu par l'indusium du type de ce genre, le C. Iriphylla, de Kaulfuss. Ce tégument est épais et ne forme qu'une seule membrane continue, même au sommet, quoique, à vrai dire, elle ait une tendance à se diviser en autant de parties qu'il y a de crénulations. Vu du côté de la marge, l’indusium est fortement crénelé. C'est en quelque sorte un Casebeeria renversé.

Le rhizome est assez petit, couvert d'écailles fauves, étroitement lancéolées; il porte un grand nombre de frondes, très-rapprochées, à pétiole un peu courbé à la base et légèrement flexueux.

\section{PTERIDE $A$.}

(Vidc suprà, pag. 4.)

52. PTERIS, L. emend.

F., Gen. filic., p. 124; tab. XI, A.

* Frondibus pinnatis.

IL Velanocaulon, F., loc. cit., p. 127.

Frondibus oblongis, ad basim bi-trifulis, apice pinnatis; stipite capilliformi, nigro, lovi, lucido fragilique; mesoneuro aterrimo; frondulis petiolatis, longissime arcuatis, linearibus, in parte stcrili dcntatis, acumine longissimo; sporotheciis ccntralibus; receptaculo lincari; anmulo lato, 18-20 articulato; sporis trigonis, lavibus, pellucidis.

Habilat in insulis Philippinis (Cuming, sinc numero).

Filix clegans, delicatula, herbacea, cxtensa; stipite basique mesoncurorum adiantinis; surculo erccto; nervillis divaricatis.

IcoN.: Tab. $\mathbf{I} I X, f g .1$.

Le stipe est capilliforme, fort lisse, et d'un noir intense; il nait au sommet d'une petite souche dressée; la plante est glabre, d'une souplesse remarquable; elle porte des frondules trifides et bifides à la base, un peu arquées en dedans. 
III. Semidentata, F.

Frondibus teneris, glaberrimis, terminali pimnata, centralibus bipinnatis, in ambitu oblongis; petiolis elongatis, basi rufescentibus, curvatis, glaberrimis, rachibus helveolis; frondulis pinnatis, segnentis ellipticis, argutè serratis; sporolleciis partem medianam marginorum occupantibus, latiusculis; indusio persistente, plano, tenui; sporangiis ellipticis; amnulo 16-18 articulato; sporis trigonis; sporangiastris pancis, clavatis, cum sporangiis immixtis.

Habitut in Novo-Granatensi, Puramos de Ocaña; altitudine 2800-3400 metr.

L. Schlim, $n^{0} 482$ (1846-1852).

Filix tenera; stipitibus bicoloribus; wizomate contorto, repente.

Icox. : Tab. XIIII, fig. 3.

Plante délicate, très-glabre, à pétioles arqués à la base, colorés et fort lisses; frondules dentées en scie, seulement vers le sommet; sporothèces assez développés, noccupant que la partie moyenne des frondules. Les pinnules se terminent en une longue pointe dentée en scie. Cette fougère acquiert probablement des dimensions supérieures à celles que donne notre planche.

Doit ètre placée à còté du P. gracilis, F., Gen. filic., p. 128.

IV. Gracilis, F., p. 128.

Frondibus glabris, tripmatis, triangularibus, elongatis; stipitibus (petiolis) longissimis, fexuosis, leclecolis, conaliculatis; segmentis brevibus, basi contractis, dentibus angulatis, longissimè selaceis; sporolleciis in medio nearginis laminarum sitis; indusio angusto, vix distincto; receptuculo mullo; sporangiis ovoideis; ammulo 18-20 urticulato; sporis minutis, trigonis brevibusque.

P. gracilis, F., Gen. filic., p. 128.

Inabitut in Bresilie (Claussen).

Filix elatu, gluberrima, debilis; stipite basi rufescente. Litobrochiie affnis, sed nervillis omminò liberis.

Icos. : Tab. XIX, fig. 2.

Espèce bien distincte, très-herbacée, à segments nonbreux profondément dentés. Le pétiole, très-long, est à la lame : : 1 :5. Les sporothèces situés au centre du segment sont trés-courts. On ne peut la confondre avec aucune autre.

\section{LONCHITIS, L.}

$$
\text { F., Gen. filic., p. } 413 \text {; tab. XI, A, fig. } 13 .
$$

Tonentosa, L. , Gen. filic., p. 143.

Frondibus tri-quadri-pinnatis, rufo-tomentosis; pilis aculis, bi-tri-articulatis; stipite et rachibus mifis, hirto-tomentosis, angustè canaliculatis; pinnis extensis, 
lanceolatis; pinnulis pimnatis, apice pinnatifdis, brevè stipitatis; pinnulis inferioribus oppositis, centralibus altemis, superioribus adnatis; sporotheciis latis, marginibus sinuatis, omnibus fertilibus; sporangiis tabacinis, ovoideis; annulo 16-18 articulato; pilis biformibus, aliis longis, contortis, pellucidis, intestiniformibus, cateris conicis, articulatis.

Habitat in insula Nossé-Bé Madagascariensi (Pervillié), et in insula Borbonia.

Filix ampla, tri-quadri-pinnatu, cinereo-lomentosa; nervillis crassis, fuscis; rachi profundè canaliculato; fasciculo lincari, circonscriptionem rachidis sequente, et formam cjusdem referente.

Icos.: Tab. XXIII, fig. 3, ad tertiam partem reducta.

(Longueur des principales divisions, 50 centim. ; des pinnules, 9 centimètres sur 3 de largeur ; le stipe atteint à la grosseur d'une plume de crğne; le rachis des pinnules est gros comme celle d'un pigeon.)

Très-belle espèce, peut-être arborescente. Quoique le caractère du genre soit ici extrêmement apparent, les sporothèces occupent, non-seulement le sinus que les segments laissent entre eux, mais encore toute la marge, en s'interrompant pour former une série de sporothèces courts et courbés en fer à cheval.

M. Hoorer a décrit, p. 58 du T. II de son Species, et figuré, tab. 87 b, un Lonchitis Madagascariensis, duquel il dit: Throughout slightly haim, "légèrement velue sur toute la surface, » ce qui ne peut se rapporter à une plante tomenteuse. Toutefois notre espèce, antérieurement décrite, en est roisine.

\section{2. CHEILOPECTON, F.}

Sровотнесns apicilaribus, depanperatis, nervillaribus, discretis, margine crassa bis plicata vestitis; indusio spurio interiore; sporangiis subsessilibus, luxẻ congestis, magnis; annulo 22-24 articulato; stomate amplo, membrana subcrustacea sacculi areolas hexagonas, regulares formante; sporis triedricis.

Froxdubus triangularibus, pinnato-pinnatifudis, pteridiformibus, segmentis angulatis; marginibus fertilium duplicato-revolutis, continuis; nervillis creberrimis, tenuibus, ad marginem scalpturatis; surculo erecto; petiolo rachique nigris, squamosis.

Genus monotypum, Mexicanum; facic pteridis et pellæarum; differt, scilicet: pteride absentia receptaculi; pellæis convolutura et nervositate marginis; cheilanthe facie, consistentia, brevitate sporotheciorum, margine replicuta absconditorum.

Dlagrosis : Tab. XX, fig. 3. C. rigidum F. magnit. naturali et partes varice aucto.

Le type de ce genre curieux a le port diun Pteris; aussi Swartz et Presi. l'avaient-ils placé dans ce genre avant quion analysàt scrupuleusement les fougères. en déterminant la situation des sporothèces et celle de ses annexes. Est-ce une 
chéilanthée? Est-ce une ptéridée? Elle semble intermédiaire entre ces deux groupes, ayant des sporothèces nervillaires terminaux, et le port et la consistance de certains Pteris.

M. T. Moore, qui nous a fourni sur cette plante des renseignements précieux, voit en elle un Cheilanthes. Pour nous, qui nous déterminons souvent d'après le por', nous croyons devoir proposer un genre nouveau, fondé principalement sur l'enroulure de la marge, qui forme une espèce de cylindre dans lequel se cachent les sporothèces; ceux-ci sont isolés et composés d'une ou de deux sporanges attachées sur des nervilles flabelliformes, un peu renflées au sommet.

Getle plante est bien plus près des Pellaca que des Cheilanthes, fougères trèsdivisées, à segments fort petits, dont les marges sont interrompues dans leur continuité. L'enroulure est persistante et cylindroïde; la marge s'amincit vers les bords, et prend l'aspect d'un indusium translucide; ainsi roulée, dans une élendue assez considérable, cetle marge se montre arec ses nervilles, à la manière de lindusium charnu des Adiantum.

Rigidu, F.

Frondibus ovatis seu triangularibus, bipinnatifulis, pinnulis suboppositis, ovatolmceolrtis, patentibus, segmentis subtriangularibus, omnibus et integrè proliferis; stipite rachique nigris, squamis rnfts, laxis vestitis; sureulo erceto, squamis integris, laneeolatis, longe aeuminatis.

Reliquice in diagnosi generis.

IIabitat in Republica Mexieana, eirea Orizabam. W. Schaffner, $\mathrm{n}^{0} 154$ (in herbario nostro); in Chalma regni Peruvia (Linn. testè Swartz); in Mecico. Presl., loc. infrie citato.

Pteris rigida, Sw., Syn.fllic., p. 104 et 299. - P. cartilaginea, Presl, Reliq. Haenke, p. $57, T . I X, f i g .3$.

Cheilanthes.... T. Moore, in Litteris.

Filix pervula, robusta, squamosa; segmentis pimularum infmis subpedatis.

Icon.: Tab. nostr. citat.

Agardi, dans sa Monograplie du genre Pteris, ne parle pas de celte espèce, soit (qu'il ne l'ait pas connue, soit qu'il ait ru en elle une plante de tout autre genre. Les poils qui se trouvent sur les lames supérieures, sont coniques et semblables à ceux qui recourrent les frondes du Callogramme (voy. Gen. filic., T. XV, fig. 1). Quoique Press ait donné une figure de cette plante singulière, nous avons cru devoir en donner une autre avec des détails qui permissent d'en reconnaître le genre. Elle reproduit la plante $n^{0} 154$, provenant de M. Schaffarer, qui l'a récoltée à Orizaba. 
(Genus inter Plerideas et Cheilantheas collocandum.)

623. SYNOCHLAMYS, F.

SPOROTHEGIIS nervillaribus, distinctis, nervillis omnibus proliferis; sporangiis laxè congestis, apicilaribus, sessilibus; annulo 18-20 articulato; sporis triedricis, seu obscurè trigonis; indusiis continuis, membranaceis, laminam totam imedientibus, ad mesonevron conniventibus.

Froxdibus pinnatis, oblongis; frondulis linearibus, nervillis scalpturatis, simplicibus vel furcatis.

Filix americana, terrestris, singularis situ sporotheciorum. Genus sessilitate sporangiarum cheilanthacea, inclusio continuo pteridea.

Diagrosis: Tab. XX, fig. 4.

Lïimpossibilité dans laquelle nous nous sommes trouvé de donner une place convenable à la seule plante qui, jusquiici, compose ce genre, nous a décidé à créer un genre pour l'y placer. Il n'y a point de réceptacle, et les sporothèces ont un lieu spécial d’élection; ce ne pouvait donc être une ptéridée. L'indusium continu, et le port des frondes ne permettait pas d'en faire une cheilanthée. C'est un genre qui unit ces deux groupes, sans pouroir raisonnablement appartenir à l'un ou à l'autre.

Ambigua, F.

Frondibus pinnatis, oblongo-linceolatis, glaberrimis; stipite rachique adiantinis, lavibus, cylindricis; frondulis linearibus, obtusiusculis, basi cordatis, brevissimè pctiolatis; ncrvillis tenuibus, scalpturatis; sporotheciis nervillaribus, dislinctis, apicilaribus; sporangiis congestis, scepe conniventibus; annulo $16-18$ articulato; sporis umbonatis triedricisque; indusiis continuis, rugosis, laminam totam incadientibus, suprà mesonevron coalitis, marginibus laceratis, segmentis upicc turgidis, claveformibus.

Habitat in Novo-Granatensi, provincia dicla de Hacha, ad Sierram nevadam (allitudo 3400 metr.) (L. Schlim, $\mathrm{n}^{0} 877 ; 1852$.)

Filix rigida, siccitate fragilis.

Icox. : Tab. XX, fig. 4.

C'est là le type de notre genre; caractérisé surtout par la présence d'un indusium attaché à la marge légèrement crénelće d'une frondule linéaire, allant s’unir à son correspondant, au-rlessus du mésonèvre, entièrement caché par cette membrane protectrice. Les deux bords de lïindusium ne sont pas soudés, mais unis par des prolongements digités, à extrémités renflées en forme de massue. Les sporanges sont sessiles comme dans les chéilanthées. 
Une autre particularité digne d'ètre notée se déduit des frondules; elles sont bombées en dessous, et offrent une ride au point de déreloppement des sporothèces; un très-court pétiole les attache au rachis, sur lequel il est légèrement décurrent. Un seul faisceau rasculaire, blanchâtre et arqué, traverse le pétiole.

\section{CIIEILANTHE E.}

\section{Acervis multis, approximatis, sæpè confluentibus.}

\section{CHEILANTHES, Sw.}

I. Variass, Hook.

F., Gen. filic., p. 155.

Frondibus bipimnatis, clongatis, ambitu lineari-lanceolatis, apice pinnatis; stipitibus trigonis et rachibus glaberrimis, rubellis; pimmulis remotis, brevissime petiolatis, bresi pimatifudis, triangularibus, lobo terminali majusculo; sporotheciis latiusculis; indusio spurio, convexo; sporangiis ovatis; ammulo 18-20 articulato. pedicello brevissimo; sporis crassiusculis, rotundis, leviter papillosis.

C. varians, Hook., Spec. filic. 11, p. 103.

C. Malaccensis et Griffethiana, F., l. cit.

C. angustifolia, Guming, Filic. Malucc., $\mathrm{n}^{0}$ 408, in Sched. nostr.

Habitat in Malacea. Griffith et Cuming.

Icos. : Tab. XI, fig. 3.

Filix clata, glabra, basi bipinnata, apice pimnata.

Cette espèce se rapproche par le port des Pellaa; mais il n'y a pas de réceptacle. Nieux étudiée, elle doit être réunie au C. Malaccensis, que nous arons reçue de $\mathbf{I}$. Cunisg sous le nom de $C$. angustifolia. Les deux spécimens de notre herbier diffèrent du C. Malaccensis par des frondes monotaxiques. Mais, comme cette plante est très-polymorphe, il faut regarder cette particularité comme accidentelle.

11. Microphilla, Sw.

Var. aspidioides, F.

Frondibus bipimatis, in ambitu lancelatis; stipite et rachi cylindricis, aterrimis, pilosis; pilis articulatis, setaceis; pimis lanceolatis, approximatis, emergentibus, curratis, glabris; segmentis ovoideis, supernè anriculatis, dein basi subpimatis, in petiolo desinentibus, terminali majusculo; sporotheciis manginalibus; indusio contimuo, tenui, pellucido; sporangiis brevè pedicellatis, ellipsoideis; amnulo 16-18 articulato; sporis crassis, nigrescentibus, rotundis. rarius trigonis. 
C. mieropliylla, Sw., Syn. filie., p. 127 ; Adiantum nicropleyllum, ejusd. Fl. Ind. oceid. III, p. 1713 ; Prodr. 135 ; Willd., Spee. filic., p. 458.

C. mieromera, Link, Horl. berol. 2, p. 36 , el Spec. filic., p. 64.

C. aspidioides, F., Gen. filic., p. 157.

Habilat in San-Domingo (Poiteau, Herb. nost.). - Jamaica ex Sieber? -

Caraeas (Moritz, $\mathrm{n}^{0}$ 39, Herb. nostr.) - Mexico, San-Pedro-Nolasco Galeotti, $\mathrm{n}^{0} 6557$, et W. Schaffner $\mathrm{n}^{\mathrm{os}} 84$ et 85 . Sierra de Santa-Cruz el in variis locis.

Filix variabilis, facie aspidiorum.

Icon. : Sloane, Jam., hist. 1, p. 93; เ. 13, fig. 2; Plumier, Filic., p. 44; .58.

Var. aspidioides, Tab. nostr. IX, fig. 1.

(Longueur des plus grands spécimens jusqu’à 45 centim. arec un pétiole de 23 centim. Les plus petits, inférieurs en dimension d'un tiers; pinnules à 4,5 centim.)

Cette espèce, que nous avons décrite sous le nom de $C$. aspidioides d'après de nombreux spécimens, est assez variable, étant plus ou moins découpée, à segments plus ou moins étroits, plus ou moins aigus et de proportions très-diverses.

Les spécimens que nous avons de la Jamaïque et de Saint-Domingue, provenant, par conséquent, des mêmes localités que celles oủ Swartz a trouvé la plante qu'il á décrite, sont bien plus délicats que ceux récoltés par MIM. Galeottr et IV. ScinfFrer au Mexique, et ce sont probablement ces différences qui avaient décidé Lisk ì créer son C. micromera; ce sont elles aussi qui expliquent pourquoi nous avions fait une espèce différente du Spécimen no 6557 des fougères de M. Galeotti, forme plus vigoureuse et à segments plus dilatés.

La planche donnée par Slodne est très-imparfaite; celle de Plunier, quoique bien meilleure, privée de détails, trop raide, à pétioles trop courts, et quelque peu grossière, nous ayant paru insuffisante, nous avons cru nécessaire de figurer de nouveau cette plante, afin de faire cesser toute incertitude sur sa détermination.

Le C. microphylla, Sw., est cultivé dans quelques jardins sous le nom de C. mufescens, qui est assez juste.

II. Cumlensis, F., Gen. filic., p. 156.

Frondibus elatis, tripinnalis, in ambitu triangularibus, glaberimis; stipilibus validis, rigidis, canalieulatis, rufeseentibus, fasciculo vasorum unico, litteran I" simulante peragratis; rhizomate squamoso; squamis lanceolatis, integris, longissimè allemualis; segmentis ovalis, oblusissimis, basi sape cremulalis, marginibus reflexis, seariosis, integris, indusiiformibus; sporangiis magnis, ellipticis; anmulo stomateque latissimis, articulis 24-28; sporis globosis. 
Habitat in Chile (G. Gay).

Filix insignis, robusta; stipite elato, firmo, lavi; surculo erecto, radicellas crassas cmittente.

C. Chilensis, F., I. c., et in Fl. Chilensi, tom. VII, p. 494.

ICoN. : Tab. XVIII, fig. 2.

Très-belle plante, l'une des plus grandes du genre; le stipe et ses divisions sont robustes, rougeàtres, luisants, surtout le stipe, qui est canaliculé dans toute sa longueur; des écailles couvrent sa base, et on les retrouve sur le rachis, mais petites, raides et presque filiformes. Les segments fructifères sont très-entiers et obtus; le terminal est un peu plus grand et plus allongé que les autres.

Nous arons dit dans le Gen. filic., l. c., que le stipe était à la fronde :: $1: 5$; il faut lire : : $3: 1$.

III. Pyramidilis, F.

Frondibus bipimatis, pyramidatis; frondulis deflexis, breve pedicellatis, pedicello rachique robustis, unisulcatis, adiantinis, rufescentibus; segmentis incequalibus, basi pimato-auriculatis, linearibus, obtusis, terminali longiove; indusio albidulo, plicato, mesonerron attingente, marginibus ciliato-fmbriato; sporangiis amplis, rotundis, sessilibus; ammo sub vigiuti articulato; sporis incequaliter triedricis.

Habitat in Republica Mexicana (vallis Mexicana); Schafmer, n 88; SanAgostin, cjusd., $\mathrm{n}^{0} 305$, et $\mathrm{n}^{0} 304$, Guatimalpan, in montibus dietis de las Cruces. Altit. circa 2700 metr.

Filix formosa, glabra, cincrascens, rigida; faciem Abietis Pinere referens; surculo crasso, squamis linearibus, mifs omusto.

Allosumus pyramidalis, Schaffner, in Litter.

Icos. : Tab. XXY, fig. 3.

Cette charmante espèce peut acquérir des dimensions supérieures à celles de la figure que nous en arons donnée. L’un de nos spécinens mesure 40 centim. environ, avec des rameaux de 9 centim. Cette fougère est quelquefois bifurquée. Les frondules ( rameaux latéraux) sont tantôt réfléchis à partir de leur point d'insertion, et tantôt redressés d'abord, puis infléchis. La couleur du pétiole est d'un rouge vineux, qui tranche agréablement avec la teinte vert-pàle de la lame supérieure, blanclıàtre inférieurement, à cause des indusium; ceux-ci se joignent sur la médiane, et entre-croisent les denticulations de leur marge, comme il arrive pour le Synochlamys ambigua (roy. Pl. XX, fig. 3, de ce volume). 
IV. Cucullais, F.

Frondibus subtripinnatis, in ambitu lanceolatis; stipitibus rachibusque fusconigrescentibus, pilis rufescentibus, laxè applicatis vestitis; frondulis alternis, lanceolatis, sursum curvatis; segmentis conformibus, apice pinnatifidis, basi pinnatis; partitionibus oblongis, glabrescentibus; sporotheciis indusio spurio, lato, cucullato donatis; sporangiis sessilibus; ammulo 14 articulato; sporis polymorplis.

Habitat ad vallem Mexicanam, W. Schaffner, $\mathrm{n}^{0} 82$.

Filix squamoso-pilosa, elastica, facie Ch. microphyllæ, sed divertissima, procipue indusiorum fabrica; rhizomate repente, fibrilloso.

IcoN. : Tab. XXV, fig. 4.

Cette espèce est remarquable par le repli de la marge des segments fructifères, laquelle s'amincit en indusium. Ce repli, qui est large, affecte la forme d'un capuchon, sous lequel se logent les sporanges. Les poils qui recouvrent le stipe et le rachis, ainsi que ses subdivisions, sont de véritables écailles réduites à leur plus grande étroitesse possible. Ils sont strangulés et terminés par une sorte de glandule.

68. NOTHOCHLENA, R. Br.

F., Gen. filic., p. 158 ; tab. XIII, fig. 2.

? Plckenetil, F. , Gen. filic., p. 159.

Frondibus lanceolatis, bipinnatis, lanuginosis; frondulis ouato-ellipticis, sessilibus, segmentis ovatis, in lobulos crenatos, obtusissimos, partitis; nervillis fabellatis, superne proliferis; tomento molli intricato, prululim adhorente, unicersali; sporotheciis laxis, depuuperatis, mediunam partem nervillarum occupantibus; sporangiis ovatis, subsessilibus; ammulo 24 articulato; sporis trigonis.

Habitat in Catania Trinacriorum, et verosimiliter in locis variis regionum calidiorum Europe australis, nec non in Africa septentrionali.

Acrostichum Catanense, Cosentin.

Filic tomentosa, subtripinnata, mollis; absentia indusii et marginibus planis Gymnogramme; facie et natura pilorum Myriopteris.

Icox. : Tab. XXIII, fig. 4 et 5, N. lanuginosa, Desv.; pars ad comparandum.

Les auteurs ont confondu cette espèce avec le Nothoc. lanuginosa, Desv., décrit par Desfontanes, Fl. atl., tab. 456, sous le nom d'Acrostichum lanuginosum, mal figuré par Barrelier el Plukexet. La planche de Desfontaises a élé reproduite par Scunumr, et c’est elle qui ourre la série des espèces domnées par cet 
auteur. Swantz, Syn., p. 14, en a fait son Acrostichum velleum, adopté par Willuesow, Filic., p. 122. Mais, d'antre part, dans ses Species inquirenda, ce même Swartz décrit un Acrostichum subcordatum, réuni à l'espèce précédente par les auteurs. Cavaxildes ( $\Lambda$ nn. hist. nat., $n^{0}$ 4, p. 97) en a parlé pour la première fois. Serait-ce là notre N. Phulienetii? Nous n'osons pas le décider; car il ne mérite pas plus que l'autre l’épithète de subcordatum. On voit quelle confusion règne à l’égard de ces deux plantes. Voici, suivant nous, les caractères qui les séparent :

\section{? Jaxtginosa, Dest.}

Segnents petils, rapprochés sur toute létendue de la lame, entiers, arrondis; i bords amincis, opaques a l'étal see, traversés par des nervilles délićes, se terminant en une courte bifurcation, qui n’atteint pas la inarge.

Sporanges portait un anneau, ayant seulement \$3 - 20 articulations et des spores triedres, translucides (ce qui tient peut-être à làge) .

Bassin de la Méditerranéc el Canaries.

Voy, notre planche XXIlI, fig. 4, pour l'analyse complete de cette plante.
? Plukexetil, F.

Segments plus grands, écartés, surtout vers le laut, tendant à derenir pinnatifides, arrondis, ondulés, crénclés, minces, laissant facilement roir, même à l'état sec, les nervilles, qui se terminent en une longue bifurcation, et vont alteignant la marge partager les crénulations en parties symétriques.

Sporanges portant un anneau ayant de 26-28 articulations et des spores opaques, triedres.

Sicile, Gatane, par Gemeluaro.

Voy. li planclıc citée, fig. 5, oủ nous donnons un détail grossi, afin de comparer les deux plantes.

Nous avions antrefois placé daus notre lıerbier ces deux fougères parmi les Myriopteris. Les sporanges ne sont pas marginales comme dans les Nothochlena, mais étendues sur toute la continuité de la nerville, ainsi quon le voit dans les Gymnogrumme. Ciest là une forme cmbarrassante. Labsence de tout indusium et des marges planes, semblerait en faire un Gymnogramme, ainsi que le roudrait II. T. Moone (in Lilleris); mais le port de ces fougeres, autrement sectionnées, est si différent des Gymnogramme, ainsi que le système pileux, que nous n'osons rien décider; nous contentant de présenter ici ces difficultés aux botanistes qui pourront plus tard, ćtudiant ces plantes in loco natali, se prononece d'une manière définitive. 
69. JAMESONIA, Hook. et Grev.

F., Gen. filic., p. 161 ; tab. XII, fig. 5.

Rotundifolia, F.

Frondibus linearibus, evolutione indefinita; rachi cylindrico, squamis piliformibus, strigillosis obsito; nevvillis flabellatis; frondulis rolundo-cordatis, brerè petiolatis, crassis, margine lcriter convolutis, approximatis, sed semper distinctis, concaviusculis, superioribus majoribus; lamina inferiore omnino prolifera; sporangiis ovatis, subsessilibus; annulo $16-18$ articulato; sporis triedricis.

Habitat in Ocaña Novo-Granatensium; altitudine 3330 metr. (L. Schlim, $\left.\mathrm{n}^{0} 363.\right)$

Icon.: Tab. X, fig. 3 .

Filix elata, rigida, multifrondulosa.

(Longueur du rachis seul, 80 centim. Je compte environ 160 paires de frondules, fui mesurent a peines 4 millim. Le stipe manque dans notre spécimen, mais il est d'ordinaire assez court.)

Nous avons déjà fait remarquer que, dans ce genre, les frondes ont une érolution indéfnie; l'extrémité se présentant toujours roulée en crosse, mème dans les individus adultes et fructifiés. Cette extrémité scmble acquérir, ell s’élevant, une vigueur croissante; aussi arrive-t-il, contrairement à ce qu'on roil dans les autres fougères, que les plus grandes frondules sont aussi les plus élevées. Cie phénomène mérite d'ètre étudié; c’est une sorte de développenent scorpiölle. Dans les autres fougères, le turion se déroule et l'accroissement cesse; ici le turion se déroule et semble en inême temps s'accroître. Il existe parmi les Polypodium une particularité pareille, mais elle est une exception; ici elle s’élève à la valeur d'un caractère générique. (Cfi. plus loin le $P$. jamesonoides et la pl. XXI, fig. 4.)

\section{IIEUIONITIDEA:}

Vix prolifica universalis, id est sporothecia laminas integre vestientia : nervillis omnibus et in trajectu toto proliferis.

74. GALLOGRAMME, F. Gen. filic., p. 169 ; Lab. XV, ...

C.ecilie, F., I. c.

Frondibus simplicibus, ovato-lanceolatis, acuminatis, longe pedicellatis, apice ad calcem fructiferis, siccitate rufescentibus; nervillis basi liberis, ad marginem 
reticulatis; sporotheciis linearibus, parallelis, angustis, in parte nervillarum liberarum solim evolutis; sporangiis ovatis, pedicellatis, pedicello sporangiastros 3-4 ferente; sporis triedricis.

Habitat in Singhapour (Malacca, Gaudichaud).

Icox. : F., Gen. filic., l. cit. (Diagnosis generis), et Tab. XVIII, fig. 1.

Filix formosa, singularis; rhizomate repente, flexuoso, crassitudine pennce corvino.

Ad memoriam beate conjugis amantissimoe dicata.

Le genre Callogramme diffère, par un caractère important, du Syngramme, J. Si., arec lequel il a des rapports de nervation. Les frondes sont monotaxiques, altachées sur un rhizome traçant, garni de très-longues radicelles, très-nombreuses et traversé par deux gros faisceaux rasculaires, arrondis. Les frondes sont écartées les unes des autres, à pétiole long, canaliculé et brunâtre; elles sont orales-lancéolées, acuminées, arrondies à la base et acuminées au sommet. La marge est ondulée. (Voyez, pour plus de détails, ce que nous disons de cette plante dans le Genera filicum, à la page plus haut citée.)

\section{ANTROPHYEA.}

Singulum sporothecium super nervillas plures transiens.

78. ANTROPHYUM, Klfss.

F., Gen. filic., p. 174.

FEEI, Schaffn., in Liller.

Frondibus lanceolatis, basi altenuatis, subsessilibus, obtusiusculis, pellucidis, margine undulutis subcrenatisque; nervillis areolas irregulares formantibus, basalibus longioribus, ommibus proliferis; sporotheciis subimmersis; rhizomate repente, radicellas crassas tomentosas emittente; sporangiis subrotundis, sessilibus; sporis triedricis.

Habitat in Republica Mexicana, circù Huatusco, W. Schaffner, $n^{\circ} 133$; cum nota rarissima.

Filir parea, arboricola; areolis incerualibus.

Icos. : Trb. XXII, fig. 1.

Les frondes croissent groupées sur un rhizome très-déprimé, entouré, comme dans toutes les congénères, d'une bourre épaisse, sous laquelle se cachent les radicelles. Les marges sont ondulées, parfois même presque crénelées, offrant çà et là quelques dents irrégulières, peut-être accidentelles; les sporothèces envahisspnt très-sourent les six pans de l'aréole. Celle espèce, que M. Schaffrer a 
bien voulu nous dédier, est faiblement caractérisée; elle doit être placée à côté de l'A. subsessile de Kunze, avec lequel, toutefois, elle ne peut être confondue, ainsi quil est facile de le voir en consultant la planche XIX des Analecta.

$$
\begin{aligned}
& \text { 80. SELLIGUEA, Bory. } \\
& \text { F., Gen. filic., p. } 176 .
\end{aligned}
$$

Mexicana, F., Gen. filic., p. 177.

Frondibus laneeolatis, spissis, eoriaceis, mollibus, utrinquè attenuatis, siceitate luteseentibus, margine undulatis; petiolo brevissimo, alato; sporotheeiis linearibus, obtusis, reetis, remotis; sporangiis subrotundis, pedicello lato, breci; annulo 14-16 artieulato; stomate angusto; sporis ovoideis.

Habitat in Republica Mexieana, Sierra de San-Pedro Nolasco, Talea, etc.

C. Jungersen, $n^{\circ} 945$ (1843-1844).

Filix nuda, molliuscula; rhizomate erasso, fibris tomentosis.

Icon. : Tab. X, fig. 4.

Cette fougère croît au Mexique sur les vieux arbres; elle apparlient à la section Loxogramme du genre Selliguea. C'est, autant que nous pouvons le savoir, la seule espèce qui appartienne au continent américain. Le pédicelle de la sporange est tronqué à tort dans la figure que nous en arons donnée.

\section{LEPTOGRAVMEA.}

Sporothecia elongata, recta (vix universalia), nuda.

\section{GYMNOGRAMME, Desr.}

$$
\text { F., Gen. filic., p. 180; tab. XIX, C, fig. } 3 .
$$

Microcarpon, F.

Frondibus pinnatis, magnis, ad partem superiorem mesonevrorum pracipue, villoso-squamosis; pinnis lanceolatis, acutis, peetinatis; raehi lamine superioris plano, marginem extensam liberam tectante; segmentis multis, alternis, oblongis, obtusis; nervillis tenuissimis, creberrimis, eirci mesonevron proliferis; sporotheeiis linearibus; simplicibus, receptaculo angustissimo; sporangiis ovatis; annulo lato, 14 artieulato; sporis ovoideis, episporiatis.

Habitat in Venezuela (Caracobo), Funcke et Schlim, $n^{\circ} 611$.

lcos: Tab. XX, fig. 5.

La simplicité des nervilles, leur extrême ténuité, l’étroitesse des sporolhèces rangés, tous à la même hauteur et linéaires; la longueur des pinnules et le grasd 
nombre de segments qui viennent s'y attacher, donnent à cette plante un port curieux, bien distinct de celui des autres Gymnogramme. Elle doit être placée à còté du Phegopteris decussala, Met texuss, Pl. Peruv. Lecheriance, no 2356, qui, pour nous, est le Gymnogramme decussata. Ces deux plantes, et sans doute quelques autres espèces inédiles, notamment une espèce de Taït, constitueront un grompe distinet, qui deviendra un sous-genre dont le caractère sera bien tranché.

La plante péruvienne a une consistance molle; elle est chargée de poils. Le réceptacle (simple renflement de la nerville au point prolifère) est à peine indiqué; il y a bien moins de segments, et ils sont plus courts; les nervilles sont plus écarlées ( 27 par centim. pour notre espèce et 19 pour le Pheg. decussula); les sporothèces moins bien régulièrement constitués. Le singulier caractère du mésonève, aplati du còté inlérieur de la lame, dont les marges débordent et recourrent la nerville hasilaire, n'existe pas. (Voy. la planche citce, fig. 5 [rachis]).

Enfin, dans notre espece, les sporothéces sont allongés, et arrondis dans le Gymnogramme dechssuta, ee qui est caractéristique. Les sporanges, en outre, se détachent par le simple frottement du doigh dans le $G$. Ilecussata, et plus difficilement dans notre espéce; aprés leur clute, elles laissent des éminences raboteuses, faciles à sentir, sous la lame du canif, qui sautille en les francluissant.

Ces deux espèces ont le port du Stegnogramme mosochlena, F. Spherrostephanos asplenoides, Kze.), mais il ny.a point dindusium.

\section{8i. CEROPTERIS, Lk.$$
\text { F., Gen. filic., p. } 182 .
$$ \\ Cunisonia.}

Noxostichi, $\mathrm{F}$.

Frondibus bipimutis, in ambitu trimunulurbus; stipitibus Rexuosis, mescentibus, cylindricis, basi panci-squamosis; rhizomate squamas adpressas, fuscas ferente; pimmlis infunis busi pimotis, intermediis pimmlifudis, supremis simplicibus; segmentis margine angustè pliralis, suprit glabris, sublis cora pallidè sulfurina abundè conpertis; sporotheciis muximis, margine approximatis, miseriatis, distinctis; sporangiis subrotundis, margnis; ammeno angusto, 20-22 articulato ; sporis triedricis, magnis.

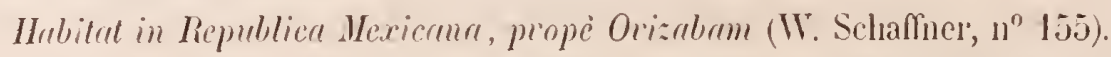

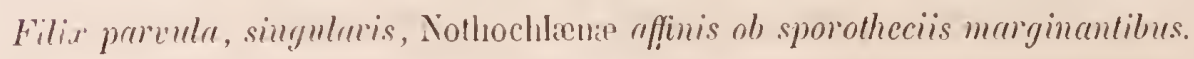

Icos. : Tub. XIII, fig. .

Espèce très-curieuse el très-distincte par des sporothèces continus, unisériaux et nervillaires. Elle a le port des Ceropteris, el la sécrétion, qui recoure les lames 
inférieures, forme une couche épaisse, dense, qui sans doute met olstacle au développement des organes reproducteurs. La nature des organes accessoires épidermoïdes, et la forme des spores, qui sont triédriques, l'éloignent du Cheilanthes candida, Mart. ę GaL., avec lequel notre plante a me analogie éloignée. Les Nothochlona sont des plantes laineuses, tomenteuses et écailleuses; les Ceropteris, ainsi que le nom en témoigne, sont des fougères cérifères.

\section{$86^{z}$ MICROSTAPIIYLA, Presl. 1849. \\ Epim. bot., p. 160.}

Gymnogrammes, Anogrammes, Acrostichi, Dareæ et Olfersiæ spec. auct. var.

Sporotheans diffusis, nevillaribus, totam nervillam proliferan oceupantibus, laxè congestis; sporangiis dorsalibus; ammulo 10-12 urtieulato; sporis ovalibus, pedicellatis.

Froxblbus dimorphis; nervillis liberis; aliis simplicibus, aliis divisis.

Filix polymorpha; debilis, saxicola, glabra.

Diagnosis : Tab. XIII, fig. 1, Mierostuphyla bifureatu, Presl.

Mierostaplygla ab Anogramınate distat, frondibus dinorphis; " Polybotrya et aliis generibus Acrostichearun, sporangiis nevillaribus.

\section{GENLS MONOTYPU.I.}

Fincata, Presl.

Frondibus lanceolatis; fertilibus pinnatis, seguentis subtrifudis aut sub integris, incequaliter dentutis; fertilibus minoribus, semper divisis, seguentis brevioribus truncatis; petiolis graeilibus, flexuosis; rhizomate repente, crassitudine pennce columbina, multas frondes ferente; sporangiis nevilluribus, crassis; nevillis in trajectu ommino, proliferis.

Itabitut in rupibus insule S. Helena (Forster, Lichtenstein, Sieboldt, Gurning, $\left.\mathrm{n}^{0} 420\right)$.

Filix polymorpha, glaberrima; frondibus aliis subsimplicibus, imegulariter dentulis, aliis piunatis, segmentis profundè divisis, subtrifulis.

(Dimensions très - variables. Yoy. la planche cilèe de ce Vémoire.)

Osmunde bifurcutu, Jacq., Collect., T. 20, fry. 2.

Acrostichum bifurcatum, Sw., Syn. filic., p. 12; et Scluklı. Crypt. Gone., T. 3. Willd., Filic., p. 11 亿.

Acrostichum dimorphum, IIook. et Grev., Filic., Tab. 145 (Frons fertilis exchusa). F., Itist. cles Acrostichies, p. 40. 
Olfersia dimorpha, Presl., Tent. pterid., p. 235.

Gymnogramme bifurcata, Kze. in Linnæa, X, p. 496.

Darea furcans, Bory, Voy. de la Coquill., p. 269; tab. 35, fig. 2 (statu sterili, diviso).

Anogramme paradoxa, F., Gen.filic., p. 64.

Microstaphyla furcata, Presl., Epim. botan., p. 160.

Nous renvoyons à l'Histoire des Acrostichées, p. 40, oủ nous établissons quel'A. dimorphum, Hook. et Grev., et l'A. bifurcatum, de Swartz, ne sont quine seule et mème espèce et que la planche donnée par ces auteurs, pèche par l'exactitude, la fronde fertile figurée n’appartenant pas vraisemhlablement aux frondes stériles.

Rien ne prouve mieux combien cette plante est embarrassante, que de la voir passer successivement dans sept genres différents. Kunze a roulu voir dans le Microstaphyla un Gymnogramme, mais il n'en a ni le port ni l'organisation. Cet auteur estimable et consciencieux ne se préoccupait pas assez du facies. Continuateur de Schkun, il a cru devoir respecter tous les anciens genres, et ce li’est que dans ses dernières années, qu'entrainé par les travaux des botanistes progressistes, il a accepté quelques genres proposés, encore ne l'a-t-il fait qu’arec une réserve extrême. Bony était bien plus éloigné de la vérité quand il voyait dans cette fougère un Darea; ne l'ayant pas étudiée fructifiée, il la nommait d’une manière un peu hasardée.

En acceptant le genre Microstapleyla, de PREsL, nous ne croyons pas devoir lui donner la même place dans la série des genres. Ce n’est pas une acrostichée, mais bien une leptogrammée, qui doit être mise à côté du genre Anogramme, et ce serait encore dans ce genre qu'on devrait la trouver si les frondes n’étaient pas diplotaxiques et appartenant évidemment à un type différent.

M. ASPLENIE

Indusium solitarium et laterale.

88. ASPLENIUM, L.

F., Gen. filic., p. 189; tab. V, fig. 3, et tals. XYII, fig. 3.

- Neottopleridastrum.

I. Coriaceun, F., loc. cit., p. 193.

Frondibus simplicibus, rigidis, coriaceis, opacis, lanceolatis utroque attenuatis; margine integro, siccitate convoluto; sporotheciis angustis, longissimis; indusio angustissimo; nervilla prolifera prominente, in receptaculo nigrescente mutata; sporangiis ovatis; annulo 18-20 et plus articulato; sporis ov'oideis, latè episporiatis. 
Habitat in Republica Mexicana (Galeotti, sine numero).

Asplenium coriaceum, F., Gen. filic., p. 193.

Icon. : Tab. XV,fig. 1.

Cette fougère a le port du Pteropsis angustifolia, Desv. Le rhizome nanque, el comme nous ne possédons qu'une seule fronde, on peut admettre qu'elle atteint des proportions plus considérables. Le mesonèvre est blanchâtre du côté inférieur de la lame; il n'est indiqué du côté supérieur que par une très-étroite proéminence. Les sporothèces, au nombre d'une vingtaine de paires, n'atteignent pas la marge qui est entière; ils forment avec le mésonèvre un angle de $20^{\circ}$ environ.

\section{Neo-granatense, F.}

$$
\text { * Euasplenium. }
$$

Frondibus in ambitu ovatis, stipite profundè sulcato; frondulis pancis, remotis, lanceolatis, longè acuminatis, basi cuneifornibus, obliquis, glabris, marginibus integerrinis, mesonevro nervillisque tenuibus; sporotheciis remotis, linearibus, longis; indusio crassiusculo, angusto; sporangiis ovatis; annulo 20 articulato ; sporis papillatis.

Habitat propè Ocaña, in Novo-Granatensi. L. Schlim, n 122 (altitud. 1200 metr.) et. $\mathrm{n}^{0} 492$ (altitud. circà 1700 meti.).

Filix pulchra, Rexibilis, panci-frondulosa; frondulis facie panicornm foliis latis.

Icon.: Tab. XIV, fig. 1.

Cette espèce, l'une des plus belles du genre, est portéc par un pétiole et les frondules par des pétiolules déliés de couleur plombée. Elle est souple, glabre dans toutes ses parties, à frondules peu nombreuses et écartées, longuement acuminées, à marge très-entière, ondulée. Le $n^{0} 122$, récolté aux mêmes localités que le $n^{\circ} 492$ des plantes de M. L. Scillin, a des proportions un peu supérieures; les frondules sont plus larges.

Le stipe est traversé par quatre faisceaux vasculaires : deux latéraux linéaires, très-légèrement arqués; un basilaire ponctiforme, et un central en forme de croissant. Les nervilles forment un angle très-aigu avec le mésonèrre, et elles atteignent parfois près de 5 centimètres de longueur, dimension qu'on peut regarder comme extraordinaire.

III. Cinlenopteron, F., loc. cit., p. 194.

Frondibus pinnatis, in ambitu lanceolatis; rachi compresso; petiolo sulcato depressoque; frondulis ovato-lanceolatis, acuminatis, glabris, brevè stipitatis, basi obliquis, infernè enarginatis, supernè gibbosis, margine crenato, crenis 
inaqualibus; nervillis antè marginem evanescentibus; sporotheciis brevibus, advltis crassis conniventibusque; indusio latissimo; sporangiis ovatis, magnis; annulo 22-24 articulato; sporis subreniformibus.

Habitat in insula Borbonica (Olivier).

Filix rigida; frondulis mollibus, crenatis; surculo crasso, squamis lanceolatis, acuminatis, margine denticulato obsito.

Icon. : Tab. XVI, fig. 1.

(Longueur totale, 30 centimètres, dont le stipe fait la moitié. Enrergure: 7 centimètres. Nous avons vil un spécimen ayant des dimensions supérieures à celles du spécimen figuré, et e'est lui qui a èté décrit dans le Genera.)

L.es pinnules alternes sont au nombre de 12 à 14 paires; elles ont une forme wale-lancéolée et s'allongent, en une longue pointe dentée. On voit au sommet un bourgeon prolifère. Le rachis est un peu flexueux, aplati, garni de quelques écailles tortillées et linéaires. La souche, qui produit un grand nombre de frondes, est grosse el chargée d'écailles ovales, longuement acuminées, opaques, à nervilles d'un brun rougeâtre. Les débris des stipes des végétations antérieures y restent adhérentes.

Cette eșpèce nous arait été donnée sous le nom d'A. obliquum, Labilu., comme provenant de l'herbier du Muséum; elle est tout à fait différente.

IV. Platrchlamis, F.

Frondibus pinnatis, oblongo-lanceolatis, glabris, petiolo sulcato et rachi depresso; frondibus inferioribus oppositis, ovato-oblongis, brevè petiolatis, obtusiusculis, basi imfernè emarginatis, supernè auriculatis, latè crenatis; nervillis remotis, tenuibus; sporothcciis subarcuatis, distontibns; nervillis smperioribus tantim fertilibus; indusiis latis, ferè semper od basim plicatis; sporamgiis ovatis; annnlo 20 articulato; sporis ot atis.

Habitat in Caracas (Moritz, $\left.\mathrm{n}^{\circ} 26\right)$.

Filix glabra, rigida; frondulis latè crenatis.

Icos. : Tab. XIV, fig. 3.

Ce qui caractérise cette espèce, ce sont les indusium, remarquables par leur ampleur. Ils dépassent de beaucoup les sporanges qu'ils recourrent; ils sont donc bombés au point fructifère, et aplatis sur les bords d'une manière brusque; étant opaques au centre et légèrement pellucides à la marge, on les croirait doubles, et il nous a fallu quelque temps pour nous assurer qu'ils étaient simples. 
V. FEEI, Kze. in Litter.

Frondibus pinnatis, squamulosis, lanceolatis, radicantibus; rachi basi violaceo, helveolo; frondulis 15-18 jugis, lanceolatis, basi cuneatis, infernè marginatis, apice extenso, caudiforme, serrato, sterili, margine bidentatis; dentibus incequalibus, subincisis; nervillis remotis, crassiusculis; mesonevro tenui, flexuoso, pallido; sporotheciiscrassissimis, turgidis, ovatis, tabacinis; indusio amplo, albido; sporangiis rufescentibus, pedicello longissimo; annulo 24-26 articulato; sporis ovatis.

Habitat in Mexico (Galeotti).

Asplenium Feei, Kze. in Litter. F., Gen. filic., p. 194.

Filix robusta; pinnulis argutè serratis, acuminatis, acumine extenso, caudiformi, serrato.

ICoN. : Tab. XV, fig. 2.

Cette espèce, à laquelle le savant ptéridographe Kuxze, dont l'affection nous fut longtemps chère, a voulu imposer notre nom, est bien distincte. La frondule terminale tend à se diviser et à devenir pinnatifide. Elle porte vers le haut un bourgeon vivipare; circonstance si fréquente dans les fougères tropicales qu'elle ne peut servir de caractère.

\section{Longipes, F., loc. cit., p. 195.}

Frondibus glaberrimis, in ambitu outis, stipite, rachi petioloque frondulurum laxis, helveolis; frondulis ovato-lancealatis, longè petiolatis, acuminatis, basi acutis, marginibus crenato-dentatis; nervillis crassis, simplicibus, marginem non attingentibus, ad partem medianam proliferis; sporotheciis longiusculis, basi ad apicem decrescentibus; sporangiis ovatis, pedicello temui, longissimo, articulato; sporis ovatis.

IIabitat in insula Zeylanica (Colonel Walker, Herbier Graham).

Filix glaberrima; frondulis folia Sorbi aucuparie referentibus.

ICON. : Tab. XVI, fig. 3.

Cette fougère est très-souple dans toutes ses parties, à stipes grèles, blanchàtres, striés el fort déliés. Les frondules, dentées à la marge, se terminent en une pointe entière. La frondule inféricure est trifoliolée dans l’un de nos spécimens, ce que la figure donnée eủt exprimé, si nous ne devions à la rigueur regarder cette circonstance comme accidentelle. 
VII. Galeottu, F., Gen. filic., p. 192.

Frondibus pimatis, glabris, in ambitu lineari-laneeolatis; frondulis crassiusculis, dimidiatis, incquilateralibus, supernè auriculatis, obtusiusculis, dentatis, areualis, inferioribus deltoideis, oppositis, obtusissimis; sporotheciis 3-5, adultis urgidis, confuentibus; sporangiis tabacinis, ovalibus; annulo 20 articulato; sporis ovoideis, episporiatis.

Habitat in Republica Mexicana, propè Oaxaca (Galeott., $\mathrm{n}^{0} 6369$; ad rupes caleareas; altitud. 2300-2500 mctr.).

Asplenium inoquilateralc, Mart. et Gal., Filie.mexic., p. 57 non Willdenow.

Filix rigida, elongata; stipite rachique ebeneis, glabeminis.

Icos. : Tab. XVI, fig. 2.

I.A. incequilaterale, Willd., Filic., p. 322, est une fougère de Bourbon, que nous possédons de Bory même, qui, le premier, l'a découverte; elle est bien différente de notre espèce. Les frondules sont linéaires, lancéolées, et les sporothèces courts; elle se rattache au pelit groupe dont le type est l'A. monanthemum des auteurs. Toutes les frondules sont prolifëres et chargées de 3-5 sporothèces; celui de la base est beaucoup plus long que les autres et mesure jusqu’à 5 millim.; cenx du scmmet, beaucoup plus courts, deviennent confluents.

\section{IIII. Leptopuyllum, L.}

Frondibus linearibus, glaberrimis, rachi petiolisque rubeseentibus, lavibus, lucidulisque; frondulis oblongis, obtusissimis, basi truncatis, crassis, dentatis, supernè crenatis, inferne integris, submonanthemis, margine turgido; sporotheciis subsolitariis, ovatis, adultis crassissimis; sporangiis ovatis; amnlo 20 articulato; sporis ovoidcis.

Habitat in Novo-Granatensi, provincice Ocañce, ad Paramos montinm, altitud. 2700-3300 metr. (L. Schlim, $\mathrm{n}^{\text {0s }} 479$ et 328.1846-1852, in Mexico, Galeotti, $n^{0}$ 6446.)

Filix angustissima, multifrondulosa; rlizomate repente, squamas lineares, vigidas, atras, opacas, cancellates ferente; frondulis inferioribus dilatatis flabellatisquc.

ICon. : Tab. XIV, fig. 2. L. Schlim, no 328, fig. 2 A. L. Schlim, $n^{0} 479$, fig. 2 B. Forma Mexicana.

Charmante espèce, linéaire, raide, dressée, dont le rachis est chargé de 50-60 paires de frondules, qui vers le haut se dégradent de dimension, en conservant leur forme, tandis que vers le bas elles s'écartent, deviennent régulières, s'élargissent transversalement et s’étalent en éventail. Les frondules moyennes sont 
cunéiformes et portent à la base une sorte de marge indiquée par une dépression. On trouve, quoique fort rarement, deux sporothèces sur chaque frondule.

La plante $n^{0} 6446$, de GaLeottr, n'en diffère pas notablement; elle est cependant plus robuste; les frondules portent plus fréquemment deux sporothèces, et ceux-ci sont plus gros.

Notre plante a des rapports avec l'A. monanthemum, Sm., dont elle diffère par des proportions de moitié inférieures; par un plus grand nombre de frondules, plutôt crénelées que dentées, plus courtes, plus obtuses, à surface froncée des deux côtés. Le pétiole est aussi plus long. La diagnose microscopique révèle d’autres différences; le pédicelle des sporanges est plus long et plus grêle dans l' $\boldsymbol{A}$. leptophyllum que dans l'A. monanthemum, les spores sont exactement ovoïdes, et quittent le sacculus sans être accompagnées de l'épispore; elles sont aussi bien plus grosses que celles de l'espèce à laquelle nous la comparons.

Rigoureusement parlant, le nom spécifique de monanthemum ne convient à aucune espèce, et il a certainement été donné à des plantes très-diverses, n'ayant sur chaque frondule qu'un, ou plus rarement, que deux sporothèces. C'est ainsi, par exemple, que nous arrivons à douter que l'A. monanthemum du Cap Vert, distribué pour C. Hocistetter, sous le $n^{0} 175$, à frondules plus écartées, portant près du sommet le sporothèce, à sporanges, ayant un anneau extrêmement étroit, divisé par 24 articulations, à spores oroïdes tuberculeux, soit bien la même plante que celle du Cap de Bonne-Espérance. Aussi lui donnons-nous dans notre herbier le nom d'A. blandulum.

IX. Extexsum, F.

Frondibus linearibus, clongatis; extensis, pinnatis; surculo parvulo, radicellas longissimas ferente; rachi ebeneo, ad latera tomentoso; frondulis ovaljbus, integris, simuatis, brevissimè petiolatis, remotis suboppositisque; sporotheciis 3-4, parvulis, subarcuatis; indusio tenui; sporangiis obovatis; anmulo 18 articulato; sporis ovalibus.

Habitat in Novo-Granatensi, provincia Ocañe (L. Schlim, $\mathrm{n}^{0} 629$ ).

Filix laxa, longissima; nervillis apice turgidis.

ICON. : Tab. XIII, fig. 2.

Cette fougère, qui sans doute est arboricole, étant dans l'impossibilité de se soutenir droite, tant elle a de laxité, est extrêmenent curieuse. Elle porte çà et là quelques gemmes, les uns non développés, les autres ayant donné naissance à de petites frondes déjà avancées. Le stipe est filiforme; la souche petite, un peu dressée, très-écailleuse; elle ne porte qu'une seule fronde dans le spécimen que nous décrivons. 
X. Pimpinellifolium, F. et Schaff.

Frondibus pinnatis, lanceolatis, apice in candam attenuatis; frondulis alternis, glabris, horizontalibus, brevè pedicellatis, ovatis, basi inferiore emarginatis, supcrnè gibbosis, margine erenatis, crenis binatis, nervillis remotis; sporotheciis 3-4 paribus, angustis, rectis, rufescentibus; sporangiis ovoideis, longè et angustè pedicellatis; anmulo 20 articulatis; sporis muricatis; sureulo subrecto.

Habitat in Huatuseo Mexicanorum suprà stipitem filicum arborescentium. Schaffner, $n^{0}$ 50. 1854.

Filix arboricola, pinnata, herbacea; frondulis erenatis, crenis rotundis, regularibus, modò Poterii Sanguisorbæ(Pimpinella minor, Gærtn.), sed forma folion diversa.

Icox.: Tab. XXV, fig. j.

Jolie espèce, remarquable par des frondules horizontales, courtement pétiolées, coupées en biseau du côté inférieur et gibbeuses vers le haut; la souche est dressée et porte plusieurs frondes fasciculées; le pétiole est faiblement canaliculé; le rachis, déprimé, a une couleur verdàtre. Les frondes se terminent par un prolongement caudiforme portant quelques frondules réduites, à une sorte de moignon obtus.

XI. Gracile, F., loe. cit., p. 198.

Frondibus pimatis, glabris, breve stipitatis; thizomate tenui, repente; frondulis supcme auriculatis, cuncatis, ad marginem dentato-incisis, llentibus oblusis; rachi complanato; sporotheciis elongatis, pancis, lincaribus; sporangiis brevè

- pedicellatis; annulo 14-16 articulato; sporis ovoideis.

Habitat in insulis Philippinis (Cuming, sine numern).

Filix parvula, currata.

Icos. : Tab. XXIH, fig. 1.

Petite espèce arec rhizome, glabre, courtement pétiolée, noffrant aucume particularité, dont la figure citée ne puisse rendre compte. Peut-être est-ce là quelque petile forme d’une espèce ordinairement plus grande?

Mil. Depauperatum, F.

Frondibus cospitosis, glabris, pinnato-pinnatifidis, tencris, in ambitu ucueolatis, apice virgatis, mudis, radicantibus; rachi aluto, flexuoso, usquè ad basim pinnatifero; pinnulis approximatis, pinnatifidis, segmentis incisis, acuminatis; 
sporotheciis ovoideis; indusio tenui, flaccido; sporangiis ovoideis, annulo $20-22$ articulato; sporis episporiatis, ovoideis.

Habitat in Bolivia (Weddell, $\mathrm{n}^{0}$ 4235).

Filix tenera, flexibilis; apice nudo radicante; surculo erecto.

Icos.: Tab. $X V$, fig. 3.

Cette espèce est délicate, glabre et presque translucide. Les frondes sont attachées, en assez grand nombre, sur une petite souche dressée. Le rachis est ailé et fronduleux jusqu'à la base, ce qui lui donne une apparence sessile. Les frondes sont flexueuses et terminées par un prolongement du rachis, nu et calleux à son extrémité, ce qui fait croire qu'elle est vivipore. Les sporothèces, au nombre de 4-6, ont un indusium flasque et blanchâtre.

L'aspect que présente la souche permet de décider que cette fougère n'a qu'une courte durée.

XIII. Argutans, F., Gen. filic., p. 194.

Frondibus lanceolatis, pinnatis, ad apicem pinnatifidis, attenuatis; stipite pubescente, suprà plano, infrà striato; frondulis lanceolatis, obtusis, subsessilibus, supernè auriculatis, infimis deflexis ; nervillis fuscis; mesoneuro pubescente; sporotheciis angustis, longiusculis, remotis; sporangiis ovatis, pedicello lato; amnulo 18 articulato; sporis ovoideis, late et irregulatim episporiatis; surculo erecto, fibrilloso.

Habitat in insula Borbonia? Sieber, $F l$. mixta, $\mathrm{n}^{0} 246$, in Indiis orientalibus (Griffith).

Filix delicatula, siccitate rufidula, apice longè attemuata.

Icon. : Tab. XXIV, fig. 2.

(Dimensions : 30 - 32 centim. de longucur totale, sur 9 centim. dans la plus grande largeur; pinnules 8 millim. de largeur).

Le spécimen reproduit dans notre planche a des proportions inférieures.

Plante assez délicate, à pinnules, les unes droites, les autres un peu arquées, courtement pétiolées et comme tronquées à la base; elles sont obtusiuscules ou brusquement terminées en pointe. La fronde est très-longuement acuminée et pinnatifide. Le spécimen lithographié provient de Sierer, et porte sur l'étiquette A. formosum, Wilud., India occidentulis. C'est sans doute une double erreur. L'A. formosum de Willdexow est tout différent, et comme Sierer n’a point distribué des plantes de l'Inde et que nous possédons l'A. argutans de l'Inde récolté par M. Griffith, nous croyons que le spécimen de Sieber est indigène de Bourbon ou de l'Ile-de-France. 
XIV. Pumluum, Sw., Syn. filic., p. 79.

Var. IIyuenopiylloïdes, F.

Frondibus pinnatis, pellucidis, glabris, apice subcaudatis, infmis trapezoideis, pinnatifidis, superioribus ovatis, marginibus obtuse et irregulariter dentatis; rachi alato; stipite filiformi, squamulas sparsas ferente; radice parvulo, erecto; sporotheciis ovato-lincaribus, obtusis, leviter arcuatis; indusio siccitate rufudulo; sporangiis ovatis; anmulo 20-24 articulato; sporis ovoideis.

Habitat in Abyssinia (Ambasea, ad altitud. 2000 metr. Schimper).

A. Schimperianum. Hochst., sect. II, $\mathrm{n}^{0} 643$.

A. anthriscifolium, Jacq., Coll. 2, fig. 3 et 4.

Varictas fronde delicatissima, pexibilis, pellucida; sporothceiis brevioribus.

Icos. : Tab. XV,fig. 4.

Le type a été décrit pour la première fois par JACQuin (Coll. 2, tab. 2, fig. 3 et 4), et Swartz, lui a donné le nom de pumilum, sous lequel il est aujourd'hui connu. C'est, comme on voit, une plante polymorphe, variant beaucoup, non-seulement par les dimensions, mais encore par les pimmules, dont les segments sont tantôt aigus et tantòt obtusiuscules.

La variété que nous figurons est remarquable par l'extrême délicatesse de son tissu, la brièveté de ses pimmules et de ses sporothèces; elle est aussi plus glabre et plus ramassée dans toules ses parties.

Les sporanges mises sous l'eau et examinées au microscope, montrent que l'anneau est très-étroit et très-résistant; il seétend en long après s’ètre débarrassé du sacculus; celui-ci, devenu libre, se roule sur lui-même et l'on a sous les yeux un corps oblong, un peu aminci à chaque extrémité, assez semblable à un fuseau. Cette particularité peut ètre observée dans notre variété, aussi bien que dans le type, quoique d'une manière bien moins marquée.

XV. Tervatum, F.

Frondibus pexuosis, glabris, in ambitu linearibus, bipimatis; rachi robusto, late canaliculato; frondulis ternatis, lateralibus dentato-crenatis, sessilibus, incequalibus, mediana majori, ommibus cuneatis, obovatis; nervillis paucis, flexuosis; syorotheciis 4-6, approximatis; indusio latissimo; sporangiis ovoideis, pedicello longiculo; annulo angusto, 20 articulato; sporis papillatis.

Habitat in Novo-Granatensi; provincia Ocañce; altitud. cireiter 1700 metr. L. Schlim, no 327 . 
Filix extensa; apice radicante, flagelliformi.

ICoN. : Tab. XVI, fig. 4.

(Longueur totale, 40 centim. et plus; frondules courtes; la centrale, 9-11 millim. de longueur; les latérales plus petites de moitié; les entrenœuds mesurent 3 centim.)

Cette espèce est extrêmement distincte et d'un port spécial, qui rappelle certaines espèces de Spircea microphylles; elle vit très - vraisemblablement sur les arbres, du moins ne parait-il pas qu'elle puisse se soutenir seule. Les frondules sont, relativement, très-courtes et disposées par paires sous-opposées; les sporothèces sont larges, et l'indusium de chacun d'eux s'étend presque jusqu'à la base de l'indusium correspondant, avec lesquels il confine. Toutes les frondules sont fertiles.

XVI. Herbaceum, $\mathrm{F}$.

Frondibus linearibus, bipinnatis, apice attenuatis, radicantibus, mollibus, herbaceis, viridibus, glaberrimis pellucidisque; pinnulis brevibus, frondulis inferioribus ovoideis; terminalibus majoribus, crenatis, cuneiformibus; rachi filiformi, alato; sporotheciis brevibus, submarginalibus, rufis; sporangiis ovoideis, pedicellatis; sporis ovalibus.

Habitat in Novo-Granatensi; L. Schlim, $\mathrm{n}^{0} 326$.

Filix tenera, debilis, prostrata, seu pendula.

Icon.: Tab. XXII, fig. 3.

(Dimensions probablement plus grandes pour la longueur que celle de la figure donnée. Les pinnules ne dépassent guère 11 à 12 millim.)

Cette espèce curieuse est herbacée et s’éloigne beaucoup par le port de ses congénères; elle ne se rapproche guère que de l'A. cladolepton. Le rachis est ailé et vert-pâle. Les frondules alternes et glabres sont pédicellées et séparées par un intervalle de 15-17 millim. C'est la plus délicate du genre; elle vit suspendue aux arbres ou couchée sur les mousses, du moins sa consistance dispose à croire qu'il en doit être ainsi. Le stipe et le rachis n'ont pas à l'extérieur cette organisation crustacée propre aux Adiantum, tandis qu'elle existe dans l'espèce suivante.

\section{yViI. Cladolepton, F.}

Frondibus elongatis, linearibus, bipinnatis, glabris, apice attenuatis; rachi rufidulo, lovi, canaliculato; pinnulis oblongis, apice pinnatifdis; frondulis bifidis, oblongis, segmentis obtusis, laminis pellucidis; sporotheciis rufis, brevibus; sporangiis rotundatis, pedicellatis; sporis ovoideis.

Habitat in Novo-Granatensi, provincia Ocaña ; L. Schlim, $\mathrm{n}^{0} 324$. 
Filix delicatula; rachi firmo; pinnulis herbaceis.

Icon.: Tab. XXII, fig. 4.

Cette espèce diffère de la précédente par un rachis ferme, lisse, luisant, de couleur rougeâtre et canaliculé; par des pinnules ovoïdes, pinnatifides au sommet. Les fi'ondules sont bifides et oblongues. Le pétiole et le rachis, à l'état de dessiccation, sont fistuleux et renferment un seul faisceau vasculaire qui y est libre; on peut les déprimer comme le chaume d'une graminée. Dans l'A. herbaceum, le pétiole est aussi uninervillaire, mais il est plein et le faisceau n'est pas libre.

\section{SCOLOPENDRIE E.}

Indusia opposita, nervillas duas sejunctas occupantia.

\section{$+97^{2}$. SCHAFFNERIA.}

Sporotuecirs linearibus, elongatis, inversis, plus minusve conniventibus; inferioribus ad latus superius venularum fertilium sitis; superioribus ad latus inferius carumdem nervillarum, omnibus oppositis, incqualibus evolventibus; indusiis crassiusculis, persistantibus; sporangiis ovoideis, pedicellatis; annulo 20 articulato; stomate angusto, paucinervato; sporis ovoideis, episporiatis.

Frondibus simplicibus, integris, crassis, subspongiosis, opacis, junioribus ferè ovoideis, adultis fabellatis; nervillis anastomosantibus, areolis subhexagonoideis, ad marginem minoribus; petiolo crasso, ebeneo; mesonevro mullo; surculo crecto, squamoso, polyphyllo, squamis lanceolatis onusto.

Disgsosıs: Schaffneria nigripes. Tab. XVII, fig. 1. Planta adulta et juvenis magnitudine naturali. 1 a) Pars aucta situ sporotheciorum et nervillarum fabrica demonstrans; 1 b) Pars multa aucta, hymenium ramosum et vasa spiralia exhibeus; 1 c) Cuticula cum stomatibus; 1 d) Fasciculi vasorum.

Genus insigne, monotypum; nervatione Antigrammatis; aspectu et consistantia Alismacearum; forma frondium folium IIydropeltidis purpureæ longè evocans, Nigripes, F. (Pro descriptione, vide suprà, characteres generis.)

Celte plante, l’une des plus curieuses de la famille des fougères, a été trouvée au Mexique par M. Schaffrer, auquel nous devons une quantité considérable de fougères mexicaines, récoltées avec l'intelligence d'un botaniste habile et sagace. La gratitude nous faisait un devoir de lui dédier cette singulière scolopendriée, afin de reconnaître l'ardeur de son zèle pour les intérêts de la science à laquelle il se consacre. 
Le Schaffneria nigripes croît dans les endroits marécageux, et la nature de ses tissus le démontre. Les trachées déroulables, assez rares dans les fougères, y abondent, et la cuticule est chargée de stomates du côté supérieur; sous cette cuticule se trouve du tissu rameux formant la masse de la fronde; tissu, comme on sait, très-rare dans le règne végétal. On reconnaît à des articulations le point de contact de chaque cellule. Le pétiole est revêtu d'une sorte de croûte fragile, que l'on retrouve dans le pétiole des adiantum; il est traversé par un faisceau vasculaire, dont les éléments sont faiblement unis. Ce support très-robuste disparaît au point même où commence l'épanouissement de la lame qui semble posée dessus. Il n'y a point de mésonèvre et toutes les nervilles ont un calibre égal.

\title{
XVII. POLYPODIE E.
}

\author{
(Vide suprà, p. 6.)
}

\section{POLYPODIUM.}

\section{Eli.jpsoideum, F.}

Frondibus pinnatifidis, in ambitu lanceolatis, pilosis; segmentis lanceatis, acutis, integris, infrà leviter curvatis, ciliatis, simubus rotundis, latiusculis; sporotheciis auratis, conniventibus sed distinctis, ellipsoideis, circà margines evolventibus; sporangiis subrotundis; annulo 14 articulato; sporis subellipsoideis; rhizomate elongato, crassitudine pennce anseris, flexuoso, squamis lanceolatis, basi latiusculis et longè acuminatis cooperto.

Habitat in Republica mexicana ad montem ignivomen Popocatepetl, altitud. 3000 met., ad arbores, et circa San-Angel, supra terram. W. Schaffner, $n^{\text {os }} 270$ et 211.

Filix formosa, flexilis; facie et dimensionibus $\mathrm{P}$. vulgare , L.

Icon. : Tab. XXI, fig. 1.

Cette espèce est charmante, et la forme ainsi que l'arrangement de ses sporothèces la rend tout à fait distincte. Les segments frondulaires sont lancéolés, un peu inégaux, ceux de la base horizontaux, les autres légèrement courbés vers le bas. Suivant qu'elle croît dans des lieux plus ou moins favorables, les segments restent étroits ou acquièrent une certaine ampleur, ce qui éloigne les sporothèces de la marge ou les en rapproche. Les pétioles et les rachis sont brunâtres, presque glabres et un peu luisants; les mésonèvres deviennent flexueux vers le haut. Le rhizome est elllièrement couvert d’écailles brunâtres, de même couleur que le pétiole et le rachis ; 
il présente sur divers points de son étendue des rosettes d'écailles que l'on croirait volontiers être de jeunes bourgeons; en les enlevant, on s'assure qu'elles entourent la cicatrice déterminée par la chute de la fronde des végétations antérieures.

II. Leptostomì, F.

Frondibus angustè lanceolatis; petiolo brevi, fusco, pilis capitatis (an viscosis?) vestito, rachi ejusdem colore, sed pilis acutis cooperto; segmentis lineari-lanceolatis, glabris, acutis, rigidis, erectis; mesonevro apice vix flexuoso; nervillis lateralibus simplicibus, brevibus; sporotheciis laxis, 5 -7 centralibus; sporangiis rotundis; annulo 12 articulato; slomate prominulo; sporis ovoideis; surculo erecto, duro, radiculas fuscas longissimas ferente.

Habilat in Mexico, propè Oriba:am ad arbores; W. Schaffner, nº 210.

Filix tenera, pectinata, flexilis; surculo temui.

Icon. : Tab. XXI, fig. 2.

Cette espèce est jolie, délicate, flexible, à segments redressés, au nombre de 40 - 50 paires; ils ouvrent arec le rachis un angle de $50^{\circ}$ environ; la souche est petite et porte plusieurs frondes fasciculées, de très-longues radicelles viennent s'y attacher. Il est probable que cette fougère n'a qu'une courte durée. La sporange est curieuse; le stoma s'allonge en bec, comme si, repoussé par les spores, il faisait hernie.

III. Letcosticox; F., Gen. filic., p. 2:10, non Kze.

Frondibus pendulis, linearibus, pilosis, pilis rufescentibus; stipile filiformi, cylindrico, brunneo; segmentis obtusis, oblongis, pilosis, pilis sparsis longis, rufis; nervillis lateralibus simplicibus, brevibus, apice lurgidis, pellucidis; mesonevro flexuoso, nigrescente, evanescente; sporotheciis subsenis, rotundis, infernè puncto calcareo, albo determinantibus; sporangiis ovoideis; annulo crasso, incequali, 14-15 articulato; sporis rotundatis, incequalibus.

Habitat in Cuba (Jameson 1845).

Filix pectinata, longiuscula, flexibilis, angusta, pilis rufis passim cooperta.

ICON. : Tab. XXI, fig. 3.

M. Mettenius réunit cette charmante espèce au $P$. subtile de Kunze et de II. Ḱlotzsch (Linncea, T. XX, p. 375). On ne peut dire de notre plante qu'elle est très-grêle, finement membraneuse, pendante, courtement pétiolée, à stipe 
bilinéaire; les sporothèces ne sont pas entourés de poils. Les proportions sont aussi totalement différentes.

Nous pensons qu'il suffira de la figure que nous donnons ici pour établir la spécificité de notre espèce, qui ne mérite à aucun titre la qualification de subtile.

IV. Jasesonoides, F.

Frondibus linearibus, multipartitis, fasciculatis, viscosis, glabriusculis, evolutione apicis indefinita; petiolo brevi filiformi; segmentis oblongis, basi ad apicem decrescentibus, obtusis, opacis; sporotheciis $6-8$, crassis, confluentibus, laminam integre tectantibus; sporangiis subrotundis; pedicello lato; annulo 14 articulato; sporis polymorphis; surculo tenui, erecto.

Habitat in Novo-Granatensi; provincia Ocaña ; L. Schlin, n 399.

Filix debilis, pendula, angusta; evolutione indefinita Jamesonix.

Icon. : Tab. XXI, fig. 4.

Cette espèce, facile à reconnaitre à sa fronde, laquelle, malgré sa longueur, ne déroule jamais complétement sa crosse, a des rapports évidents avec le P. subscabrum, de Klotzsch (Linn., T. XX, p. 377), mais nous ne pouvons rapporter à notre plante ni les caractères laciniis lanccolato-linearibus, horizontalibus, distantibus, ni les soris parvis, oppositis, de M. KLorzsch, ni les folia suprà breviter setosa atque segmenta 1 1/2 (pouce) longa, non plus que les $12-15$ paires de sporothèces de M. Metrenius. De plus, nous croyons que le caractère tiré de l'érolution indéfinie de la fronde n'aurait pas échappé à ces observateurs sagaces.

V. Blandum, $F$.

Fronde profundè pinnatifida, ovoidea, triangulteri, petiolo brevi, curvato, pilis rufis, longiusculis; rachi nigrescente; segmentis glaberrimis, opacis, cartilagineis, undulatis, enerviis, curvatis; sporotheciis ferè marginalibus, remotis; sporangiis ovoideis; annulo 12-14 articulato; sporis subtrigonis; sporangiastris racemosis, unilateralibus.

Habitat in America australi; regione ignota.

Filix rigida, clastica, facie propria.

Icos. : Tab. XXII, fig. 5.

Cette espèce, que nous possédons en herbier depuis longues amlées, s̀y trouve représentée par un seul spécimen qui, peut-être, ne donne pas les dimensions ordinaires de la plante. Le mésonèvre est assez large et les nervilles latérales extrêmement courtes. La fronde est presque triangulaire et garnie d'une vingtaine 
de paires de segments extrèmement étroits et diversement courbés. Les sporangiastres ont une disposition que nous n’avons vue nulle part ailleurs : ils sont unilatéraux, en grappe, et résultent évidemment de la transformation des anneaux de la sporange.

\section{SEnile, F.}

Frondibus basi et centro pinnatis, apice pinnatifidis, linearibus, pilis incanis onustis; petiolo rachique debilibus, capillaceis; frondulis sessilibus, basalibus rotundis, alteris ovatis, viridibus, lamina inferiore pilosior; sporotheciis rufis, 3-4, pilis rufis, longissimis, numerosisque circumdatis; sporangiis ovoideis, pilos tenuissimos, rigidos, longissimos ferentibus; sporis subreniformibus; surculo parvulo.

Habitat in Novo-Granatensi, provincia Ocaña. L. Schlim, n 364 .

Filix mollis, delicatissima, petiolo rachique capilliformibus ; facie Asplenii Trichomanis, sed villosissima.

Icon.: Tab. $X X V$, fig. 1.

Cette espèce est remarquable par sa laxité; elle vit, sans doute, suspendue aux arbres ou parmi les mousses sur lesquelles elle s'étale. Elle méritait, plus que toute autre, de porter le nom spécifique de trichomanoides. Les poils qui recouvrent les lames inféricures sont mous, blancs et fort longs. Nous n'avons pas constaté nettement le caractère de la souche; peut-être est-ce un rlizome? Les frondes y sont nombreuses et rapprochées. Aucune autre espèce ne nous a montré sur le sacculus des sporanges des poils aussi longs.

VII. Camptonevron, F., Gen. filic., p. 237.

Frondibus pinnatifidis, abrupte terminatis; stipite gracili; rhisomate squamoso; squamis rufescentibus; segmentis remotis, linearibus, obtutiusculis; parcè ciliatis; rachide et mesonerris puberulis; nervillis abbreviatis, simplicibus; mesonevro undulato fusco; sporotheciis parvulis, remotiusculis; terminalibus; sporangiis parvulis; annulo 11-13 articulato; sporis nigrescentibus, ovoideis rotundisque.

Habitat in Cuba (Linden, $\mathrm{n}^{0}$ 1886).

Varietas Polypodii tenuifolii. Ilumb. Nov. Gener. in Willd., Spec. flic., p. 186?

Filix flaccida, debilis; segmentis cum rachi angulum $15^{\circ}$ metientibus.

Icon. : Tab. XXIII, fig. 1. 
M. Metrenius (Monogr. du genre Polypodium) rapporte cette espèce au P.tenuifolium, H. B., Nov. Gen., 1, 9. Willd. V, 185, laquelle serait le P. tenuius et undosum de Plumier, Fil. 66, T. 85. Elle a, en effet, d'incontestables rapports arec cette espèce; cependant HuMBoLd écrit : soris valdè approximatis, ce qui n'a pas lieu pour notre plante, et nous ne royons pas que l'épithète d'undosum, qui est attribuée à l'espèce de Plumier, lui convienne. La figure citẻe plus haut donnée par cet auteur, se rapporte à une plante bien plus robuste que la nôtre.

\section{Viii. Pectinellum, F.}

Frondibus pinnatifido-pectinatis, semper curvatis; stipitibus rachique brevè tomentosis; surculo erecto, radicellas longas, fuscas fercnte; segmentis linearibus, obtusiusculis, usquè ad rachim incisis; laminis glaberrimis, siccitate viridibus; nervillis simplicibus, marginem non attingentibus; mesonevro flexuoso; sporotheciis crassis, conniventibus, laminam totam occupantibus; sporangiis ovatis; annulo 14 articulato; sporis ovalibus.

Habitat ad Meridam Americanomum novorum, Moritz, nº 239.

Filix parva, curvata, elastica; frondibus ccespitosis; stipite rachique tomentosis.

ICON. : Tab. XXVII, fig. 2.

Ce n'est là ni le $P$. otites, L., ni le $P$. pectinatum, L., ni le P. taxifolium, L., ui le $P$. plumosumWilld. Le tomentum, très-serıé et très-court, qui recouvre les stipes et le rachis, est formé de poils raides, acuminés et de couleur roussâtre. Les sporothèces forment deux rangées; il en existe 4 à 5 sur chacun d'eux; ils sont assez gros, et occupent la partie moyenne du segment.

IX. Cu'bense, F., Gen. filic., p. 241.

Frondibus ovatis, pinnatis, hirsutulis, articulatis; thizomate repente, crassitudinc pennce anserince, squamis basi rotundis, longè acuminatis, abruptè terminatis obsito; stipite hclveolo, lavvi; frondulis lanceolatis, obtusiusculis, dentato-crcnatis, basi inaquale cuncatis, pilosiusculis; ncrvillis dichotomo-flabellatis, nigrcscentibus, ramo primario basilari fructifero; sporotheciis crassis, rotundis, apicilaribus; rcceptaculo ovato, apice nervillo turgida, translucida, formato; sporangiis ovatis, 14 articulato; sacculo, circi annulum, pilos rigidos fcrente; sporis ovoidcis, sporulos rotundos inserentibus.

Habitat in Cuba (Linden, sine mumero).

Filix dendricola, repens, pinnata; frondulis oppositis, supremis comatis.

IcoN. : Tab. XXVI, fig. 1.

(Peut-être existe-t-il des spécimens plus grands que celui qui a servi à la diagnose.) 
Nous avons peu de choses à ajouter à la description donnée. Les frondules sont presque opposées, un peu échancrées inférieurement, obtusiuscules et ciliées; les sporothèces sont plus rapprochées du mésonèrre que de la marge. Les poils des frondules, assez courts, obtus, ne présentent que deux ou trois articulations.

II. Тн. Moore, qui a vu notre planche, croit qu'elle se rapporte au Goniophlebium subpetiolatum (Polypodium, Hook., Icon.). Cette plante, dit-il, si elle reste petite, aurait une nervation libre, qui en ferait un Polypodium, et, si elle devient grande et vigoureuse, des nervilles anastomosées, qui en feraient un Goniophlebium; assertion très - extraordinaire, mais qui acquiert un grand poids, venant d'un observateur aussi consciencieux que l'est M. TH. Moorf.

\section{PHEGOPTERIS, F.}

(Vide suprà, pag. 13).

I. Tenella, F., Gen. filic., p. 243, in enumeratione.

Frondibus pinnatis, supernè pinnatifidis, lanceolato-linearibus; pinnis glaberrimis, basi remotiusculis, pedicellis et rachibus tenuibus, crinalibus; frondulis ovatis, cuneiformibus, undulatis, brevè pedicellatis; basilibus suprù auriculatis; nervillis simplicibus, mesonevro undulato; sporotheciis oligocarpidibus ; sporangiis laxé angustis, subsessilibus; sporis lavibus, lutescentibus, uniformibus, dorsalibus: surculo (radice) fibroso.

Habitat in Cuba (Linden).

Filix parvula, delicalula; translucida; unnua?

Icos. : Tab. XXV, fig. 2.

Cette espèce, dont nous possédons de nombreux spécimens, tous identiques, les uns stériles et les autres fructifères, est certainement la plus petite du genre; les frondes croissent en faisceau sur une racine fibreuse; elles ont une tendance à devenir bipinnées. Cette fougère est de courte durée et peut être annuelle.

\section{4. gONIOPHLEBIUI, PresI.}

F., Gen. filic., p. 254, tab. XXI, fig. 2, et tab. XXIV B, fig. 2.

I. Rihagidiolepis, F.

Frondibus pinnatifidis; stipite depresso et rachi squamosis; segmentis lanceolatis, basi contractis, suboppositis, acutis, assurgentibus, suprà glaberrimis, infra dense squamosis; squamis adpressis, niveis, in ambitu laceris, centro coloratis; 
sporotheciis rotundis, magnis, kermesinis, basi squamis cinctis; receptaculo elliptico; sporangiis ellipsoideis; annulo 12-13 articulato, pedicello longissimo, vittato; sporis ovoideis subreniformibusque:

Polypodium rhagadiolepis, F., Gen. filic., p. 237.

Habitat in insula Cuba et in Mexico, in sylvis dictis de Yerba Buena, Linden;

W. Schaffner, $\mathrm{n}^{\mathrm{ns}} 200^{a}$ et 325 , propé Mexico, et n. ${ }^{\circ} 200^{\circ}$ circà Orizabain (1854-1855).

Filix elegans, squamosa, spissa; rhizomate repente, crassitudine pemne anserince. Icon. : Tab. XIX, fig. 3.

(Dımensions : il existe des spécimens plus grands que le spécimen dessiné.)

Cette fougère, mieux étudiée, nous a montré que les nervilles, au lieu d'ètr'e libres, étaient anastomosées. Les squammes, de couleur roussâtre, se décolorent en vieillissant. Les sporothèces sont gros, dorés, au nombre de 8 - 10 de chaque côté du mésonèvre.

\section{Villeminianum, F.}

Frondibus longè lanceolatis, pimatifidis, multifrondulosis; stipitibus vachique mifopilosis; segmentis monoareolatis, alternis, lanceolatis, integris, sursim curvalis, basi latioribus, infcrne decurrentibus, simubus ogivalibus, obtusiusculis, attenuatis; marginibus, in sicco, leviter et angustè revolutis; suprà glaberrimis, subtis tomentosis; tomento rufo, squamis raris immixto; pilis, aliis crinalibus rigidis, temibus, aliis latioribus, passim strangulatis; sporotheciis 20-26, ovoideis, crassis, rufescentibus, in tomento subimmersis, connicentibus; rcceptaculo lineari, fusco; sporangiis ovoideis; anmulo 14 articulato, cum pilis (sporangiastris?) immixtis; sporis triedricis.

Habitat in Ocaña Novo-Granatensium (Paramos). Altitud. 3400-3700 metr. I. Schlim (1846-1852).

Filix formosa, pendens, mescens, crassiuscula, elongata.

Icon. : Tabl. XXVII, fig.3, magn. nut.; $3^{a}$ pili continui lamince infer.; $3^{b}$ pili articulati ejusdem partis; $3^{c}$ pili cum sporangiis immixtis; $3^{d}$ sectio stipitis vasculum unicum demonstrans; $3^{2}$ squamce pauce ad laminam superiorem sparse.

Grande plante très-nettement caractérisée, pendante, molle, nu. élastique, très-probablement arboricole, hérissée de poils, entremêlés de rares écailles sur toute la surface inférieure, tout à fait glabre en dessus; à segments opaques et cartilagineux, arqués vers le sommet de la fronde. Le réceptacle est linéaire et occupe une nerville libre dans une aréole basilaire. Le système pileux est tout à fait remarquable. Les diverses parties de la plante sont eouvertes de deux sortes de poils; les uns, très-déliés, allongés comme des crins el continus; les autres, aussi fort 
longs, rubanés, portant 12 -14 étranglements. Les poils, qui se trouvent mêlés aux sporanges, sont plus courts, mais organisés de même, avec un sommet globuleux. Serait-cè là des sporangiastres?

Cette belle et curieuse plante est destinée à rappeler le nom de M. le docteur Villeyix, médecin et botaniste distingué, auquel nous derons une longue série de planches dessinées avec une grande perfection, et surtout avec une connaissance approfondie de la structure des fougères, dont il a contribué à éclairer l'organograplic.

\section{CAMPYLONEVRON, Presl.}

(Vide suprà, p. 14.)

Minus, F., Gen. filic. , p. 258.

Frondibus brevè pedicellatis; stipite tenni, subtìs planiusculo striato; laminis lanceolatis, longè actminatis, basi attenuatis, leviter arcuatis, margine undulato-crispatulis; mesonevro nervillisgne temuibus; nervillis curvantibus, approximatis, nervillas duas proliferas ferentibus; sporotheciis parvis, rotundis, depauperatis dorsalibus; sporangiis rotundis; amnulo crassissimo, 12-13 articulato; sporis crassis, lavibus reniformibusque.

Habital in America anstrali.

Filix repens; frondibus longè acnminatis; marginibus inaquali dentato-crispis; rhizomate crassitudine pennoe colmmbince.

lcos. : Tab. XXXIV, fig. 3.

Cette espèce n'est petite que relativement; elle est souple et brunâtre par des;iccation. Les nervilles sont fort déliées et les sporothèces occupent la partie moyenne des prolongements nervillaires prolifères. Nous croyons, sans en être certain, qu'elle vit à la Guyane française; mais l'indication précise nous manque.

\section{CRASPEDARIA, Lk.}

(Tide suprà, p.15.)

SUrixayexsis, F., Gen. filic., p. 264.

Frondibus ovatis, brevè petiolatis, acuminatis, glaberrimis, translucidis, fertilibus et sterilibus conformibus; nervillis scalpturatis, mesonevro aterrimo, areolis primariis magnis; rhizomate tenni, rigido, squamoso, sqnamis fulvis, lanceolatis; sporotheciis uniserialibus, remolis, receplacnlo crasso, punctiformi; 
porangiastris clavceformilus, subtorulosis, cum sporangiis ovoideis immixtis; annulo 16 articulato; sporis ovalibus, in parte centrali scrobiculatis.

Habitat in Guyana Batava, Leprieur; in herbariis variis vagat sub nomine specifico Polypodii Surinamensis.

Filix longè repens, subpapyracea; frondulis integris, remotis.

Icon. nostr. XVII, fig. 2.

Nous regardons comme espèces nourelles les deux plantes suivantes :

$1^{0}$ Le Craspedaria lanceolata, F., Herb. La Craspédie lancéolée. Surinam, Hostmann, $n^{0}$ 324; frondes stériles lancéolées, chargées de rares écailles entières, à pétiole court, très-écailleux; frondes stériles fort longues et fort étroites, chargées de 26 - 30 sporothèces renfermant des spores noirâtres.

$2^{\circ}$ Le $C$. Javanensis F., Herb. La C. javanaise. ZøLlinger, n 1086 ; plante de Java. Nous l'avons vue seulement à l'état stérile.

\section{ASPIDIE E.}

(Vide suprá, p. 22).

\section{CYSTOPTERIS, Bernh.}

Brevinervis, F., l. cit., p. 300.

Frondibus tripinnatis, fasciculatis, in ambitu lanceolato-ovatis; partitionibus distantibus; stipitibus et rachibus filiformibus, parcè villosis; pinnulis in ambitu subtriangularibus; pinnellis ovalis; segmentis pellucidis, ovoideis; nervillis margine remotis; sporotheciis depauperatis, terminalibus subterminalibusque; indusio parvulo; sporangiis brevè pedicellatis; amnulo angusto; sporis" ovoideis, muriculatis.

Habitat in Cuba (Linden, $\mathrm{n}^{0} 1876$ ).

Filix tenerrima, pellucida, flexibilis; surculo crassiusculo; stipitibus basi squamis angustis onustis; pilis rachidis mastoideis, subpedicellatis.

Icon. : Tab. XXVI, fig. 2.

Cette jolie espèce de Cuba a des frondes nombreuses, courbées, qui s’élèrent d'une petite souche dressée, garnie d'un assez grand nombre de radicelles roussâtres. Les divisions des rachis sont sétacécs. Elle est remarquable par la grande délicatesse de son tissu. 
XX.? DICKSONIEA.

\section{Indusio cupuliformi, a prima atate aperto.}

166. WOODSIA, R. Br.

F., Gen. filic., p. 337.

Ilexicañ, F.

Frondibus lanceolatis; pinnulis suboppositis, crenatis, breve pedicellatis, obtusissimis, glabris; stipite rachique subglabris; sporotheciis marginalibus, latis, confluentibus; receptaculo punctiformi, squamas quatuor, laciniatas, angustas, ad apiccm in pilos articulatos partilas, ferente; sporangiis subsessilibus; anmulo 18 articulato; sporis ovalibus.

Habitat in Republica Mexicana, propè San-Angel (W. Schaffner, nº 306 , 1855).

Filix parva, angusta, surculo erecto, subglauccsccntc; sporotheciis subterminalibus.

Icon.: Tab. XXVI, fig. 3, 4 ct 5, W. hyperborca pars, al comparandum, ct fig. 5, Sporothecia physcmationum.

Cette petite plante ressemble beaucoup au Woodsia hyperborea, R. Br. Elle en diffẻre néanmoins par les écailles qui entourent le sporothèce à la base. Ces écailles sont au nombre de quatre, disposées en croix, connées à la base et divisées vers le tiers de leur étendue, en longs poils intestiniformes, ondulés et d'une longueur considérable. Nous arons représenté, $p l$. cit., le sporothèce du Woodsia hyperborea et celui de notre espèce. La comparaison qu'on en fera peut servir à constater lindividualité de chacune de ces plantes. M. Ilooker, p. 109 de son Genera flicum, a donné (fig. 2) un détail grossi qui n’est point exact. Les sporothèces, représentés distincts et éloignés, sont toujours confluents. L’ammeau des sporanges est plus étroit et compte un nombre considérable d'articles.

Les écailles situées autour du réceptacle ponctiforme constituent-elles un indusium ? Cela est douteux. Le rôle de ce tégument étant purement de protection, ces écailles ne peuvent en tenir lieu, étant toujours dilatées. C'est cette considération qui nous fait croire que le Woodsia nappartient pas au groupe des Dicksoniées, mais bien plutôt à celui des Polypodiacées. C'est une question que nous examinerons dans le Mémoire suivant, au genre Physematium. 


\title{
IIUITIÈME MÉMOIRE
}

SUR

\section{LA FAMILLE DES FOUGERES.}

\author{
DESCRIPTION \\ D'ESPËCES NOUVELLES
}

ÉT

\author{
ANNOTATIONS \\ RELATIVES AUX PRÉCÉDENTS MÉMOIRES.
}

\section{ESPĖCES NOUVELLES.}

\section{ACROSTICHÉES.}

(Voy. plus haut, 1. 1 et 23 ).

1. AGROSTIGIIUM, F.

I. Glaucum, F. - L'Acrostic a froxde gladque.

Frondes stériles obovales-lancéolées, obtuses, coriaces, atténuées à la base; mésonèvre évanescent; pétiole égalant la lame en longueur; les fertiles plus étroites, plus longues, à lames plus courtes que le pétiole; sporanges couleur de tabac; rhizome rampant, couvert de belles écailles dorées, linéaires et longuement atténuées.

Port et consistance de l'A. conforme, Sw., du Cap.

Mexique, près de Cordoba. (IV. Schaffner, $\left.n^{0} 16 ; 1854.\right)$

(Dimensions : frondes stériles, 20 centim. de longueur sur 2 centim. environ de largeur: frondes fertiles, plus longues d'un tiers, arec une lame plus courte et -plus étroite.) 
II. Schlinense, F. - L'A. de Schliy.

Frondes fertiles et stériles de mème forme, à nervilles condensées, lancéolées, aiguës au sommet et à la base; marge entière et cartilagineuse; pétiole court, blanchâtre, écailleux; souche dressée, avec écailles, portant des frondes trèsrapprochées.

Port et consistance membraneuse de l'A. scandens, Bory; F., Hist. des acrostich., spec. 17.

Nouvelle-Grenade, province d'0caña, dans les forêts, à 2,300 mètres environ d'altitude. (L. Sclilim, no 622; 1846-1852.)

(Dimensions : longucur des frondes stériles, $34-38$ centim., sur un peu moins de 3 ecntim. de largeur; le pétiole est à la lamı : : $1: 5$. Les frondes fertiles sont un peu plus petiles el de coulcur rouge-brunâtre en-dessous.)

\section{LOxchophyllui, F. - L'A. ex FER de LAyce.}

Frondes stériles lancéolées, légèrement courbées en dedans, à nervilles écartées, de consistance papyracée, translucides, ondulées, à pétioles courts, rassemblées en faisceau sur un rhizome fort dur, atteignant la grosseur du doigt; les fertiles extrêmement étroites, plus longuement pétiolées, les uns et les autres terminées en une longue pointe ondulée. - Est assez roisine de l'espèce précédente par le port et la consistance.

Mexique, près de Huatusco, sur les fougères en arbres. (IV. Scliaffner, $\left.\mathrm{n}^{0} 19 ; 1854.\right)$

(Dimensions : frondes stériles, voir l'A. Schlimense; frondes fertiles, 25-27 centim. sur 7-8 millim. de largeur; le pétiole fait la moitié de la dimension totale.)

IV. Venustum, F. - L'i. d'aspect agréable.

Frondes en touffe très-serrée sur un gros rhizome, portant la trace du pétiole des frondes antérieurement développées; les stériles de moitié plus courtes que les fertiles, toutes lancéolées, aiguës, atténuc̉es aux deux extrémités, cliargées d'écailles ciliées, longuement acuminées, blanchûtres en vieillissant; sporanges d'aspect jaunâtre; écailles de la partie inférieure du stipe entières.

Est analogue à l'A. rubiginosuin, $\mathrm{F}$, avec une squamescence toute différente.

Mexique, Mecameca, la Pucbla. (W. Schaffner, $n^{0} 322$ b. c.; 1855.)

(Dimensions: frondes stériles, 17-20 centim. sur un centim. de largeur; pétiole de 3-5 centim. Frondes fertiles, 30-32 centim. de longucur, sur $\overline{7}-8$ millim. de largeur; leur pétiole est à la lame : : $4: 3$.)

Cette espèce, qui croît sur la terre, est employée au Mexique en pharmacie; elle y remplace le Scolopendrium officinarum, L., d'Europe. 
V. Gratum, F. - L'A. de port gracieux.

Frondes stériles ovales-lancéolées, obtusiuscules; pétiole long, grêle, blanchâtre, écailleux, ainsi que les lames; écailles roussâtres, lancéolées, ciliées; les fertiles un peu plus longues et de même forme, à lame plus courte; rhizome rampant, couvert d'écailles fermes, brunâtres et luisantes.

Mexique, au Popocatepetl, à 2,600 mètres d'altitude. (Schaffner, $n^{\text {os }} 279$ et 322 b; 1855.)

(Dimensions: frondes stériles, 23 - 25 centim. sur un peu plus de 2 centim. de largeur; le pétiole égale la lame; fr. fertiles, 28-30 centim. sur 15 millim. de largeur; le pétiole est à la lame : : 2 : 1.)

Cette espèce a quelques rapports avec l'A. venustum, F.

VI. Roezli1, Schaffn. - L’A. de Roëzl.

Frondes stériles lancéolées, obtusiuscules, courbes, atténuées à la base, abondamment couvertes sur la lame inférieure d'écailles roussâtres, ovoïdes et ciliées; celles de la lame inférieure ayant la même forme, mais blanchâtres, plus grandes et plus épaisses; frondes fertiles plus courtes, arrondies à la luase; rhizome rampant, sur lequel se fixent un grand nombre d'écailles; celles - ci lancéolées, acuminées et rougeâtres.

Mexique, au Popocatepetl, à 2,600 mètr. d'altitude. (W. Schaffner, $n^{0} 280 ; 1855$.)

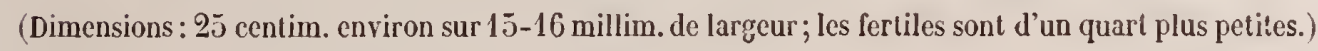

Elle a quelques rapports avec l'A. hirtum, Sw.

VIl. Interyedium, F. — L'A. intermédiaire.

Port et dimensions de l'A. rubiginosum, F. Rhizome rampant, muni de très-longucs radicelles pinnées, glabres; il est chargé d'écailles pâles, orales et acuminées. Frondes lancéolées, à petites écailles fauves, déchiquetées, et semblables à des poils étoilés; les fertiles sont étroites.

Mexique, Huatusco, sur la terre. (IV. Schaffner, $n^{0} 22 ; 1854$. )

VIII. C.illolepis, F. - L'A. A Belles ÉGAilles.

Frondes stériles oblongues, atténuées à la base, abondamment couvertes sur les deux lames d'écailles lancéolées, dorées, ćlégamment ciliées et mollement appliquées; on les retrouve sur les pétioles, plus étalées et moins nombreuses; frondes fertiles de mème forme, à péliole plus délié; la souche qui purte les frondes est serrée et couverte des débris de la base des stipes.

Mexique, par Galeotti.

(Dimensions : 4 centim. de longueur; le stipe ẹs à la lame : : $5: 2$; la lame mesure en largeur 3 millim.; la souclse atteint a la grosseur d'une aveline.) 


\section{LOMARIEE.}

\section{LOMARIA, Willd.}

(Vọez plus haut, p. 24.)

ECLOMARIA.

\section{Frondes pinnatifides; les fertiles sous-pinnées.}

\section{Mexicaxa, F. - La Lonare mexicaine.}

Frondes stériles lancéolées, terminées en une longue pointe hastée, portant inférieurement des segments triangulaires, arqués, fovoïdes et acuminés; stipe et rachis discolores, lisses et glabres; les jeunes pousses sont linéaires et parfois entières; frondes fertiles pinnées, à segments (frondules?) linéaires, étalés; indusium continu, s'ouvrant sans déchirure; rhizome sinueux, couvert d'écailles lancéolées, acuminées, villeuses et lâchement imbriquées.

Mexique (Galeotti, no 6465), Totutla, Mirador, Inatusco (IV. Schaffner, $\left.n^{0} 100 ; 1854\right)$, sur les fougères arborescentes.

(Dimensions : frondes stériles, de couleur ardoisée, un mèlre de longueur el plus, sur 7 centim. d'envergure; frondes fertiles, 50 centim.; frondules, 6 centim.)

Est analogue à la Lomaria Plumieri, Desv.

II. Arguta, F. - Li L. a Marge dentée ex scie.

Frondes stériles lancéolées, glabres, à segments profondément dentés, dents en scie; les fertiles plus longues, portées sur un long pétiole ayant l'aspect d'une tige de scirpus, et renfermant plusieurs faisceaux vasculaires (3?), devenant libres par le desséchıment dı tissu cellulaire que ce pétiole renferme à l'état virant; segments fertiles linéaires, flexueux.

Mexique, vallée d'Orizaha, Cerro del agua, à 2,700 mètres d'altitude. (W. Scliaffner, n" $98 ; 1854$.

(Dimensions: frondes slériles, 46 centim. sur 8 - 9 centim. d'envergure; segments, 8 millim. à la hase; frondes fertiles, $65-70$ centim.; le pétiole est à la lame: : 2:1.)

A une analogie lointaine avec la $L$. Spicant, Desv.

\section{Frondes stériles pimnées.}

III. Agrodonta, F. - La L. a dexts aiguës au somet.

Frondes stériles ovales; pétiole lisse, fulvescent, chargé à la base de grandes écailles lancéolées, longuement acuminées; rachis déprimé, profondément sillonné; frondules lancéolées, acuminées, dentées seulement au sommet, arrondies à la base 
et assez longuement pétiolées, étalées, cartilagineuses, à nervilles serrées et à mésonèvre écailleux; les stériles à rachis très-robuste et sillonné; frondules très-longues, étroites; dressées; lames aiguës, contournées au sommet, chargées d'écailles et pliées sur leur moitié, étant desséchées.

Mexique, à Huatusco et Totutla. (W. Schaffner, $\left.\mathrm{n}^{0} 102 ; 1854.\right)$

(Dimensions : frondes stériles, 56-60 centim.; frondules, 10 centim. de longueur sur 2 de largeur; frondes fertiles, 46 centim., moins le pétiole, qui manque; les plus longues pinnules, 15 - 17 centim. sur 4 millim. de largeur.)

Rappelle un peu la L. striata, Sw.

IV. Aurata, F. - La L. DORÉE.

Frondes ovales, lancéolées, couverts d'écailles dorées; les stériles à rachis épais, parcouru par 5 faisceaux vasculaires; frondules sessiles, longuement elliptiques, obtuses aux deux extrémités, à nervilles déliées, ayant un aspect doré; marge cartilagineuse et un peu ondulée; frondules fertiles dressées, sensiblement pétiolées, portant à l'extrémité un mucron obtus; l'indusium, qui est assez large, se déchire en s'ouvrant.

Nouvelle-Grenade, province d'Ocaña, dans les Paramos, à 2,600 -3,300 mètres d'altitude. (L. Schlim, no 394; 1846-1852.)

(Dimensions : la partie fronduleuse mesure 50 centim. pour les frondes fertiles et stériles; les frondules stériles ont 8-9 centim. sur 7-8 milim. de largeur; les fertiles sont un peu plus longues et linèires.)

\section{BLECHNUN, L.}

(Voy. plus haut, p. 25.)

\section{Schlimense, F. - La Blecinne de Schlin.}

Frondes glabres, ovales - lancéolées, paucifrondulées; pétiole et rachis pâles et flexibles; frondules courtement pétiolulées, cordiformes à la base, lancéolées, entières, la terminale plus longue et ondulée; sporothèces continus, appuyés contre le mésonèv'e, commençant un peu au-dessus de la base pour occuper les $4 / 5$ de la lame; indusium étroit.

Nouvelle-Grenade, province d'Ocaña, à 1,200 mètres d'altitude. (L. Schlim, $\left.n^{0} 752.\right)$

(Dimensions : 35 centim. de longueur jusqu'à la base de la frondule terminale; 6 paires de frondules, les plus grandes mesurant 10 centim. de longueur sur 2 centim. de largeur. La terminale atteint jusqu’à 14 centim.) 


\section{ADIANTÉES. \\ 48. ADIANTUM, L.}

(Voy. pages 4 et 27.)

\section{Tricholepis, F. - L'Adinte a indusium poilu.}

Fronde ovale en son pourtour; pétiole et rachis glabres, lisses, de couleur noire foncée; frondules arrondies, assez longuement pétiolılées, poilues sur les deux lames; sporothèces très-peu nombreux, de grandeur inégale; indusium trèsvelu; rhizome rampant, écailleux; écailles linéaires, acuminées, fauves.

Adiantum fragile, Mart. et Galeott. Filic. mexic., p. 72, non Swartz. Var. : Pubescens.

Ilexique, sur les rochers au bord du Rio Grande de Lerma, près de Guadalaxara. (Galeotti, nº 6445.)

Jolie plante, très-différente de l'A. fragile, même comme variété. Ici les frondules ne sont pas articulées, tandis qu'elles le sont dans l'A. frugile, Sw., circonstance qui explique comment les frondules se détachent si facilement du rachis de l'espèce de Swartz.

II. Extexsuy, F. - L'A. PRoLosgé.

Fronde très-dilatée, à rameaux divariqués, glabre; rachis et pétiole lisses, luisants et rougeàtres; rhizome rampant, noueux, à longues radicelles; frondules assez longuement pédicellées, divisées en lobes obtus, assez profonds, glabres; sporothèces à indusium cordiforme, papyracé.

Mexique, près d'Orizaba et de Iluatusco. (IV. Schaffner, $n^{\text {os }} 40$ et $41 ; 1854$. )

(Dimensions: longneur, 65-70 centim., ct probahlement plus; les pinnules peuvent alteindre jusqu'a 2 centim.; on compte sur les pinnules fructifères de ja à 7 sporothèces.)

Cette belle espèce avait été énumérée dans le Genera, p. 114, mais non décrite : nous remplissons cette lacune. Les frondules sont quelquefois plus larges que hautes. III. Oralescexs, F. - L'A. a Froxdules orales.

Les frondules tendent à la forme ovale; elles se chargent de j-7 sporothèces, dont quelques-uns sont confluents; toute la plante est glauque, bleuàtre et glabre. Les lames sont articulées sur le pédicelle.

Saint - Domingue. (Bory.)

(Dimensions : les frondules ont en moyenne 12 millim. de largecur; quoique les rameaux soient dirariqués, les frondules sont redressées contre les rachis.)

Jolie espèce, dont il faudrait voir d'autres spécimens; elle a des rapports avec l'A. trapezoides, F., niais elle s'en distingue, entre outres, par des frondules symétriques, ovales. 


\section{PTÉRIDÉES.}

\section{PTERIS, L.}

(Vọ. page 31.)

\section{Paucinervata, F. - La Ptéridée a yervilles rares.}

Frondes pinnées à la base et pinnatifides au sommet, qui se prolonge en une longue pointe linéaire et ondulée; souche dressée, à longues radicelles grisâtres; pélioles lisses, rougeâtres, glabres; pinnules basilaires pinnatifides, dressées; segments stériles oblongs, dentés, crénelés au sommet, obtus; segments fertiles entiers, arqués; les uns et les autres à nervilles écartées et en très-petit nombre; sporothèces naissant près de la base des segments; ceux-ci assez larges et munis d'un indusium très - mince.

Mexique, près de Mirador, à la Barranca de San Martin. (W. Schaffner, $n^{0}$ 152.)

(Dimensions : 50 centim. de longueur et plus; pinnules, 14 - 16 centim.; la pointe mesure 5 centim., les segments $3-4$, sur un millim. de largeur à la base.)

Espèce très-remarquable par ses pétioles de couleur rouge de sang, par l’appendice caudiforme qui termine les pinnules, et par des nervilles, distantes les unes des autres de 8 - 9 millim.

\section{Feet, Schaffin, in Litter.}

Frondes d'aspect blanchâtre; stipe et rachis jaunâtres; port et dimensions du $P$. aquilina, L.; lames tomenteuses, minces en dessous, glabriuscules en dessus, à segments fructifères complétement envahis par les sporothèces, lesquels, pour s'unir, semblent descendre jusqu'au fond du sinus; sporanges dorés; nervilles nombreuses et très-serrẻes.

Nexique, près de Iluatusco. ( W. Schaffner, $n^{\text {ns }} 138$ et 141, et au Popocatepetl, par le mème n. ${ }^{0}$ 186.)

(Dimensions inféricures à celles des $P$. aquilina, L., el lanuginosa, Bory; le stipe tomenteux, à la base, ne présente dans sa coupe aucun arrangement de vaisseaux comparable à celui du $P$. aquilina.)

III. Muricella, F. - La P. spinclescente.

Frondes pinnées au sommet et bipinnées à la base, de consistance molle, transparentes, à segments oblongs, dentés, crénelés au sommet, chargés sur le rachis des pinnelles, et sur le mésonève de longues épines pointues, molles et blanclıàtres; pétiole fortement sillonné, rubescent ; rachis blanchàtre; sporothèces courts, médians, à indusium rougeâtre, assez largee.

Mexique, près de Cordoba et de Huatusco. (W. Schaffner, n $143 ; 1854$.)

(Dimensions: longueur totale, 90 centim.; pinnules de la base, presque opposées, 24 centim.; segments, 9-12 millim., portant des sporothèces de $2-3$ millim. de longucur.) 
Cette espèce, molle et délicate, a des rapports avec la $P$. repandula, Lisk, Spec. filic., p. 56 ; mais dans notre espèce le sommet des segments est fortement crénelé, tandis qu'il est dit du P. repandula : pimnellis integerrimis, caractère qu'on retrouve dans la $P$. nemoralis de Willdexow.

\section{PELLEA, Lk.}

(Vọ. plus haut, p. 4.)

\section{Wedpellaxi, F. - Le Pellea de Weddell.}

Frondes sous-bipinnées; pinnules ternées à la loase; frondules bifides vers le centre et simples au sommet; segments obtusiuscules, courtement mucronés, un peu roulés à l'état de dessiccation; nervilles en relief, nombreuses et serrées; stipe et rachis très-glabre, très-robuste; souche bulbiforme, arrondie; à squammes faures, unicolores, molles, entières et atténuées au sommet.

République de Bolivie, province de Tomina. (H. A. Weddell, $\mathrm{n}^{0} 3778$; 1845 - 1846.)

Fougère robuste, à souclıe bulbiforme écailleuse.

(Dimensions : $15-17$ centim. de longueur; frondules, $3-4$ centim.)

Cetle espèce, quoique voisine du P. ternifolia, Lk., en diffère par une souche sur laquelle les frondes naissent en groupe, laissant, après leur chute, la base du pétiole, qui persiste. Cette souche a la forme d'un bulbe de la grosseur d'une châtaigne, portant une grande quantité de squammes. Celles-ci sont unicolores, et non noires, marginées de blanc comme dans le $P$. ternifolia, Lk. Notre espèce diffëre de l'espèce de Lixk par une consistance plus ferme, et par un tissu plus serré. La souche que nous venons de décrire ressemble à la base condensée de plusieur's espèces d'Isoetes d’Algérie.

\section{ONYCHIUN, Kilfss.}

\section{Multifide. F, - L'Oxichide Multifide.}

Frondes multifides, très-glabres, très-délicates; à segments étroits, capillaires, aigus, souvent bifides; frondes fertiles plus larges, portant $3-4$ dents au sommet; indusium roussâtre, épais, très-large; nervilles écartées; sporanges courtement pédicellées, mêlées de sporangiastres; anneau portant 14-16 articles; spores triẻdriques.

Cuba. (Linden.)

Foug̉èré délicate, multipartite, herbacée; segments fertiles et stériles dissemblables. 
(Dimensions : longueur totale, 36 centim.; les plus longues pinnules, 9 centim.; les segnents fertiles, 2 nrillinı.; les stériles, trois fois plus étroits.)

Dans les autres espèces, les indusium des deux moitiés du segment fertile se joignent sur le mésonèvre, ce qui n’a pas lieu dans l'o. multifidum, du reste réclamé par ce genre.

\section{LITOBROCHIA, F. \\ Gen. filic., p. 134. \\ * cajpteria.}

\section{I. Galeottil, F. - La Litobrochie de Gileotti.}

Frondes pinnées, bipartiles à la base, glabres; pinnules pinnatipartites pectinées, courtement pétiolées, sommet caudiforme; segments oblongs, nombreux, presque entièrement fructifiés, laissant entre eux des sinus arrondis à la base; nervilles basilaires uniaréolées, unissant les segments; indusium étroit; sporothèces épais à la maturité des sporanges.

Nexique. (II. Galeotti, Oaxaca et Teotalingo, $\mathrm{n}^{0}$ 6 485. )

Grande espèce, ayant les dimensions et le port du $P$. nemoralis, Willd.

M. Galeotti la dit arborescente, sur la note qui accompagne le spécimen, type de cette espèce.

\section{- eclitobrochia.}

I. Grandis , F. - LA L. A GRandes dimensions.

Frondes amples, très-glabres, de consistance sèche; nervilles ıléliées, faisant saillie sur la face supérieure; rachis blanchâtre; pinnules profondément pinnatifides, pétiolées; à segments lancéolés, laissant entre cux de larges sinus, au fond desquels descendent et se joignent les sporothèces, qui laissent libre to sommet des pinnules. Ce sommet s'allonge en une pointe mousse dentréc. La pinnule intermédiaire est pinnatifide.

Mexique, à la Barranca de San Francisco, près de Mirador (W. Schaffner, $\mathrm{n}^{0}$ 14. 1 ), à Cuba, par Morelet, et à Saint-Domingue, par de Tussac.

(Dimensions : nous avons une pinnule mesurant 40 centim.; les segments ont $10-11$ centim., sur 15 millim. de largeur; nous en comptons 10-12 paires. Toute la plante a un aspect légèrement ardoise; elle est herbacéc.) 


\section{Hevipteris, F.}

Frondes pinnées-pinnatifides, très-glabres; frondules pétiolées, acuminées, presque opposées; segments légèrement arqués, dentés, mucronés; des deux basilaires, le supérieur est notablement le plus grand.

Celte espèce provient de M. Schaffner, qui l'a récoltée dans la vallée du Mexique; elle est indiquée comme très-rare et ne porte point de numéro. Elle mesure 36 centim. environ, avec des frondules qui atteignent $13-14$ centim., sur un peu moins de 3 centim. de largeur. Il faudrait la revoir sur dautres spécimells.

Elle est analogue à la Lilobrochia Orizaba, F.

\section{HYPOLEPIS, Bernh.}

\section{Chllexsis, F. - L'Ilypolépide Chiliexie.}

Fronde tripinnée, étalée; divisions pinnaires et frondules pétiolées, obtusiuscules; segments oborés, crénelés, lobés, avec 3 -4 paires de sporothèces assez gros ; sporanges à large anneau, portant 12-14 articulations; spores ovoïdes.

Le pétiole de cette fougère est rolsuste, brun rougeâtre, sillonné, très-rude, couvert à la base d'écailles crépues, qui lui donnent une apparence tomenteuse ; elle est éoailleuse sur les rachis, velue sur les rachéoles et le mésonèrre des segments, le rhizome est sinueux, rampant et rameux.

Chili, Valparaiso (Gaudichaud, sul Diksonia), San Juan Fernandez (C. Gay), près de la colonie Arique, province de Valdivia. (W. Lechler.)

Rappelle par le port le Polypodium rugulosum; Labill., Pl. nov. Holl. , t. 249.

(Dimensions : un peu inférícures à eelles du Pteris aquilina, L.) 


\section{CHEILANTHE E.}

(Vor. plus haut, p. 3i.)

63. MYRIOPTERIS, F.

F., Gen. filic., p. 149, tab. XII, fig. 1.

I. Cineiloglyphis , F. - La Mrrioptéride a Marges Épaisses.

Frondes bipinnées, épaisses; à rhizome rampant, couvert d'écailles serrées; à pétiole et à rachis robustes, revêtus de poils cloisonnés; frondules globuleuses, à nervilles en relief et à marges renflées, très-glabres en dessous; sporothèces plongés dans une laine épaisse.

Mexique, Orizaba, à 2,500 mètres d'altitude. (W. Schaffner, $n^{\circ}$ 91.)

(Dimensions : lóngueur, $10-13$ centim.; pinnules, $11-13$ millim.)

Cette jolie espèce, l’une des plus petites du genre, a des lobules arrondis. présentant des marges épaisses, sur lesquelles les nervilles laissent une impression très-marquée, qui leur donne une apparence réticulée; ces lobules, devenus fertiles, sont à peu près globuleux. Le rhizome, gros comme une plume de pigeon, est recouvert de squammes fortement imbriquées, et traversé par un seul faisceau vasculaire cylindrique.

II. Rufa, F. - La II. Roussatre.

Frondes tripinnées, ovoïdes en leur pourtour, à pétiole cylindrique, roussittre, ainsi que le rachis; frondules bipinnées, les deux inférieures écartées; segments épais, oroïdes, le terminal plus large et sourent trilobé; tous courerts en dessous de poils blancs, étranglés d'espace en espace. La marge des segments fertiles est étroitement roulée en dehors; une laine roussàtre, très-ahondante, est mêlée aux sporanges.

Mexique, près de San Andres Clıalahicamecha, rulcan de Orizaba, ả 2600 mètres d'altitude. (IV. Schaffner, $\left.n^{\circ} 83 ; 1855.\right)$

(Dimensions: $16-18$ centim.; les julus grands segrments, 25 millim.; le pétiole fait la moitie de lis hauteur totale.)

Celte jolie espèce n’est point indusiée; cepeudant la marge repliée sur les sporanges est plus pâle et tend à s'amincir. Le pétiole est çà et là courert de petites proéminences sous-épineuses. 
(Voy. plus haut, p. 49.)

\section{Plicinosi, F. - La Nothochlennde givée.}

Frondes linéaires-lancéolées, à rlizome bulbeux, couvert d'écailles faures, trèslougues, linéaires, dressées; à slipes et à rachis rufescents, arrondis, portant des écailles blanchâtres, lancéolées, déchiquetées en leur pourtour et très-caduques; frondules sessiles, obtusiuscules, oblongues, élargies et quelquefois lobées à la base, qui est cordiforme, abondamment couvertes en dessus d'écailles déchiquetées blanches, et en dessous d'écailles roussâtres ciliées plus abondantes; marge fructifère légèrement roulée sur les sporanges; sporothèces étroits, tout it fiit marginaux, soulerant les écailles pour se mettre directement en rapport arec lá lumière.

Mexique, vallées de Toluca et d'Orizaba. (W. Sclıaffner, $\mathrm{n}^{0} 167$ c.)

(Dimensions: port, radication el sepuammes du rhizome du N. simuala, hilfss. Les frondules sont jus étroiles.)

Cetle espèce ne diflère du $N$. sinuata, Kifss., que par ales frondules sessiles, plus étroites, ondulées, mais très-fréquemment entières. Dans l’espèce à laquelle nous la comparons, les sporotlieces sont larges et toujours cachés par les écailles; ici ils sont étroits et se montrent entourés des écailles quils redressent. Le rhizome est chargé d’écailles différentes de forme, minces, souples, mais non tortillées au sommet. Serait-ce une variété du $N$. simuata? La sessilité des frondules, et la disposition des sporothèces à se montrer à nu, nous font croire à la spéciñcité de cette plante.

\section{LEPTOGRAMVÉES.}

(Vo!. plus haut, p. 43.)

84. GYMiNOGRAMIIE, Desr.

(Voy. plus haul, p. 43.)

\section{Procurexs, F. - Le Grmograme trachaxt.}

Frondes pinnées-pinnatifides, oblong'ues, portées sur un long pétiole lilanchâtre, couvert de poils étalés, largement sillonné, ainsi que le rachis; pinnules lancéolées, acuminées, sessiles, toutes étalées; sporotlıèces ellipsoïdes, ne s'élevant pas aí-dessus de la moitié des segments el s'altacliant sur la nerville, sans la modifier.

Mexique, sur le Popocatepetl, à 2,800 mètres environ d'altitude. (IV. Schaffner, $\left.\mathrm{n}^{\circ} 293 ; 1855.\right)$

(1)imensions: celles du Polypodium Phegopteris des auteurs.) 
Cette plante est remarquable par son rhizoric non écailleux, d'une longueur considérable (plus de 40 centimètres); ì en juger par l'écartement des frondes, il s’accroit très-rapidement. Des radicelles l'entourent de toutes parts. Les sporothèces, dans l'àge adulte, ont une couleur de tabac. La plante est souple et grêle; elle croit sur la terre.

\section{Helieoluy, F. - Le G. a pétiole palleteux.}

Frondes bipinnées, glabres, à rachis couleur de paille et comme satiné; pinnules courbes, pétiolées, lancéolées, terminées en un long acumen pinnatifide; frondules lancéolées, sessiles, obliquement tronquées àla base, aiguës, crénelées; les inférieures réfléchies; sporothèces plus rapprochées de la marge que du mésonèvre, portés sur clıacune des deux bifurcations de nervilles qui s'épaississent au point prolifëre, en manière de réceptacle.

Nourelle-Grenade; province d'Ocaña, dans les Paramos (déserts montag̨neux), ¿ 2,500 et jusqu’à 3,400 mètres. (L. Schlim., n 368.)

(Dimensions des pinnules centrales, 98 - 30 centim.; les frondules mesurent un peu plus de 3 centim., sur 6 millim. de largeur; il en existe une trentaine sur chaque pinnule.)

Un caractèrc curieux est à noter : Les ncrvilles sont bifurquées et toutes les bifurcations fertiles, à l'exclusion de la base de chacune d'elles.

Nous ne possédons pas la plante entière.

NB. Nous arons en herbier plusicurs fougères appartenant à ce genre; nous nous contenterons sculement de les indiquer, pour ne pas accroitre un groupe dont la validité est très-contestable.

1. Cireilosorus, F. - Le G. a sporothèces Marginalx.

Grande espèce, pinnée-pinnatifide, gllabre; à sporothèces ellipsoïdes ou arrondis marginaux.

Mexique, au Popocatepetl, près de Iluatusco. (IV. Schaffner, $n^{0}$ 215.)

2. Serrclata, F. - Le G. dexticllé ex scie.

Nous ne connaissons que les pinnules de ectte belle espece mexicaine; elles sont lancéolées, longuement acuminées, à segments oblongs, dentés en scie au sommet; les sporothèces sont appurés sur le mésonère. Elle a été recucillic au Mexique par M. Scinffier.

3. IIelexexsis, F. - LE G. de S.Miste-Ilélèye.

Écailleuse sur le rachis et villoso-tomenteuse sur les rachéoles des pinnules; celles-ci sont sessiles, décussées, à segments sinués-crénelés, durs et presque 
coriaces. Les sporothèces petits, presque ronds, naissent sur presque toutes les nervilles. Elle nous a été donnée comme provenant de l'ìle Sainte-Hélène.

4. Mollis, F. - Le G. Mou.

Espèce cultivée, molle, glabre, pinnée - pinnalifide; à pinnules sessiles lancéolées; sporothèces marginaux formés d'un très-petit nombre de sporanges et assez fréquemment n’étant constitués que par une sporange mique; elle est fort distincte. Nous ne connaissons pas sa patric. - Port du Polypodium Phegopteris des anteurs.

85. CEROP'TERIS, Lk.

(Voyez plus liaul, p. 44).

I. CIIRYSODIA.

I. Obtusa, l. - la Céroptéride a segulexts obtus.

Frondes lipinnées à la base et pinnées au sommet, lancéolées; pinnules inférieures distantes; frondıles en petit nombre, crénelées et pinnées à la base, terminées par un segment ollong, très-obtus; pétiole assez grêle et strié, de coulcur paille; sporothèces commençant à la base des segments, mais ne se continuant pas jusqu’à la mar'ge.

Nouvelle-Grenade, province liio de la Ilacha, à 3400 mètres environ d'altiturle dans la Sierra-Nevada. (L. Sclılim, n" 873; 1852.)

(Dimensions : 40 centim. de longueur tolale; frondules 3 centins. seulement sur $8-9$ millim. de largerur a la lase.)

Cette espèce est facile à recommaitre ì la brièveté de ses pinnules latérales, distantes les unes des autres et fort étroites. Liexsudation séreuse est d’un jaune assez vil. le pétiole et le rachis sont grèles et blanchâtres.

II. ARGIRIA.

Il. Schaffieri, F. - La C. de Schlaffier.

Frondes oroïdes-lancéolées, bipimnées et tripinnées à la base; pétioles rougreâtres, lisses, nus, un peu luisants, largement canaliculés; rachis et rachéoles de mème couleur; pinnules lancéolées; segments épais, terminés par un sommet ovale, très-arrondi, base presque incisée. Les nervilles se dessinent en relief sur la lame supérieure; sporothèces occupant toute l'éteudue des nervilles; rhizome rampant, à très-longues radicelles, portant des écailles fauves, étroites.

Mexique, près d'Orizaloa, dans les lieux secs et exposés au solcil. (W. Schaffner, $11^{0} 165$ a et $165 b$, dans les licux liumides.)

(Dimensions : longueur totale, $30-40$ centim.; les plus grandes pinnules mesurent 8 centin., el les pinaules basilaires $10-12$ millim.) 
Les frondes ont une apparence crêpue; la marge des segments fructifères forme un épais bourrelel; elle a des rapports avec le C. tartarea, Lk. La marge se replie sur les sporothèces.

III. Plicata, F.

Frondes ovales-lancéolées, bipinnées à la base et simplement pinnatifides au sommet; pétioles et rachis courbés vers le haut, courerts d'une poussière abondante, comme farineuse; segments épais, oblongs; sporothèces recourrant entièrement les lames et à demi cachés par les marges repliées; souche écailleuse portant un grand nombre d'écailles faures, linéaires et ondulées.

Mexique, près de Tolutla. (WV. Schaffuer, $n^{0}$ 164.)

Petite fougère, à pédicelles roussàtres, luisants, canaliculés, à segments terminaux des pinnules très-obtus; remarquable par des segments fertiles, à marge repliée sur les sporothèces. L’anneau des sporanges est très-large; on y compte environ vingt articulations. Les frondes sont attachées en grand nombre sur une petite souche qui semble dressée el qui porte des radicelles tomenteuses. Proportions inférieures à celles des autres espèces.

IV. Serrata, F.

Frondes oblongues, pinnées-pinnatifides, fasciculées sur une souche assez petite et dressée; le stipe est assez long, luisant, fragile, fortement canaliculé, couleur d'acajou, avec un rachis de mème couleur et sensiblement courbé vers le haut; frondules de la base lancéolées, sessiles, longuement acuminées, pinnées inférieurement; segments aiguëment dentés, ovales, obtus, auriculés, à dents inégales, assez longues; sporothèces très-serrés, occupant le centre de la lame et se dessinant en relief sur. une épaisse couche de peussière blanclie et farineuse.

Mexique, Orizaba. (W. Scliaffiner, $n^{0}$ 162.)

(Dimensions : $36-40$ centim. de longueur; les frondules inférieures mesurent environ 8 centim., sur 2 centim. d'envergure.)

Fougère très-élégante, délicate, souple, élastique.

\section{ASPLENIÉES.}

(Yoy. plus haut, p. 46.)

\section{ASPLENIUM, L.}

* Elasplexili.

\section{Progrediens, F. - L'Asplénie a grosse fronde termisile.}

Frondes pinnées, ovales-lancéolées, à stipe rougeâtre, délié ou robuste, suivant les expositions, avec un sillon irès-prononcé, glabre, ainsi que le rachis; rhizome abondamment couvert d'écailles étroites, presque capillacées, cancellaires et de 
couleur vineuse. Frondules pédicellées, lancéolées, inégalement dentées, à dents grosses et obtuses, légèrement rugueuses en dessus, alténuées en une très-longue pointe, dentée, incisée à la base, entière et oblique; la terminale est beaucoup plus grande que les autres et montre une tendance évidente à devenir lobée vers la partie inférieure; sporothèces étroits, imbriqués, naissant près du mésonèrre dont ils ne s'éloignent que vers le sommet qui est stérile.

Hexique; sur les fougères arborescentes près de Iluatusco. (IV. Schaffner', $\mathrm{n}^{0} 5.4$; 1854; et à Orizalıa, jar le mềne, $\mathrm{n}^{0} 449$; 1856.)

(bimensions : longheur totale, 30 - 40 centim.; pinnules, peu nombreuses, 16 - 18 centim., sur une largeur de 2-3 centim. vers lit partie inferinure.)

II. Grande, F. - Grande Aspléxie.

Frondes pinnécs, ovales-lancéolées; à płnnules pinnatifides, lancéolées, longuement acuminées; à segments portant 3-5 dents obtuses; sporothèces, deux, et plus rarement trois paires, protégés par un très-large indusium mince, blancliătre, membraneux; l'un de ces sporothèces est hasilaire, distant des autres et confine arec le mésonèrre. Stipe bisillonné, lisse et de couleur plombée; il porte à sa lase, ainsi que le rlizome, des écailles lancéolées, courtes et teintées de rose.

Mexique, Barranca de San Vartin el de San Francisco, près de Mirador. )W. Scliafner, $n^{0}$ 74.)

(Dimensions : celle helle espèer alteint prés d'un mètre de lonģ⿻上丨e ; les pinnules centrales sont courberes vers In bas; il en existe une trentaine, el chincune d'elles est divisée en 20 segunents environ. Ces pinnules mesurent lit centim, de longratir, sur 2 de largenr.)

111. Mypterox, F. - L'A. A ixdesiun ex alle de Molcie.

Frondes bipimnées, orales-lancéolées en leur pourtour, souples, très-glabres et très-lıerbacées; à slipe et à raclis déprimés; frondules lancéolées, presque sessiles; à segments orales, décurrents, dentés, à dents terminées par un long mucron piliforme; 3 à 4 sporothèces sur clarque segrment; ils sont recouverts d'un indusium très-mince, memlsraneux, semblable à l'aile de la mouche domestique. Le stipe est sillonné et couvert d'écailles étroites de couleur rose.

Mexiyue, près d’Orizalı, 2200 mètres environ de hauteur. (W. Schaffiner, n 70 , et sur le Popocatepell, $n^{0}$ 29.'.

(Dimensions : $65-70$ centim. de Iongurur, sur $15-18$ centim. d'envergure.)

Lïndusium est très-large, mince el membraøıcux, el ressemble à celıi de l'A. grande, quoique un peu moins large. 11 II! a, au reste, entre ces deux plantes que celte seule analogic.

IV. Crassides, F. - Lì. a grosses dexts.

Frondes pinnées, glabres, oroüdes; frondules de grande dimension, lancéolées, pétiolulées, ovales-lancéolées, inéquilatérales à la base, atténuées en pointe au 
sommet; dents crénelées à la marge, à dents grosses, épaisses, et comme calleuses; nervilles écartées, noiràtres; sporothèces allongés, linéaires, n'atteignant pas la marge, portés sur la branche supérieure de chaque nerville, au point de la première bifurcation; indusium étroit, linéaire, épais et noiràtre.

Touvelle-Grenade, province d'Ocaña, dans les Paramos (déserts des montaguses), à 3500 oul 4000 mètres. (L. Schlim, n ${ }^{0} 393$.)

(bimensions : longueur 50 centim., el proballement plus; nous comptons 12 paires de pinnules sur notre spécimen; elles sont sensiblement égales et mesurent 12 centim., sur $9-5$ de largeur.)

V. Atilirioides, F, - L'A. a port d’Athrion.

Frondes pinnées, oblongues-lancéolées, terminées en pointe; pinnules dressées, presque.sessiles, lancéolées, acuminées, pinnatifides, à segments incisés; stipe deux fois sillonné, de couleur plombée, lisse; sporothèces courts, occupant la partie supérieure des seģments; rhizome assez gros, couvert d'écailles étroitement lancéolées, noiràtres et cancellaires.

Mexique; à la Barranca de San Martin. (W. Schaffner, n 75 , et Orizaba, n" 伍'; 1850.)

(Dimensions : 60 centim. de longueur, arec des pinnules dont les plus grrandes n'excèdent pas 8 ceniim. sur $8-9$ millim. de largyeur.)

\section{Mastigopirllum, F. - L’A. Prolifère.}

Frondes pinnées, lancéolées, terminées en un long jet nu, filiforme et radicaut. Il est arqué et se dirige vers le sol; frondules ovales, lancéolées, largement crénelées, obliques-cunéiformes à la base et obtusiuscules au sommet; stipe et rachis lisses, de couleur brune-rougeâtre, très-glabres et un peu luisants; sporothèces linćairos, assez courts et centraux, au nombre de $8-9$ paires.

La Guadeloupe, par Perrottet.

(Dimensions: longucur $\mathbf{4 0 - 4 5}$ centim. jusqu’à la naissance du jel qui conlinue le ractris , el qui n’a pas moins de 20 centim. L'envergure est de $8-9$ centim.)

\section{- Dareastrci.}

\section{Flagelliferuit, F. - L'A. Fldgellifère.}

Frondes bipinnées, glabres, herbacées; stipe rougeàtre; rachis terminé en un lunğ jet radicant, filiforme; pinnules lancéolées-ovales, pétiolées, écartées; pinnelles pinnatifides arec un segment libre, ovoïde, plus grand que les autres à la base; 2-4 sporothèces sous-marginaux.

Nourelle-Grenade. (L. Schlim, $\mathrm{n}^{0}$ 03.)

(Dimensions : longucur 50 centim. du jet ou coulant qui est dénudé et fort long; pinnules 10 centien. d'envergure au centre.)

Le nom spécifique n’indique pas une particularité rare dans la famille des 
fougieres; nous l'arons indiquée dans l'A. mastigoplyllum, et nous la retrourons dans le $1^{0} 655$ des plantes de Colombic, distribuées par Fuxck. Les pinnules de celle espice, que nous nous contentons d'indiquer, sont plus courtes, à segments plus serrés, dentés au sommet, à sporothèces plutôt oroïdes que linéaires. Nous lui donnons le nom d’A. Funcliii, pour rappeler la mémoire du botaniste-royagenr yui lin dercourerte le premier.

\section{IIV. DIPLAZIÉES. \\ 99. DIPLAZIUM, SW.}

1. Simlingase, F. - La Jirlazie de Schlin.

Frondes pinnées, glabres, à stipe sillonné et déprimé; à frondules presque sessiles, orales-lancéolées, grandes, pellucides, souples et minces, se terminant en cour ¿ la base, et acuminées au sommet, crénelées à la marge; nervilles déliées, la basilaire, qui est prolifìre, atteint la marge; sporothèces les uns grands, appuyant leur base sur le mésonère, les autres, en petit nombre, plus petits, naissant au contre de la frondule.

Nouvelle-Grenade; province d'Ocaña. (L. Schlim, nº 601.)

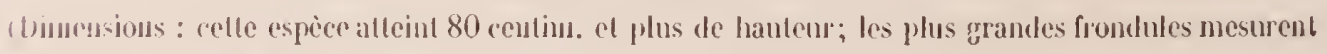
$123-14$ centim., sur emiron 3 centim. de largenr.)

II. Canptocarpon, f. - La D. a sponothèces amovés.

Frondes lipinnées, glabres, orales, rufesentes à l'état de dessiccation; stipe sillomné; pinnules lancéolées, dressées; pinnelles nomlı'euses, aiguës, cunéiformes ¿i la base, crénelées; sporollièces allongés, épais, courbés, connivents, inégaux, recourrant presque entièrement la lame.

Mexique; Cordoba; récoltée par A. Nieto et communiquece par M. W. Schaffuer, $\mathrm{n}^{0} 69 ; 185^{\prime}$.

(bimensions : la prartie fronduknuse mesure 40 centimn.; le stipe est tronqué; pinnules de la hase de la fronde 20 centim.; pimelles 3 centin., sur $\bar{T}-8$ millinu. de largeur. Vous con comptons $1 \overline{7}-18$ sur chatpue pinuule.)

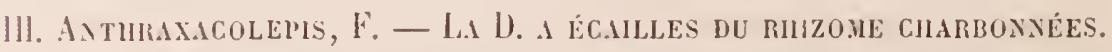

Frondes pinnées ou lipinnces, toujours pinnatifides au sommet, de consistance épaisse, oparjues, à frondules assez longnement péliolées; frondules raides, irrégulic̀rement dentées, et à dents cartilaginenses assez grosses; sporothèces linéaires, inégaux; stipe et raclsis couleur-paille; rhizome grros, muni de longues radicelles tomenteuses, portant vers la partie supérieure des écailles épaisses, romme cliarbonnées, oroïdes, obtuses el à marge entière.

Mexigue; IIuatuseo. (IV. Schaffirer, $n^{0}$ 267.)

(bimensions : longueur variable depuis 30 jusqu’a 50 centim. Elle se rapproche du D. Shepherdi; Lh.) 
IV. Nelaxopodum, F. - LA D. a stipe noiratre.

Frondes bipinnées, glabres, à pinnules écartées, assez longuentent pétiolées, base dı rachis brusquement nigrescent et dilaté; pinnelles crẻnelées; sporothèces déliés.

Luzon; iles Philippines. Cuming, $\mathrm{n}^{0}$ 29. Ce numéro, dans notre herbier, renvoic au D. ebenum, J. Sm., ce qui est évidemment une erreur d'étiquette.

(Dimensions : longueur : environ 40 centim.; pinnules 11 - 12 centim., sur 6 centim. d'enrergure.)

V. Momllexse, F. - Li D. de Monilla.

Frondes multipinnées, arborescentes? glabres, à pinnules lorizontales, dout le rachis est jaunâtre el triangulaire; pinnelles courtement pétiolées, tronquées ì lit base, très-longuement et très-finement acuminées et crénelées; mésonèrre flexueux : nervilles en saillie, toutes prolifères.

Madagascar; ile Mohilla, par M. le contre-amiral de Hell.

(Dimensions : très-grande espèce, dont nous n'arons que des pinnules mesurant fu centim.; fr's pinnelles opposces á la base, puis alternes, ont environ 9 centim., sur 3 centim. de laryeur.)

VT. Fee, SChaffaer, in Litter.

Frondes souples, membraneuses, pellucides, ovoïdes en leur pourtuur, un peu luisantes, bipinnées à la base, pinnées au centre, pinnatifides au sommet; stipee of rachis lisses, jaunâtres; pinnules pétiolées, écartées, ovales-lancéolées, accuninées; pinnelles et segments crénelés, denses, oroïdes-lancéolós; sporothèces assez. courts, presque tous basilaires, épais et dorés. Elle est glabre dans tontes ses parties.

Belle fougère très-rare; Barrancas de San Martin et de San Franciscu; État de Vera-Cruz, élévation 2500 mètres. (1T. Schaffner, $n^{\circ} 265 ;$ 185\%.)

(Dimensions : 1 mètre et plus de hauteur; pinnules mesurant 20-22, sur 8-9 centim. de laryegrer; sporothèces atteignant à peine 2 millimètres.)

NB. Nous avons reconnu que le D. acutale, F. Gen. filic., p, 215, doit ètr rémi au D. lonchophyllum de Kuxze (LIXX.E. T. XIII, p. 141). C’est aussi l'Aslmium dculcuifosum de Desvaux.

\section{POLYPODIEES.}

(Voy. plus haut, p. 6 et 57. )

POLYPODIUI, L., Emenl.

(Voy. plus haut, p. 8.)

A. FROXDES NCES.

- Pinnatifules.

I. Spissum, F. - Le Polypode a consistance épaisse.

Fronde presque pinnée, épaisse, lancéolée en son pourtour; segments profundéntent crénelés, olutus, amincis en pétiole; rachis et pétiole robustes, noirâtres, chargés 
éa et là d'écailles cancellaires, d'une structure très-élégante; sporothèces extrèmement geros, connivents, proéminents, courrant toute la surface de la lame et indigués sur la lame supérieure par une ponctuation.

Nouvelle-Grenade; province d'Ocaña dans les Paramos, à plus de 3000 mètres d'altitude. (L. Schlim, n 4 19.)

Port et dimensions du P. vulgare, L., d'Europe.

II. C.allulepis, F. - Le P. a belles Écallles.

Fronde lancéolée, courcrte de poils mous et blanchâtres; segments oblongs', élargois vers la base, obtus, ciliés, laissant entre cux des intervalles qui disparaissent en approclıant du rachis; mésonère flexucux; nervilles deux fois bifurquées; sporolhèces gros, au nonbre de 8 - l't paires, distincts, occupant toute la lame; pétiole et rachis brunâtres, courtement poilus; rhizome rampant, de la grosseur lu petit doig̣l, courert de magnifiques écailles oroïdes, terminées en une longue pointe; elles sont ciliées à la marge, de couleur faure-dor'e et lìchement appliquées en coussinet.

Hexique; sur le Popocatepetl, près de Necameca, à 2700 mètres d'altitule. (IV. Schaffner, $n^{\text {os }} 271$ et 272 ); elle est arboricole et pendante.

Port du l'. v'ulgare, L., arec les dimensions supéricures.

III. C.amptorhillarien, F. - Le P. a seguexts arqués.

Fronde longuement lancéoléc, à segments nombreux, dressés vers le lıaut, linéaires dlans la plus grande partic de leur étendue, mais très-élargis par la base; complétement aryuées, et se recourrant les unes et les autres; lames supérieures cliargées de poils très-courts, roussitres ainsi que les poils, plus abondants et jlus longs, qui recourrent le rachis; lames inféricures fructiferes dans toute leur étendne, se chargeant l'une vingtaine de paires de sporothèces gros, distincts et jaunâtres.

Sonvelle-Grenade; province d'Ocaña. (L. Schlim, nº 128.)

L. $11^{\circ} 398$ du même botaniste est galabre; peut-être est-ce là le $P$. curvatum, de SWI:T7?"

(Dimenions: 70 centim. el plus; nous comptons 60 segrments de chaque cote de la fronde.)

11. M lolepis, F. - LE P. A ÉCAlles (DU RHIZOME) CrÉPUES.

Fronde oroïle-lancéoléc, çà el là squammeuse; à segments écartés, laissant entre eux de larges sinus; ils sont élalés, linéaires-lancéolés, dilatés à la base et crénelés vers le sommet qui est stérile; sporothèces au nombre de 14-17 paires, distincls, dorés, brunấtres; impressionnant la lame supérieure; le pétiole est lisse, sillonné, chargé, ainsi que le rachis, de quelques écailles de couleur vineuse; le 
rhizome est rampant, de la grosseur d'une plume d'oie, avec écailles crêpues de forme toute spéciale.

Port et dimensions du P. vulgare, L., segments plus étroits; ceux de la base notablement plus longs que les autres.

Mexique; Iluatusco, Orizaba et au Popocatepetl, à 2700 mètres d'altitude. (W. Schaffner, $\mathrm{n}^{\text {os }} 191,192$ et 274 partim. Ilerb. F.)

I. Cileilostictum, F. - Le P. a harge ponctuée.

Frondes pinnatifides, glabres, articulées sur un rlizome rampant, couvert de petites écoilles ovoüdes et crèpues; stipe canaliculé, rougeâtre, ainsi que le rachis; segments linéaires - lancéolés, acuminés, à dents écartées vers le sommet, simplement ondulés jusqu’à la base qui est un peu rétrécie; lame supérieure marquée de petits points irrégulièrement arrondis, indiquant le sommet des nervilles; sporothèces gros, assez distants, occupant toute l'étendue de Ia lame.

Port du P. vulgare, L., avec des frondules étroites, rapprochées et élalées.

Mexique; Orizaba. (W. Schafner, $n^{0} 453 ; 1856$. )

(Dimensions : longueur totale 45 centin.; le stipe fait la moilié de celle dimension; frondules inférieures au nombre de 20-24, et mesurant 5- 7 centim., sur $7-8$ millim. de largeur. 16 - 18 paires de sporothèces. La frondule terminale est assez courte.)

V. Pubescens, F. - Le P. pubescent.

Frondes pinnatifides, lancéolćes, portées sur un rlizome rampant, de la grosseur d'une plume de corbeau, couvert d'écailles, les unes ovales, les autres lancéolées, acuminées, tontes de couleur roussâtre, avec une teinte plus foncée à la base; stipe robuste, canaliculé, strié, couvert, ainsi que les lames, d'une pubescence courte et serrée; segments presque opposés, oblongs, élargis à la base, terminés en pointe mousse, à marģe dentée; les deux inférieurs réclinés; sporothèces écartés, médians.

Mexique; Iluatusco, à Dos-Puentes; indiquée comme très-rare. (W. Schaffner, $\left.n^{0} 181 ; 1854.\right)$

Fougère brune par dessiccation; stipe et rachis de couleur plombée; a quelques rapports avec le $P$. clinoophorum, Kunze, du Brésil.

(Dimensions : longúeur 40 centim.; segments inégaux ayant 7 centim. de longueur, sur $10-11$ millim. de large.)

* Pinnées.

VII. Echinolepis, F. - Le P. A ÉCAILles (DU RHizone) Héfissées de POILS.

Fronde ovale-lancéolée, glabre; petiole bicanaliculé; frondules rapprochées, lancéolées, crénelées, pointues, presque sessiles, régulièrement arrondies ì la base; nervilles noirâtres, deux fois lifurquées, portant, au milieu de chaque 
moitié des lames, des sporothèces arrondis, écartés et dorés; rlizome assez gros, clıargé de frondules écartées, et couvert d'écailles ovoïles, hérissées de poils courts et raides sur leurs deux surfaces.

Mexique; Cordoba. (W. Schaffner, $n^{\circ}$ 188.)

(1)imensions : Iongueur $35-38$ centim., sur 11 centim. d'envergure; largeur des frondules a la base $16-18$ millim.; rhizome de lia grosseur du doiggt. Nous comptons 13 paires de pinnules.)

VIII. Artiropodiun, F. - Le P. a froddes articulées.

Fronde oblongue; à stipe strié, glabriuscule; rachis at mésonèvres courtentent tomenteux; frondes fasciculées sur le sommet d'un rhizome dressé, courert de larges cicatrices, concaves au point d'attache des anciennes frondes, il est chargé l'écailles roussàtres, ovoüdes; frondules lancéolées, acuminées, les paires inférieures réfléchies; les supérieures sessiles-adnées; sporothèces arrondis et rapprochés de la marge.

Vallée du İlexique; Iluatusco, Cordoba et Orizalıa, sur les arbres et sur la terre.

(IV. Schaffner, $11^{\text {os }} 185$ et 186. .)

(Dimensions : longrueur totale 1 metre el plus; le stipe est ì lil fionde:: $1: 2$; les plus longues frondules mesurant 16 centim., sur 15 millim. de largerer; le rhizome alleint la grosseur du doigh ed il est fort dur, noir d'abèue el chargé do longues fibrilles; 12 faiseaux vasculaires lincaires to par(ournt.)

\section{B. ESPĖCES ÉG.IILLELNES.}

IX. Inc.inoides, F. - Le Polmode mlanchatre.

Port et dimensions du $P$. incrmme, des auteurs; il en differe seutement par des segments portant sur un sommet sensiblement élargi, 3-4 paires de gros sporothèces. Les nervilles sont libres, tandis que dans le $P$. incrumum, elles sont anastomosées, ce qui est tout à fait caractéristique.

Mexique; Iluatusco. ( $\mathrm{W}^{*}$. Schaffncr, $\mathrm{II}^{0}$ 199.)

Les dimensions sont un peu inférieures à celles du $I$. incamm, Sw.

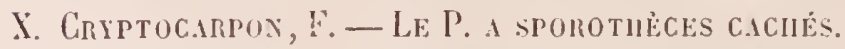

Fronde pectinée, étroitement lancéolíe, très-souple; à pétiole couvert d'écailles blanchâtres, furfuracées; segments nombreux, linéaires, aiģus, à marge ondulée, surtout vers le haut; sporothèces 5-8, distants, cachés sous les écailles des lames, à la manière des pleopellis; nervilles libres.

Mexique; Cordoba. (W. Schaffner, $n^{0} 194$. )

(Dimensions : 50 centim. de longueur, et probablement plus, sur $3-\frac{1}{4}$ centim. d'envergure; Ie pétiole est à la partic fronduleuse : $: 1: 4$ ou à 5 . Les segments ont a peine 2 centim. de largeur; nous en comptons jusqưa 80 paires; la fronde se termine en une pointe caudiforme, onduléo et fruclifère.) 
XI. Nirosti, F. - Le P. a Écailles blaxc-de-Neige.

Fronde peclince, lancéolée, parfois linéaire, couverte, dans toutes ses frarties, d'écailles blanc-de-neigee, comme furfuracées, plus rares sur la lame inférieure; elles ont un point rougeâtre au centre et sont très-déchiquetées; seģment: linéaires, étalés, pointus, subitement élargis à la base; nervilles libres; sporothèces marginaux, serrés, petits, émergeant du milieu des écailles, sous l'aspect de petits groupes rougeâtres, distincts; rhizome assez délié, auquel s'attachent une trèsgrande quantité de fibrilles brunâtres; il est couvert d'écailles épaisses, ovoïdes, obtusiuscules et entières.

Mexique; Huatusco. (WV. Schaffner, $n^{\sigma}$ 193.)

(Dimensions : 30 centim. environ de longucur, sur 2,5 a 4 4 cenlim. d'envergure; seggments 2 millim.; nous comptons sur une fronde près de 50 paires de seguments.)

\section{PHEGOPTERIS, F.}

(Vọ̣cz plus haui, P. 62.)

\section{Blepilarodes, F. - La Piégoptéride ciliée.}

Frondes pinnées-pinnatifides, assez rohustes; pinnules sessiles, presque régulièrement opposées, lancéolées, à segments ciliés, ovoüdes, obtus; ceux du sommet entiers, ceux de la base dentés et à dents obtuses; tous portant des poils blanchâtres sur les mésonèvres; pétiole rougeâtre, irrégulièrement déprimé et garni de quelques aspérités; sporothèces arrondis, distincts, au nombre de $\mathbf{1}-\mathbf{6}$ sur chargue segment; sporanges làchement geroupées, peu nombreuses.

Bourbon; de Montlrison.

(Dimensions : longueur 50 centim. environ; pinnules centrales $10-11$ centinl.; les phas longs segments, qui sont au centre de la pinnule mesurent 2 centim.)

II. Auplificata, F. - La P. a Base Élargie.

Frondes pinnẻes-pinnatifides, orales-allongées; pinnules lancéolées, sessiles, finissant en une longue pointe dentée; segment basilaire inférieur allongé et dirigé vers le bas; il est fortement crénelé, landis que les autres, un peu arqués, sont seulement ondulés. Ils portent à la lase des sporothèces arrondis, rapprochés de la marge. .

Mexique; Cordoba. (W. Schaffner, $n^{0}$ 219.)

(Dimensions : longueur de br fronde, 1 mètre 50 centim. et plus. La lanie seule mesure 85 centim.; pinnules de la base 30 centim., sur 2,5 d'euvergure; nous en comptons plus de 30 paires, séparécs par uIn entrenœud d'environ 3 centim. de développement.)

\section{Stexolepsis, F. - La P. A ÉCAllles (Du Rilizone) Étroites.}

Frondes fasciculées, pinnatifides au sommet, bipinnées à la base, très-flexilles, molles, délicates, amples et dilatées, oroïdes en leur pourtour; pinnules 
lancéolées, les basilaires écartées, redressées, les autres liorizontales, à jimelles lincéolées, plus ou moins découpées, olstusiuscules, à segments ovoïdes, chargés de 3-4 paires de sporothèces arrondis, dorés; pétiole strié, écailleux, blanchàtre; souche dressée, grosse, à très-longues filtrilles; fronde courerte d'écailles dorées, lıisantes, linéaires, atteignant jusqu’à à deux centimètres de longueur.

Mexique; près de Huatusco. (W. Sclaffner, nº 239. Herb. F.)

(Dimensions : longueur de la fronde 60 centim. el plus; pinnules de la base 25 centim., avec des pinnelles de $5-6$ centim.)

IV. Inpressa, F. - La P. a Nertilles ex relief.

Frondes rigoureuses, oblongues, pinnées et pinnatifides; stipe tri-canaliculé, gros et raide, couvert d'écailles lancéolées, caduques arec des poils courts, étalés qui le hérissent; rachis flexueux, profondémeat sillonné, revètn des mèmes poils; frondules lancéolées, presque sessiles, terninées par une pointe prolongée en queue; segments nombreux, oblongs, formant des sinus étroits; nervilles simples, . en relief; sporothèces rap|roclıés de la marge; un peu ronlée sur clle-mème; ils ne sont composés rue d'un très-petit nombre de sporanges.

Mexique; Cordoba, IIuatusco et Totutla. (IV. Schaffner, n² 218; 185'.)

Cette magnifique espece a quelques rapports avec le P. sculpturata, F., Gon. filic., p. 245, de Bourbon.

(Dimensions : Iongueur tolale 1 mètre 25 centin.; une trentaine de frondules; celles-ci mesurant 15-16 centin., sur 19-14 millim. d'enrergure. Je cumpte an dela de 40 segments prar frondules, et chacun d'eux a près de 20 nervilles.)

\section{Pilostel, F. - L.i P. cx peu porlée.}

Frondes pimato-pinmatifides, oblongues, stipe pailletenx, glabrescent, ainsi que le rachis, plane vers sa partie inférieure et manifestement ondulé; pinnelles sessiles, étalées, à angle droit, étroitement lancéolées, obtusiuscules; lames glabres, à l'exception des nervilles, sur lesquelles naissent des poils assez longs, blanchâtres, rigides; surtout rers la lame supérieure; sporothèces petits, peu fournis de sjoranges et presque toujours recourerts par la marge qui se contourne.

Mexique; sans autre indication. Linden, $11^{0} 126$; (W. Selaffner, à Orizala, $\mathrm{n}^{0} .498 ?$ ? 1856.)

(I)imensions : longueur $40-50$ centim. sans la stipe; frondules 7 centim., sur $11-12$ millim. de largeur; centre-1lœuds 25 millim. environ.)

Voisine du P. concima, F. dont elle diffère par des poils rares, presque spinescents, qui semblent se détacher de la nerville et en faire partie. Dans les spécimens 498 et 500 , de M. Schiffarr, les frondes sont fasciculées; le rhizome est dressé, chargé des débris de la base des anciens stipes; ils se rapprochent de l'espèce récoltée par M. Linden, mais diffërent bien peu du P. concimna. 
VI. Blanda, F. - LA P. Agréable.

Frondes pinnées-pinnatifides, ovoïles, glabres, papyracées, à pinnules en ovale allongé; les deux inférieures plus courtes et réfléchies; nervilles se dessinant en relief sur les deux lames; stjpe délié, blanchàtre, sillonné en dessus; rachis un peu velu; dix paires environ de sporothèces arrondis, occupant les deux tiers inférieurs de la lame; rhizome rampant, entouré de fibrilles.

Mexique; Mirador. (W. Schaffner, $n^{\circ}$ 222.)

(Dimensions : longueur de la fronde $2 \check{-}-2 \overline{7}$ centim., sur 7 centim. d'envergure dans la plus grande largeur; elle derient brusquement pinnatifide.)

Les lames sont transparentes, à nervilles simples et déliées; les sporothèces plus rapprochés du mésonèrre que de la marge. Le shizome atteint à la grosseur du petit doigt d'un enfant.

VII. ? Melaxorachis, F. - La P. a Rachis yoir.

Frondes pinnées-pinnatifules, oblongues en leur pourtour, à stipe et à rachis noir, luisant, du moins à la base, portées sur une souche dressée, munie de radicelles raides èt couverte d'écailles étroites, linéaires, acuminées; frondnles lanceolées, les supérieures courbées vers le hant, les inférieures vers le bas; les frondules, courtement pétiolées, ont des segments inférieurs libres, oblongs et crénelés. Les lames sont glabres; on ne troure de poils rers le haut dn rachis et sur les nervilles.

Ilexique; IIuatusco. (W. Schaffner, $n^{0} 238 ; 185 \%$.)

(Dimensions : longueur 50 centim.; pinnules 9 sur 20 - 24 millim. d'envergure.)

Celle espèce curieuse, remarquable par un stipe semblable à ceux des capillaires, est stérile. II. W. Schaffare met en note que celte fougère est peut-ètre Im Alsophila jeune. Rien ne dispose à croire que cette hypothèse soil fondéc.

VIII. ? INequalis, F. - La P. a FroNdules ivég.lLes.

Frondes tripinnées; divisions primaires oblongues, pétiolées, pinnées-pinnatifides; rachis blanchàtre, portant trois sillons vers la partie supérieure, chargé d'écailles longues, extrêmement étroites, ciliées; frondules très-courtement pétiolées, oblongues-lancéolées, terminées par une pointe triangulaire; segments orö̈les, glabriuscules, très-obtus, crénelés en la marge; sporothèces médians; spores papilleux.

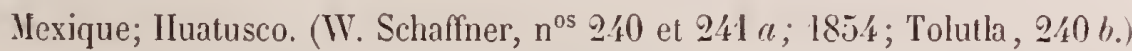

(Dimensions : longueur des divisions primaires, les seules que nous ayons rues, 40-50 centim. de longucur, une vingtaine de frondules alternes, plus grandes diun còté que de l'autre; frondıJes $6-I$. centiu., sur $2, \bar{j}$ à 3 centim. d'envergure.) 
Fougère très-ample, à sporanges làchement groupées; l'anneau est large, mais non oblique, ce qui ne permet pas d'en faire un Alsophila. Cependant elle est arborescente, et M. W. Schaffarer dit que le tronc est épineux.

\section{GONIOPTERIS, Presl.}

\section{IMhiholshina, F. - La Gonoptéride de Lady Dalinousie.}

Frundes pinnées, oblongues, à pinnules ovales-lancéolées, obliques et rétrécies à la base, très-longuement et très-finement acuminées; couvertes en dessous d'un duvet court et serré; lames finement ponctuées en dessus, sessiles, portant à la marge des dents raides et cartilagineuses; nervilles en saillie, unies par des transverses, formant d'étroites aréoles; sporothèces arrondis, serrés, disposés sur deux rangées et entourés de poils nombreux, assez longs.

Indes-Orientales. (Lady Dalhousie, Herb. Graham.)

(bimensions : longueur, mesurce à la base de la pinnule terminale, 36 cenlim.; pinnules 19 eentim., sur 3,5 centim. de largeur, la pointe amincie n'a pas moins de 30 centim. Il n'existe que 5 paires de pinmules.)

Celte espèce, ainsi que le G. mollis, F., Gen. fil., p. 251, est romarquable par des sporanges, dont la surface est de toutes parts liérissée de longs poils raides, pointus, si abondants qu'ils en cachent la structure, et leur donnent, en petit, l’aspect d’une égagropile.

\section{GONIOPIILEBIUM, Presl.}

(Voy. plus haul, 1. 62.)

$$
\text { * PIXITIFIDES. }
$$

\section{Chosulocheilon, F. - Le Gosiophlebion a marge Chrtildginelse.}

Fronde pinnatifide, très-glabre, terminée en une longue pointe crénclée, à pétiole et à rachis de coulcur-paille; segments inégaux, oblongs, obtusiuscules, imbriqués, à nerrilles dessinćes en relief; mésonèvre flexueux et éranescent; slorothices gros, fuures, ne dépassant pas les deux tiers supérieurs de la lame; rlizome rampant, sur lequel les frondes sont articulées.

Port ct dimensions du Polypodium vulgare, L., arec des segments plus rapprochés.

Nouvelle-Grenade, dans les Paramos, ou déserts des montagnes, province de lío de la Hacha, à 2600 mètres d'altitude. (L. Schlim, $\mathrm{n}^{0}$ 1007.)

II. Molestud, F. - Le G. paradoxal.

Frondes pinnatifides, lancéolées, souples ; stipe lisse, glabre, blanchâtre, articulé sur un rhizome ramcux, à écailles lancéolées, acuminées; segments membraneux, transparents, souples, formant, en s'unissant, de larges sinus, qui se rétréeissent vers le haut; nervilles déliées, difficiles à reconnaître, constituant de 
larges aréoles; sporothèces unisériaux, arrondis, naissant entre le mésunèvé, qui est flexueux, et la marge qui est chargée de dents peu marquées et écartées.

Mexique; près de Huatusco, Cordoba et Orizaba. (W. Schaffner, $n^{0} 180$.)

(Dimensions : Iongueur 50-60 centim. et plus; le stipe est à la lame : : $1: 2$; les plus longs segments mesurent 5 centim., sur 12 millim. de largeur au centre; il existe au delà de 36 paires de segments pinnulaires; le rhizome est de la grosseur d'une plume à écrire.)

\section{Calaguala, F. - Le Calaguda de dexico.}

Frondes pinnatifides, flexibles, ovoïdes-lancéolées, à stipe ou pétiole rufesceut, articulé, lisse et glabre; segments étalés, nombreux, rapprochés, larıcéolés, translucides, légèrement arqués, aigus, auriculés supérieurement, marge ciliée, portant quelq̣ues dents écartées; nervilles déliées, rufescentes à leur point de* départ du mésonèrre, plus pâles, en se dirigeant vers la marge; sporothèce naissant sur la nerville basilaire; rhizome traçant, de la grosseur d'une plume d'oir.

Vallée du Mexique où elle abonde. M. W. Schaffner, de qui nous tenons cette plante, dit que c'est le Calaguala des pharmacies de Mexico, et on lit daus Nartens et Galeotti, Fil. Mexic., p. 184, que toutes les fougères à rhizonte rampant et à fronde glaucescente portent ce nom, ce qui explique comnıent les pharmacographes diffèrent sur la désignation nominale de l'espèce de fongère qui fournit le Calaguala.

(Dimensions : Iongueur 60 centim. et plus; envergure, au centre de la fronde, 15 centinı; pétiole plus court que la lame. Ses frondes naissent écartées sur un rhizome atteignant dans l'un tle nus spécimens une Iongueur de près de 60 centim.)

\section{Axisoneron, F. - LE G. a SEgiexts ixégaux.}

Frondes pinnatifides, glabres, ovales-lancéolées; stipe lisse, blanchàtre, noueux in la base; segments translucides, comme rentrus au centre, à marge ondulée, portant quelques dents fort courtes; nervilles déliées; sporolhèces unisériaux, naissant au sommet d'une nerville basilaire, assez longue et courbée vers le mésonérre; derniers segments réfléchis. Rhizome rampant, écailleux; écailles fortement imbriquées, fauves.

$$
\text { Mexique; Orizaba. (W. Schaffner, } n^{\text {os }} 182 \text { et } 458 \text {.) }
$$

(Dimensions : Iongueur 60 centim., sur 22 - 24 centim. d'envergure vers le bas; largeur des seygrne'uts 15-17 millim. Nous possédons des spécimens plus petits qui ressemblent assez au Polypodiume vinlgare d'Europe.)

\section{Lepidotrichum, F. - LE G. a ÉCAILles pollues.}

Fronde pectinée, ovale-lancéolée, couverte inférieurement d'écailles roussàlıes, appliquées, nombreuses, à marge blanchâlre ciliée, terminées par un long poil ; segments lancéolés, étroits, raides et pointus; sporothèces naissant entre la marge et le mésonèrre; stipe profondément sillonné, courert, ainsi que le rachis, 
d'écailles très-lâchement imbriquées, à pointe sétacée, longue et courbée; sporothèces distincts, ellipsoïdes, rougeâtres, entourés d'écailles dressées, prenant l'apparence d'une fausse marge; rhizome rampant, chargé d'écailles roussâtres, soyeuses et abondantes.

Mexique; Cordoba. (W. Schaffner, $n^{0} 198$; Orizaba, $n^{\circ}$ 451.)

(Dimensions : 70 centim. de longueur, sur 17-20 centim. d'envergure vers le centre; les segements n’ont ģuère que 7 à 8 millim. de largeur; nous en comptons environ 40 paires.)

VI. Ritertexs, F. - Li G. REPlíe.

Frondes ovoïdes, oblongues, très-glabres, olivâtres par dessiccation; frondules alternes, dressées, lancéolées, aiguës, atténuées à leurs deux extrémités, ondulées, dentées; lames portant une seule aréole qui l'occupe presque tout entière; pétiole et rachis profondément sillonnés et déliés; sporothèces unisériaux, arrondis.

Polypodium distichum. (IV. Schaffner, in Lilter.)

Mexique; près de IIuatusco. (IV. Schaffner, $n^{0} 189$; Orizaba, $n^{0}$ 450.)

(Dimensions : longueur 70 centim.; frondules 16-18, sur 10-15 millim. de largeur. Nous possédons un sprècimen à frondules ètroites presque linėaires.)

La disposition singulière que prend quelquefois, en se desséchant, cette plante est assez facile à expliquer. Quoique le rachis et le pétiole soient très-grêles, le sillon quils portent est très-large; c’est sur les bords de cette espèce de canal dilaté que s'attachent les frondules par un pétiolule très-délié. Pendant la dessiccation, ce sillon se resserre et rapproche ainsi ces frondules qui se portent toutes dı mème còté, de manière à appliquer les lames supérieures des unes contre les lames supérieures des autres, ainsi qüil arrive dans le sommeil de certaines espèces de légumineuses.

\section{lil. Jyrrilolepis, F. - Le G. a ĖGalles rolssatres.}

Fronde lancéolée, pectinée; pétiole robuste, bicanaliculé, poilu , écailleux , roussâtre , ainsi que le rachis, chargé d'écailles rufescentes abondantes; segments lancéolés, obtusiuscules, étalés, élargis à la base, et plus développés ver's le haut, à marge ondulée; lames relues en dessus, cliargées d'écailles roussâtres en dessous; sporollièces distants, au nombre de 14 - 16 paires, tons couverts d'écailles; le lhizome est flexueux, à rameaux latéraux très-courts, arec des écailles lancéolées, termmées par une pointe longue et raide; nervilles formant des anastomoses.

Nexique; Huatusco. (W. Schaffner, $n^{0}$ 197.)

(Dimensions : 60 centim. et plus de longueur, sur une envergure de 8-9 centim.; les segments n'ont guc̀re que 5 millim. de largeur; nous en comptons une trentaine de paires, el les inférieures sont écartćes.) 
Vili. Loxgicaule, F. - Le P. a long pétiole.

Fronde oblongue-lancéolée, portée sur un rhizome flexueux, á écailles imbriquées, lancéolées; segments lancéolés, sous-opposés, écartés, resserrés à la base, le terminal caudiforme, tous couverts en dessous d'écailles lancéolées, noirâtres au centre, très-lâchement imbriquées; sporothèces marginaux, distincts, rougeâtres, entourés d'écailles; pétiole arrondi, canaliculé, beaucoup plus long que la lame; nervilles formant des anastonioses.

Nouvelle-Grenade; Rio-lIacha. (L. Schlim, $\left.n^{0} 847.\right)$

(Dimensions : $26-28$ centim. de longueur, sur 4-4,5 d'envergure; 17-19 paires de seguments, laissant entre eux un intervalle de 7-8 millim.; clles ont à peine 4 millim. de largeur.)

$$
\text { - PINTÉES. }
$$

\section{Plectolepis, F. - Le G. a Écailles pliées (ex long).}

Frondes oblongues - lancéolées, à stipe rougeâtre, lisse, strié, noueux à la base, frondules opposées, aiguës, sessiles, pileuses, chargées de poils courts, crénelées et légèrement cordiformes à la base; nervilles primaires noirâtres; nervilles secondaires déliées et difficiles à voir; les basilaires formant une grande aréole au milieu de laquelle se trouve une nerville prolifẻre libre; sporothèces unisériaux, gros et dorés, occupant toute la longueur des frondules; rhizome de la grosseur du petit doigt, avec des écailles roussâtres, à base arrondie, et pliées sur leur marge.

Mexique; près d'Orizaba. (WV. Schaffner, $\mathrm{n}^{0}$ 187.)

(Dimensions : longueur 60 centim. et plus; pinnules, les unes horizontales, les autres courlies et dressẻes, les deıx inféricures réfléchies, mesurant $15-18$ centim., sur 2,5-2,8 centim. de largoeur.)

La singulière disposition des écailles a valu à cette plante le nom spécifique que nous lui avons donné; elles ont une base arrondie, dont les bords sont courbés et pliés vers le centre; ces écailles, terminées par une longue pointe linéaire, portent des poils raides, courts et nombreux.

X. Serratum, F. - Le G. a Frondules dextées ex scie.

Frondes pinnées, ovoïdes en leur pourtour, courtement pétiolées et finement pubescentes sur toutes leurs parties; frondules lancéolées, oblongues, opposées vers le bas, puis alternes, sessiles, pointues an sommet et à marges dentées: les inférieures, légèrement infléchies; nervilles brunâtres, formant une seule aréole qui naît de la base pour se ferner seulement vers le sommet; sporothèces arrondis, distincts, plus rapprochés du mésonèvre que de la marge, n'occupant que la moitié supérieure de la frondule; rhizome de la grosseur du petit doigt, abondamment couvert de belles écailles roussâtres, à base arrondie, brusquement terminées en une longue pointe, dentée; fibrilles radicales pinnées, longues et tomenteuses. 
Mexique; Orizaba. (WV. Schaffner, $n^{0}$ 495; 1856.) Indiquée comme épiphyte et comme terricole.

(Dimensions : longueur 27-30 centim.; une douzaine de paires de frondules, qui mesurent à la base 7 centim., sur 15 millim. de largeur.)

Le rhizome a une organisation roisine de celle du G. plectolepis, F.

115. CaMPYLONEVRON, Presl.

I. Macrosorum, F. - Le Caiprlonèvre a gros sporothèces.

Frondes simples, à marge sinueuse et cartilagineuse, pétiole assez lonğ; rlizome tortueux, couvert d'écailles oroïdes-lancéolíes, très-finement cancellaires; nervilles en relief, noirâtres, formant des courbes flexueuses, médiocrement bombées, émettant deux courtes nervilles prolifères qui se chargent an sommet de très-gros sporothèces.

Nouvelle-Grenade; province d'Ocaĩa, dans les Paramos (déserts des montagnes), 2800 à 3500 mètres d'altitude. (L. Schlim, $1^{\circ}$ 440.)

(Dimensions : longueur 40 centim. environ, largeur $3-3,5$ centim.; le pétiole est à lis lame : : $1: 4$.)

II. Caudatum, F. - Le C. terminé ex queue.

Frondes lancéolées, terminées brusquement en une longue pointe linéaire, atténuée. vers le bas, un peu ondulée en son pourtour; aréoles émettant, rer's leur sommet, qui est anguleux, deux nerrilles droites, destinćes à devenir prolifëres; le sommet de ces nervilles se renfle et forme, vers le côté supérieur de la lame, de petits points calcaires, régulièrement disposés; rhizone rampant, délié, à longues fibrilles, peu rameuses; écailles brunâtres à base élargie.

Ilexique; Cordoba et Iluatusco, sur les fougères en arbre. (WV. Schaffiner, $n^{10} 176 ; 185 \%$.)

(Dimensions : Iongueur $36-40$ centim., sur 3 centim. de lirgeur.)

Les aréoles sont remar(puables en ec qu'elles ne forment pas unc véritable courbe vers le haut, mais bien une ligne brisće. Toutes les nervilles sont flexucuses et de même calibre.

\section{CHRYSOPTERIS, Lk.}

\section{Graxdis, F. - La graxde Chrisoptéride.}

Pinnatifide comme toutes ses congénères; ses segments mesurent jusqu'à 36 centin. Les sporothèces, de couleur dorée, forment de cinq à six séries sur les lames qui sont membraneuses, transparentes, ondulées-dentées, et impressionnées sur la lame supérieure par les sporothèces.

Nagnifique espèce de la Nourelle-Grenade; province d'Ocaña. (L. Schlim, $\mathrm{n}^{0}$ 598.) 
II. LANosa, F. - LA C. Laneuse.

Espèce réduìte aux dimensions du Polypodium vulgare, L., avec cinq à sept paires de segments, plus larges, obtus, laissant entre eux des sinus assez dilatés; marge épaissie, portant quelques dents peu profondes et obtuses.

Mexique; à San Angel. (W. Schaffner, $n^{0} 311$.)

III. Microdictya, F. - La C. a petit réseaU.

Port de l'espèce précédente, à segments obtus très-rapprochés; consistance des lames, épaisse et comme cartilagineuse; les aréoles sont petites, toutes égales en dimension et constituées par des nervilles très-déliées, brunâtres; les sporothèces assez gros sont disposés sur une seule série.

Mexique; près d'Órizaba. (IV. Schaffner, $n^{0} 203$. )

123. DRYNARIA, Bory.

(Toyez plus haut, p. 16.)

‡. 1. PLEOPELTIS.

Crassinervata, F. - La Drivare a grosses nervilles.

Frondes cartilagineuses, épaisses, lancéolées, acuminées, permettant cependant de voir que les nerrilles forment des aréoles étroites, courbes, irrégulières, surtout les basilaires, quelques-unes sont terminées par un appendice dressé, stérile. Ces nerrilles se détachent en couleur rert-sombre sur les lames; les marges sont un peu roulées du côté inférieur; sporothèces très-gros, n'occupant que la moitié supérieure de la fronde; réceptacle elliptique; rhizome rampant, flexueux, portant des frondes espacées.

Mexique; rallée d'Orizaba, sur les vieux arbres. (W. Schaffner, $n^{\circ 8} 173$ et 48?; Cordoba, $\mathrm{n}^{0} 174 \mathrm{a}$.)

(Dimensions : longucur 16-18 centim., sur 15-18 millim. de largeur; 12 paires de sporolhèces distants.)

Cette espèce est facile à reconnaître: $1^{0}$ à sa transparence, circonstance fort ratre dans ce genre; 20 à ses nervilles épaisses, de couleur vert-sombre, couleur qui ne s'efface que vers la marge.

II. Mexicaxa, F. - LA D. Mexicaixe.

Frondes lancéolées, très-longuement acuminées, pétiolées, coriaces, laissant cependant roir, quoique difficilement, des aréoles peu nombreuses, formées de nervilles déliéeset appendiculées, non-saillantes; margre ondulée, rouléelégèrement en dehors; mésonèrre noir dans toute son étendue du còté de la lame inféricure; rhizome très-long, tomenteux. 
Grammitis elongata, Mart. et Gal., Foug. mexic., p. 28, non Sw. (partim). Mexique; Vera - Cruz (Galeotti, nº 6321); la Puebla, par M. Sčliafner, $n^{0} 179$, et sur le Popocatepetl, $\mathrm{n}^{\circ} 292$.

(Dimensions : longueur, clle peut attcindre jusqu'à 30 centim., sur 25 millim. de largeur au centre. Nous comptons une vingtaine de paires de sporollèces ovoïdes, occupant la moitié rétrécie de la fronde; la pointe est stérile.)

\section{PLEURIDIUM, F.}

Gen. filic., p. 273.

Axgustum, F. - La Pleuride a froxde étroite.

Fronde étroitement lancéolée, épaisse, coriace, se terminant en une longue pointe qui se dégrade lentement dans ses dimensions; sporothèces très-gros, sur 5-7 de lauteur, très-rapprochés; sporanges très-longuement pédicellées; anneau se détachant du sacculus avec la plus grande facilité; spores gros, ovoïdes; réceptacle globuleux, très-noir, indiqué sur la lame supérieure par une tache ponctifornie.

Nouvelle-Grenade; dans les forìts de la province d'Ucaña, à 2.400 mètres environ. (L. Schlim, $11^{0}$ 610.)

(Dimensions : longueur 70 centim., sur ull peu plus de 3 centim. de largeur.)

\section{CYCLODIEES.}

(Voy. plus liaut, p. 20.)

\section{POLISTICHUN, Roth.}

I. Graide, li. - Le graid Polystic.

Fronde bipinnée, ovale; stipe robuste, brunâtre, luisant, lisse, portant trois sillons vers la base, qui est couverte d'écailles dressées, épaisses, lancéolées, acuminées, carénées, brunâtres et discolores vers la marge; rachis sinueux vers le haut, portant des écailles déliées, un peu crépues; pinnules linéaires-lancéolées; pinnelles ou frondules pétiolées, auriculées, dentées-mucronées, cunéilormes à la base; sporothèces : $1-6$ paires, assez petits; indusium Irès-caluque.

Mexique; Huatusco. (W. Schaffner, $1^{0}$ 217.)

(Dimensions : longueur 1 mètre 25 centim. Les plus longues jinnules 20 cenlim., sur 2,5 centim. l.e stipe est à la lane :: $1: 4$, il alteint la grosseur du petit doiggt; les écailles n'ont pas moins de 2 centim. Squammation tout à fait spéciale. On trouve entre ces écailles, qui sont lâchenent imbriquées, u:ı tomentun gुrisâtre très-abondant.) 
II. Lepidonajes, F. - Le P. TRÈs-Écailleux:

Fronde ovale-lancéolée; pinnules courbées, rapprochées, élroitement lancéolées, aiguës, sessiles; pinnelles auriculées, mucronées, cre̊nelées; le stipe, le rachis et la partie inférieure des lames sont entièrement couverts d'écailles fauves, velues, molles, soyeuses, munies d'une longue pointe flexible. Les sporothèces, à l'état adulte, courrent entièrement les lames.

$$
\text { Java. (Lobl, } \mathrm{n}^{\text {D 262.) }}
$$

(Dimensions : longueur de la fronde, moins le stipe, lequel dans notre spécimen est tronqué, 34 centim.; pinnules 8 centim., sur 15 millim. d'envergure.)

\section{Neo-Zelandicui, F. - Le P. de la Nouvelle-Zélande.}

Fronde bipinnée, glabre, lisse, écailleuse; pinnules ovales - lancéolées, pinnatifides vers leur tiers supérieur, pétiolées, terminées en une pointe dentée; pinnelles épaisses, coriaces, opaques, ovales, dentées en scie; celles de la base des pinnules sont seules libres et crénelées; six à huit sporothèces déprimant la fronde sur chaque pinnelle; indusium très-caduque.

Nouvelle-Zélande. (Mosseman, $\mathrm{n}^{\circ}$ 617.)

(Dimensions : longueur 45 a 50 centim.; pinnules 10 centim. environ, sur $3-4$ centim. d'envergure; notre spécimen est bifurqué.)

Se rapproclie du $P$. coriaceum, Schott.

IV. Scinzolobium, F. - Le P. a segments incisés.

Fronde ovale-lancéolée, bipinnée dans toute l'étendue des pinnules; stipe très-gros à la base; mais s'amincisssant bientôt pour donner naissance à un rachis flexible, filiforme au sommet; ce stipe est chargé d'écailles ovales-lancéolées, striées. Les pinnules sont étroitement lancéolées, très-souples, sessiles, à rachis écailleux ; pinnelles courtement pétiolées, distantes, incisées, à ircisions longuement mucronées; il y a 4-5 paires de sporothèces qui gardent leur indusium; celui-ci est membraneux, plane et fort mince.

Bourbon. (De Montbrison.)

(Dimensions : longueur, 1 mètre 25 centim.; pinnules 10-12.centim.; pinnelles 15 millim. Le stipe est à la lame :: $1: 3$.)

\section{Tetragonum, F. - Le P. tétragone.}

Fronde bipinnée, ovale-lancéolée; pinnules très-rapprochées et imbriquées, sessiles, à dernières pinnules recouvrant le rachis, qui est quadrangulaire, ainsi que le stipe; celui-ci abondamment couvert d'écailles glumacées, raides, ovales-lancéolées, tortillées au sommet, opaques, luisantes, quelquefois noires en leur centre: celles qui confinent avec le rhizome, plus étroites et souples; pinnelles très- 
rapprochées, crénclées-dentées, à dents mutiques; sporothèces assez gros, protégés par un indusium d'apparence rougeâtre.

Chili. (C. Gay.) C'est le P. vestitum, de Remy, Fl. Chil. Crypt., p. 517; évidemment différent de la plante de Swartz.

(Dimensions : longucur, 45 centim., sur 14 environ d'envergure; les pinnules, 8 centim., sur 2 de largeur.)

II. liaciICHLANA, F. - LE P. A INDUSIUM FRANGÉ.

Fronde bipinnée, ovale-lancéolée; stipe et rachis jaunâtres et paléacés; pinnules sessiles, lancéolées, longuement acuminées, courbées vers le sommet de la fronde; pinnelles écartées, rhomboïdales, gibbeuses vers̉ le haut, courtement pétiolées, très-obtuses; marges inférieures entières; marges supérieures et sommet portant des dents épineuses; $4-7$ sporothèces et 2 ou 3 sur l'oreillette; indusium trèslarge, irrégulièrement arrondi, déchiqueté dans son pourtour; ombilic coloré.

Mexique; au Popocatepetl, à plus de 3000 mètres. (T. Schaffner, $n^{0}$ 290.)

(Dimensions : longueur, 1 mètre 25 centim.; pinnules, 18 -19 centim.; pinnelles, $10-11$ millim.)

Cette espèce diffère de l'A. aculeatum, Rotr, par son indusium frangé et inégalement arrondi: très-souvent irrégulier et plane. Les pinnules linéaireslancéolées, acuminées, sont garnies d'un nombre considérable de fiondules oroïdes, très-obtuses, entières, portant en dessus une gibbosité obtuse et quelques dents blanchâtres, qu'on ne retrouve que sur la marge supérieure.

NB. Le Polystichum aculeatum, Rotis, se troure au Vexique arec des variations de forme très-remarquables; telles sont:

I. Aculeatiu, Roth.

a INCist 1, F.

Pinmules Irès-arquées, acuminées, à pinnelles très-divisées, dont les segments sont très-longuement sétacés.

Cordoba des Mexicains. (IV. Scliaffner, $n^{0}$ 250.)

II. Aculeatui, Roth.

3 GRACHE, F.

Délicat, ovale-lancéolé, à pinnules courtes, chargées de pinuelles ovales, dentẻesmucronées.

Guatimalpan et San Agostin. (W. Schaffner, n 315.)

III. Aculeatum, Roth.

$\gamma$ Disti.is, F. 
Fronde pinnée vers le quart supérieur, pinnules et pimnelles distantes; celles-ci trèspeu découpées.

Totutla des Mexicains. (W. Schaffner, $n^{0}$ 116.)

NB. Le Phegopteris nitens du Genera, p. 246, ayant un indusium, devient le Polystichum nitens, F.

\section{HEVICARDION, F.}

$$
\text { Gen.filic., p. } 282 .
$$

\section{Macrosorum, F. - L'Hémicardie a gros sporotilèces.}

Fronde pinnée, très-longuement ovale-lancéolée, glabre, à frundules étroites, lancéolées, fortement crénelées, mais seulement dans leur moitié supérieure; sporothèces gros, connivents, rassemblés au centre de la feuille; indusiums bruns, rougeâtres, persistants, larges, épais, portant au centre une fossette et s'étendant sur deux rangées; la troisième indiquée seulement par quelques sporothèces.

Nouvelle-Grenade; province d'Ocaña, ì 13 ou 1500 mètres d'altitude. (L. Schlim, $\left.n^{\circ} 658.\right)$

(Dimensions : longucur, 86 centim., sans le stipe, ce qui dispose à penser qu'clle atteint plus d'un mìtre; frondules, 13-14 centim. au centre de la fronde, sur $11-12$ millim. de targeur; it y a environ 40 paires de pinnules.)

Cette plante diffère de ses congénères par des frondules fortement crénelées, à crénulations arrondies par la base; ces mêmes frondules présentent supérieurement une gibbosité très-manifeste, les sporothèces sont deux fois plus gros, sourent connivents et rapprochés du mésonèvre par séries.

\section{MMBLYA, F.}

(Voyez plus loin Phanerophlcbia.)

Latifolia, F. - L'A MBlye a LARges frondes.

Frondes oblongues, à stipe assez grêle, blanchâtre, sillonné profondément; frondules peu nombreuses, oblongues, lancéolées, assez longuement pétiolées, acuminées, obliquement arrondies à la base; marge sinuée, dents courtes et rares; sporothèces occupant toute la surface de la lame, plus nombreux et plus gros, lorsqu'ils confinent avec le mésonèvre; sporanges portées sur un réceptacle orvïde, noirâtre. 
Nourelle-Grenade; province d'Ocaña, à 1200 ou 1500 mètres d'altitude. (L. Sclilim, $\mathrm{n}^{0}$ 656.)

(Dimensions : longueur, 50 centim. cuviron; nous ne complons que 4 paires de frondules, qui mesurent de $16-18$ centim. de longueur, sur 3-3,5 de larģeur, la terminale est plus large.)

Diffère de l'espèce-type par des sporothèces occupant toute la surface de la lame, plus gros et plus nombreux, la première série adossée au mésonèvre, tandis que dans l'A. juglundifolia, Presl., cette même première série est centrale; elle en diflëre encore par des marges sinuées, ne portant qu'un très-petit nombre de dents; par des frondules peu nombreuses, larges, arrondies à la base. Les nervilles ne sont pas en relief et forment des anastomoses plus nombreuses. Elle est aussi plus robuste.

\section{ASPIDIUM, Sw.}

\section{A. ESI'ECES PINNÉES-PINNATIFIDES.}

* IIDCSIUM GLABRE.

I. Albicaule, F. - L'Aspidie a stipe blavcilatre.

Jolie espèce, glabre, pinnée-pinnatifide, terminée en une longue pointe pinnatifide, très-aiguë; pinnelles lancéolées, étroites, sessiles, à pointe entière; derniers segments, surtout les supérieurs, plus longs que les autres, libres jusqu'à moitié de leur étendue; sporothèces petits, rapprochés, confluents au dernier âge; indusium glalıre, uniforme; anneau des sporanges portant jusqu’à vingt articulations; stipe et rachis blanchâtres; rhizome rampant.

Vallée du Mexique. (IV. Schaffner, n² 2.45.)

(Dimensions : lougurur , 66 ceulim., sur 16 - 18 d'envergure; pinnelles, 1 centim. environ de largeur; je compte jusqu’à 18 paires de pinnules, séparces les unes des autres par un entrenœud de $1 \bar{j}$ millim. environ.)

Cette espèce, dont l'indusium est tout à fait glabre, doit prendre place à côlé des A. molle, patens, violascens, Laulfussï; espèces roisines, autant Aspidium que Nephrodium, et l'on doit y réunir l'A. Natalensis, de Port-Natal, velu sur toutes ses parties, remarquable par un raclis sensiblement quadrangulaire.

II. Microcillexa, F. - L'.l. a petit indusiun.

Frondes très-élancées, oblongues, pinnées-pinnatifides, couvertes sur le pétiole, le rachis et les mésonèrres, d'écailles linéaires, étalées et souvent crépues; frondules lancéolées, presque sessiles, aiguës, alternes; segments oblongs, trèsobtus, libres vers les deux tier's supérieurs; nervilles simples, toutes fertiles en leur centre; sporanges très-condensées, recourertes d'un indusium glabre, extrèmement petit, qui disparaît à la maturité. 
Mexique; Orizaba. (W. Scliaffner, $\mathrm{n}^{0} 459 ; 1856$.)

(Dimensions : longueur 1 mètre; pinnules 10 - 12 centim., sur 16 - 18 millim. de largeur; la fronde se termine brusquement en une pointe pinnatifide. La base du pétiole est abondamment couverte d'écailles fauves, étalées, lancéolées, à marge entière.)

III. Pauper, F. - L'A. chétif.

Espèce délicate, à frondes légèrement arquées, portées sur une souche dressée; stipes couverts de poils qui se retrouvent sur les lames supérieures; pinnules courtes et relativement assez larges; sporothèces écartés; indusium glabrescent; nervilles des segments très-déliées et très-distantes; il n'y en a que 5 - 6 de chaque côté des lames.

La Martinique. (Mlle Rivoire.)

(Dimensions : longueur, 22-24 centim., sur 8 d'envergure; celte espèce est facile à reconnaitre a ses nervilles simples, éeartées, beaucoup moins nombreuses que dans ses congénères.)

IV. Chrysocarpon, F. - L'A. a sporothèces dorés.

Frondes ovales-lancéolées, pinnées-pinnatifides dans leur plus grande étendue; à nervilles bifurquées; pinnules inférieures bipinnées; stipe et rachis abondamment couverts d'écailles roussâtres, ovales-lancéolées, finement dentées sur leurs bords; pinnules sessiles, lancéolées, aiguës; à segmenls crénelés à la base et dentés au sommet; pinnules inféricures, triangulaires, plus courtes, à derniers segments pinnés; sporothèces gros, rapprochés, de couleur dorée-tabacine; indusium bombé, glabre, étroitement cordiforme.

Port et dimensions de l'A. Filix-mas, dont elle a le rhizome.

Mexique; au Popocatepetl, à 3000 mètres' d'altitude. (W. Schaffner, $n^{0}$ 289.)

V. Pseudo-Filix-yas, F. - L'A. Fausse Fougère-MaLe.

Frondes pinnées - pinnatifides, ovales en leur pourtour'; stipe blanchâtre, à écailles de la base fauves, ovoïles et entières, celles du lıaut, ainsi que celles du rachis, plus colorées, plus étroites et ciliées; pinnules étalées, lancéolées, acuminées, à segments elliptiques, crénelés, les inférieures plus profondément que les autres; nervilles serrées, bifurquées; pinnules basilaires pinnées, élargies, stériles; sporothèces 4-5 paires, pâles, portant un indusium glabre et cordiforme.

Port de l'A. Filix-mas, arec des pinnules plus longues, mesurant 15 ceutimètres, la base est bipinnée; nous avons un spécimen qui mesure plus d'un mètre.

Vallée du Mexique. (W. Schaffner, $\left.n^{0} 253.\right)$

V. Ciieiloplotiuni, F. - L'A. a indusium glabre.

Frondes pinnées-pinnatifides, largement lancéolées, pétiole et rachis couleur de paille, glabres, tendant à la forme quadrangulaire; frondules étalées, quclquefois même courbées vers le bas; les fertiles étroitement lancéolées, sessiles, alténuées, 
opposées inférieurement, fructiferes de la base au sommet; les stériles plus larges; segments oblongs, entiers, peu distants; sporothèces marginaux, très-rapprochés el confluents; indusium glabre; souche dressée.

Port et consistance de l'A. Thelipteris, Sw.

Mexique; Orizaba. (IV. Scliafner, 1856.)

(Dimensions : Iongueur, 50 centim. environ, sur $16-18$ centim. denvergure; le stipe est à la lame $:: 1: 4$.)

VII. Olizab.e, F. - L’A. d’Orizari.

Frondes oblongues, glabres, à pétiole, rachis et mésonèrres blanchàtres, à frondules lancéolées-linéaires, sessiles, atténuées au sommet en une longue pointe dentie en scie, segments oblongs, légèrement arqués; une memlırane blanchâtre et pellucide les unit à la base; sporothèces médians, distincts, laissant stérile le liers supérieur de la lame; indusium glabre, rougeitre, très-déprimé au centre et bombé en son pourtour.

Mexique; Orizaba. (IV. Schaffner, 1856.)

(Dimensions : longueur, 1 mètre et probalılement plus; une trentaine de pimnules dont les plus longues mesurent jusqui it 30 centin., sur 2 centim. en leur centre; 5 - 7 paires de sporothèces.)

Très-grande et tris-belle espèce, très-roisine des Neplerodium, arec lesquels on pourrait la placer sans trop d’inconvénients. Elle se rapproche de lia planche 22 de Sculiunr, donné pour l'Aspidium pennigerum, de la Nouvelle-Zélande.

ilit. Nigriciule, F. - L'A. a stipe Nolr.

Pinnée-pinnatifude, poilue sur toutes ses parties, tandis que les indusiums sont glabrescents; pinnules lancéolées, écarties, opposées dans le bas, à nervilles flexueuses; le stipe est noir, comme dans les adiantes, ce qui sépare cette espèce de toutes celles arec lesquelles on pourrait la confondre.

Indes-Orientales. (Griffith.)

(Dimensions : longueur, 40 centim. environ, sur 12 d'envergure; les sporolhèces sont marginaux.)

IX. SQumagru, F. - L'A. SQUaMgère.

C'est l'A. Thelipteris, Sw. ß. squamigerum, de Sculecutexdall, Adumbrat., p. 23, du Cap (Drège), qui ne peut ètre rapproché de l'A. Thelipteris, Sw., plante américaine. Quoique la plante soil glabre, les lames se recouvrent de grandes écailles que soulèvent les sporothèces, sans les détacher; elles donnent aux frondes une épaisseur et $n$ m poids considérables.

S. Ajeristonevron, F. - L'A. a Nervilles shiples.

Frondes lancéolées, écailleuses sur le stipe et sur les mésonèvres inférieurs; pinnules 
courtement lancéolées, à segments découpés jusqu’à la base, oroïdes el crénelés; nervilles simples; $3-5$ paires de sporothèces assez petits; indusium glabre, bombé, un peu froncé; stipe délié, flexible, brunàtre et un peu luisant, portant à la base des écailles étroitement lancéolées, très-longuement acuminées et à marge entière.

Culba.

(Dimensions : longueur, $57-60$ centim. Le stipe est à la fronde :: $1: 4 ;$ pinnules, 5-5,5 centim. de longucur, sur 12 millim. de largeur; nous comptons au dela de 30 paires de pinnules, séparées les unes des autres par un intervalle de 2 centim., au centre de la fronde. Teinte générale brunàtre.)

Xi. Microcarpon, F. - L'A. a petits sporothèces.

Frondes pinnées-pinnatifides, ovales-lancéolées; stipe blanchâtre; rachis quadrangulaire; pinnules-lancéolées, à segments ovales, arqués, à nervilles simples, fructifères en leur milieu; $10-12$ paires de sporothèces fort petits, roussâtres; indusium cordiforme, glabre.

Mexique; près de Cordoba. (IV. Schaffner, $n^{0} 214$.)

(Dimensions : longueur 90-92 centim.; pinnules de la base, 13 centim., sur 3 centim. de largeur; les dimensions se dégradent jusqu'au sommet qui ne forme plus qu'une longue pointe pinnatifide; nous comptons environ 20 paires de pinnules.)

$$
\text { ** INDLSIIH VELU. }
$$

Xil. Coxspersoides, F. - L'A. conspersoïde.

Frondes oblongues, à rachis couleur de paille, plane en dessous, fortement sillonné en dessus; couvert, ainsi que les mésonèvres, de poils courts, blanchâtres; frondules lancéolées, très-étalées, sessiles, velues sur la lame inférieure, ğlabres en dessus; segments oblongs, aigus, entiers; les inférieurs plus grands, irrégulièrement dentés, donnant à la pinnule une apparence sem̧i-décussée; nervilles simples; indusium hlanclıâtre, velu, paraissant orbiculaire par le rapprochement du sinus.

Nexique; Orizaba. (W. Schaffner, $n^{\text {os }} 335$ et $463 ; 1856$.) Saint - Domingue, de Tussac. Cuba?

(Dimensions : longueur 80 centim. à 1 mètre. Les pinnules de la base 17 - 19 centinn., sur 2 de largeur.)

M. IV. Sciraffner dit de cette plante qu'elle porte sur le rhizome des frondes, in orbem dispositis.

\section{XiII. Obtusilobui, F. - L'A. a seginents trìs-obtus.}

Fronde ovale-lancéolée, flexible, délicate, translucide; stipe strié, écailleux à la base, porté sur une souclıe dressée, munie de très-longues radicelles brunâtres; écailles roussàtres, entières, linéaires; rachis grisâtre et tomenteux; pinnules lancéolées, cordiformes à la base; mésonèvre supérieur, poilu-tomenteux; segments 
arrondis, soudés dans le tiers ou dans la moitié de leur étendue, à nervilles simples; 6 - 8 paires de sporothèces à indusinm cordiforme; il se montre, au microscope, chargé de quelques poils courts et cylindriques.

Vexique; Huatusco. (IV. Schaffner, $n^{0}$ 213.)

(Dimensions : Iongueur 60 centim.; pinnules 10 - 11 centim., sur 20 à 22 millim. de largeur.)

\section{FRONDES DEUX OU TROIS FOIS PINYÉES.}

XIV. APERTUM, F. - L'A. OUVERT.

Grande espèce à frondes bipinnées, et tripinnées dans les dernières divisions de ses pinnelles, très-ourertes, ovales-lancéolées en leur pourtour'; stipe gros à sa partie inférieure, relevé d'aspérités, et clıargé dans le bas d'écailles lancéolées, fort longues et acuminées; toute la plante est glabre et à rachis nus, blanchàtres; les pinnules reproduisent la forme de la fronde; les pinnelles sont formées de segments étroits, obtus et crénelés, portant 3-4 paires de sporothèces, recouverts d'un large indusium glabre, réniforme et inégal en son pourtour.

Mexique; Huatusco, sur les vieux clıênes (W. Schaflner, $n^{0} 73$ ), el aussi au Mexique, à Cuernavaca, par M. Craveri, $n^{0} 736$ (cx Schaffner).

(Dimensions : la plante pent atteindre 1 mètre on mème davantage; le slipe, à la base, est gros comme le pelit doigt d'un enfant; les principales pinnules mesurent 20 centim.; les pinnelles 4, et plus; il existe entre les pinnules de la base 9 centim. d'intervalle.)

XV. Inquinass, F. - L’A. Maculé.

Frondes pinnées - pinnatifides ver's le haut, bipinnées vers le bas, tout à fait glabres, délicates, transparentes; frondules pétiolées, lancéolées, tous les segments dentés en scie; nervilles bifurquées; sporothèces peu nombreux, écarlés; indusium cordiforme, glabre, épais, à sinus court, 12 articulations à l'anneau; spores succinoïdes.

Mexique; Orizaba, dans les montagnes. (WV. Sclıffner, $n^{0} 71 ; 1854$ ).

(Dimensions : longueur 30 centim. enriron; stipe et rachis rougeâtres, déliès, lisses; pinnules de la base $4-5$ centim., sur 2 centim. de largeur.)

Il faudrait revoir d'autres spécimens de cette plante pour être bien sùr de la spécificité. La souche est dressée et porte plusieur's frondes rapprochées. Les sporothèces sont indiqués du còté inférieur par une tache brunàtre.

XVI. Agatolepis, F. - L’A. A ÉCAILles ÉlÉGaNtes.

Fronde délicate, translucide, bipinnée, port el dimension du Cystopteris fragilis, Bernh.; glabre, oroïde; stipes groupés sur une souche dressée, renflée à la base, et d'apparence bulbeuse; belles écailles fauves, lancéolées, aiguës et pellucides; 
sporothèces distincts; indusium blanchàtre, glabre, mince et cordiforme. L'anneau des sporanges porte de 16 à 18 articulations.

Mexique; près de San Angel (II. Schaffner, $n^{0} 309$ ); trouvée près de San Agostin, avec des scgments plus étroits.

\section{XViI. Diastematocarpon, F. — L’A. a sporotilèces Écartés.}

Fronde bipinnée, étalée, glabre, délicate; pinnules ovales, pétiolées, à rachis un peu ailé, aplati; pinnelles lancéolées, obtusiuscules, dentées au sommet, à segments courbés en dedans, les supérieurs plus longs que les autres, ovoïdes el ofus; sporothèces très-écartés les uns des autres, à indusium cordiforme, jaunàtre.

Nouvelle-Grenade; province d'Ocaña, dans les forèts, à 2400 mètres environ d'altitude. (L. Schlim, no 621 .)

(bimensions : longueur des pinmules 18-20 centim., sur 8-9 d'enrersure; pinnelles de la lots mesurant 5 centim., sur 2 centim. de longueur, séparées les unes des autres par un intervalle de $\overline{7}-$ !) rentim. Les pinnelles ne portent qu'un petit nombre de sporothèces, distants les unes des autre's d'environ 3 à 5 millim.)

Le $n^{0} 54$ du même auteur, provenant de la mème localité, ne nous parait ètre qu'une simple forme de celle plante.

YVIII. Citrysolepis, F. - L'A. a ÉCAilles dorées.

Frondes bi-tripinnées, délicates, triangulaires, couvertcs de tuutes parts de poils cendrés, courts et serrés, qui leur donnent un aspect tomenteux; pinnules infërieures portant deux pinuelles pédiaires; toutes sont sessiles el à partitions obtuses. Segments fortement crénclés, ovalcs et chargés de J゙, \& ou j paires de sporotliéces: indusium cordiforme; stipe moins chargé de poils que le rachis; le rlizome, qui est rampant, tire de la présence de magnîịues écailles dorées, formant un épais coussinct, un caractère de beauté très-remarquable; elles sont luisantcs, étroitement lancéolées et à marge entière; la parlie inféricure du rhizonte porte des fibrilles courertes rlc longs poils soycux, de mème conleur que les écrilles.

Cap Vert. (Wech.)

(Dimensions : longuenr de la fronde 40 centim.; pinnules inferiemess 17; rcailtes a centin.: proils des radicelles $6-7$.)

XIX. Dissectum, F. - L'A. a Fronde disséquée.

Fronde quatre on cinq fuis pinnéc, orale, glalıce, à pinnules étalécs, ovaleslancéolées; derniers segments ovales, gibbeux supérieurement, trés-petits, chacun d'eux porte un seul sporollıèce, rer's la partie sıpérienre. L'indusium est brınàtre; l'anneau porte 18 arliculations; les spores sont papilleux.

Nouvelle-Grenade: province d'Ocaña; dans les Paramos de San Pedro, à environ 3500 mètres d'altitude. (L. Schlim, $\left.n^{0} 323.\right)$

(Dimensions : Iongneur 65 centim., et probablement davantage; rachis et racheobles canaliculés: pinnules primaires 18 a 20 centim.; pinnules secondaires 6 centim.) 
Celte espèce, très-curieuse et très-distincte, qui s’éloigne de toutes ses congénères, est nettement caractérisée par son nom spécifique.

\section{CYSTOPTERIS, Bernh.}

(Voy. plus haut, p. 65.)

\section{Daliousiana, F. - La Cistoptéride de lady Dalinousie.}

Fronde quadripinnée, grêle, oroüde, disséquée, très-glabre, à derniers segments bifides, linéaires, falciformes, inégaux, pointus, portant à la base de la bifurcation des sporothèces lâchement unis; indusium court, blanc, très-mince; spores l'éniformes.

\section{Ceylan. (Iady Dalhousie; herbier Graham.)}

(I)imensions : longueur 30 centim. environ; les pinnules, très-pointues, ainsi que toutes les divisions de la fronde, mesurent 7 centim. Le stipe est blanchatre.)

\section{NEPHRODIUII, Presl.}

\section{Oppositum, F. - La Nepirodie a pinnules opposées.}

Frondes ovales-lancéolées, molles, villeuses, presque laineuses, pinnées-pinnatifides, à pinnules lancéolées, sessiles, aiguës, entièrement fructifiées; les inférieures décroissantes, réfléchies; stipe et rachis blanchâtres, lisses et velus; nervilles simples, les trois supérieures stériles; sporothèces 4-5 sur chaque segment; indusium villeux, cordiforme.

La IIartinique. (IIlle Rivoire.)

(Ihimensions : longueur 60 centim. el plus; envergure 17 centim.; pinnules 11 millim. de largeur; elles sont longuement acuminees, et la pointe est fertile.)

Il. Scimffyeri, F. - La N. de Schiffener.

Frondes simples, ovales en leur pourtour, glabres, sèches; stipe très-long, canaliculé; frondules stériles, ovales-lancéolées, notablement pétiolées, ayant un long acumen entier; frondules fertiles sourent plus étroites, les unes et les autres cunéiformes à la base et portant des nervures saillantes, simples; les basilaires longues ne s'unissant pas toujour's; lames criblées de très-petites ponctuations; toutes les nervilles sont fructifëres; sporothèces presque marginaux, toujours ristincts, petits; sporange réniforme, altachée obliquement.

Ilexique; Barranca de San Francisco, près de Mirador. (W. Schaffner, $n^{0}$ 244.)

(Dimensions : 75 centim. Le slipe est à la lame : : $3: 2 ; 7-8$ paires de frondules; celles-ci de grandeur variahle, mesurant de 20 à 30 centim. de longueur, sur 4-7 de largeur.) 


\section{DAVALLIEES.}

\section{MICROLEPIA, Presl.}

Effusa, F. - La Microlépide dilatée.

Fronde tripinnée, très-glabre, souple, orale, pyramidale en son pourtour; stipe et mésonèvre rougeâtres et lisses; pinnules ovales-lancéolées, flexueuses, trèslonguement acuminées, acumen fertile; pinnelles de la base ovoïdes, à segments inférieur et supérieur plus longs; segments en ellipse allongée , fortement crénelés, obtus; sporothèces presque marginaux, largement ouverts à leur sommet, fructification universelle, toutes les nervilles de la fronde, sans exception, étant fertiles.

Pulo-Pinang. (Lady Dalhousie; herbier Graham.)

(Dimensions : Iongueur 60 centim., sans le stipe qui est Ironqué; les plus longues pinnules 25 centim. arec des pinnelles basilaires qui mesurent $5-6$ centim.)

Toute celte plante, qui est fort belle, a en herbier une teinte rougeâtre trèsloncée; les sporothèces se devinent sur la lame supérieure aux bosselures arrondies très-saillantes quïls déterminent.

\section{ALSOPHILEEES.}

\section{ALSOPHILA, R. Br.}

\section{Schifficieriaxi, F. - L'Alsopullie de Schaffier.}

Frondes....; pinnules ovales - lancéolées, terminẻes en pointe aiguë, pédicellées; rachis bombé, lisse et glabre inférieurement, sillonné en dessus et à sillons remplis de poils fauves, laineux, très - abondants, intestiniformes et articulés; pinnelles glaucescentes, lancéolées, arquées en dedans, très-découpées, aussi couvertes de poils laineux; segments linéaires-pinnatifides, portant sur clıque découpure un sporothèce, dont les sporanges sont làchement unies; l'anneau, dont l'obliquité est très-peu prononcée, a une trentaine d'articles épais; les spores sont triédriques.

Mexique; San Martin, près de Huafusco. (WV. Schaffner, n²32.)

(Dimensions : hauteur du trone 2 mètres à 2 mètres $1 / 2$ (Schaffiner); la pimnule sur laquelle nous établissons notre diagnose, n’a pas moins de 50 centint. ; les pinnelles, au nombre de 30 environ, sont lancéolées, à segments élroits, nombreus.)

II. Alrea, F. - L'A. A Frutits dorés.

Frondes.... ; pinnules glabres; rachis rougeâtre, portant quelques poils ; pinnelles lancéolées, sessiles, écartées, avec une pointe stérile un peu ondulée; seg̣nent basilaire inférieur fort petit et ovale; lames entièrement couvertes de sporothèces dorés, serrés, connivents, au nombre de $\bar{\jmath} 7$ sur chaque côté du mésonèvre; on 
troure, mêlés arec les sporanges, dont l'anneau est très-épais, oblique et composé de vingt articulations environ, des poils intestiniformes et des écailles; les spores sont trigones.

Cyathece spec. (Schaffner, in Litteris.)

Arbre épineux qui s'élève à plus de dix mètres (Schaffner).

Iexique; près de Cordoba, à mille mètres d'altitude, trouvée par II. Rozl. (II. Schalfner, n 264.)

\section{HEMISTEGIA, Presl.}

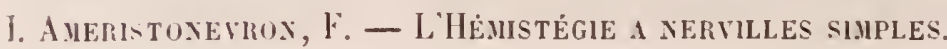

Frondes....; frondules pinnées, gllabres, cartilagineuses; pinnelles lancéolées, sessiles, obtusiuscules, à segments très-obtus, peu profonds, à nervilles en saillie, simples; les basilaires très-longues; sporothèces pelits, écartés, toujours dislincts; dix environ sur cliąue moitié des lames.

Guyane française. (Poiteau.)

(Jimensions: Iongueur des frondules $14-17$ centim., sur 3 centim. de largeur.)

Nous avons négligé à dessein de noter un caractère, lequel, s’il est constant, serail extrêmement remarquable. On troure près des mésonèvres des bosselures (unlla) irrégulièrement arrondies et universelles. Kuxze rapporte cette espèce curipuse à l'II. spectabilis, dont les nervilles sont bifurquées ct toutes prolifères, ce fui double le nombre des sporothèces.

NB. Nous derons encore appeler lattention des botanistes sur une espèce récoltír, dans les Indes-Orientales, par lady DALıocsie; à frondules articulées, pélinlées; à segnments contractés à la base; sporothèces indiqués sur la lame supél'ieure par des enfoncements très-marqués; nous en faisons l'H. contracta, F.

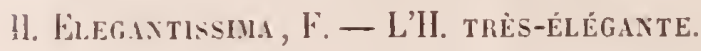

hachis robuste, couvert de poils cylindriques épais, solides, articulés, opaques, de structure spéciale, ayant l'aspect de la sciure de bois; frondules nombreuses, alternes, luisantes, glabres, olivâtres inférieurement, brunes-rougeâtres supérieurement, à nervures hasilaires formant une courbe à large ellipse, les latérales simples, à sommet terminé en une longue pointe dentée; les segments obtus sont si peu profonds que la lame a une apparence crénelée; sporothèces, 6-8 paires: sporanges pyriformes; $10-12$ articulations seulement à l'anneau; spores irrégulièrement trièdres.

Mexique. (Linden.)

(Dimensions : longucur des frondules 40 centim. el plus, sur 4 de largeur.) 


\section{CYATHÉES.}

179. CYATHEA, Sm.

I. Hexaguxa, F. et Scliaffn.

Frondes glabres; stipes et rachis à écailles éparses; pinnules orales-lancéolées; pinnelles lancéolées, glaucescentes en dessous; à sommet aigu, denté - crénelé, à segments ovoïdes, légèrement arqués, crénelés; sporothèces sous-marginaux; indusium pellucide, mince, fragile; anneau oblique, large; spores trièdres, à surface d'apparence striée.

Vexique; près IIuatusco. (W. Scliaffner, n" 237.)

(Dimensions : tronc hexagone, complétement lisse, inerme, sans cicatrices, d'une hauteur de 8 - 10 mètres.)

Il. Articulata, F.

Stipe de la fronde, de la grosseur du pouce; armé inférieurement d'épines droites, noires, luisantes et robustes; pinnules articulées sur le rachis dont elles se détachent facilement; elles sont ovales - lancéolées, à rachis tomenteux en dessus, garnies de pinnelles sessiles, assez écartées, prolongées en queue, glabres et colorées en brun-rougeâtre par la dessiccation; sporothèces attachés au mésonèvre des segments; anneau oblique, portant 12-14 articulations; indusium extrêmement ample; spores triérlriques.

Vexique; Villa-Alta et Talea. (Galeotli, $\mathrm{n}^{0}$ (i531.)

Cetle espèce est remarquable par ses pinuules articulées sur le rachis, comme le sont les frondes de plusieurs polypodiées sur leur rhizome. 


\section{REIIARQUES SUR DIYERS GENRES DE LA FAIILLE DES POLYPODIACÉES.}

\section{ACROSTICHÉES.}

F., Gen. filic., p. 41 .

1. Acrosticium, F. - Ce beau genre s'est considérablement accru depuis quelques années, particulièrement en espèces américaines, étudiées pour la plupart par M. Klotzsch (Limnea, XX, ann. 18/7). Nous venons d'en décrire (pag. 67 et suiv.) plusieurs autres, presque toutes mexicaines. Il est raiment merreilleux le voir des formes aussi variées llans un genre à type aussi simple; mais qui ne connait l'admirable variété des curres le la nature, ainsi que l'étendue de ses ressources, qui sont infinies!

Nous avons dit ailleurs que nous avions cru devoir conserver le nom d’Acrostichum à ce genre, l'un des plus nombreux de la famille, afin de ne pas trop inultiplier les synonymies déjà si nombreuses. Nous regrettons que cette consilération n’ait pas rallié à notre opinion un plus grand nombre de botanistes, car il en est encore qui conservent le genre Elaphoglossum, pour ne donner le nom d'Acrostichum qu’au plus petit nombre des espèces réunies par nous dans notre genre Chrysodium.

Comme genre, l'Acrosticlum est parfaitement distinct et très-nettement limité, mais la distinction des espèces présente d’assez grandes difficultés. Nous avons dit (Hist. des Acrost., p. 8), que les frondes étaient lomomorphes et diplotaxiques, c’est-à-dire, de mème forme, mais à fructification séparée, les frondes étant, les unes stériles et les autres fertiles. Les frondes ne deviennent prolifères que par arrèt de développenent, aussi sont-elles, en général, de plus petite dimension; mais ces différences sont très-variables, et les rapports de grandeur difficiles à établir. Il faut s’aider du rhizome, que l'on n’a pas toujours ou que l'on a incomplet, ainsi que de la squammescence, en se rappelant toutefors que dans les herbiers les écailles se détachent et font souvent d'une plante très-squammeuse une plante chaure.

C'est ici le licu de payer un tribut public de gratitude à M. W. Scinffacr, pharmacien au Mexique, qui nous a généreusement enrojé près de trois cent

1. Ces numéros d'ordre correspondent à ceux du Genera filicum. 
cinquante espèces de fougères mexicaines récoltées avec un soin admirable, ce botaniste n’ayant négligé aucun moyen de compléter chaque espèce par de nombreux spécimens. Plantes avec rhizome, jeunes ou adultes, développées sur des terrains de toute nature et soumises à des influences opposées, enfin tout ce qui peut servir aux diagnoses, a été réuni de manière à laisser sans excuses les fautes dans lesquelles peut tomber le botaniste sédentaire. Ces fougères nous ont été d'un grand secours, et il en est résulté des observations et des rectifications que nous avons cru devoir consigner dans ce Mémoire.

4. Polybotrya, B. - M. Tu. Moore, dans soll Genera filicum (1857) place dans ce genre le genre Microstaplayla de Presl, que nous avons adopté. Il ('n fait donc une Acrostichée, mais les sporanges étant nervillaires, ce rapprochement, assez bien indiqué par le port, ne peut être accepté comme suffisamment fondé. (Voyez plus haut, p. 45.)

6. Rhipidopteris, Schott. - Il arrive parfois que la lane fertile devient multilobée, comme pour se rapprocher de la lame stérile, qui est multipartite.

19. Nevroplatrcerios, Pluck. - Ce même botaniste a créé, entre les Acrostichées et les Lomariées, un groupe intermédiaire, les Platycériées, dont ce genre est le type. Nous l'acceptons volontiers, composé de ce seul genre. Mais il nous semble que le Dryostachyum ne peut pas être séparé des Polypodiées, et que le Jenkinsia, s'il n'est pas une Vittariée, ce que nous ne pouvons décider, n’ayant jamais ru cette plante, doit bien plutòt prendre place à còté des Drynaria, dans ce même groupe des Polypodiées.

\section{VITTARIÉES.}

$$
\text { F., Gen. filic., p. } 85 \text {. }
$$

31. Cuspidaria, F. - Ge genre, fort naturel, n’a que des espèces à nervilles anastomosées. Dans le C. furcata, F., l'union des nervilles s'opère près de la marge par une courbe, et dans le C. subpinnatifida, près du mésonèvre. Cette particularité a paru suffisante à M. J. Surti (Bot. du voy. d'IIerald, Ic., 232), pour constituer un genre Dicranopteris, qui peut-être eût dù conserver le nom de Cuspidaria. (Voyez la Monographie des Villariées, p. 25 et suiv.)

\section{PTÉRIDÉES.}

$$
\text { F., Gen. filic., p. 12't. }
$$

42. Pteris, L. - Les espèces suivantes donnent lieu à quelques remarques: $1^{\circ}$ P. flaccida, Bory, de Saint-Domingue, qui frgure dans l'énumération des espèces données dans le Genera filicum, p. 125, ne semble différer du P. hirsuta, Lmrk., 
que par la consistance, s'étant développée très-probablement dans des lieux lumides et ombragés.

2o P. Iriphylla, Mart. et Gal., Foug. mexic., p. 51 , pl. 14, fig. 1, est une espèce parfaitement distincte; nous avons pu nous assurer que le caractère spécifique était constant; mais comme il existe déjà un P. triphyllı, Igarılh, genre Pteris, p. 18, plante de Madagascar, le nom dunné pour la plante mexicaine doit être cliangé en celui de P. trifoliatu.

$3^{\circ}$ P. propinqua, J. Sm. (Cuming, Filic. Plhilipp., n" 409), recueilli à .lalacca n'est pas non plus la plante portant le même nom, clıez 1 gardh, genre Pteris , p. 65 . l'espèce de J. Smith est irrégulièrement divisée, et le nom de $P$. incequalis pourrait lui ère très-convenablement appliqué.

$4^{0}$ P. pellucens, J. Sm. (Cuming, Filic. Plilipp., nº 8), n'est pas le P. pellucens d'Igardh (genre Pteris, p. 13), duquel cet auteur dit : Frondis ternatce ramis sulsimplicibus... laciniis lineari-oblongis. Nous en faisons le P. Plitippinensis, à fronde ovoïde-lancéolée, lipinnée à la hase; à frondules pétiolulées, lancéolées, caudiformes au sommet; à segments oblongs, denticulés; à sporothèces ni basilaires, ni terminaux.

$5^{\circ} P$. aquilina, L., non-seulement croit-elle dans presque tous les terrains, mais encure dans la plupart des régions du glole; elle est aussi très-polymorplıc. On la trouve au Ilexique, ayant les segments caudifères glabres; avec pétiole et raclis rougeàtres. Nous en faisons une var. $\beta$. mexicamu.

43. Pellata, Lk. - Ce genre correspond au genre Plaryloma de M. J. Sinitl. Il est impossible de décider lequel, de cet auteur ou de Link, doit avoir la priorité; la fondation des deux genres ayant eu lieu en 1841; le Species filicum de Link, donnant la description létaillée de cing espèces, semble le présenter avec un caractère plus imposant.

У. Tir. Moore, dans son Inlex filicum (1857), conserve ce genre Platylomu, J. Sm.), et il en fait le type d'un groupe distinct, les Platylomées, quoiquiil soit uni aux Pléridées, par les plus étroites analogies.

Les espèces suivantes domnent lieu à quelques observations:

$1^{\circ}$ P. cordula, indiqué dans le Genera filicum, p. 130, est celui de Sieber et non celui de Cavanilles. La première espèce est africane et l'autre américaine.

20 $P$. atro-purpuren et temifolin, espèces bipinnées: se présentent quelquefois simplement pinnćes de manière à faire croire à des espèces distinctes.

$3^{\circ}$ P. temifolia, Lk.: nous possédons cette plante du Mexique, avec un fracies tout particulier, qui rappelle les Galium; les frondes jeunes sont couvertes d'une si grande quantité de poils cotonneux, blanc-de-neige, que l'on croit aroir sous les yeux une petite touffe de coton posée à l'extrémité d'un support; cette particularité devient d'antant plus singulière que le pétiole est glabre. Sans doute, cette forme est une 
espèce distincte; elle a été récoltée près de San Angel par II. W. Schaffner ( $\mathrm{n}^{0} 321$; 1855). On retrouve ces poils cotonneux, articulés d'espace en espace, sur le rachis de la plante adulte. Lorsqu'il aura été possible de comparer d'autres spécimens de cette plante avec le $P$. ternifolia, il y aura peut-ètre lieu de reconnaitre, comme espèce, un $P$. lanuginosa.

55. Onychiun, Klfss. - Il existe entre ce genre et le Phorolobus des rapports que déjà nous avons indiqués (Gen. filic., p. 131). Mais le genre Phorolobus est diplotaxique et l'Onychium monotaxique; ce qui les sépare encore et plus complétement: c'est la présence de nervilles sur Yindusium du Phorolobus.

Parmi les espèces admises dans ce genre, il en est de paradoxales; telle est l’O. Capense, qui a le port d'un Acropteris. Et l'O. robustum, qui est un Allosums pom. Kuxze, plantes, lune et l'autre fort ambiguës et très-difficiles à classer.

59. Ayphiblestra, Pr. - Le port de l’unique espèce de ce genre rappelle celui des grandes espèces de Bathmium et de Cardiochlona. La nervation est pareille, quoique la fructification soit bien marginale et rigoureusement la mème que celle des ptéridées; on trouve çà et là, sur les frondes, et près de la marge, des sporothèces arrondis, nus et semblables à ceux des polypodiées. Ils sont épars et naissent sur un plexus de nervilles, comme dans les drynaria. C'est un fait curieux que nous derions signaler.

\section{CHEILANTHÉES.}

61. Adintopsis, F. - Nous croyons devoir faire rentrer dans ce genre, le Cheilanthes pteroides de Swartz, et le diviser en deux sous-genres, destinés à établir les rapports qui existent entre les genres Adiantum et Cheilanthes.

\section{Euddiaxtopsis (Adiantastrum).}

Radiata (Adiantum, Auct.) - paupereula (Adiantum, Kze.*Hypolepis, Ilook.*); Pteroides (Cheilanthes, Sw.; Casebeeria, Presl.).

2. Cheillantilastrum.

Capensis (Adiantum, Thunb.) - ellorophylla (Cheilanthes, Radd.) - speetabilis (Cheil. Brasiliensis, Radd.; Iyypolepis, Lk.)

63. Mrriopteris, F. - Les espèces de ce genre prennent place parmi les plus élégantes de la famille des fougères. Les frondes sont attachées sur une souche (H. paleacea, F.; Cheilanthes lendigera, Hooker non Sw.), sur un rhizome flexueux très-allongé (M. villosa, F., C. lendigera, Sw.) ou bien sur une racine fibreuse (M. gracilis, F.). La tendance de la marge des frondules à s'infléchir sur les sporothèces de l'extérieur à l’intérieur est très-manifeste, et il en résulte des plicatures très-diverses. Dans la jeunesse et à l'état stérile, les frondules sont planes et translucides, comme dans les Cystopteris. Elles s’épaississeut en devenant 
fructifères, et la marge repliće, tantôt se modifie et tantôt ne se modifie pas. Les sporothèces se dérobent donc plus ou moins complétement à l'action de la lumière, et s'entourent en outre d'une bourre abondante. Ces frondes sont tantôt écailleuses et tantôt villeuses.

Il règne une certaine confusion parmi les auteurs en ce qui concerne le C.lendigera, cultivé dans nos jardins. Nous n'avons vu cette plante que privée d'indusium, et Swartz lui en attribue un (Syn., p. 328). Link (Spec.filic., p. 66), qui arlopte la synonymic de Swartz, place cette plante parmi les espèces à marge réfléchie sur les sporanges et ne dit rien de l’indusium. C'est donc une autre espèce, af nous lui avons donné un autre nom. II serait possible, au reste, que les deux plantes, celle de Swartz, avec indusium, et celle de Link, sans indusium, fussent l'une el l'autre cultivées sous un même nom.

Deux Nothochlcena, le $N$. lamuginosa, Desv., et le $N$. Plukenetti, mieux étudiés, me paraissent devoir rentrer dans le genre Myriopteris. Ces plantes sont divisées en lobules pareils à ceux des autres espèces; mais comme ils sont unis entre enx par une épaisse couche de tomentum, ces lobules paraissent infiniment plus développés qu’ils ne le sont en réalité. (Voy. pag. 40.)

De tout ce qui précède, il résulte la nécessité d'établir comme il suit la nomenclature des espèces.

1. EuMYRIOpteris.

(Margine in indusio Iransformala.)

Marsupianthes* (Cheilanthes lendigera, Mart. et Gal., $n^{\circ}$ 6256, non Auct.) - villosa (Ch. lendigera, Sw. non Link.; Pleris, Cavan.) - minor (Cheilanthes, Mart. et Gal.*) tomentosa (Cheilanthes, l.k., kze.; Nolhoehlena, J. Sm.) - rufa, F.

\section{Cuemlatimastrum.}

(Jlargine pro indusio.)

Scariosa (Chcilanthes, Kaulf.) - paleacea (Cheilanthes, Mart. et Gal.; C. lendigcra, Link et Ilortor.; Ch. myriophylla et C. clegans, Desv., Journ. Lot., IV, 13*) - gracilis* (Ch. vcstila, Richl, non Sw.) - indula (Cheilanthes, kze.) - contracta (Ch. hirla, var. conIracla, Kze.) - intermedia (Ch. hirla $\beta$. intermedia, Kze.) - chciloglyphis, F.).

66. Lleuritopteris, F. - Les espèces de ce genre, toutes étroitement unies, sont difficiles à caractériser. Il faut bien plutôt en réduire le nombre que de l'augmenter. Vues avec des proportions différentes, clles ont pu paraître distinctes quoiquil en soit autrement. La couleur de la sécrétion séreuse a paru déterminante, sans l'être en effet. Il existe des nuances nombreuses de couleur depuis le jaune 
vif jusqu'au jaune pàle, bien voisin de la teinte blanche. C'est là ce qui explique, comment nous avons pu dire en parlant de l'A. Mexicana (Gen. filic., p. 154): lamina inferiore granulis cerineis albidis cooperta, au lieu de dire; granulis cerincis sulfureis. De nombreux spécimens du Mexique, dus à la générosité de M. Schaffner, nous permetlent de nous rectifier. Si done l'A. dealbata a pour caractère constant la couleur blanche de la sécrétion, on ne la trouverait pas au Mexique, où elle serait remplacée par l'A. Mexicana, et la patrie de cette espèce serait restreinte aux Indes-0rientales. L'A. argyrophylla, qui n'en est qu'une simple modification, serait particulière à l'ìle Bourbon. Quant à la plante de l'herbier d'Abyssinie, récoltée et éditée par Schimper sous le $n^{0} 1123$, nous ne voyons aucune différence essentielle- entre elle et l'A. Mexicana. La planche 138 des Icones filicum, de MM. Hooker et Gréville, reproduit l'A. farinosa, espèce bien distincte, aujourd'hui cultivée dans les jardins d’Argleterre. Par suite des remarques qui précèdent, nous établissons comme il suit la concordance synonymique des Aleuritopteris.

\section{LAMinis SUbtUS PULtere alBo CONSPERSIS.}

Argentea (Cheilanthes, Kze.; Pteris, Auct. plurim. Langsd. et Fischer*) - argyrophylla (Pteris, Bory) - dealbata (Cheilanthes, Desv., C. farinosa, Ilook. el Grev., șnonym. plurib. exclus.*) - candida (Cheilanthes, Nart. et Gal.) - pulveracea, Presl (Casebeeria, J. Sm.) - Indica, F., Gen. filic., p. 154.

2. Layinis stbTts PLLtere FlaVidelo CoNspersis.

Sulfurea (Pteris, Cavan. - Ilexicana, F., Gen. filic., loc. cil.; Cheilanthes dealbata, Schimper non Desv.; Fl. Abyssin., $\mathbf{n}^{\circ} 1123$ ).

67. Cineilanthes, Sw.

Le C. 'Chcrophyllum, Ilart. et Gal., Fougères mexicaines, $\mathrm{n}^{0}$ 6367, sub Allosoro, n'est pas la fougère cultivée sous ce nom à Leipzig, telle, du moins, qu'elle nous a été communiquée par Kunze. Elle se rapporte à une fougère, aussi du Nexique, dont nous avons fait un C. chcerophylloides. Nous possédons un herbier de nombreux spécimens des deux plantes, et il nous a été facile de reconnaitre qu'elles étaient parfaitement distinctes.

Le G. Malaccensis, F., Gen. filic., p. 157, a eté réuni au C. Griffthiana, loc. cit. (Voyez plus haut, p. 36.)

\section{Nothochlena, R. Br.}

Les $N$. sinuata. Ilfss., et $N$. loxvis, Mart. ct Galeotti, sont des espèces très-ruisines. La radication est la même, ainsi que la nature des écailles qui recouvrent un rhizome arrondi, ayant une apparence bulbeuse. Le $N$. lavis est bien plus rare que l'autre; il a des frondules plus épaisses, plus arrondies, toujours 
glabres en dessus, tandis que dans le $N$. sinuata la lame supérieure porte des écailles semblables à des poils étoilés. Est-ce suffisant pour constituer deux espèces?

Les $N$. ferruginea, Willd, et $N$.rufa, Presl, solt réunies avec raison. C'est une plante polymorphe qui varie fréquemment dans la couleur et les dimensions.

\section{IIÉMIONITIDÉES.}

$$
\text { F., Gen.filic., p. } 164 .
$$

71. Botryogramue, F. - M. Hoorer a publié, dès 183̈8, ce beau genre sous le nom de Ceratodactylis, el M. J. S.ıтt, qui l’a créé, lui a donné le nom de C. osmmndoides. L'antériorité ne nous appartient donc plus et il nous reste à expliquer comment nous n'arons pu reconnaitre notre plante, comme identique arec la planche XXXYI de l'ourrage du botaniste anglais.

Notre justification se trouve tout entière daus l’inexactitude des détails donnés dans la planche cilée plus haut. Ia figure 6 montre sur la frondule une nervure perpendiculaire au mésonèvre, qui coupe les nervilles, lesquelles sont en réalité lilıres jusqu’à la marge. De plus, la diagnose indique des sporothèces arrondis, tandis qưils sont linéaires et continus, les nervilles étant prolifères dans toute leur éteıdıe. A l’époque de la maturité, les sporanges, toujours extrèmement nombreuses, se touchent, et la frondule prend l'apparence d'une Icrostichéc. En outre, la figure 7 reproduit un anneau complet, ce qui ne pent être; cnfin, les couleurs ne peuvent se rapporter à la plante vivante, ni màme desséchée dans les lierbiers. Nous ajouterons encore que le nom de Ceratodactylis osmundoides donne l'idée d'une plante ì segments digités el raides; du reste, clle ne ressemble nullement à l'Osmunda regalis, ressemblance qui lui aurail valu le non spécifique donné par M. J. Sмпт.

Au reste, la priorité du genre n’appartiendrait ni à M. Suru, ni à nous, mais bien à Lagasca, qui a fait de cette fougère le type de son genre Llavea (Gen. ef Spec., pl. 33 .

84. Grumograme, Desi. - Ce genre, si justement démembré, repose sur des caractères légers et pourrait, sans trop (linconvénients, être réuni au genre Plegopteris; si cette opinion était admise, il faudrait peut-être y faire entrer le goure Anogramme. Dans le genre Phegopteris, renfermant des fougères semblables de port à des Aspidium, et à sporothèces nus, les sporanges en se groupant forment des sphérö̈des, d’une manière beaucoup plus générale que dans les Polypodimm, qui presque tous constituent des ellipses. Les Gymnogramme seraient donc des Phegopteris, dont les sporothèces tendent à l'élongation. 
Mais cette tendance n'est pas égale chez tous; ce qui est universel, c'est le petit nombre de sporanges qui composent ces groupes et le peu d'adhésion de chacune d'elles; on pourrait dire même que dans quelques espèces elles sont éparses; ajoutons que, faiblement adhérentes à la lame, le moindre frottement les en détache; mais ce ne sont pas là des caractères de genre.

Les auteurs qui s'occupent des fougères conservent le genre Gymnogramme, et, au licu de le restreindre, comme nous avons cru devoir le faire, ils en étendent considérablement les limites. C'est pourtant l'un des plus artificiels de la famille.

85. Ceropteris, Lk. - Toutes les espèces de ce beau genre d'une si facile détermination, en raison de l'exsudation de nature céreuse qui recouvre la partie inférieure des frondes, appartiennent à l'Amériqug tropicale; elles sont surtout communes au Mexique.

Beaucoup d'auteurs en font des Gymnogramme, quoique le port soit bien différent, et que les sporothèces aient une situation tout autre. Ils occupent la partie supérieure des nervilles prolifères, que souvent ils envahissent en totalité, sans avoir aucun point d’élection particulier.

Ces fougères ont le facies des Aspidium; il n'y a point parmi elles de frondes pédiaires. Les sporanges sont en quelque sorte empâtées dans la sécrétion céreuse, qui leur a valu le nom qu'elles portent. Les frondes sont d'ordinaire glabres, et les écailles ne s'élèvent guère au-dessus du rhizome; la sécrétion en tient licu, et les frondes semblent sêtre épuisées à la produire.

Elles prospèrent dans les jardins botaniques, et la facilité avec laquelle se déreloppent leur's spores, s'oppose très-souvent au déreloppement des spores des autres espèces de fougères qu'on y sème.

Lisk a désigné diverses formes comme provenant d'hybrides, et ce célèbre botaniste en a indiqué deux entre autres sous les noms de Martensii et de Massoni.

Il pouvait sembler extraordinaire alors de voir le mot hybride, attribué à des fougères qui n'ont point d'organes sexuels; mais la découverte de M. de Suminski, de laquelle il résulte que chez ces plantes existent des anthéridies et des pistilidies, les uns regardés comme organes màles et les autres comme organes femelles, ainsi que la présence d'un embryon qui serait fécondé, rendent maintenant le fait possible; ce qui arrive dans nos jardins pourrait fort bien se produire dans l'ordre naturel; aussi croyons-nous avoir reconnu des hybrides mexicaines spontanées, mais qu'il n’est possible de déterminer que sur les licux. 


\section{ASPLÉNIÉES, F.}

87. Atryriuy. - Le type auquel se rattachent les Athyrium est très-uniforme; ce sont de grandes plantes, à frondes toujours glabres, très-divisées, d'une texture extrèmement délicate, à segments dentés ou incisés. On ne comprend guère comment certains auteurs, en refusant de conserver le genre Allyrium, conservent le genre Allantodia, dont la réunion avec les Athyrium, semble impérieusement commandée.

Nous appelons l’attention des botanistes sur les espèces suivantes:

$1^{\circ}$ A. incisum, F., Gcn. filic., p. 187, trouvée dans le Berry; nous a été adressée de l'Amérique septentrionale. C'est une forme extrêmement étroite de l'A. Filix-famina.

20 A. Michauxii, F., Asplcnium, Auct. Se trouve au Mexique avec des formes très-diversifiées; elle ne parait pas différer' de l'Asplcnium angustum, de Willdenow.

$3^{\circ}$ A. corsicum, F., se rapproche des Allantodia des iles du Cap Vert.

$4^{0}$ A. scandicinum, Klfs., sub Allantodia, de Bourbon, et l'A. Poirctianum, Gaud., réunis jar Presl, Epim. bot.. p. 67, ne nous paraissent pas identiques.

88. Asplexiuy, L. - Les espèces suivantes donnent lieu à quelques obselvations :

$1^{\circ}$ A. mclanocaulon, Willd, de l'Amérique septentrionale et du llexirue, est le représentant de notre $A$. Trichomanes, Sw., auquel il peut être réuni, ainsi quele proposent plusieurs auteurs. C'est une forme un peu plus délicate et plus petite dans toutes ses proportions.

$2^{\circ}$ A. Adiantum-nigrum, L., est réuni, par Kunze, à l'A. Serpentini, Tausch. et Presl. Nous croyons ces deux espèces distinctes.

$3^{\circ}$ A. acutum, Bory, n'est sans doute qu'une forme de l'A. Adiantum-nigrum, L., assez distincte pour constituer une variété.

Les A. Adirntum-nigrum, L., et A. furcutum, sont deux types, auxquels se rattachent plusieurs formes regardées comme espèces par les auteurs.

Mlème observation pour l'A. auritum, Sw., et par l'A. Mexicanum, Mart. et Gal.

4. A. pendulum, F., Gerr. flic., p. 196 (1850), est la même plante que l'A. harpeodes, Kze., Linnow XVIII, p. 329 (1844). Il résulte donc des dates que l'antériorité appartient à Kunze.

89. Hypochlanys, F. - Le caractère sur lequel est basé ce genre est uniquement tiré de l'indusium. Ce tégument protecteur, au lieu d'être attaché à 
la partie supérieure et latérale de la nerville, comme dans tous les genres du groupe des Aspléniées, s'attache vers la base, de manière à recouvrir, en se redressant, non-seulement les sporanges, mais encore le point de la nerville sur lequel il se fixe. C'est pourquoi nous lui avons donné le nom de Hypochlamys, qui équivaut à celui de indusium infère. Dans les genres à indusium double, Scolopendriées et Diplaziées, les nervilles sont fructifères en dessous et en dessus; mais les indusium des nervilles fixés par le bas se dirigent dans le sens de leur attache. Dans l'Hypochlamys, au contraire, il se redresse pour aller recouvrir les sporanges. Cette singulière disposition, qui demande beaucoup d'attention pour être reconnue, permet de dire que l'indusium est véritablement infère, el que les sporanges sont supères. Dans les Allantodia, devenus pour nous des Athyrium, l'indusium est tout autrement situé.

Ce caractère important tiré de lindusium excepté, les espèces de ce genre sont, par le port et par la manière dont ce tégument protecteur est bombé, de véritables Athyrium.

Le Diplazium Sorzogonense, Presl. Récolté à Leyte, des Philippines (Cuming, Filic. Philipp., no 301, est pour nous l'Hypochlamys Sorgonensis; l'indusium étant infère et les sporanges supères.

Les Hypochlamys conchatum et pectinatum, du Genera filicum, sont une seule et même espèce qui doit conserver le nom de Pectinutum; c'est par erreur que sur la planche XV'II, fig. 3, il a été écrit Conchatum pour Pectinatum.

94. Woodwardia, F. - Nous avons séparé ce genre en deux sections: Woodwardia et Doodya.

Dans le premier sous-genre, les frondes sont pinnées-pinnatifides, à segments dentés, portant à la marge des dents raides et cartilagineuses. Les nervilles sont dessinées en relief sur les lames. L'indusium est bombé, occupant l'aréole basilaire des frondes et celle des segments. La patrie de ce genre s'étend des Asturies espagnoles au cap Vert. Une espèce est mexicaine; une autre espèce, qui nous est inconnue, japonaise.

Dans le deuxiène sous - genre, les frondes sont pinnées ou pinnatifides, à frondes ou à segments frondulaires dentés; à dents raides, cartilagineuses; à nervilles dessinées en relief sur les lames, qui sont très-feraces. L'indusium plane ou légèrement bombé, assez court, droit ou arqué, ne remplit que rarement l'aréole basilaire fructifère; les sporothèces forment des séries simples et plus rarement doubles. La plupart des espèces habitent la Nouvelle-Hollande; quelques-unes sont néo-zélandaises ou javanaises. 
L'exposé de ces caractères inontre la nécessité de réunir les Doodya aux Woodwardia; la structure de la fronde, celle de l'indusium, la situation des sporothèces, tout rend nécessaire cette réunion. L'espèce qui unit les deux sousgenres est le Doodya blechnoides, All. Cunningham; Doodya maxima, J. Sm., devenu pour nous le Woodwardia blechnoides.

M. W. Schaffner nous écrit qu'il n'a jamais trouvé le $W$. radicoms, var. $\beta$. Mexicana à l'état radicant. Ayant vu de nombreux spécimens de cette belle fougère, nous croyons que c'est une espèce bien caractérisée, et nous lui restituons le nom de W. spinulosa, donné par MII. Martens et Galeotti, dans leur mémoire sur les fougères mexicaines, p. 64 .

\section{SCOLOPENDRIÉES, F.}

96. Scolopexdrium, Sw. - Le Scolopendrium mimus, F., espèce donnée avec doute comme pyrénéenne, appartient rraisemblablement à une autre localité. M. Pullipre, de Bagnères, a bien voulu nous envoyer plusieurs spécimens d'un Scolopendrium pyrénéen, de forme naine, stérile, récolté sur les flancs du Pic-du-Midi, à 2400 mètres daltitude, et il nous a été facile de reconnaitre lc S. officinarum, Sm., dégradé de ses proportions ordinaires, en raison de la grande élévation à laquelle il croit. Notre plante, dont toutes les frondes sont fructifères, est beaucoup plus étroite, sagittée à la base, à. nervilles plıs épaisses et plus serrées; la souche qui les porte a des écailles cancellaires, des stipes plus robustes et plus courts; il n’y a donc pas à hésiter, et l'on peut reconnaitre notre espèce comme parfaitement distincte de ses congénères.

\section{STRUTIIOPTÉRIDÉES.}

$$
\text { F., Gen.filic., p. } 226 .
$$

107. Ceratodactylis, J. Sin. - Nous avons dit plus haut, p. 117, que ce genre, placé par nous dans les Struthioptéridées, était le même que le genre Botryogramme, Gen. filic., p. 166, t. XV, C, et nous avons expliqué conment l'étude que nous avions faite de la planclıe de M. Bauer, dans le Gencra filicum, de M. Hooker, nous arait égaré. Maintenant que nous arons constaté l'identité des deux genres, il nous reste seulement à recomnaitre que le Ceratodactylis, Hoor., (Llavea de Lagasca), ne peut ètre placé dans les Adiantacées, subdivision des Adiantariées, où l'a placé M. Hooker, d’après M. J. Surth; il doit rester suivant nous, dans les Hémionitidées. Le groupe des Struthioptéridées se troure donc réduit à deux genres : Struthiopteris, Willd., type du groupe, et Onoclea, L. 


\section{VII. POLYPODIÉES.}

Nous avons fait remarquer, dans la préface du $7^{\mathrm{e}}$ Mémoire, à quel point M. Mettenius avait réduit les genres de ce groupe, et nous avons cru devoir nous élever contre cette prodigieuse concentration de genres, et, par conséquent, d'espèces. Les seuls genres qui aient échappé à la fusion sont les genres Phegopteris, Goniopteris, Lecanopteris, Aglaomorpha, Dictyopteris et Dryotachyon.

Ce groupe renferme quelques genres dissidents; il peut être partagé d'après le facies en plusieurs sous-groupes; savoir:

1. EUPOLYPODIÉES.

Plectopteris, F. - Cryptosorus, F. - Grammitis, Sw. - Polypodium, L. - Goniophlebium, Presl. - Campylonevron, Presl. - Niphobolus, Klfss. - Craspedaria, Link. Chrysopteris, Link. - Microsorium, Link. - Drynaria, Bory. - Pleuridium, F. Dryostachyon. J. Sm.

2. PHÉGOPTÉRIDÉES.

Phegopteris, F. - Goniopteris, Presl. — Dictyopteris, Presl.

Aglaomorpha, Schott.

3. AgLAOMORPHÉES.

4. DiptéridÉEs.

Dipteris, Reinw.

5. LÉCAXOPTÉRIDÉES.

Lecanopteris, Blum.

108. Plectopteris, F. - Il faut y attacher le genre Calymmodon, de Presl, lequel a pour type le Polypodium cucullatum, Nees et Blum, Nov. act., p. 121, t. XII, 3, devenu plus tard pour Blume, Fl. Javce, p. 119, tab. L, fig. 3, un Grammitis. Nous ne pouvions reconnaitre dans les figures plus haut citées, la plante recueillie à Luzon, des Philippines, et distribuée par Cuming sous le n 206. Le genre Calymmodon, de Presl, n’a point été admis par M. Metтexius, et pourtant il repose sur un double caractère, l'un physiologique et l'autre organique. Les sporothèces sont latéraux, attachés sur le còté supérieur de la nerville médiane; les sporanges sont donc dressés, et le côté infériẹr reste stérile. La moitié de la lame se redresse, se replie et va couvrir le sporothèce, pour l'abriter contre la lumière qu'il est dans la nature des organes reproducteurs de redouter. Cette plante est la seule dont les sporanges soient attachés sur le côté supérieur de la nerville, à l'exclusion de la partie inférieure, afin de faciliter le redressement de la moitié de la lame et de former ainsi une 
sorte de gaîne, parfaitement distincte. Si cette moitié se soudait, on aurait en petit l'organisation du légume, et la nerville serait un placentaire.

Nul genre ne nous semble mieux justifié. Il n'est plus monotype, et roici les deux espèces qu'il renferme:

\section{Plectopteris gracilis, $\mathrm{F}$.}

Gen. filic., p. 230, t. 19.

B. Polypodium cucullalum, var. $b$, Netten. Polypod., p. 33.

Fronde pinnatifide, molle, à segrments ciliés, tous distincts, et de mẻme forme; les fertiles une fois plus petits que les stériles.

\section{Plectopteris Calymiodon, $\mathrm{F}$.}

Polyp. cucullatum, Nées et Blum., loc. cit.

Xiphopteris, Spreng., Syst., IV, 43.

Grammitis, Blum., Fl. Javce, loc. cit.

Calymmodon cucullatum, Presl, Tentam. pter., p. 203, t. IX, fig. 1.

Frontle pinnatifide, coriace, à segments fertiles unilatéraux; les fertiles six fois plus petits que les stériles.

109. Criptosonus, F. - Ce genre diffère de tous les genres du groupe des Polypodiées par un caractère curieux, celui de l'immersion des sporanges et de leur situation sous-cuticulaire, et particularité curieuse suffisante pourla maintenir. Cfr., Gen. filic., p. 231, tab. X, fig. 3.

Il laut bien distinguer l'immersion totale et sous-cuticulaire de la simple dépression dans laquelle sont quelquefois logés les sporothèces de plusieurs espèces de Polypodiacées. On comprend, en effet, qu'il ne s’agit alors que d'un simple effet inécanique, tandis que la véritable immersion indique pour les sporohèces une tendance physiologique très-différente.

C. Dioncea, F., loc. cit.

II. Nettenius veut que cette espèce soit le Polyp. venulosum, de Blume, Enum. Fl. Iov", p. 128; ce botaniste, en parlant des sporothèces, dit subimmersis, submarginalibus; ce qui ne peut se rapporter aucunement à notre plante. Blume ne parle pas non plus des cils marginaux qui nous ont fait donner à ce Cryptosorus le nom spécifique, très-caractéristique de Dionaea. Nous croyons ḍonc notre plante aussi distincte comme espèce, que distincte comme genre.

110. Gramitis, Sw. - La valeur de ce genre réside particulièrement dans te port, la forme toujours linéaire et l'intégrité constante de la marge. Toutes les espèces sont fasciculées sur une petite souche, quelquefois annuelle. Le réceptacle est plus ou moins allongé. Les espèces, plus sourent villeuses que glabres, jamais écailleuses, n'acquièrent que de faibles proportions; le sacculus est souvent cou- 
vert de longues pointes. Il n’arrive pas, même accidentellement, que les frondes deviennent pinnatifides. Le G. furcata, lui-même, ne fait pas exception, puisque la division de la fronde a lieu par le sommet et non par la marge. Le genre Polypodium, avec lequel M. Mettrius le réunit, a d'autres tendances physiologiques; la marge se divise toujours, devient sinueuse et pinnatifirle. Ce sont des plantes robustes, squammigères, à rhizome écailleux, à réceptacle arrondi et ovoïde, à sacculus des sporanges glabre; le grammitis n'est pas dans ces conditions.

Si nous roulions chercher des analogies entre ce genre et quelques autres de la famille des fougères, nous les trouverions parmi les espèces à frondes simples du genre Drynaria, de la section des Pleopeltis; plantes essentiellement squammigères, à nervation réticulée.

Nous appelons l'attention sur les deux espèces suivantes:

$1^{0}$ Grammitis limbata, F., $6^{\mathrm{e}}$ Mémoire sur les Fougères, p. 6, tab. V, fig. $1^{\mathrm{re}}$, rapporté par M. Mettenius au G. marginella, Sw., Syn. filic., p. 22, devenu un Polypodium. Si nous comparons avec la nôtre, la planche de Schkuhr, qui donne la plante de Swartz, nous ne pouvons nous dispenser de les trouver différentes. II. Ḱlotzsch en fait la variété minor de son Mecosorus marginellus. Le $G$. limbata serait donc la var. major de cette mème fougère, qui aurait été trouvée à la Guyane anglaise. Notre espèce, qui provient de la Guadeloupe, est tout à fait glabre et n'a, nous le croyons du noins, aucune analogie véritable arec la plante de Swartz, si ce n'est pourtant la marge discolore. entourant la fronde.

$2^{0}$ G. nana, F., loc. cit., p. 7, t. VI, fig. 1. Nous avons dit, dans notre liagnuse, que nous ne croyons pas avoir cette petite plante dans son état normal, et peut-ètre, en effet, ainsi que le pense MI. Nettenius, est-ce une forme du G. hirtella et du G. pusilla, de Blume, Enum., p. 122, représentés pl. XLVi, fig. $1-6$ de la Flore de Java. Toutefois nous ferons remarquer que la fig. 4 , à sporothèces centraux ne peut pas se rapporter à notre plante, dont les spuruthèces sont appuyés contre le mésonèvre.

111. Polvpodium, L. - Les espèces de ce genre curieux sont essenticllement pinnatifides, à segments découpés jusqu'au rachis et séparés, les uns des autres, par des sinus arrondis, à diamètre assez large. Les sporothèces sont loujour's unisériaux; les sporanges terminales, à réceptacle ovoïde ou ellipsoïde.

M. Mettenius a reconnu quil y avait des anastomoses dans la plupart des Polypodium à frondes chargés d'écailles, ce qu'avant lui, d'autres botanistes avaient remarqué. Ce caractère existe, en effet, dans les $P$. hirsutissimum. 
Radd.; incanum, Sw.; rhayadiolopis, F.; lanosum, F.; remolum, Desv.; thyssanolepis, A. Br.; squammatum, L.; biauriculatum, Hook, et dans les P. longicaule, lepidotrichum et pyrrholepis, de notre herbier. Autant que nous avons pu le voir, car ce genre de recherches est fort difficile, les mailles formées sont très-peu nombreuses et sans appendices.

Le port de ces plantes en fait des Polypodium; la nature de la squammescence des Drynaria, section des Pleopeltis; la nervation des Goniophlebium; et c'est daus ce dernier genre qu'elles derraient rigoureusement être placées el nous le constatons simplement. N'ayant point ici à faire un species, il suffira de cette observation, à laquelle nous ajoutons les remarques suivantes, concernant diverses espèces déjà connues:

$1^{\circ}$ P. cancellatum, F. , $6^{\mathrm{e}}$ Mém., p. 12, tab. VII, fig. 2, réuni au P. Lindeniamum, lize, Filic., p. 83, tab. CXXXIV. Un examen attentif de ces deux plantes nous les fait voir différentes.

$2^{0}$ P. delicrtulum, Mart. et Gal., Filic. mexic., p. 35, tab. VII, fig. 1, incliqué seulement comme plante mexicaine, se trouve aussi à Saint-Domingue, oi elle a été récoltée par De Tussac. (Herb. F.)

$3^{\circ}$ P. filipendulafolium, F., $6^{\text {e }}$ llém., P. 11, tab. V, fig. 2, doit être réuni au P. subfalcatrom, Blum., Filic. Jav., p. 186, tab. LXXXVII, A, B.

$4^{\circ}$ P. cllipticosorum, F. Gen. filic., p. 239; c'est le P.xanthotrichum, Kl., Limnaa, t. $\mathrm{XX}, \mathrm{p} .376$.

5" P. gibbosum, F., n'est pas le P. trichomanoides, Sw. Dans la plante de Swartz, la souche, qui est petite et dressée, annonce une plante de courte durée; lans notre espèce la souche, grosse et rameuse, appartient à une plante très-vivace, de longue durée.

$6^{\circ}$ P. subfalcatum, J. Sm., Énum. foug. Philipp., nº 205 de Cuming, ne parait pas différer du $P$. trichomanoides, Sw.

$7^{\circ}$ P. Serriculu, F., Gen. filic., p. 238 , et $6^{\text {e }}$ Mém., p. 9, tab. VIl, fig. $1^{\text {re }}$, est réuni an P. trichomanoides, de Swartz. Si nous comparons la figure donnée par Schliuhr (tab. X), avec la nôtre, laquelle est très-exacte, nous pouvons les croire différentes l'une de l'autre. Notre espèce est très-longue, très-raide, coriace, à segments écartés, à pétiole long et nu. (Consultez les ourrages et les planches cités.)

$8^{\circ}$ P. microlepis, F., Gen. filic., p. 235, 6 Mém., p. 8, tab. Vl, 2. L'étroitesse des segments pinnulaires est telle qu'il ne nous a pas été possible de constater si les nerrilles sont libres ou anastomosées. Toutefois, cette même étroitesse nous fait croire qu'elles n'ont point d'anastomoses. 
112. Phegopteris, F. - Les espèces de ce genre difficile, ayant presque toujours de très - grandes dimensions et devant occuper, pour être figurées de grandeur naturelle, une planche in-folio, laissent une lacune considérable dans le cadre iconographique des fougères. Il en résulte que bon nombre d'espèces sont douteuses ou d'une détermination difficile. Les diagnoses qui en ont été données, s'appliquant à des plantes d'une amplitude souvent extraordinaire, sont vagues et insuffisantes. On connaît bien les espèces européennes; les autres le sont plus imparfaitement. Une monographie qui donnerait la figure des plantes de ce genre, serait un bel et riche ourrage.

Voici quelques notes concernant diverses espèces de ce genre :

$1^{\circ}$ Ph.cordata, F. , $6^{\text {e }}$ Iém., p. 13, tab. VI, fig. 3. Nous ne l'arions rue que récoltée à Cuba; elle vit aussi au Mexique, près d'Orizaba. M. W. Schaffner dit qu'elle est rare. Les frondes sont radicantes, ce que n'exprime pas la figure citée. En général, la Flore des fougères de Cuba et du Nexique, diffère très-peu.

$2^{\circ}$ Ph. nervosa, F., loc. cit., tab. II, fig. 3. Il n'est pas dit dans la description que la fronde est prolifère au sommet; mais on voit, en y regardant bien, ce caractère exprimé sur la planche citée.

$3^{\circ} \mathrm{Ph}$. adenochrysa, F., Gen. filic., p. 245.

Les points brillants qui se trouvent sur la lame inférieure des frondes de cette belle espèce; sont de très-petites glandes ovoïdes-pyriformes.

$4^{\circ}$ Ph. nitens, F., Gen. filic., p. 246, devient un Polystichum, le P. nitens. Les indusium sont caduques; mais il en restait encore un qui nous a révélé le genre.

$5^{\circ}$ Alsophila pilosa, Mart. et Gal., Filic. Mexic., 1. 78 , tab. XXII. Polypodium rude, Kze., Linn. XIII, p. 133, F., Enum. in Gen. filic., p. 236, est pour nous le Phegopteris pilosa; l'anneau n'est pas oblique et les sporanges ne sont pas pas accombantes, les unes à l'égard des autres.

113. Goniopteris, Presl. - Le port de ces plantes n'est pas le même pour toutes les espèces. Elles sont pinnatifides, pinnées et pinnées-pinnatifides.

$1^{\circ}$ Les Goniopteris, à frondes pinnatifides, ont des lames chargées de poils étoilés, et une grande tendance à devenir prolifëres. Les nervilles basilaires sont seules unies à leurs correspondantes; elles vivent aux Antilles: G. affinis, F. ; ferax, F.; incisa, Presl; scolopendrioides, Presl.

$2^{0}$ Les Goniopteris pinnés, à frondules crénelées, ne montrent qu'une seule aréole basilaire : G. prolifera, Presl.

$3^{\circ}$ Les Goniopteris pinnés, à frondules dentées en scie et à nervilles monoaréolaires: G. Lobbiana, F. 
$4^{0}$ Les Goniopteris pinnés, crénelés, multiaréolaires: G. barbata, F, et Madagascariensis, F.; celle-ci ayant deux aréoles basilaires, ainsi que le G. crenata, Presl.

$5^{\circ}$ Les Goniopteris pinnés, crénelés, à nervilles latérales, toutes unies à leurs correspondantes; émettant, vers le sommet, des aréoles avec un appendice dressé, qui s'unit aux aréoles supérieures, de manière à former une série continue d'aréoles secondaires, fort petites. Nous en faisons un sous-genre: Microgonium, qui renfermera les G. repanda, F.; crenato-dentata, F.; Dalhousiana, F.; meniscioides, F. (G. prolifera, J. Sm. non Sw.), et mollis, F.; elles vivent aux Indes-Orientales.

6. Les Goniopteris à nervilles toutes unies à leurs correspondantes, ınais émeltant des prolongements libres à leur sommet. G. Rivoirei, F.; G. latifrons, F.

$7^{\circ} \mathrm{E}$ enfin les Goniopteris à frondes pinnées-pinnatifides, uniaréolaires : $G$. asymetrica, F.; cheilocurpa, F.; megalodus, Presl; aristata, F.; patens, F.; subtetragma, Presl; tetrayona, Presl; Portoricensis, Presl; ces dernières seules ont le port des Pheyopteris.

115. Camprloneviox, Presl. - Parmi les espèces de ce genre, par nous énumérées on décrites, il en est quelques-unes élablies, autant d’après le port que d'après la nerration; les C. angustifolium, tceniosum, Jamesoni et Cubense, par exemple.

M. Mettexius réunit au Polypodium tconiosum, Willd., dont nous arons fait un Campylonerron, les P. angustifolium, Sw.; loreum, Klfss; spartosorum, Spr ; leucorlizon, Klotzsch; nodosum, Ḱlotzsch ; solutum, Klotzsch; cnsifolium, Willd., et mème notre Campylonerron Cübense. Sans nous prononcer sur la validité de toutes ces réunions, ce qui nous entraînerait trop loin, nous nous contenterons de faire remarquer que le $P$. angustifolium semble bien différent du P. taniosum. Il a le port d'une Vittaria, avec une seule aréole costale et une seule rangée de sporothèces. Les frondes sont courbées d'une manière très-marquée. Nous comprenons que si par la pensée on élargissait la fronde, il se formerait plusieur's rangées d'aréoles, el, que par conséquent, il y aurait plusieur's rangées de sporothèces; mais ce serait lả construire une plante et interpréter la nature; pour constater la spécificité, il suffit de la permanence de la forme et de l'absence d’intermédiaires; or c'est ce qui arrive pour le $P$. angustifolium, Sw. Du reste, l'organisation el la disposition du rhizome sont les mêmes dans les deux espèces que nous examinons.

Le P. tonniosum, de nos jardins botaniques, n'a pas une nervation tout à fait semblable à celle du P. teniosum, Sw., de notre herbier (L. Schlim, Paramo de San Pedro (Nouvelle Grenade), n ${ }^{\circ} 314$; Moriz, Caracas, nº 5 . Nous possédons 
encore une forme du P. toeniosum, L. Schlim, $\mathrm{n}^{\circ}$ 310, aussi de la NouvelleGrenade, à fronde acuminée, tendante à la forme lancéolée; elle peut devenir la variété acuminatum, de cette espèce.

Il y a donc pour nous, comme nettement caractérisées par la nerration, trois espèces :

1. Le Campylonevron anguslifolium, F. (an Goniophlebium?). Polypodium anguslifolium, Sw. et Willd. P. ensifolium, Willd., Filic., p. 152. P. leucorhizon, Klotz., Linn., t. XX, p. 400. Radd., Filic. Brasil., tab. XXIT, fig. 2.

2. Le C. laniosum, F., Polypodium, Willd., P. dimorphum, Lk.; Cuba; Linden, nº 2024; Mexique, à Orizaba; W. Schaffner, $n^{\circ} 117$ et 486 , avec une variété à frondes plus ou moins étroiles sur le même rhizome.

$3^{\circ}$ Le C. loreum, F.; P. loreum, haulf., Kze., Fl. 1839. Nourelle-Grenade; Paramo de San Pedro, L., Schlim, $n^{\circ} 314$ et Horitz, Caracas, $n^{\circ} 5$. (Herb., F.)

Le C. Cubense, F. (royez p. 15), est aussi réuni par M. Mettenius au C. taniosum, fougère dont ce botaniste fait un Polypodium. Il nous semble que notre espèce est bien distincte. Les frondes ne sont pas linéaires, mais lancéolées et le pétiole est distinct. Enfin, si l'on examine les deux nervations, on voit qu'elles diffèrent complétement; pour s'en convaincre, il suffira de comparer le fragment grossi que nous avons donné, tab. III, fig. 2 du $6^{\mathrm{e}}$. Iémoire, arec la planche 117 des suites à Sclıkuhr, par hunze, Polypodium solutum, auquel I. Mettenius rapporte aussi notre plante, devenues l'une et l'autre, pour ce botaniste le Polypodium toeniosum, de Willdenow.

Nous ajouterons à ce qui précède quclques observations concernant trois autres espèces:

$1^{\circ}$ C. minus, F. Cette espèce est rapportée au Polypodium fasciale, de Willdenow, par M. Mettenius, qui renvoie à la planche 127 b, des fougères de Plumier, laquelle n'a que de faibles rapports avec notre espèce, de forme et de consistance différentes; mais nous croyons que la fronde stérile de l'Acrostichum Breutelianum, Kize, Filic., tom. II, tab. CII, mise par erreur à côté de la fronde fertile d'un Acrostichum d'espèce inconnue, mais à coup sûr disparate, est bien le $C$. minus, décrit dans le Genera, p. 258. Le C. Lapathifolium, Presl, Polypodium lapathifolium, de Lamarck, espèce dont nous possédons un spécimen authentique, est différent; les nervilles latérales, au lieu d'être courbes, étant droites et à peine sinueuses.

$2^{\circ}$ C. Moritzianum, F., n'a pas la mème nervation que le C. repens, Presl, arec lequel le réunit M. Mettenius.

$3^{\circ}$ C. Xalappense, F., est la seule espèce qui soit pourvue d'un long pétiole. La lame s'amincit un peu en coin, pour laisser le pétiole parfaitement nu et distinct. En recommandant la nervation, comme un sùr moyen d’arriver à la détermination des espèces, nous aurions dû ajouter qu'une grande attention était nécessaire. 
Toutes les espèces décrites par nous diffèrent essentiellement les unes des autres par la nervation, mais les descriptions sont très-souvent insuffisantes pour exprimer les caractères qui les séparent.

118. Craspedaria, Lk. - G. Geslasiana, F., 6e Mém. Filic., p. 15, tab. IV, fig. 2, a des frondes stériles plus arrondies que dans la figure citée; clle est fort rare au Brésil. C'est le no 1014 de l'herbier de L. Sculim, plantes de la NouvelleGrenade, province d'Ocaña.

119. Cinrsopteris, Lk. - Ce beau genre dont le type est le Polypodium ıureum, L., présente de grandes difficultés dans la détermination des espèces; peu d'entre elles ont été figurées, et aucune ne l’a été récemment. Il existe donc peu de moyens de eomparaison et de contrôle. Celles qui sont cultivées dans nos jardins le sont sous différents noms, circonstance qui augmente encore la confusion. La nervation est ici d'un grand secours; mais on s'en est peu servi. WiLldexow a soigneusement établi les différences qui séparent les Polypodium, passés dans le genre Chrysopteris: C.dulce, aureum, decumanum, sporodocarpum et areolatum, tous, à l'exception de la première espèce, cultivés dans les jardins de botanique.

Nous faisons remarquer, en passant, que l'on croit reconnaitre sur le rhizome dı Ch. aurea, Lk., une disposition spiraloïde des écailles.

Tableau synoptique des espèces du genre Chrỵsopteris.

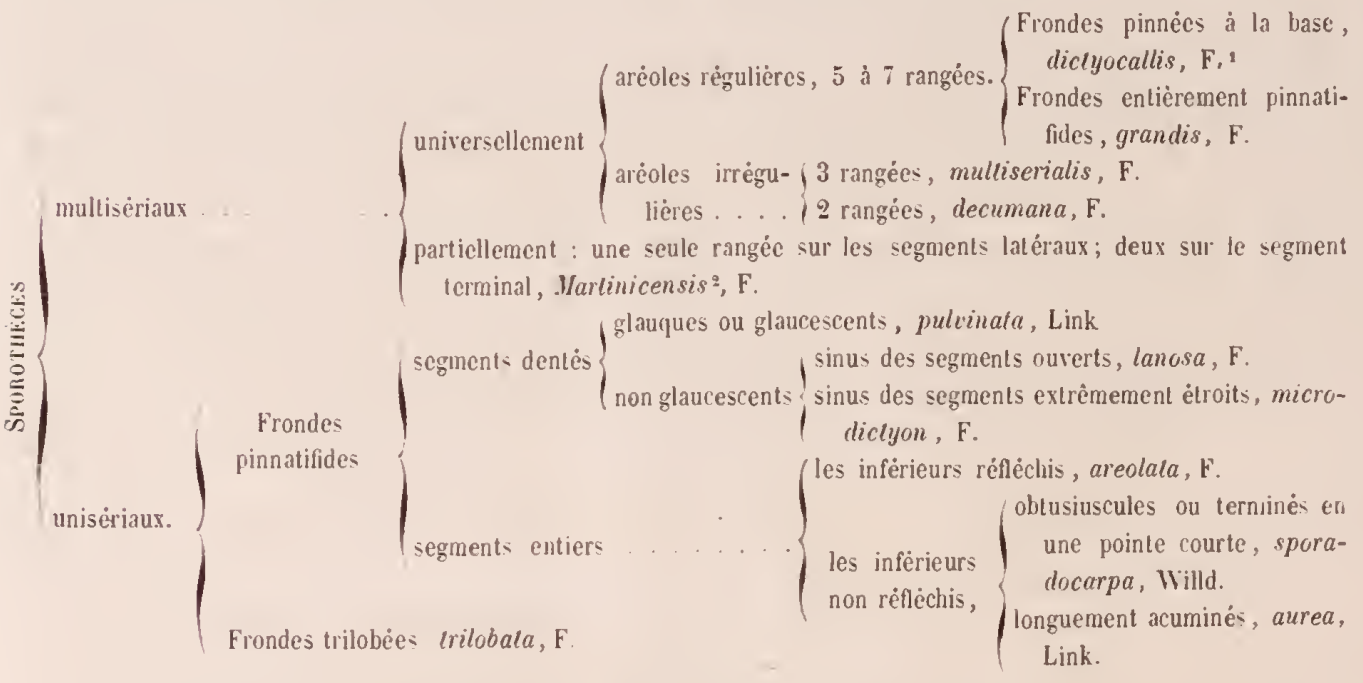

1. Plante terrestre, à rhizome entouré d'une grande quantitẻ de fibrilles.

2. Écailles du rhizome dorées et luisantes. 
123. Drmiaria, Bory. - Le réceptacle, sur lequel sont attachées les sporanges, varie de forme et peut servir quelquefois à distinguer les espèces. La forme la plus générale de ce support, simple modification de la nerville au point prolifère, est l'ellipsoïde. Exemples : crassinervata, F., Mexique; Prieurei, F.; stenoloma, F.; Billardieri, F. (Polypodium scandens, Labill.); Zeylanica, F. (Ceylan); macrocarpa (Polypodium, Bory); il s'allonge et devient linéaire, exemple:torulosa, F.; elongata (Grammitis, Sw.); lepidota (Pleopeltis, Kze); angusta, H. et Bonpl. Il se réduit et devient ponctiforme. Exemples:pllebodes (Pleopeltis, Kze); oodes, F. (Polypodium, Kze); Mexicana, F. Il est remplacé par une cavité, en forme de bourse, dans le stenophylla , F., et par une dépression, au fond de laquelle se logent les sporanges; Exemples : vestita, F.; Raddiana (Polypodium pleopeltidifolium, Radd.); undulata, F. Amboine; Chilensis, F.; excavatu (Polypodium, Bory); percussa, F., Polypodium, Cavan.

La deuxième division du genre Drynaria, Eudrynaria, à sporothèces non mèlés d'écailles, est moins naturelle que la première, celle des pleopeltis, dont les espèces ont un facies commun. Dans les Eudrynaria, le réceptacle est d'ordinaire ponctiforme.

La nervation des Pleopeltis est difficile à reconnaitre, les frondes étant coriaces et opaques; dans quelques espèces, les aréoles sont presque entièrement dépourrues d'appendices. Toutes les espèces de ce sous-genre ont des lames chargées d'écailles peltées, les mêmes que celles mêlées aux sporothèces.

$1^{\circ}$ D. Prieurei, F., Gen. filic., p. 271 , est réuni au Gremmitis lanceolatu, Schk, devenu un Polypodium pour M. Mettenius. En comparant la figure donnée dans le Cryptogamische Gewichlise, t. VII, et celle de notre 6e Ilémoire, tab. II, 6, on ne reconnaît aucune analogie véritable; dlans la plante de Swartz, le réceptacle est presque linéaire et dans notre espèce largaement ovoïde.

$2^{\circ}$ D. elongata, Sw. sub Grommitide. Dans tous les spécimens de cette plante que nous arons vus, la marge est rélléchie sur la lame supérieure et non sur l'inférieure, comme si elle tendait à recourrir les sporothèces; le contraire a lieu chè le D. Prieurei, F.

$3^{\circ}$ D. vestitu, F., Gen. filic., p. 271, 6e Mém., p. 16, tab. IV, fig. 3, pourrait ètre, suivant II. Ilettenius, le Polypodium polylepis, Rœm., Limn. XIII, p. 131: ce que nous ne pourons vérifier.

$4^{\circ}$ D. angusla, H. et B., sub Pleopeltide. Ilumboldt en parle comme d'une petite espèce; le pétiole mesure un pouce, la fronde 2 à 3 pouces; les sporothèces sont de la grosseur d'une graine de moutarde. Ce même auteur, dans le Synopsis planter. orb. nov., I, 76, la fait un peu plus grande, et nous croyons, en effet, qu'il 
faut la réunir au Polypodium pleopeltidifolium; mais notre D. Lomlosa semble absolument différent; il a de plus grandes proportions, un réceptacle linéaire, des sporothèces presque opposés et confluents; rien de tout cela ne se troure dans la plante de IIumboldt, non plus que dans celle de Raddi.

$5^{\circ}$ D. pimalu, F., loc. cil., p. 272, serait, suivant II. Uettenius, le Polypodium Gaudichaudii, Bory, Anı. des sc. nat., sér. Ire, tom. V, tab. Xill. Nous en avons reçu des spécimens du llexique qui mesurent jusqu'à 20 centim. de longueur sur un centim. de largeur. Les frondes fertiles sont terminées brusquement par une petite pointe mousse stérile. Les sporothèces sont profondément enfoncés dans la lame; il n'y a pas de réceptacle; c'est à tort que nous arons dit (Generch filicum p. 272), qu'il n'y avait pas d'écailles peltées mêlées aux sporanges ; on en trome quelques-unes; c'est doncune espèce de drynaria, section des pleopellis.

$6^{\circ}$ D. stenolomn , F. , $6^{e}$ Mémoire, p. 18, pl. 5, fig. 4. Il existe à la face supérieure des lames, fertiles et stériles, mais principalement sur celles-ci, des corps écailleux, cliarnus, blancs-de-neige. On les trouve sur plusieurs autres fongères, au point correspoudant aux sporothèces, mais ici elles ont un caractère particulier, étant pédicellées, comme de petites fongosités. Le tissu en est extrêmement serré. M. Mettenius fait de cette espèce une simple variété du $P$. angustum, sous le nom de angustissimüm, Kze, herbier; mot équivalent à stenolome, exprimant que les découpures ou segments sont étroits.

\section{CYCLODIEES.}

128. Phaxerophlemia, Presl. - Nous avous dit, dans le Genera, que Presl avait représenté anastomosées vers le haut, les nervilles de son genre Phanerophlebia, quoique ce nom exprimàt que les nervilles devaient être libres comme elles le sont en effet dans le type, Asplenium nobile de Schlecutexdat, fidèlement reproduit par Kívze, dans les suiles i Scukume, t. LXVII. Or, il nous est bien prouvé que Prest a décrit, sous les noms d'Amblya et de Phanerophlebia, une seule et même plante, à nervilles anastomosées, qui n’est pas l’Aspidium nobile, Schl., mais bien l'A. juglandifolia (Polypodium, II. et B.), arec indusium: Phancrophlebia; sans indusium, après la chute de ce tégument par vétusté: Amblya. Presl ne connaissait pas la Gyclodiéc à nervilles libres, devenue le type le notre genre Phanerophlebia. Voici, arant d'aller plus loin, comment nous établissons la concordance synonymique des deux types génériques :

1. Phaverophlebia, F. - Nervilles libres.

Asplenium nobile, Schlecht., Linnaza I, p. 610; Kze, suites à Schik., p. 155, tab. LXII, nec P'resl nee llook., nee J. Smith - avec deux espèces : P. nobilis, F., non Preș, el P. pumila, F. (Aspidium, Mart. et Gal., $\mathrm{n}^{\circ} 6251$ ). 
2. AмвLу , F. - Nervilles anastomosées.

Amblya juglandifolia, Presl, Tent., p. 184, tab. VII, fig. 22 ; Indusiis delapsis, et Phanerophlebia nobilis, ejusd., loc. cit., p. 85 , tab. II, fig. 19; Statu indusiato; Polypodium juglandifolium, II. ct B., Nov. gen., VII, tab. CILXV - avec deux espèces : A. juglandifolium, Typus, et A. latifolia, F. (L. Schlim., Nouv. Gren., prov. d'Ocaña, $n^{\circ} 656$.)

Les types des genres Phanerophlebia et Amblya sont l'un et l'autre mexicains et de même facies; mais la nervation fournit un caractère qui les différencie; dans le Phanerophlebia, les nervilles sont libres, et dans l'Amblya, anastomosées.

Peut-on regarder comme accidentelle, cette circonstance? La chose nous semble impossible. Il peut se faire quę les nervilles d'une fougère, organiquement libres, forment quelques rares anastomoses, ce qui pourtant est assez rare; mais il ne peut jamais arriver que d'une manière universelle la même plante se montre avec des nervilles libres sur toutes les frondes d'une touffe, puis toutes anastomosées sur d'autres. Rien dans tout ce que nous savons de l'organisation des fougères, ne dispose à le penser.

\section{ASPIDIÉES.}

135. Aspinium, Sw., reduct. - Le caractère générique le plus important est tiré de l'indusium, qui est réniforme ou cordiforme, attaché par le sinus; cependant, en y regardant de près, il est facile de s'assurer qu'il existe des modifications de forme et aussi difers modes d'attache. Ce sont ces différences qui ont permis d'établir comme sous - genres:

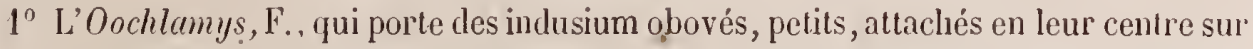
la nerville et dans toute leur étentue. Ils se soulèvent latéralement, sans jamais se détacher, et comme ils ont la même couleur que la nerville, on les croirait doubles, comme ceux des Diplazium. Nous n'avons indiqué qu'une seule espèce d'Oochla$m y s$, tandis qu'il existe huit à dix Aspidium, ainsi organisés.

20 L'IIypodematium, Kze, qui a un indusium semblable à celui des Aspidium, mais bombé, avec des bords entiers; il est profondément déprimé en son centre.

$3^{\circ}$ L'Amauropeltá, lize, le plus faiblement caractérisé de tous, qui n'a pas deux sortes d'indusium, ainsi que le prétend Kunze. La marge des segments fertiles est repliée sur les sporothèces comme dans certaines Cheilanthées; mais c'est lả une circonstance sans importance; le caractère qui a le plus de valeur, c'est la situation des sporothèces : ils sont terminaux. 
$4^{0}$ Le Camptodium, F., dont les indusium amples, bombés, réniformes, ménisciödes; beaucoup plus larges que hauts, sont attachés sur le sommet de la nerville prolifère, et fixés par une large attache basilaire. Le port du type est différent de loutes les autres espèces d'Aspidium, el se rapproche en petit des Bathmium.

La planche 75 des suites à Schkuhr par liunze a été faite d'après la plante de notre herbier récoltée à Saint-Domingue par De Tussąc.

Depuis l'époque oủ elle a été publiée, nous arons reçu un spécimen de la même plante récoltée par II. Hombron, en 1839, à Balaou, l'une rles iles Viti.

Le genre Complodium nous paraît devoir être adopté, comme distinct.

Nous avons reconnu que notre Aspidium extensum est I'A. melanostictum de Kuvze, in Linn., XIII, p. 148; cn outre, au lieu de Linden, il faut lire Galeotti.

136. Crstopteris, Bernlı. - En disant que le C. fragilis, plante cosmopolite, présentait suivant les localités des différences appréciables, et que l'on pourrait reconnaître plusicurs espèces distinctes, décrites sous un même nom, nous ne songions point à les établir; aussi n’ont-elles pas pris place dans la table du Gener Ce sont seulement des indications de formes données, en attendant que sur les lieux il soit possible de recomnaître si ces formes sont ou non des espèces, ce que le mode de déreloppement des lrondes et la structure des souches peurent senls permettre de décider. Nous nous contentons donc de les réunir au C. fragilis, en ajoutant seulement le nom du pays: C. fragilis, Bernh., Mexicana, Chilensis, Azorica et Abysinica, non pour annoncer des espèces, comme nous renons de le dire, mais simplement pour indiquer des modifications de forme, résultant des rlimats ou des stations.

\section{NÉPHROLÉPIDÉES.}

148. Nerhnolepis, Schott. - Le caractère qui sépare ce genre du Lepidonerron est facile à reconmaitre; il est tiré du mode d'attache de lindusium. Le Lopillonerron a le sien fixé au centre, comme dans les Polystichum, arec des inarges libres dans tout le pourtour; c'est au sommet du sinus qu il sattaclie comme dans les genres Aspidium, 'Oleandra, Cardiochlena, Faydenia el autres genres du groupe des Ispidiées. Le Nephrolepis a un indusium réniforme, sous-orbiculaire et non cordiforme, el ce tégument est attaché par sa base tout entière, de manière à n'être soulevé que partiellement à la maturité des sporanges. C'est sur cette différence, tirée d'un organe, auquel on accorde arec raison la plus grande valeur taxonomique, que sont établis nos caractères différenciels. Du reste, le port des Lepidonerron et des Nephrolepis est peu différent. Si l'on refusail de reconnaitre ces deux genres, il faudrait rejeter tous ceux qui sont établis sur des différences déduites de l'indusium et le nombre en serait considérable. 


\section{DICKSONIÉES.}

166. Woodia, R. Br. - Le genre Physematium, de Kaulfuss, a été réuni par les ptéridographes modernes au genre Woodsia, dans lequel est venu se fondre le genre Hymenocystis, de C. A. Meyer. Ainsi constitué, le genre Woodsia semble inadmissible, et la nécessité de rétablir le genre Physematium, parait démontrée.

Dans le genre Woodsia, il n'y a point d'indusium, mais seulement des écailles entourant le point d'attache des sporanges et parfaitement étalées, quel que soit l'état de la plante, et divisées vers le sommet en expansions filiformes articulées. Ces corps ne constituent pas plus un indusium que les écailles observées dans le genre Pleopeltis.

Dans le genre Physematium, au contraire, existe un indusium infère, globuleux, d'abord parfaitement clos, puis s'ourrant irrégulièrement à son sommet pour laisser communiquer les sporanges avec l'air extérieur. Cette organisation est tellement roisine de celle des Sphceropteris, R. Br., qu’jl n’y aurait aucun inconvénient à réunir ce dernier genre au Plıysematium, à côté duquel, il doit être placé.

Il faut donc ainsi nous résumer :

1. Woodsia, R. Br.; Polypodiacées à indusium toujour's ouvert, mêtne à la naissance du sporotlièce.

2. Physemalium; Kaulf., Dicksoniées à indusium gylobuleux, clos dans sa jeunesse.

Le genre Hypoderris de J. Smith parait avoir aussi un indusium écailleux, caliciforme, frangé à la marge; ne l'ayant jamais vu, nous ne pouvons nons prononcer sur sa validité. Cependant, sur ce que nous en savons, nous serions disposé à le placer parmi les Polỵpodiées pour en faire un petit groupe distinct, les Woodsices, dort le genre Woodsia serait le tỵpe.

\section{FAUTES A CORRIGER.}

Page 21, ligne 14. Au lieu de enervis, lisez enervibus.

- 33, ligne 21, Cheilopecton, lisez Cuenloplecton.

- 39, avant-dernière ligne. $\Lambda$ u lieu de $T a b .456$, livez 256 .

- 52, ligne 30. Pour le dernier mot, lisez lanceolatis.

- 54, ligne 1. Au lieu de Pag. 79, lisez 76.

- 73, ligne 4. Au lien de Ptéridée, lisez ptéride.

- i6, ligne 22. Au lieu de Pl. nov. Holl. T. 242, lisez 241
Page 78, ligne 2. Au lieu de Pag. 49, lisez 39

- 82, 3 e ligne du bas. Au lieu de Crassines, lise\% Crassidens.

- 85, ligue 28. Aul lieu de dculentiosum, lisez denticulosum.

- 89, ligne 34. Au lieu de Stexolepsis, liser STENULEPIS, 


\section{TABLE ALPIIABÉTIQUE DES $6{ }^{\circ}, \tau^{\circ}$ ET $8^{\circ}$ MÉHOIRES.}

NE. Yous mettons une * aux plantes figuries dans les Mémoires 6 et 7 .

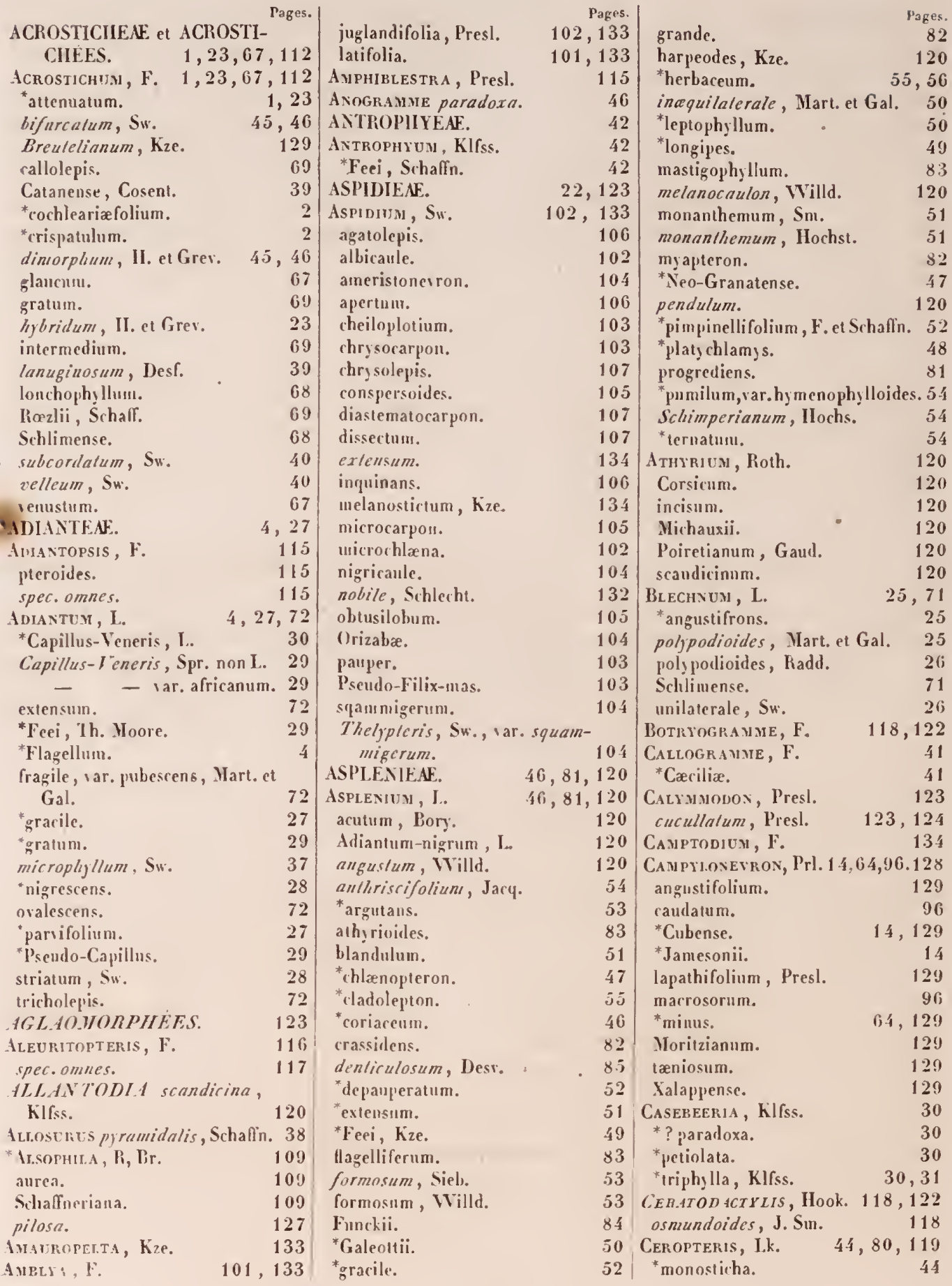


TABLE ALPIIABÉTIQUE.

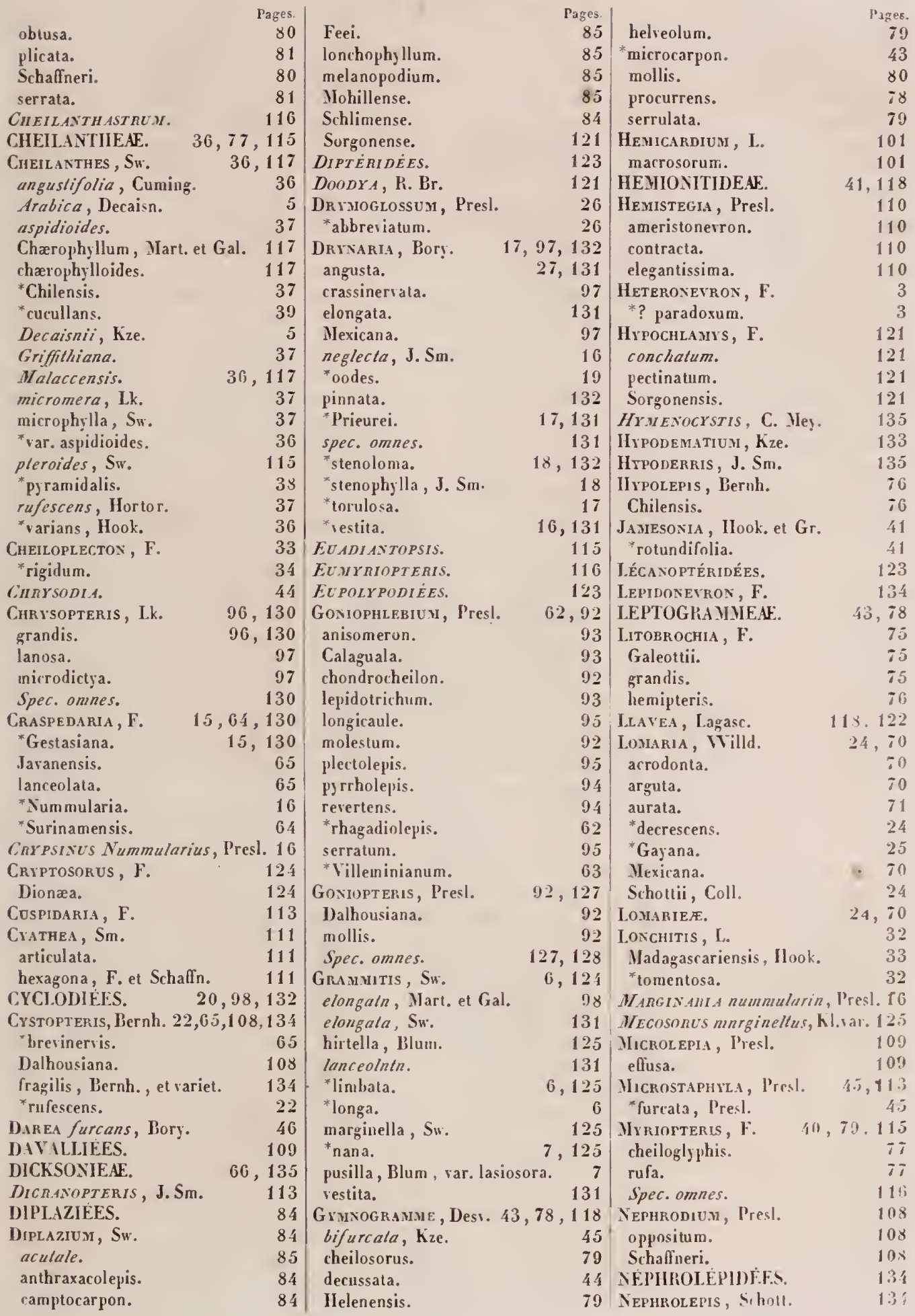




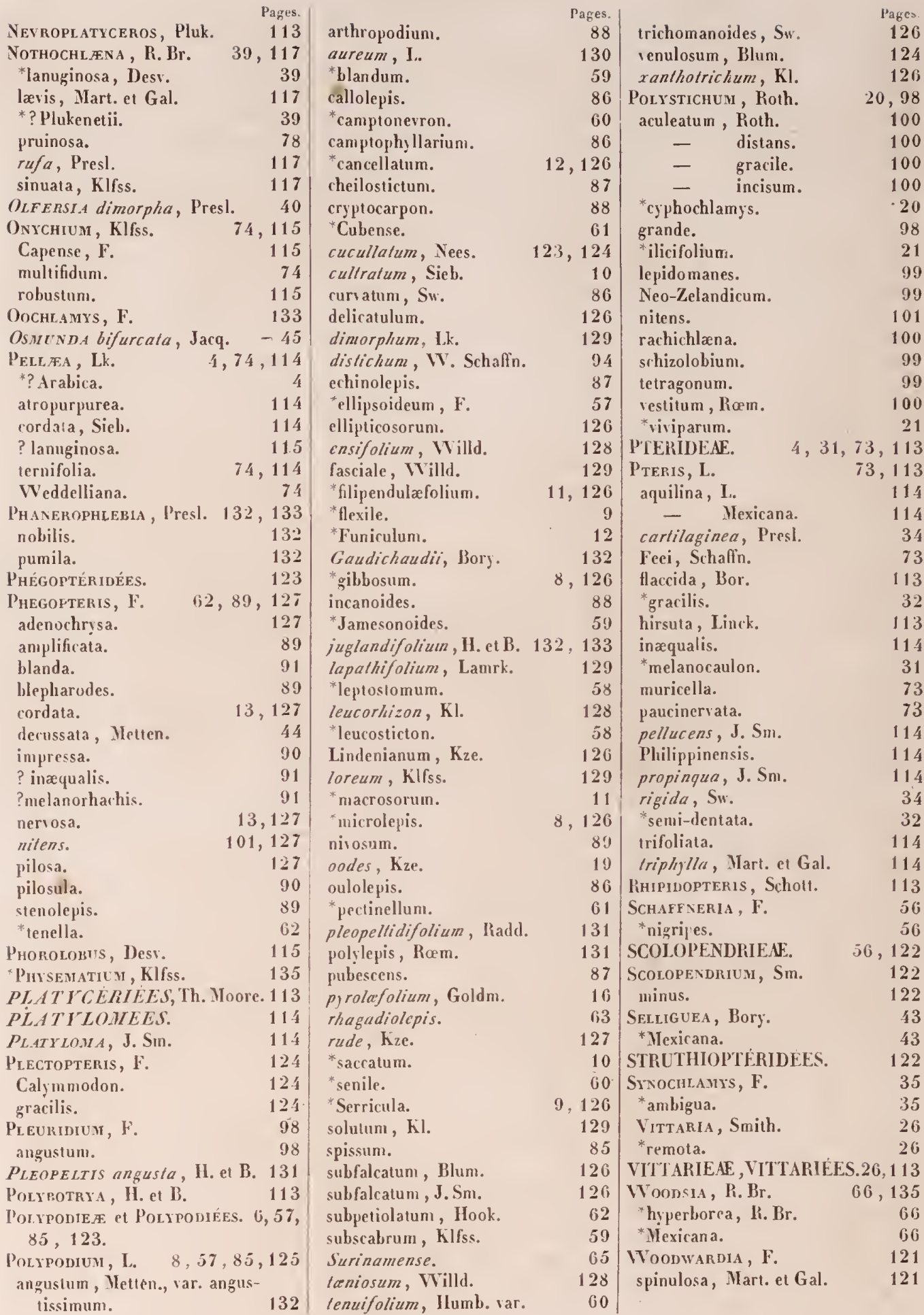




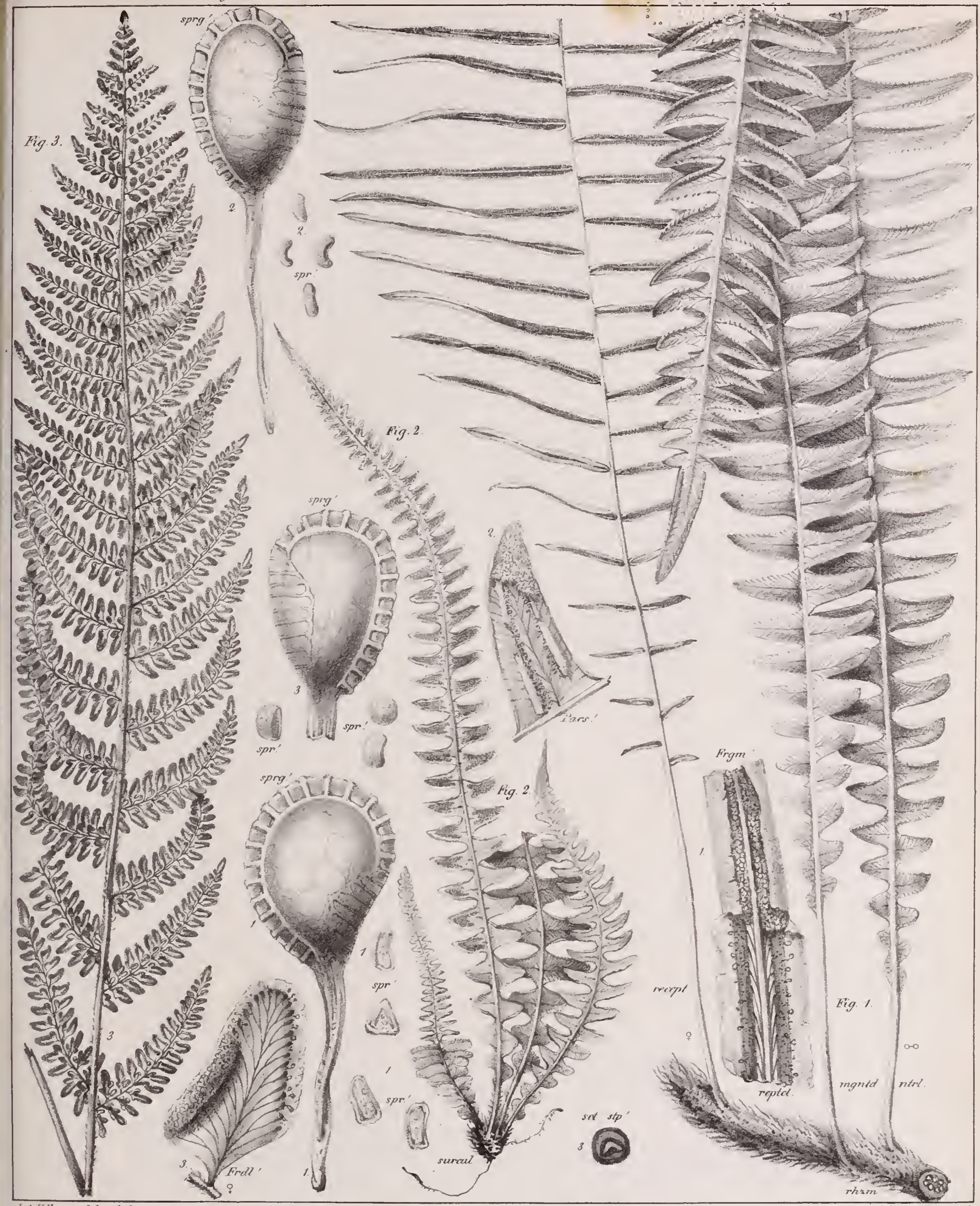





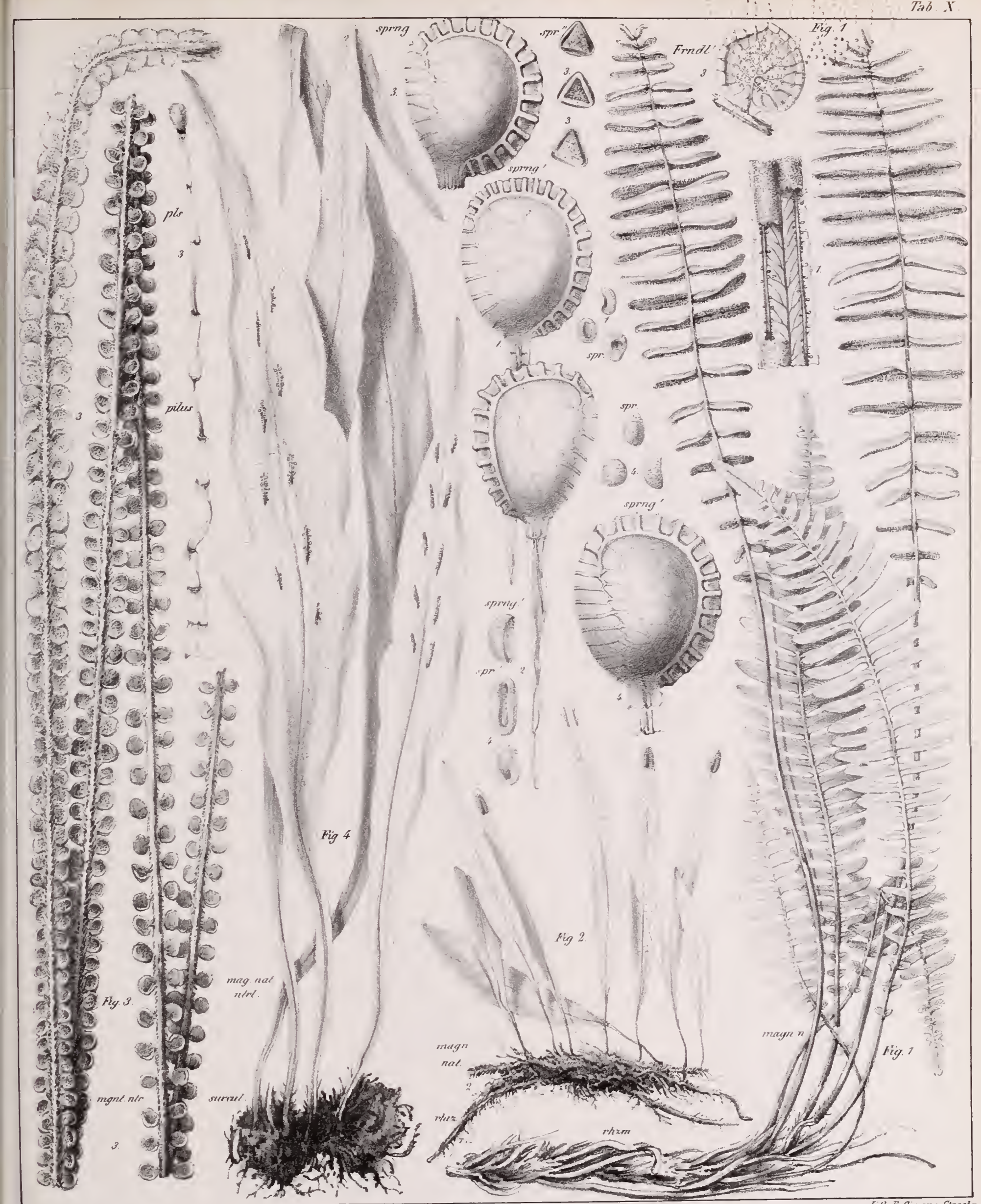





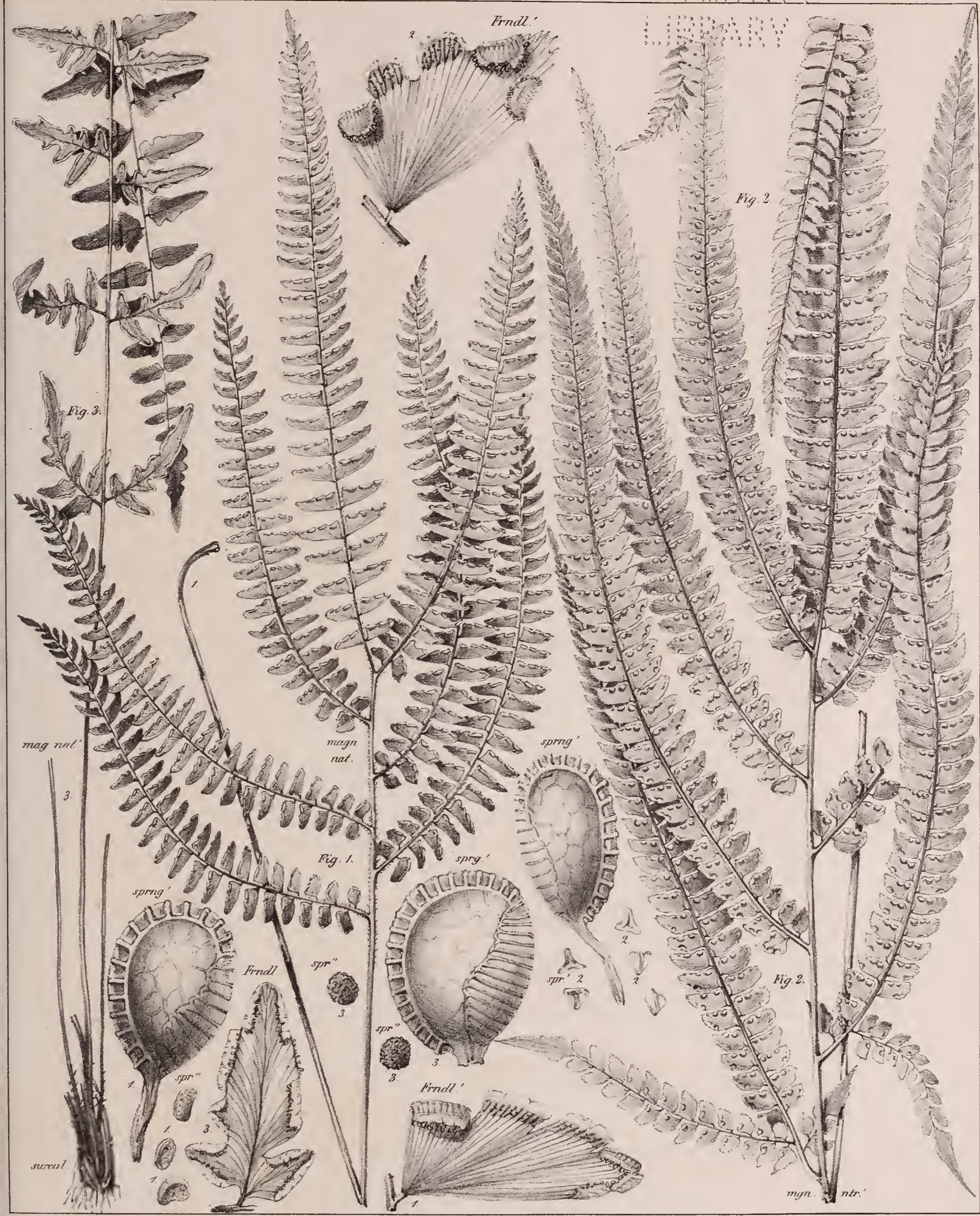

Fig 7. Adiantum gracile, $F$ ? Fig. 2. Adiantum nigrescens, $P$. 



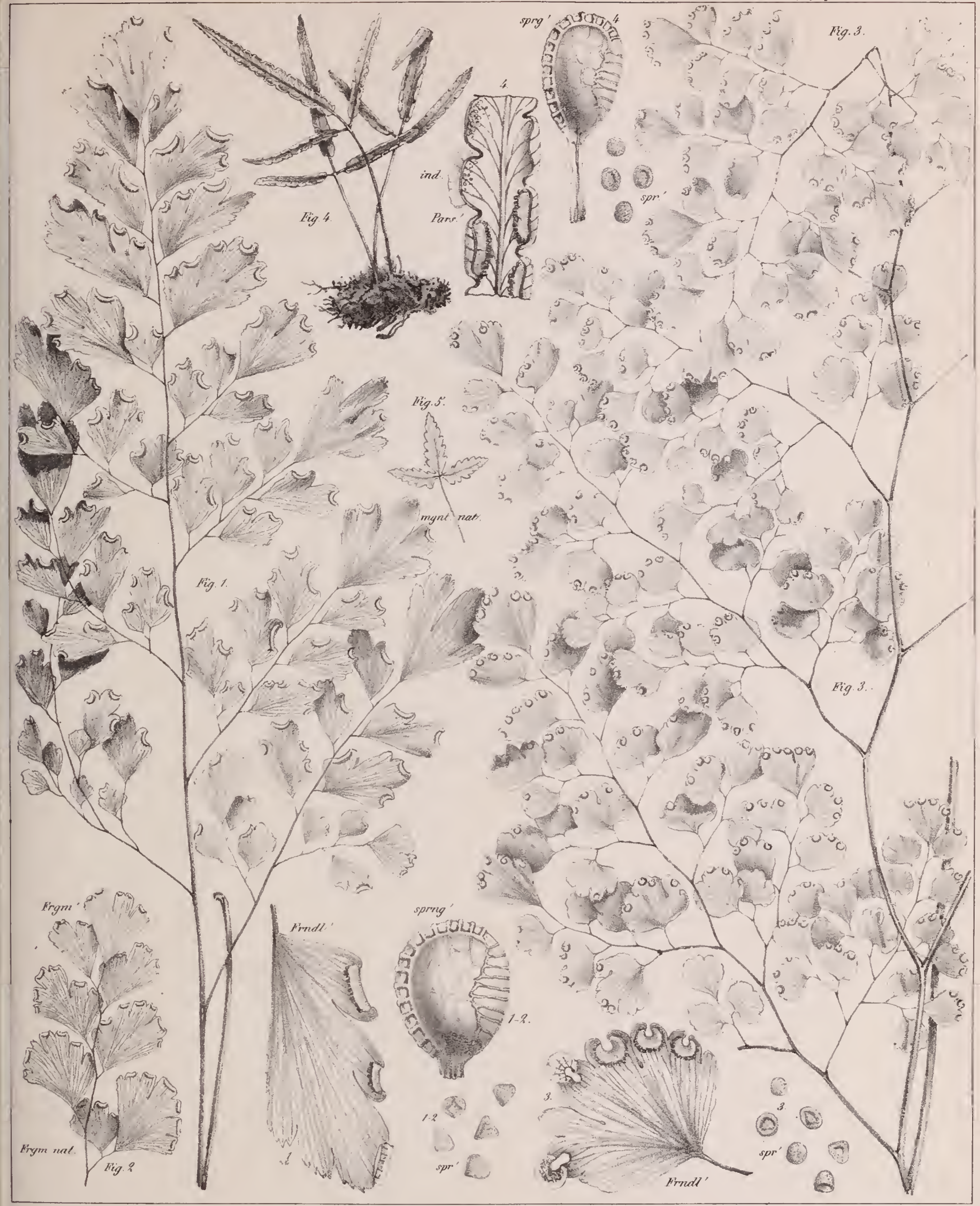





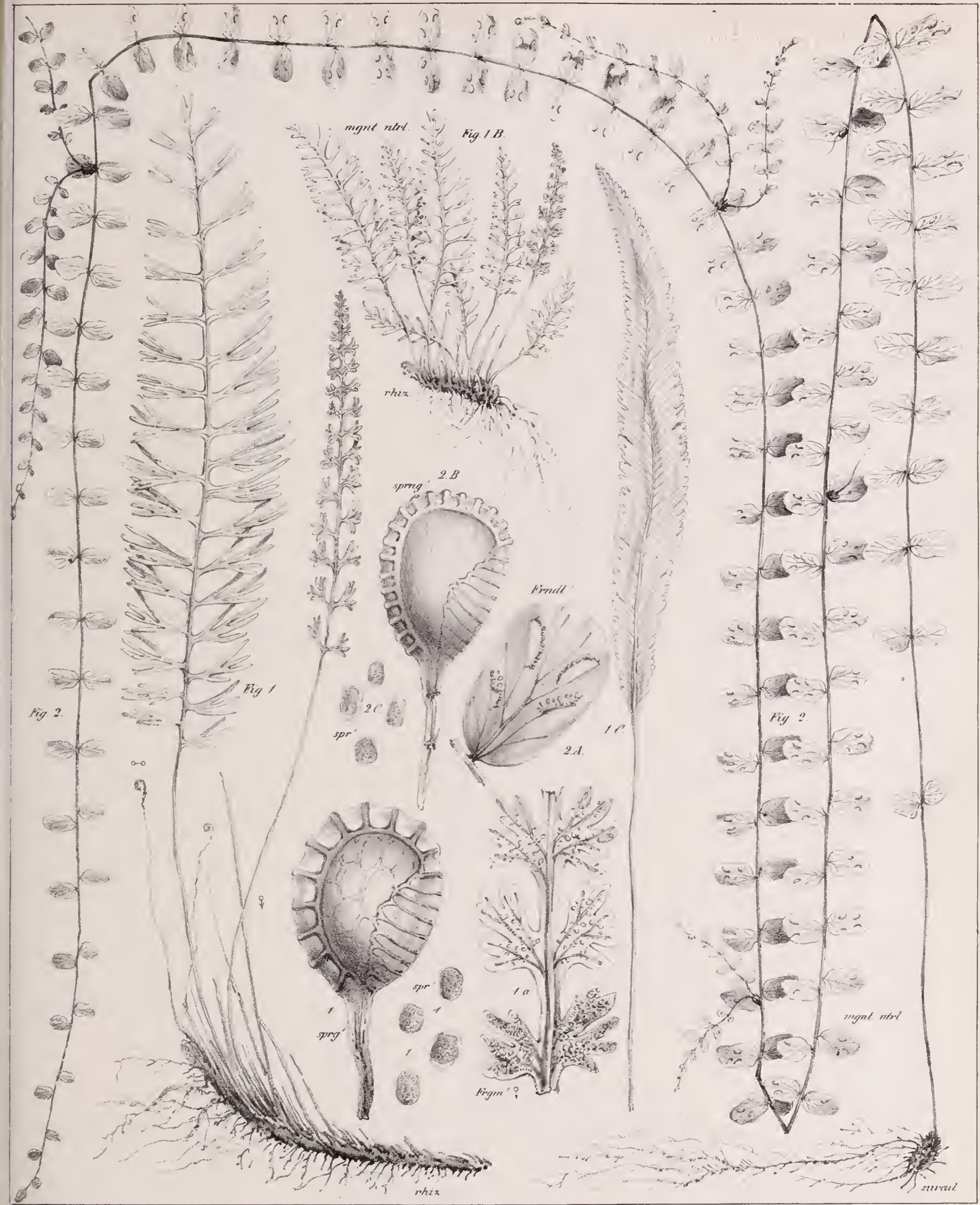

Fig., Microstaphyla furcute, $F . \quad$ Fig. Asplenium cxtensum, $F$ 




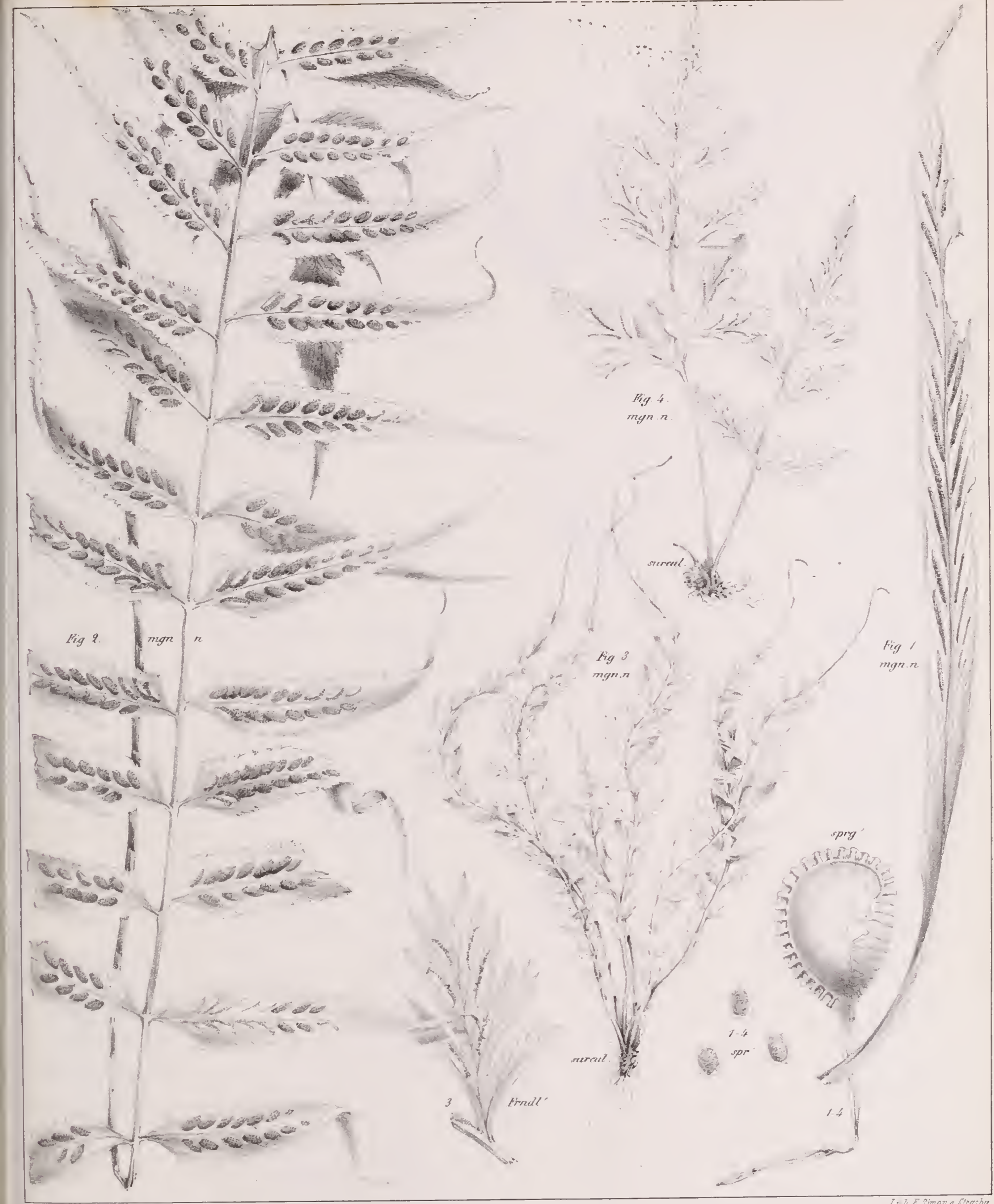

fig. Asplenium corixcaum, $F$. lig? Ficei, Fient
Fig.3. Aspleniun tepauperatum, $F$. Pig.4. pusmilum, sm 




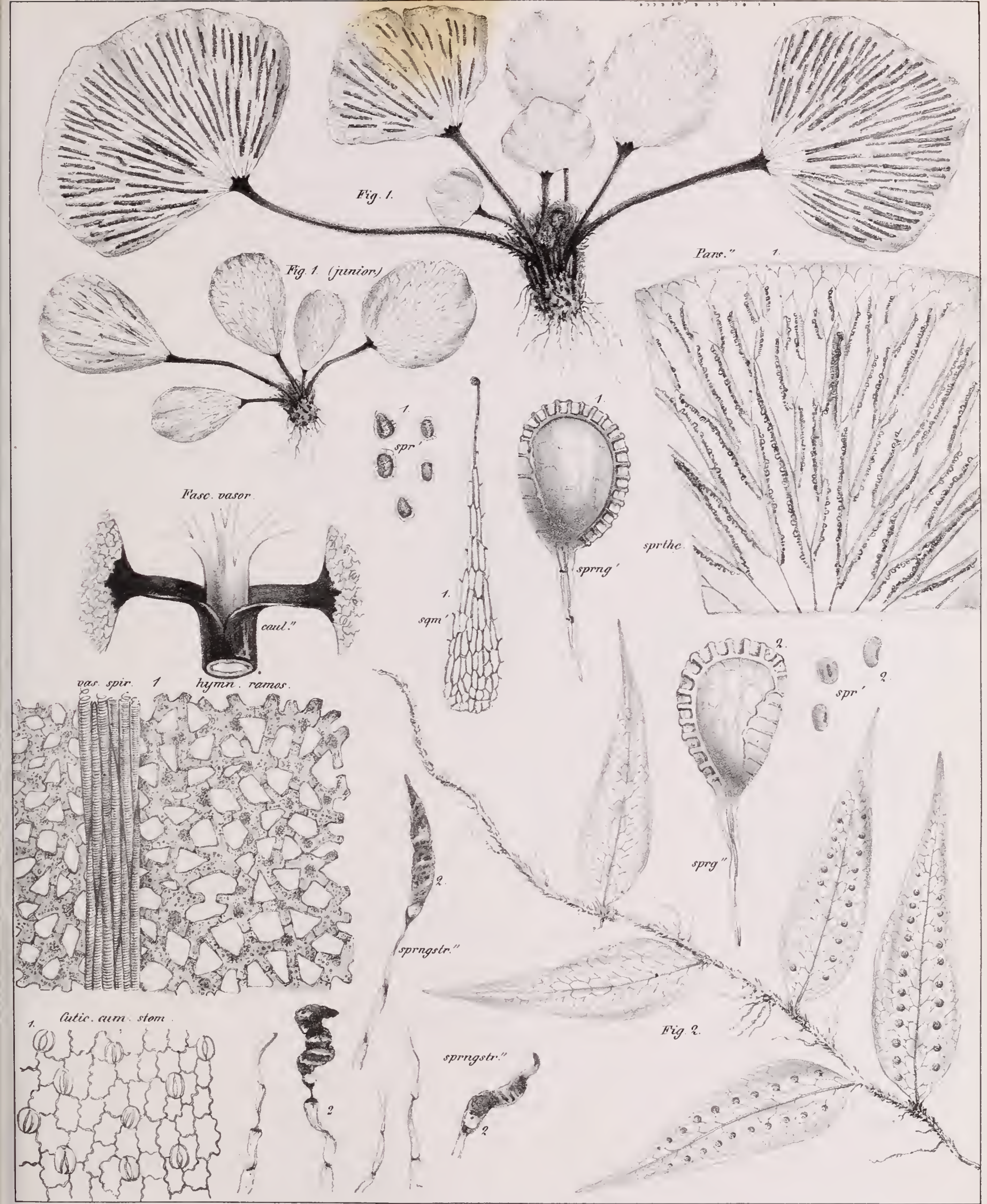




FH, Clis NOVN.

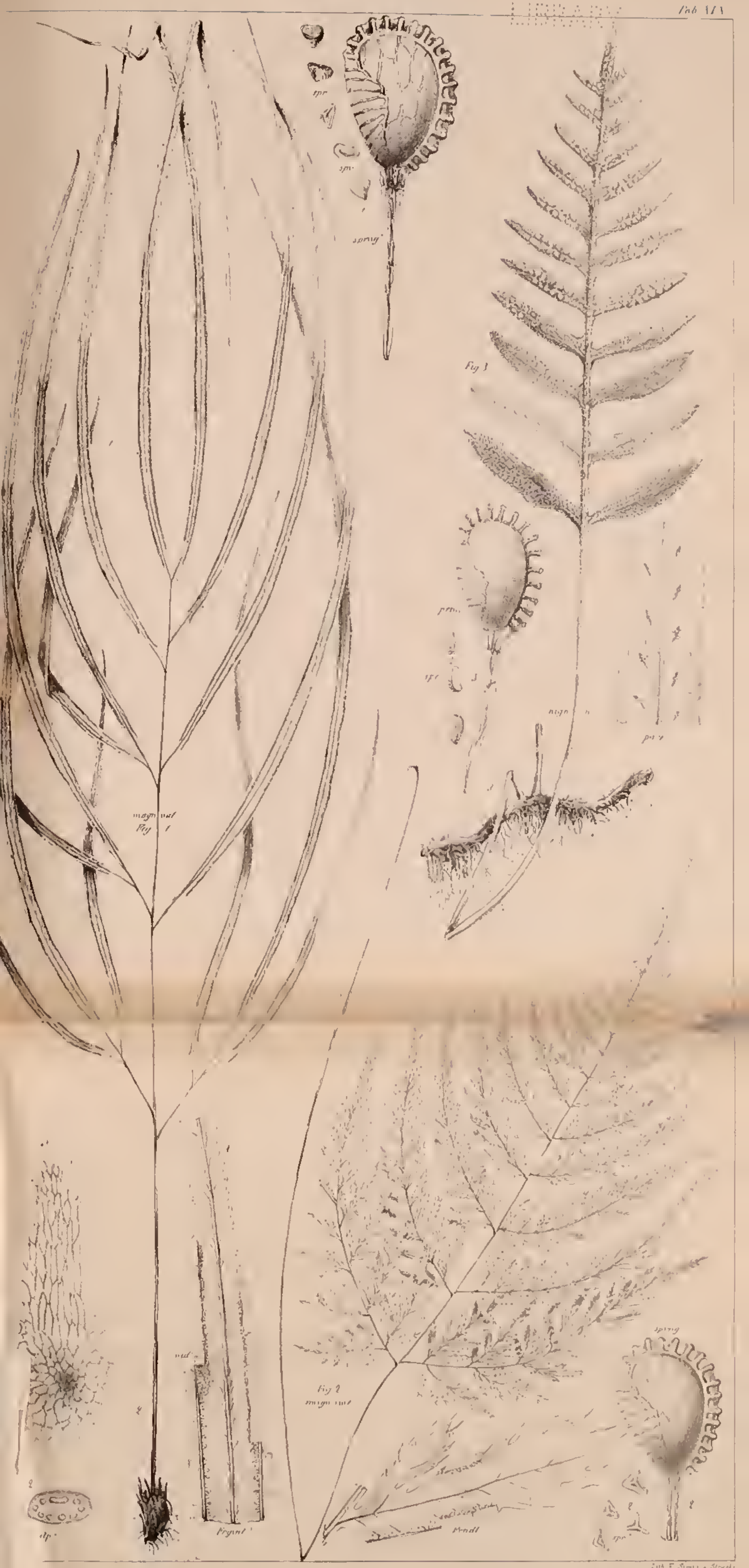





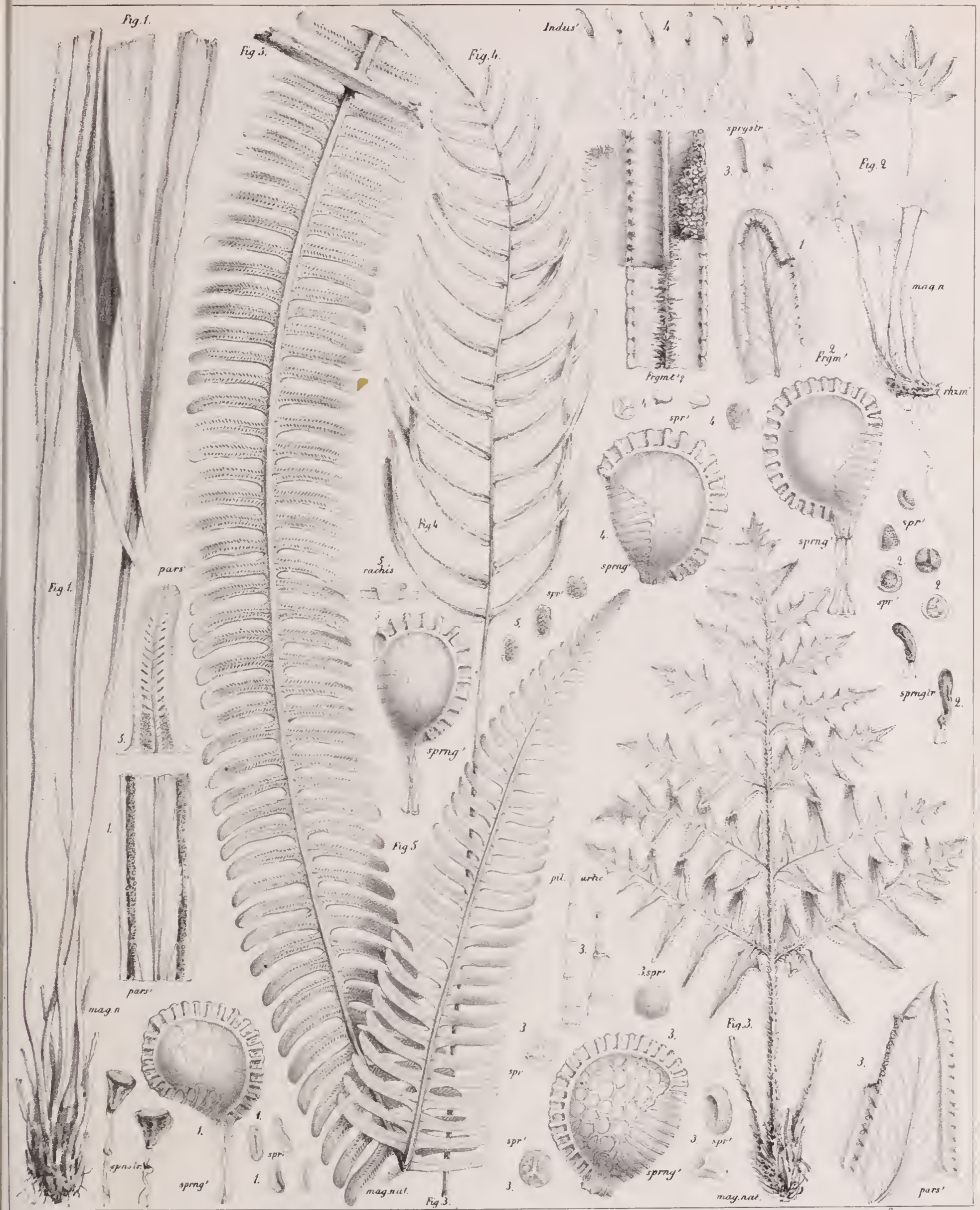

fis, Villaria remotn, $P$ ?

Fig.2. Cas ebecria paradoxa, $F$

Fig.3. Cheiloplecton rigidum, $P$

ragh. Synochlamys ambigua, $P$ 



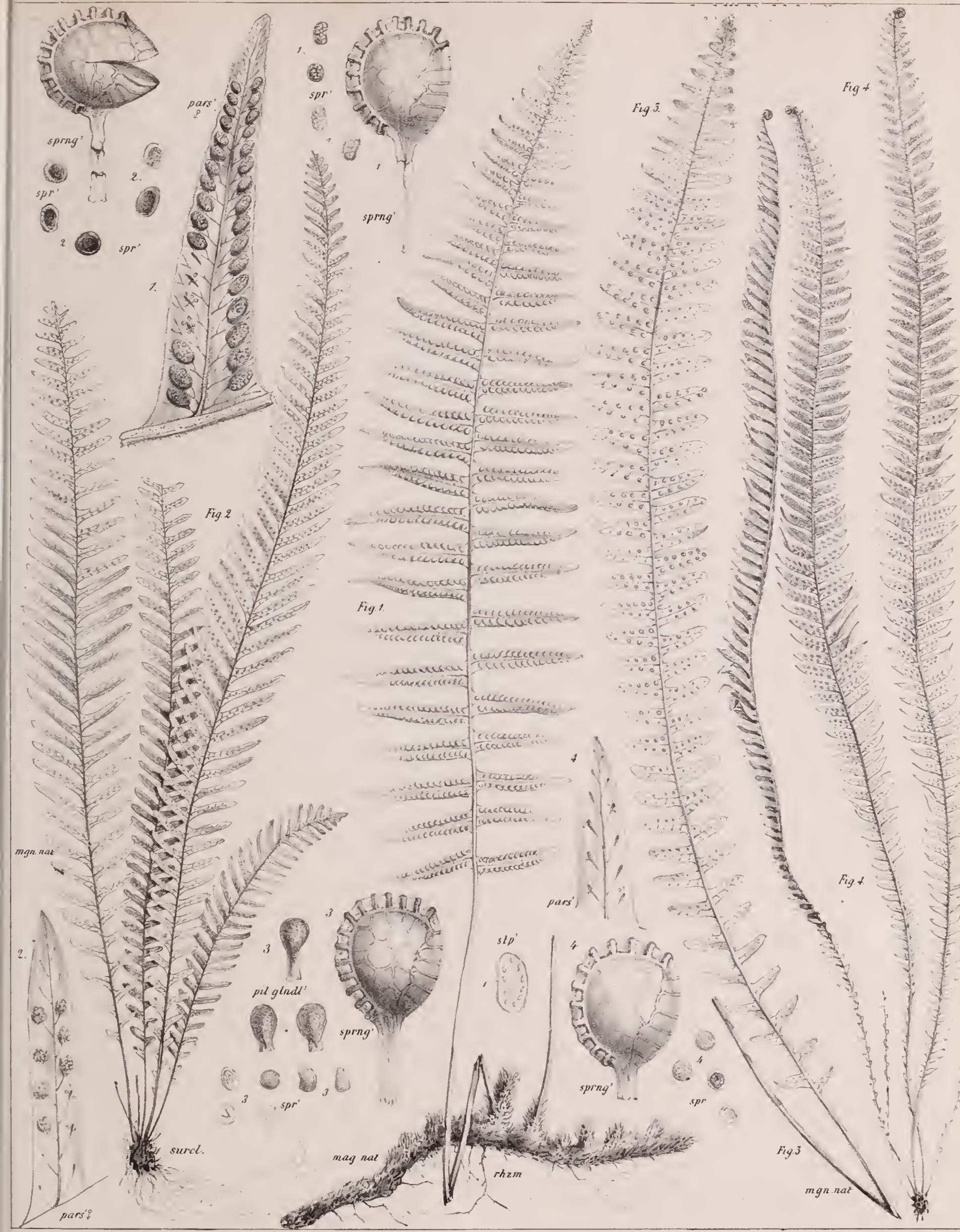





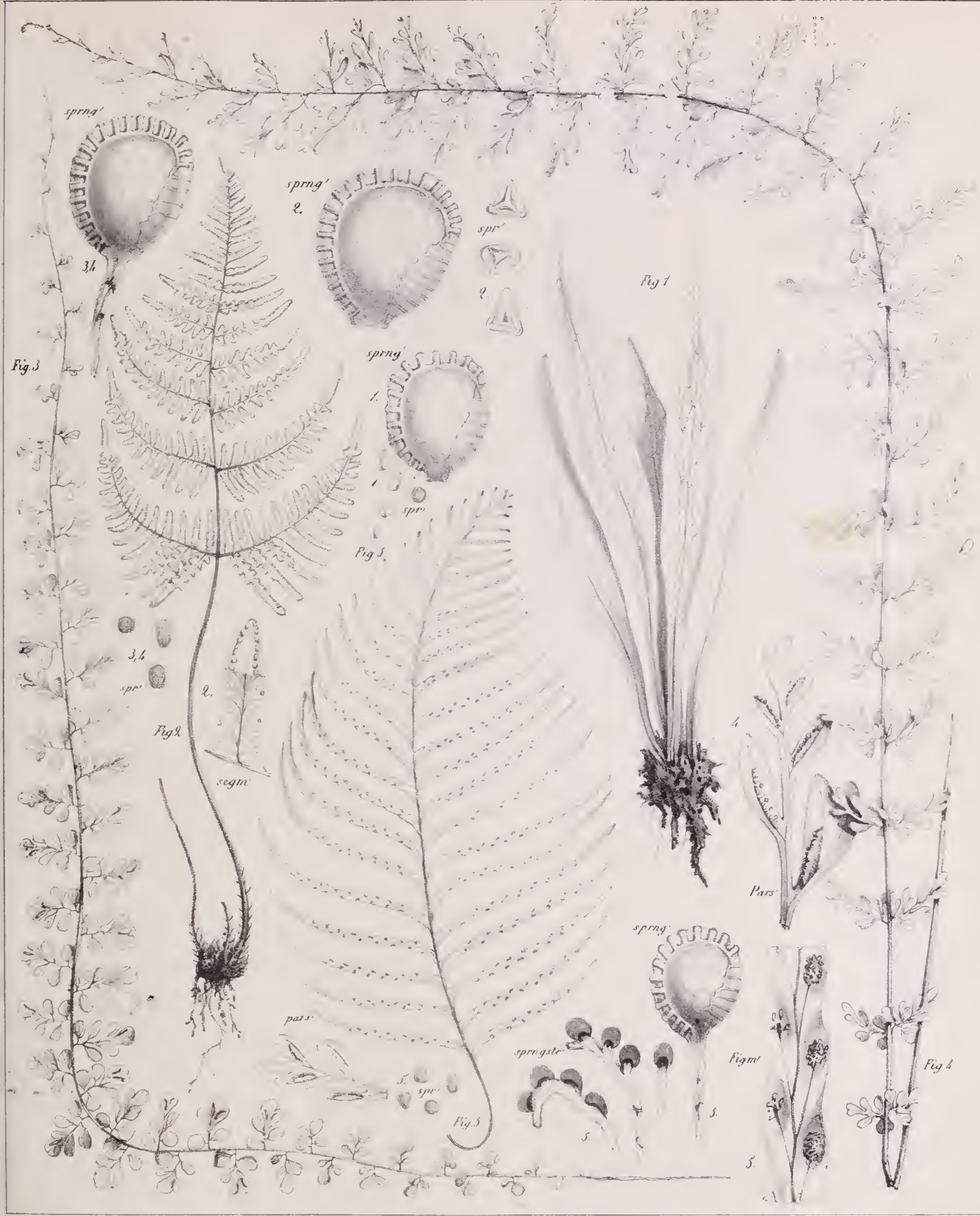

Figt Introphyum fee, sctioff 



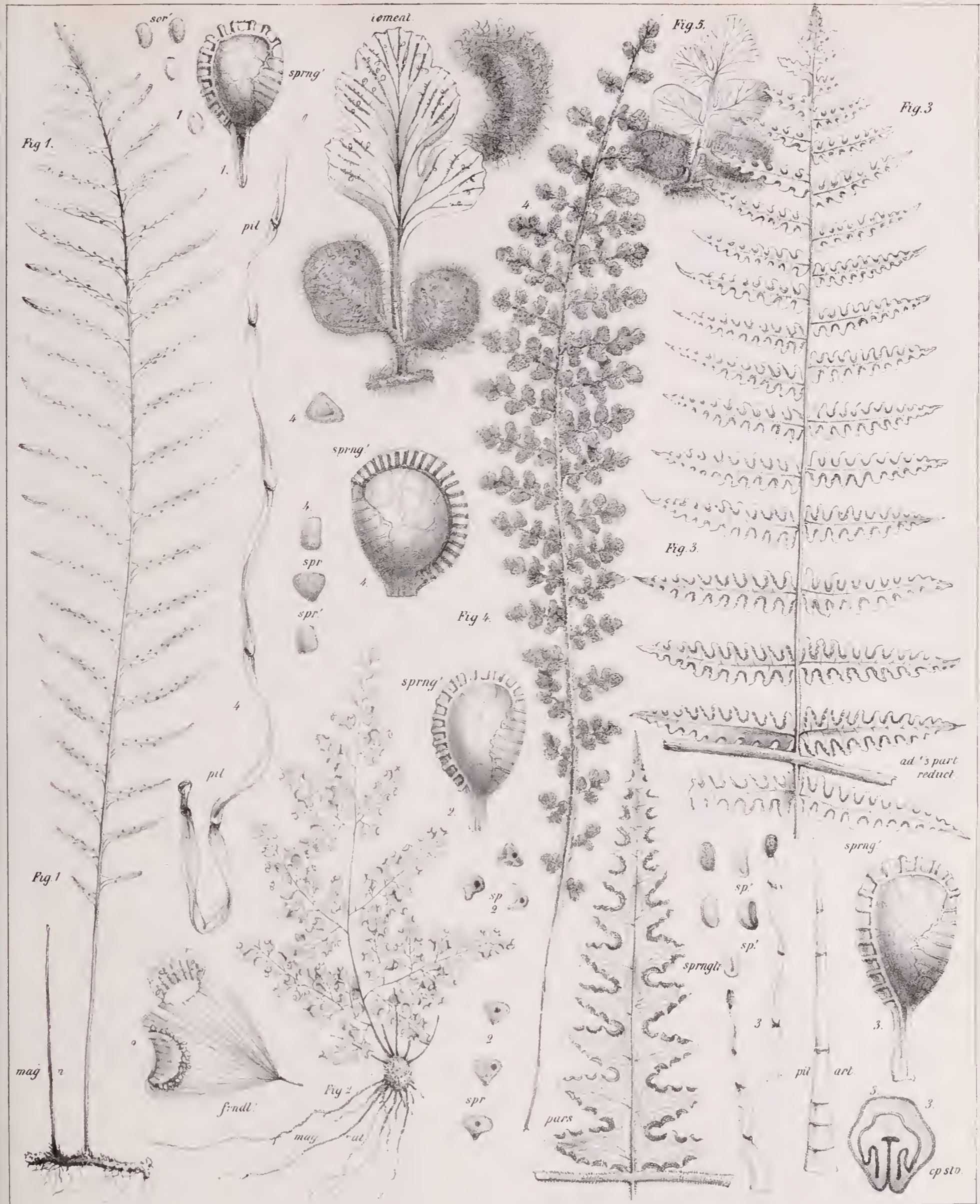

Fig. 1. Polypodium camptonevron, $F$.

Fig.2. Adiantum paraifolium, $F$.

Fig.3. Lonchitis comentosa, $F$

fig.5 Nothorhlaen a lenuginosa, Deso pars ad camparandum. 



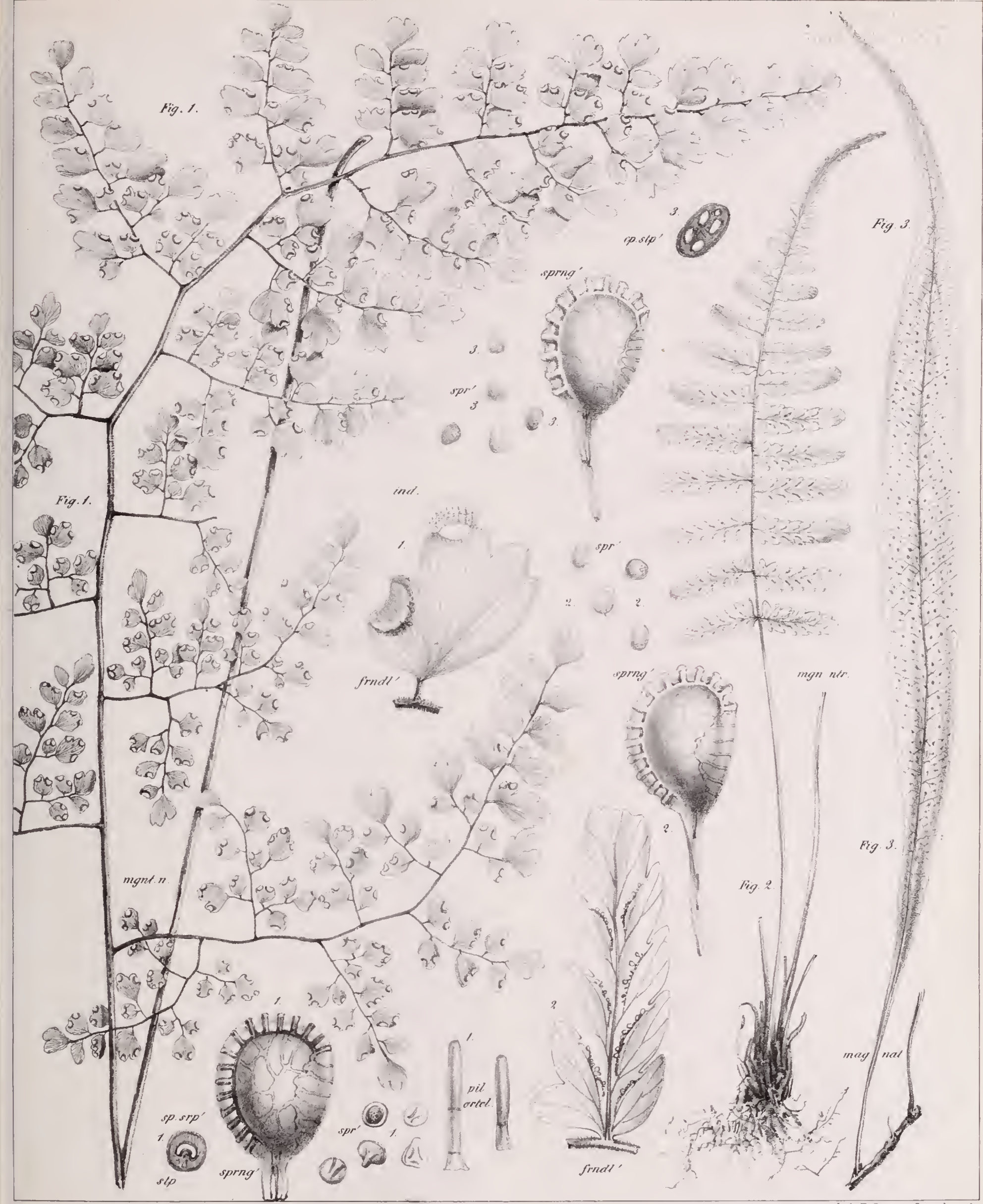

Prgt Adiantum Peei, Th, moore.

Figl. Asplenium argutans, $f$ 


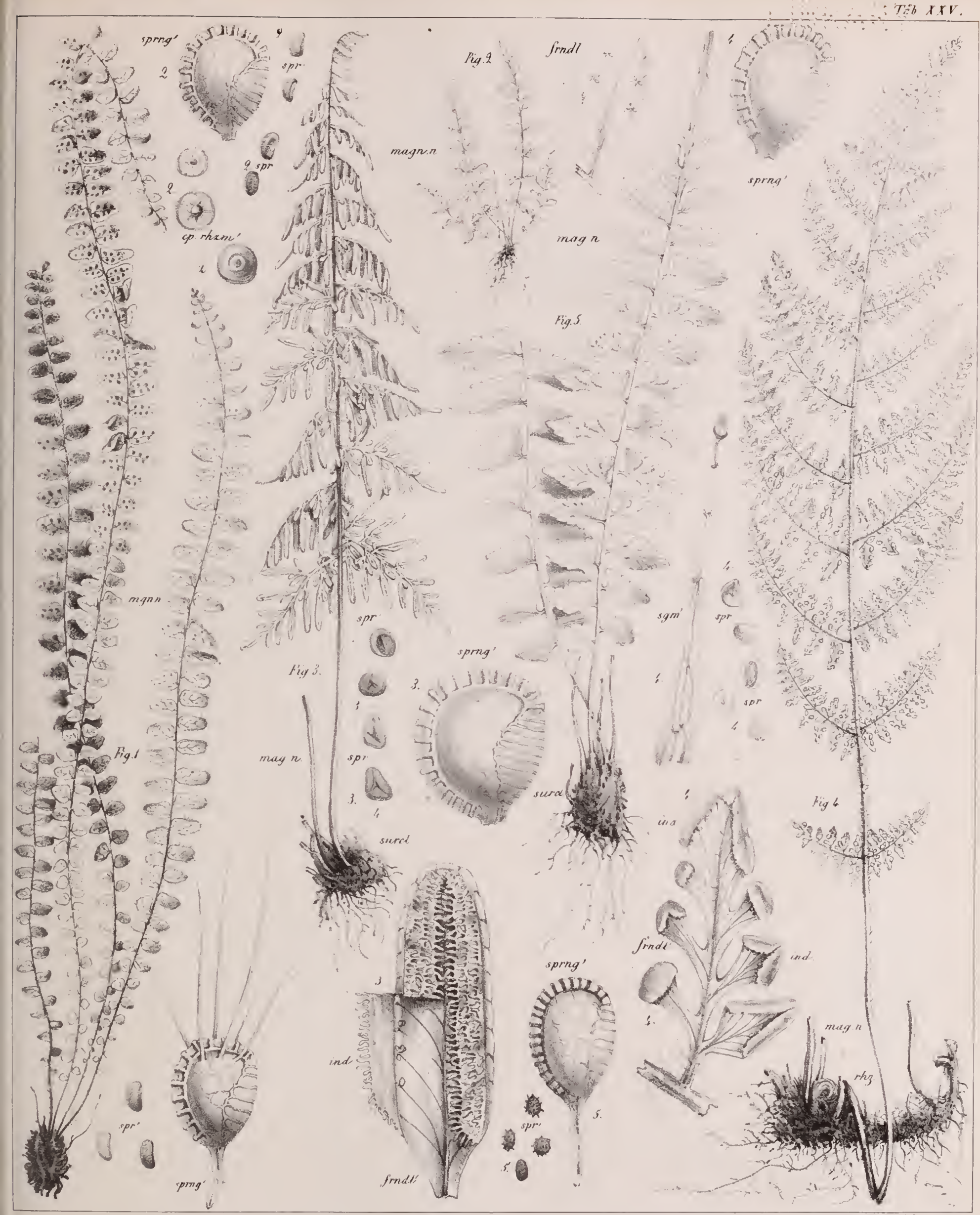

Pig. 1. Polypodium senile, $P$

fig 2. Phegopleris knella, $F^{\prime}$ 



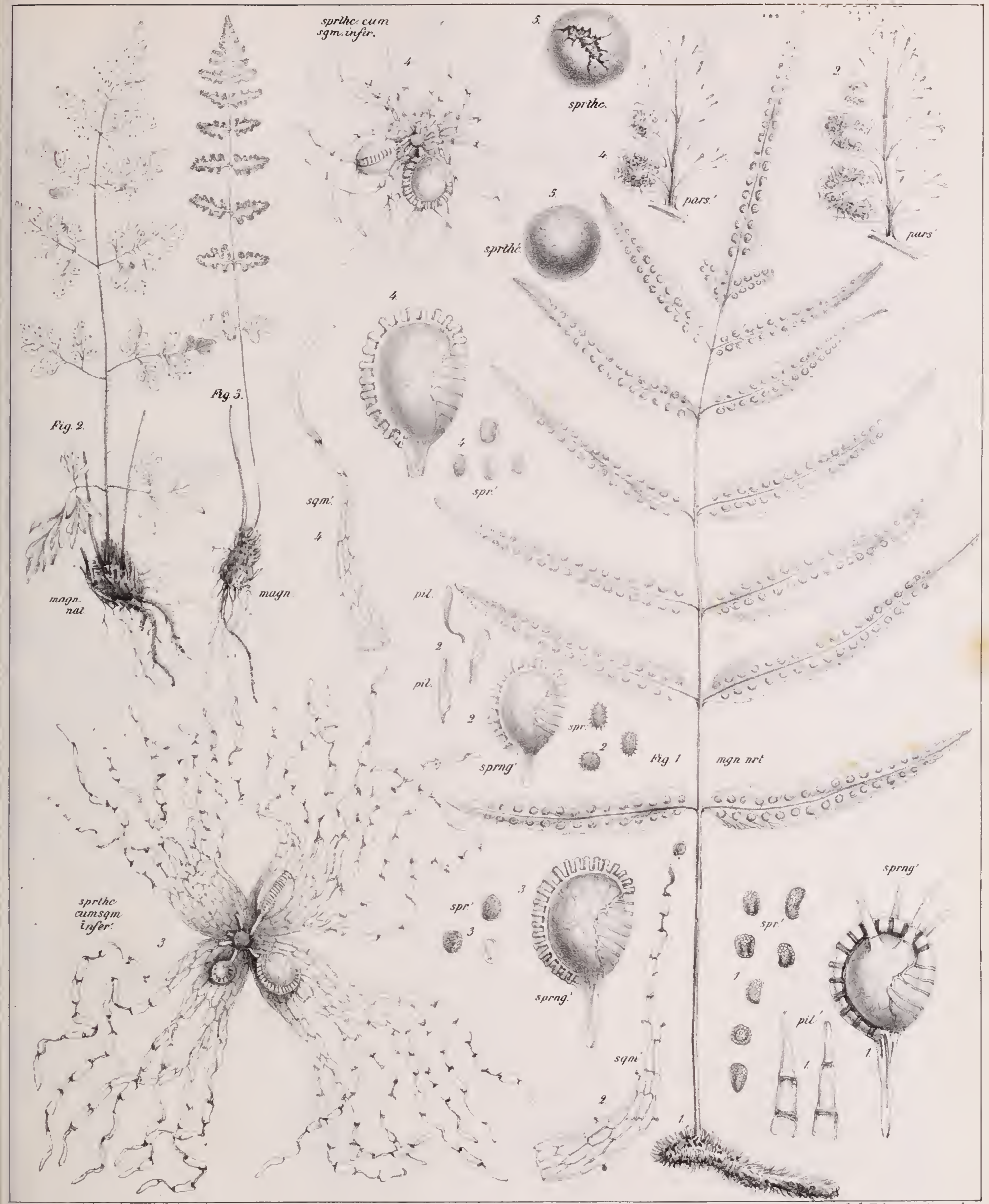





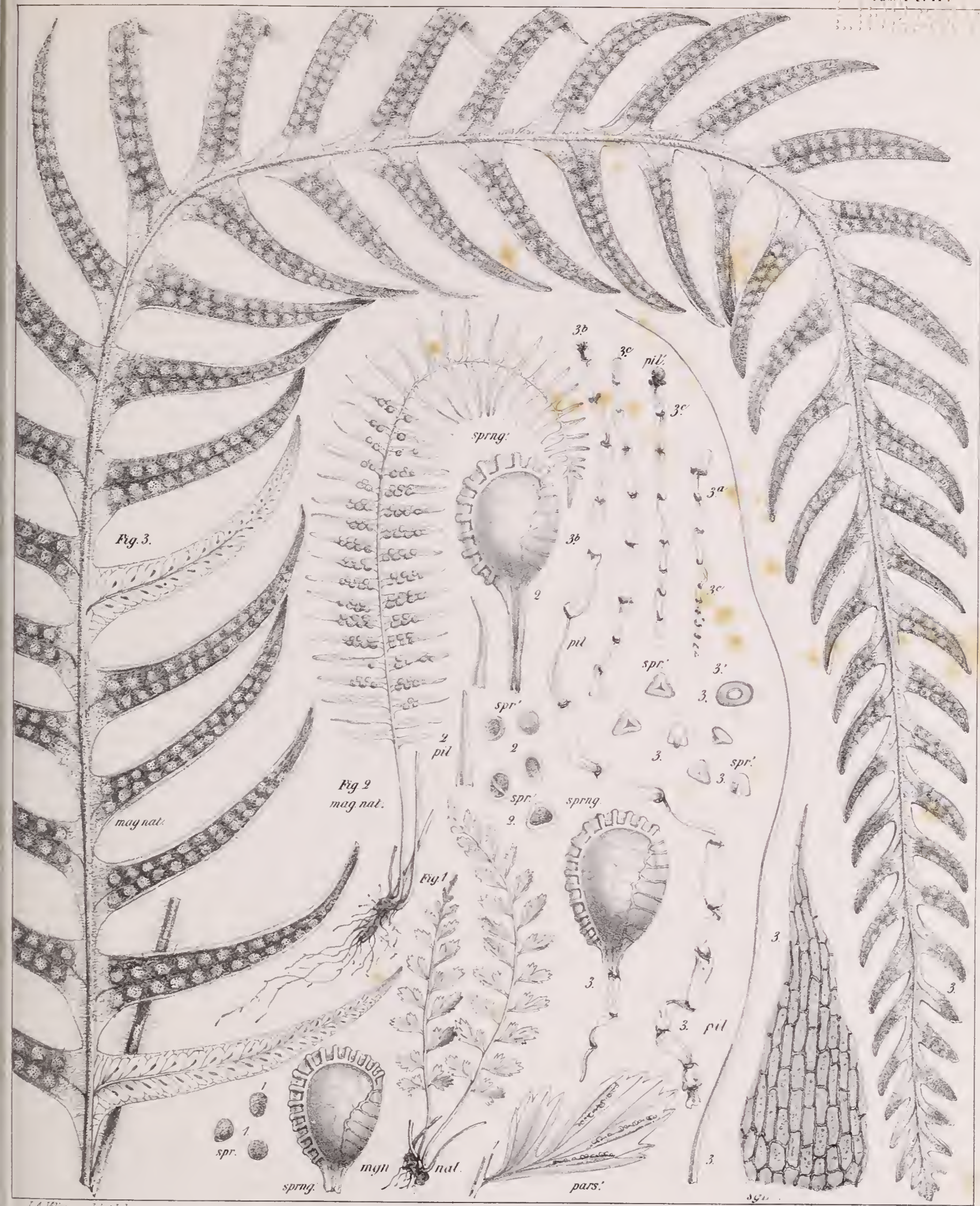

Fig. 1. Asplenium gracile, F. Fig. 2. Polypodium pecinellums, 

(1) 


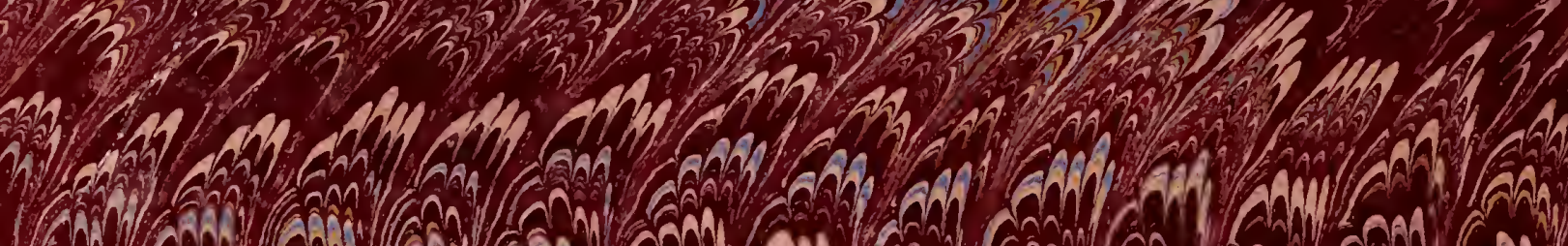

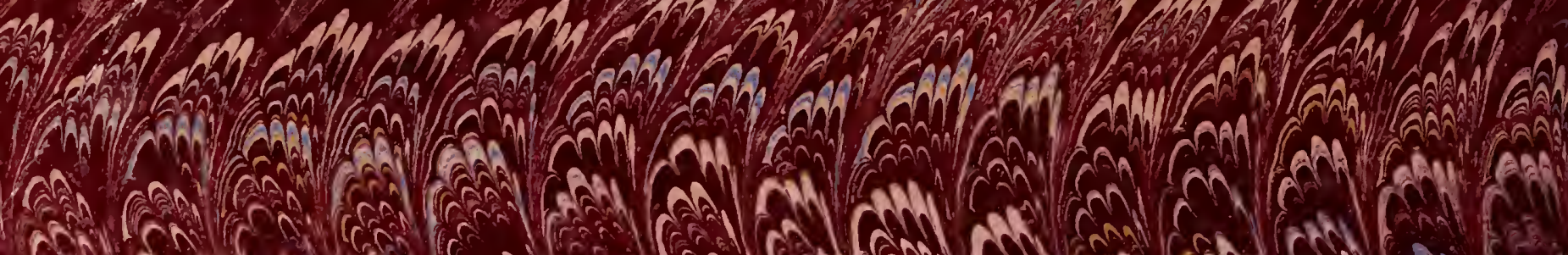

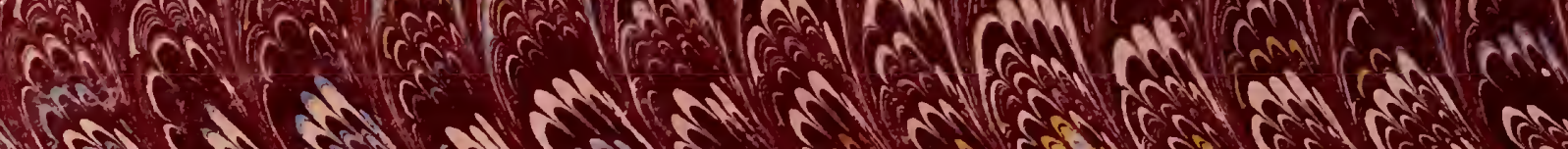

(c)

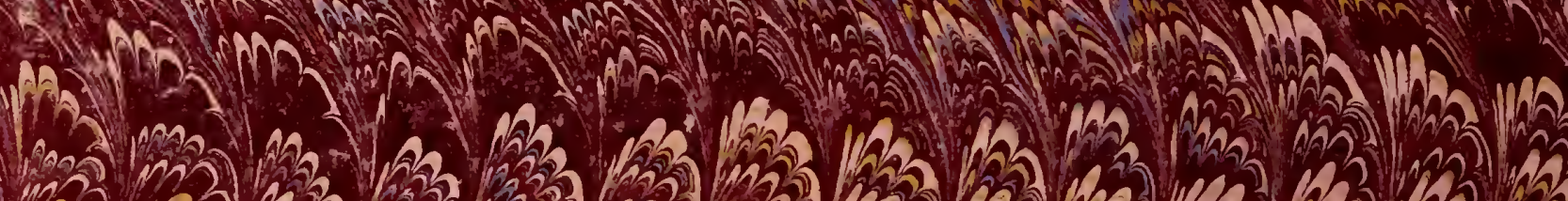

(1)

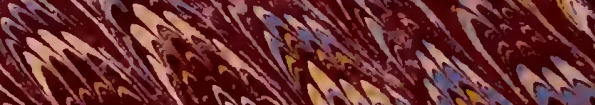

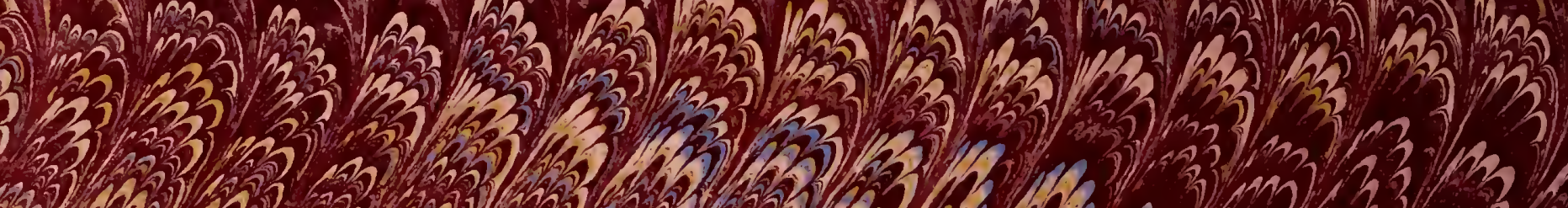

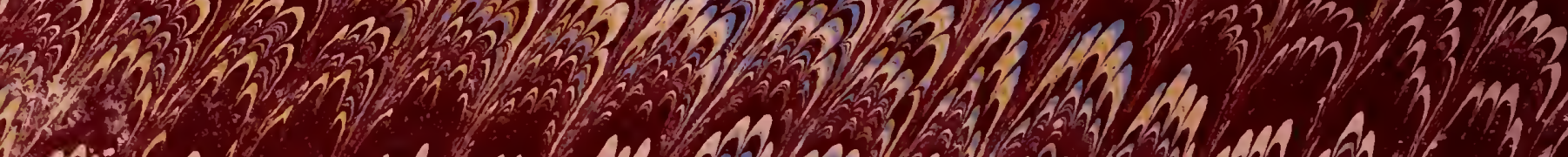

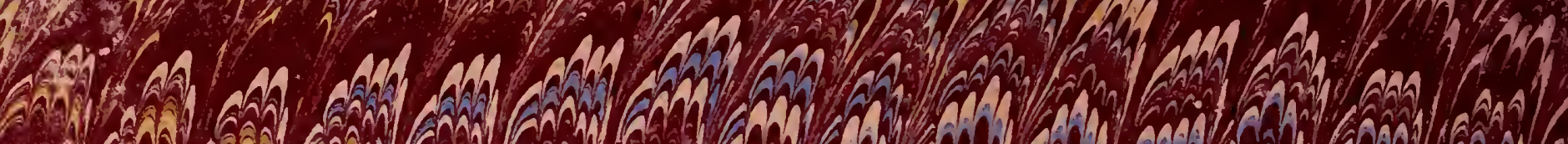

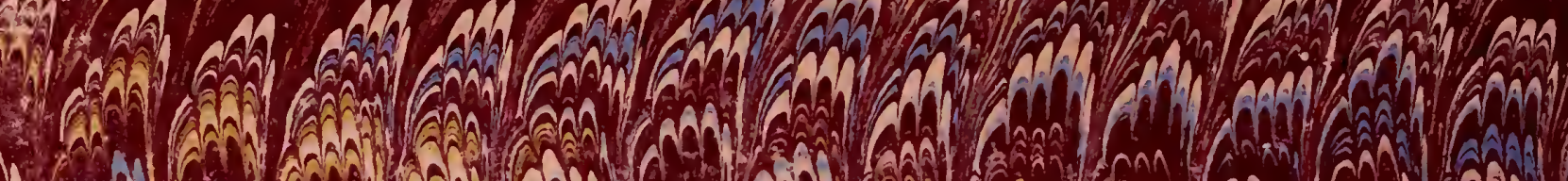

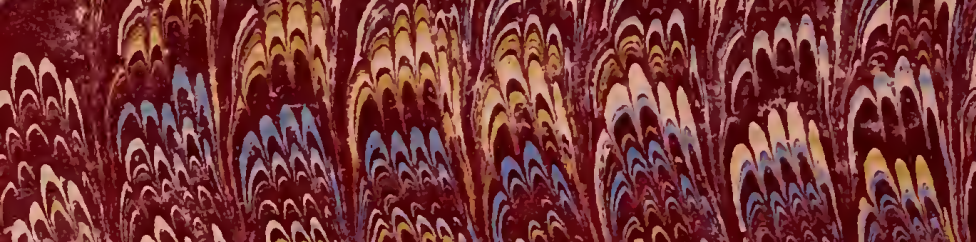

Wh

and

Anventing

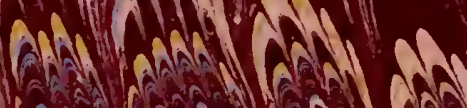

Na fall

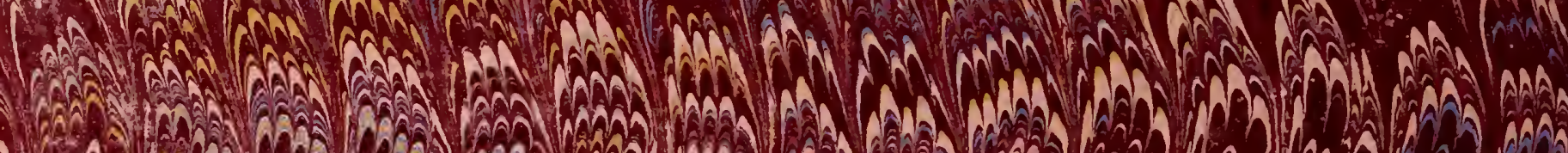
(N)

2

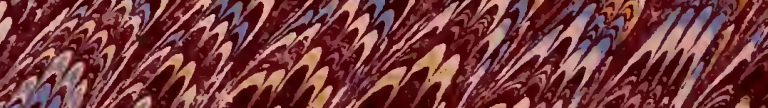

$1 \%$

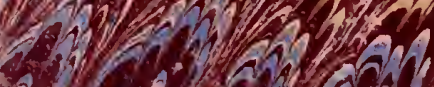

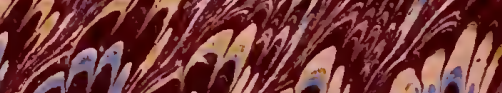

I. A

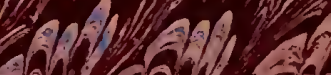

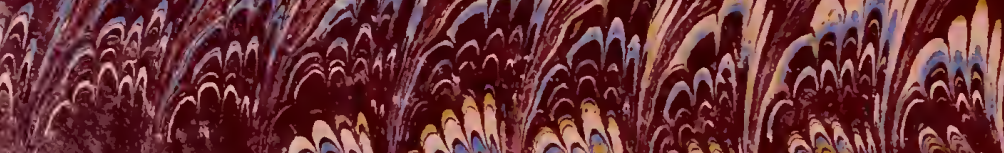



SES

-

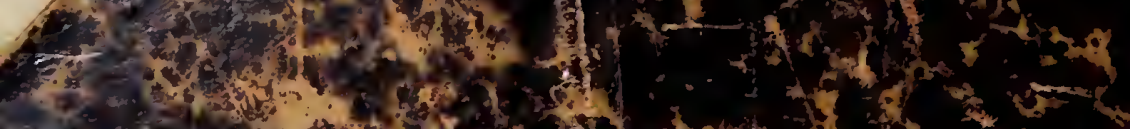

1.

T.

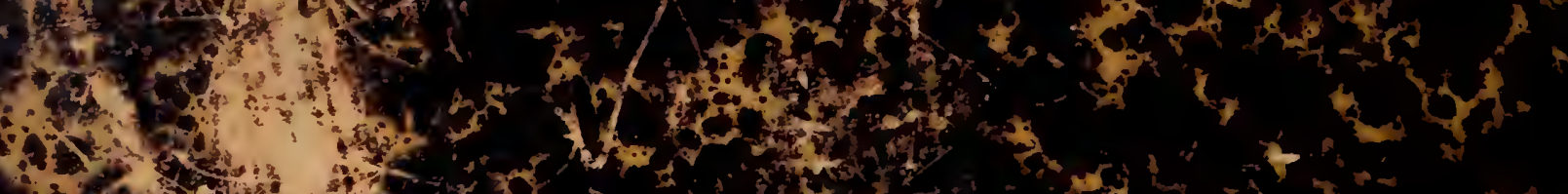

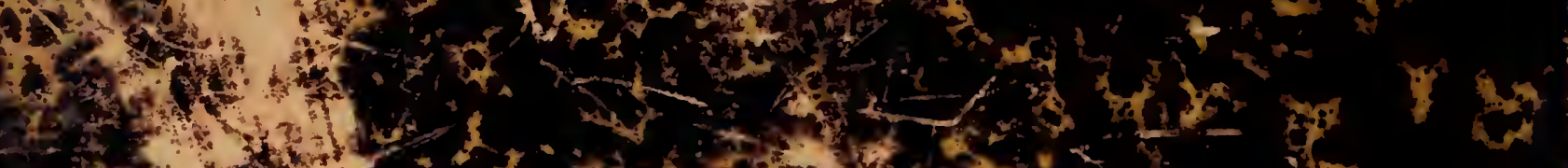

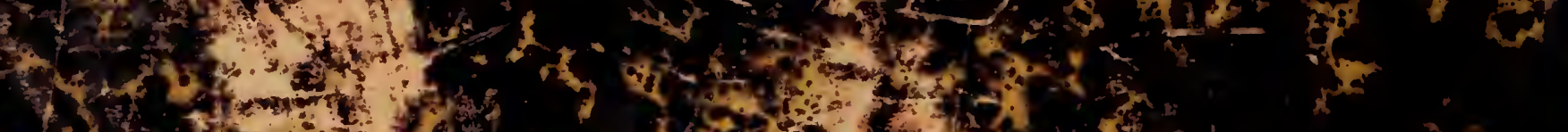
ats

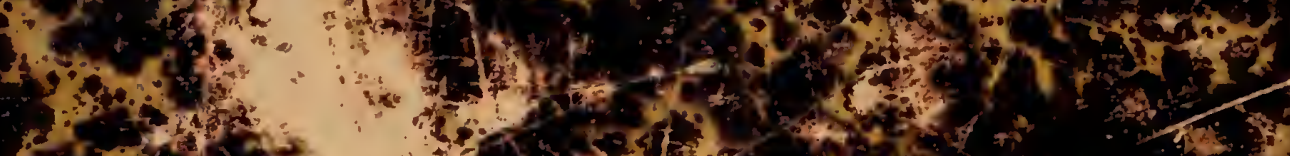
3.

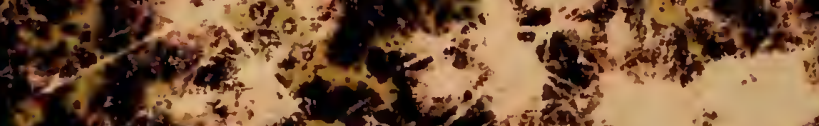

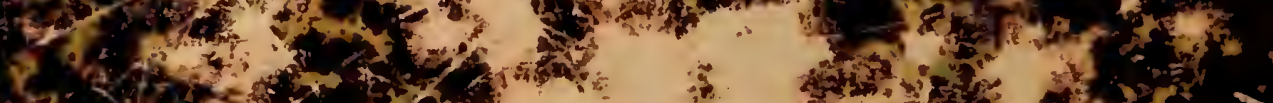

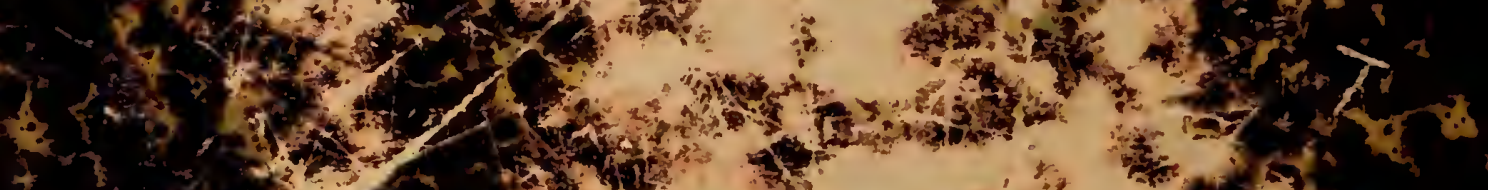

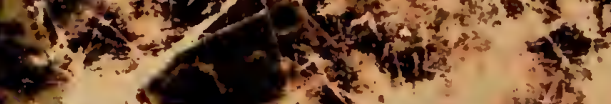

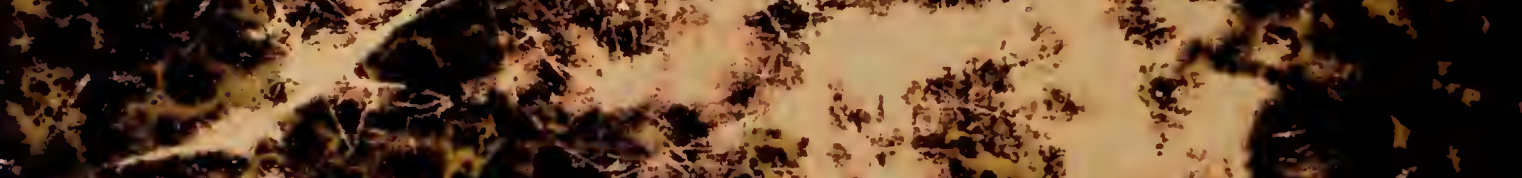

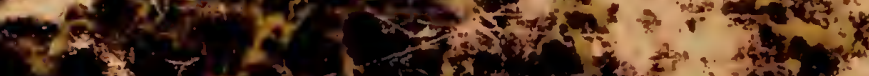

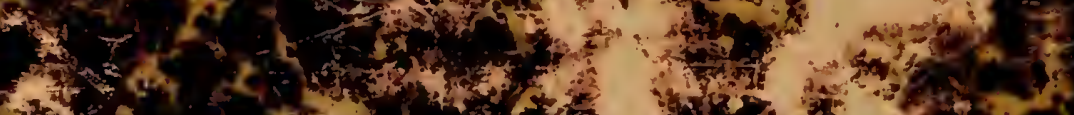

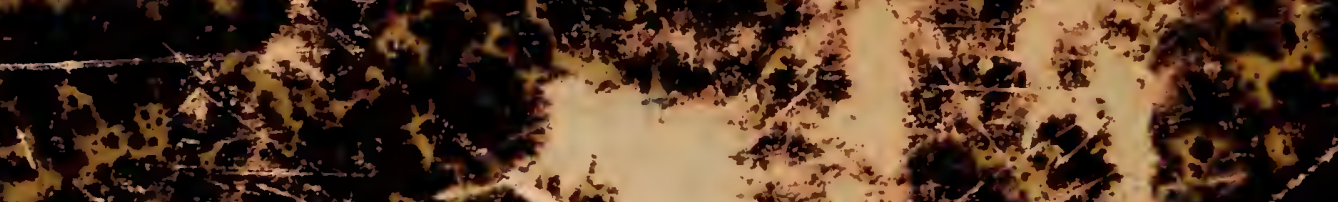

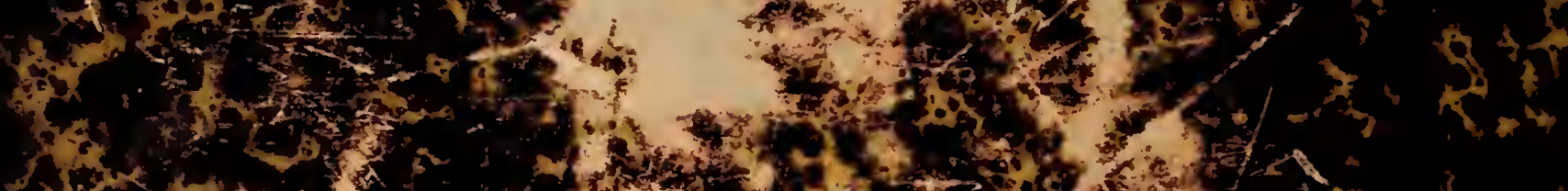

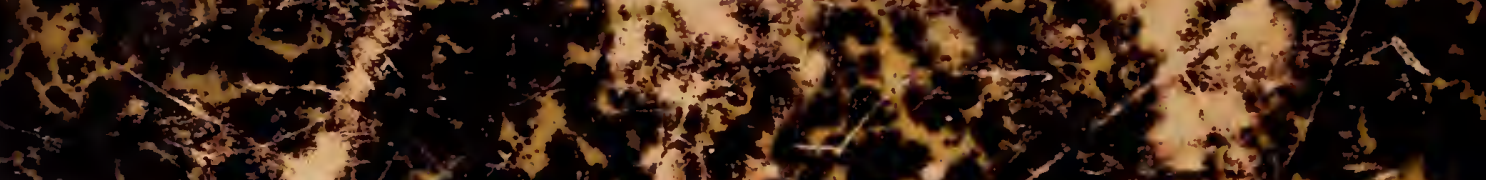

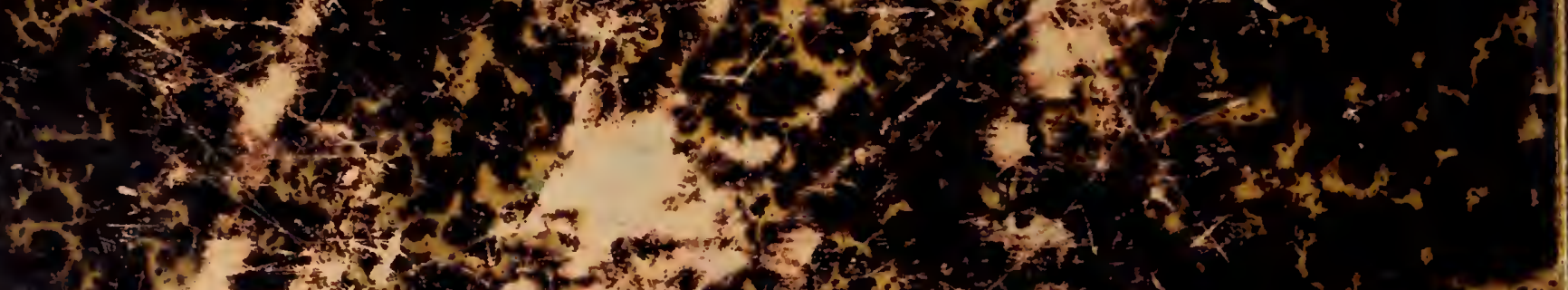

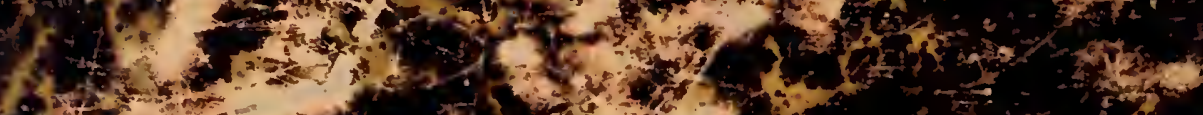
$1+3 x^{2}+2$

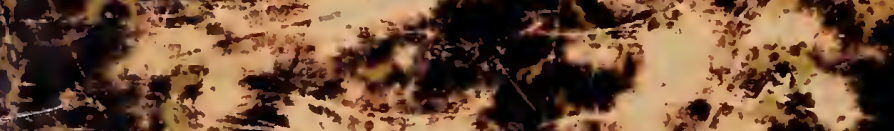

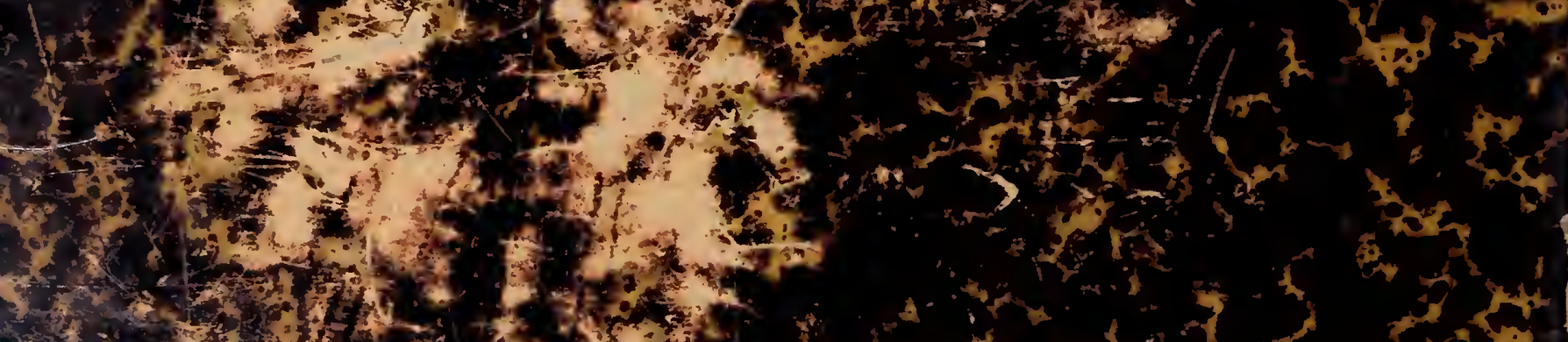

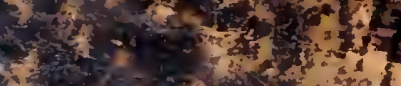

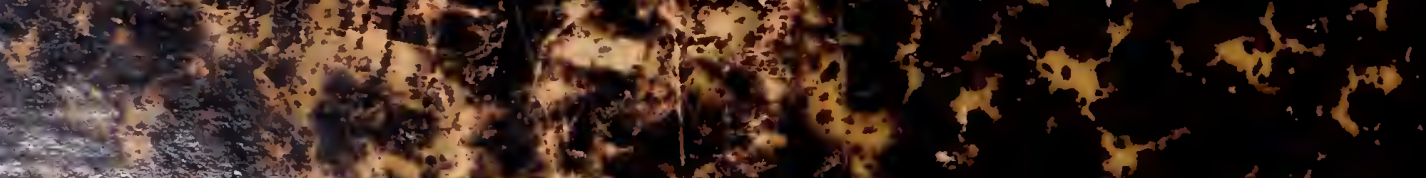

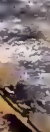
$-3014$ - anders

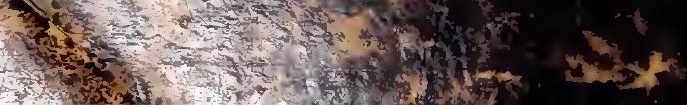
1. 